\title{
Characterization of Greater-Than-Class C Sealed Sources \\ Volume 2: Sealed Source \\ Characterization and Future \\ Production
}

Greater-Than-Class $C$

Low-Level Waste Management Program

September 1994 


\title{
Characterization of Greater-Than-Class C Sealed Sources Volume 2: Sealed Source Characterization and Future Production
}

\author{
Gerald Harris \\ Anna Griffel \\ September 1994 \\ Idaho National Engineering Laboratory \\ Idaho Falls, Idaho 83415
}

Prepared for the

U.S. Department of Energy

Assistant Secretary for Environmental Management

Under DOE Idaho Operations Office Contract DE-AC07-76ID01570 


\begin{abstract}
Sealed sources are small, relatively high-activity radioactive sources typically encapsulated in a metallic container. The activities can range from less than $1 \mathrm{mCi}$ to over $1,000 \mathrm{Ci}$. They are used in a variety of industries and are commonly available. Many of the sources will be classified as Greater-Than-Class $C$ low-level radioactive waste (GTCC LLW) for the purpose of waste disposal. The U.S. Department of Energy is responsible for disposing of this class of low-level radioactive waste.

The characterization of a sealed source is essentially a function of the type of radiation it emits, the principal use for which it is applied, and the activity it contains. The types of radiation of most interest to the GTCC LLW Program are gamma rays and neutrons, since these are emitted by the highest activity sources. The principal uses of most importance are gamma irradiators, medical teletherapy, well logging probes, and other general neutron applications.

Current annual production rates of potential Greater-Than-Class C (PGTCC) sources sold to specific licensees were estimated based on data collected from device manufacturers. These estimates were then adjusted for current trends in the industry to estimate future annual production rates. It is expected that there will be approximately 8,000 PGTCC sealed sources produced annually for specific licensees.
\end{abstract}




\section{SUMMARY}

This report, the second of three volumes investigating sealed sources that may eventually become Greater-Than-Class C (GTCC) low-level radioactive waste (LLW), characterizes sealed sources and estimates current and future production rates of sealed sources sold to specific licensees. Information on which to base the production estimates were obtained from the U.S. Nuclear Regulatory Commission's Sealed Source and Device database and by contacting sealed source and device manufacturers.

This report comprises three parts. The first part, comprising Chapters 1 and 2, presents the purpose and scope of the report and summarizes concepts of radioactivity relevant to the uses of sealed sources. The second part, comprising Chapters 3 through 5, discusses the uses and construction of sealed sources. The final part, comprising Chapters 6 and 7, estimates the annual production of potential GTCC (PGTCC) sources, discusses current trends in the industry, and presents conclusions of this report. Because this report focuses on characterizing sealed sources and estimating annual production rates of sealed sources sold to specific licensees, the following paragraphs summarize the results and conclusions contained in Chapters 3-6.

Chapter 3, Source/Device General Descriptions, describes the function of the source/device, the isotopes and activities of the sources, and the major manufacturers. It identifies nine categories of sealed sources: calibration devices, medical sources, well logging sources, portable gauges, irradiation sources, fixed gauges, general neutron application sources, $x$-ray fluorescence sources, and other sources or gauges.

While there is a wide variety of sealed source applications, both the principles governing those applications and the designs of the sources are similar. There are two broad radiation techniques: irradiation and gauging. In irradiation techniques, radiation is used to change the properties of the material being irradiated (e.g., kill bacteria, sterilize products, modify polymer properties). In gauging applications, properties of the material being examined (e.g., thickness, density) are assessed by the effect they have on the transmitted or scattered radiation.

Chapter 4, Sealed Source Construction, discusses general sealed source construction and also describes American National Standards Institute (ANSI) and U.S. Nuclear Regulatory Commission (NRC) performance requirements that sealed sources must meet.

For the user, the importance of a sealed source is not so much what the source contains as what it emits. Hence, source construction is designed to allow radiation to be emitted while containing the radioactive isotope. The design of the source must meet three general criteria: (a) the radiation emission from the source must be satisfactory for the ultimate application, (b) there should be no release of radioactive material due to loss of integrity of the source seal even after prolonged service life, and (c) the sealing material must be compatible with the prospective environment of the source.

Several typical designs are illustrated in this chapter.

Chapter 5, Source/Device Characterization (SDC) Database, describes the development of the SDC database. It is based on the NRC's Sealed Source and Device Registry (SSD) database. The SSD database includes company names, addresses, model numbers, isotopes, and maximum activity levels. However, the SSD does not include other information that is needed by the GTCC LLW Program, such as source volumes or whether the source is welded or soldered. The SSD also does not list specific activities of multiple models listed on the same registration certificate. Because of this lack of specificity on some models and lack of information relevant to the GTCC LLW Program, the Program modified the SSD to gather some of the above information, and produced the DOE SDC database. 
Chapter 6, Annual Production Estimation, discusses what information was requested from manufacturers, the methods applied to estimate the annual production of PGTCC sources sold to specific licensees by isotope and device type (i.e., the incremental numbers of sources), and the results.

The annual production estimates are for PGTCC sources, as opposed to GTCC sources.

- $\quad P G T C C$ sources exceed the Class $C$ concentration limits when the concentration of radioactive isotopes is calculated over the source capsule volume.

- $\quad$ GTCC sources exceed the Class $\mathrm{C}$ concentration limits when current disposal practices are used. Current disposal practices allow concentration averaging to occur over the disposal container, with some restrictions. That is, of those PGTCC sources, concentration averaging removes the sources with the lowest activities and averages their radionuclide activity over the volume or mass of encapsulation media filling an entire waste container, thereby reducing the concentration to a level acceptable to a near-surface LLW disposal facility.

This report deals almost exclusively with PGTCC sealed sources. Most of the PGTCC sources will not become GTCC LLW. The PGTCC values represent the most basic estimates, and can be used as a foundation on which to apply any assumptions regarding packaging or concentration averaging. The impacts of packaging volumes and concentration averaging practices on these estimates are explored in other studies.

Manufacturers were contacted by phone and by letter. The quality of the data was influenced by the response rate and response quality, both of which were less than satisfactory. The response rate was low. Many manufacturers did not want to release past production rates, claiming justifiably that this data was proprietary; others determined that the level of effort to retrieve past production data was too great, therefore, it was not worth their time. Some manufacturers claimed that they had no PGTCC material. The response quality was also less than satisfactory; some companies sent general instead of actual production figures, claiming again that the information was proprietary.

Because data gathered from manufacturers were of limited value, survey results from specific licensees were also used to make estimates of the annual production of sealed sources held by specific licensees for the low, base, and high cases. The low case estimates production of 4,700 sources annually, the base case estimates 8,000, and the high case estimates 11,500. The isotopes Am-241 and Cs-137 account for the majority of the sources. While there is a moderate amount of uncertainty in these estimates, manufacturers felt the estimates were reasonable.

While particular companies or device types may be experiencing growth, overall the markets for devices containing PGTCC sources are either stable or shrinking. Companies are moving toward less toxic substances, for example, using x-ray tubes instead of gamma sources. Also, companies are replacing isotopes that are difficult to dispose of with those that can be more easily disposed of. And in some applications, nonradioactive techniques are replacing methods that use radioactive isotopes. These factors are reflected in the estimates for future production.

\section{Extrapolations to All Licensees}

This report is the second of three volumes. This report and Volume 1 discuss sealed sources held by specific licensees, while Volume 3 concerns sealed sources held by general licensees. These reports give estimates of the total number of PGTCC sources (those whose activity is averaged over the source capsule) and the number of GTCC sources (assumed here to be those remaining after concentration averaging has been performed over the disposal container, as explained in Appendix D of Volume 1). 
Volume 1 estimates that, in 1992, the number of PGTCC sources held by specific licensees was 89,000 ; the estimated 1992 number of GTCC sources is 28,400 . In this report, Volume 2 , it is estimated that 8,000 PGTCC sources are sold per year to specific licensees.

Volume 3 estimates that the general licensee population possesses roughly $36 \%$ of the total 1992 number of GTCC sealed sources. Together with the GTCC sources held by specific licensees (from Volume 1), this yields about 44,000 total GTCC sources held by all licensees. The results presented in Volume 1 and Volume 3 for GTCC sealed sources are summarized in Table ES-1.

Volume 3 estimates that the general licensee population possesses roughly $63 \%$ of the total 1992 number of PGTCC sealed sources. Together with the PGTCC sources held by specific licensees (from Volume 1), this yields about 250,000 total PGTCC sources held by all licensees. The results presented in Volume 1 and Volume 3 for PGTCC sealed sources are summarized in Table ES- 2 .

For general licensees, Volume 3 extrapolates the estimated annual number of GTCC sources sold to the number of PGTCC sources sold. When those results are added to the number of PGTCC sources sold to specific licensees (reported here in Volume 2), the resulting estimate is 24,000 PGTCC sources sold to all licensees per year. This is shown in Table ES-3. 


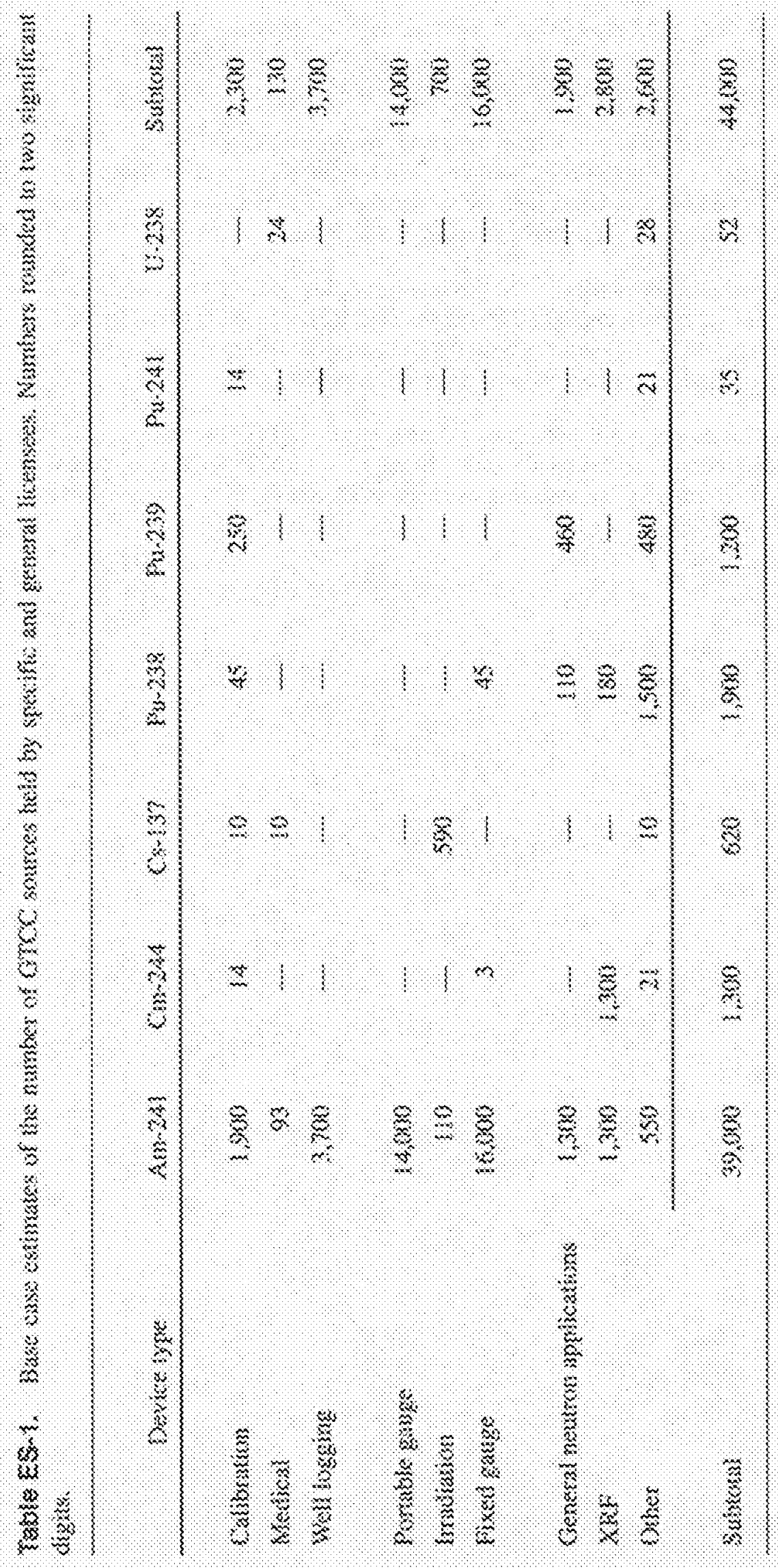

vilis 


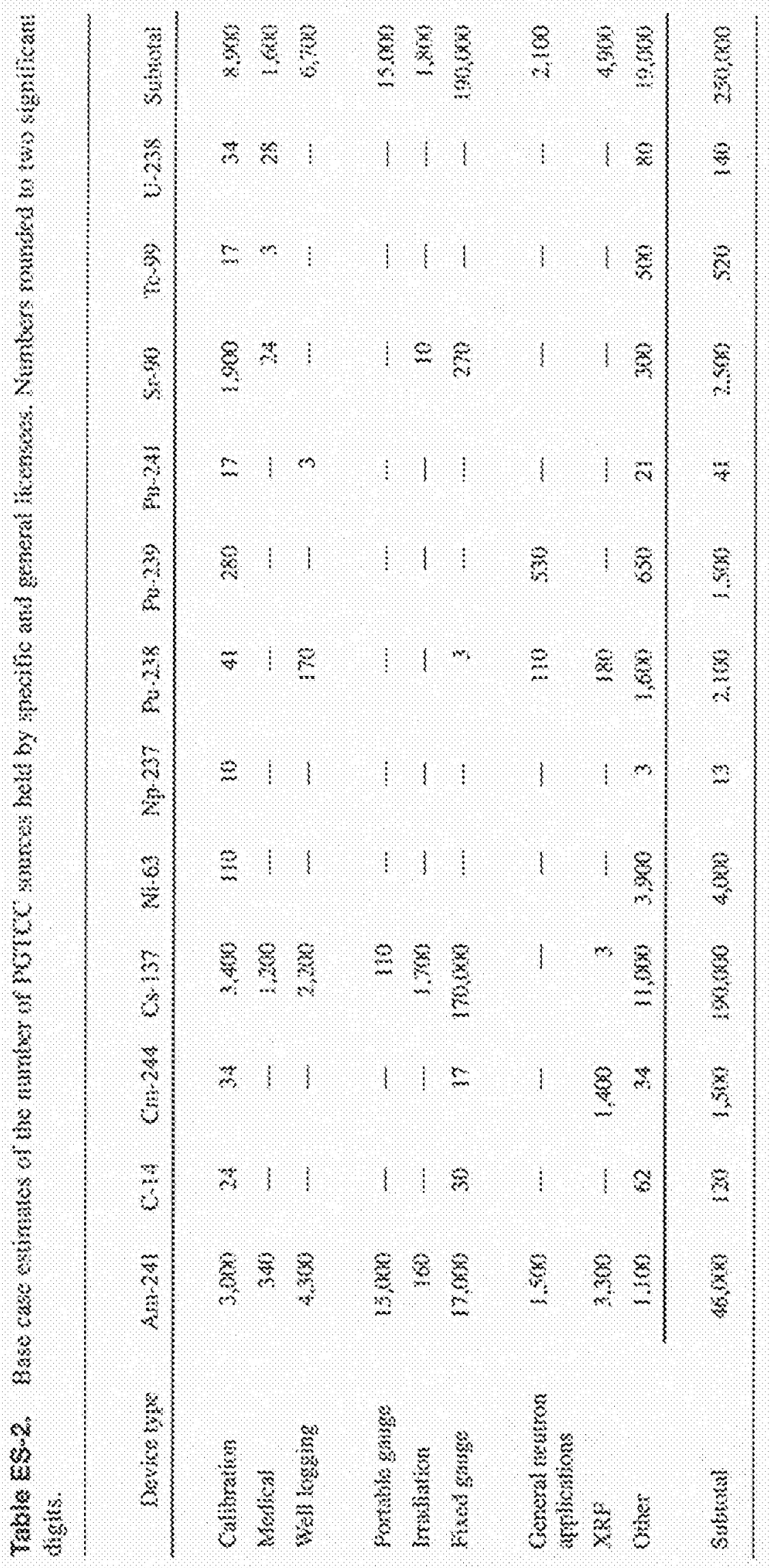




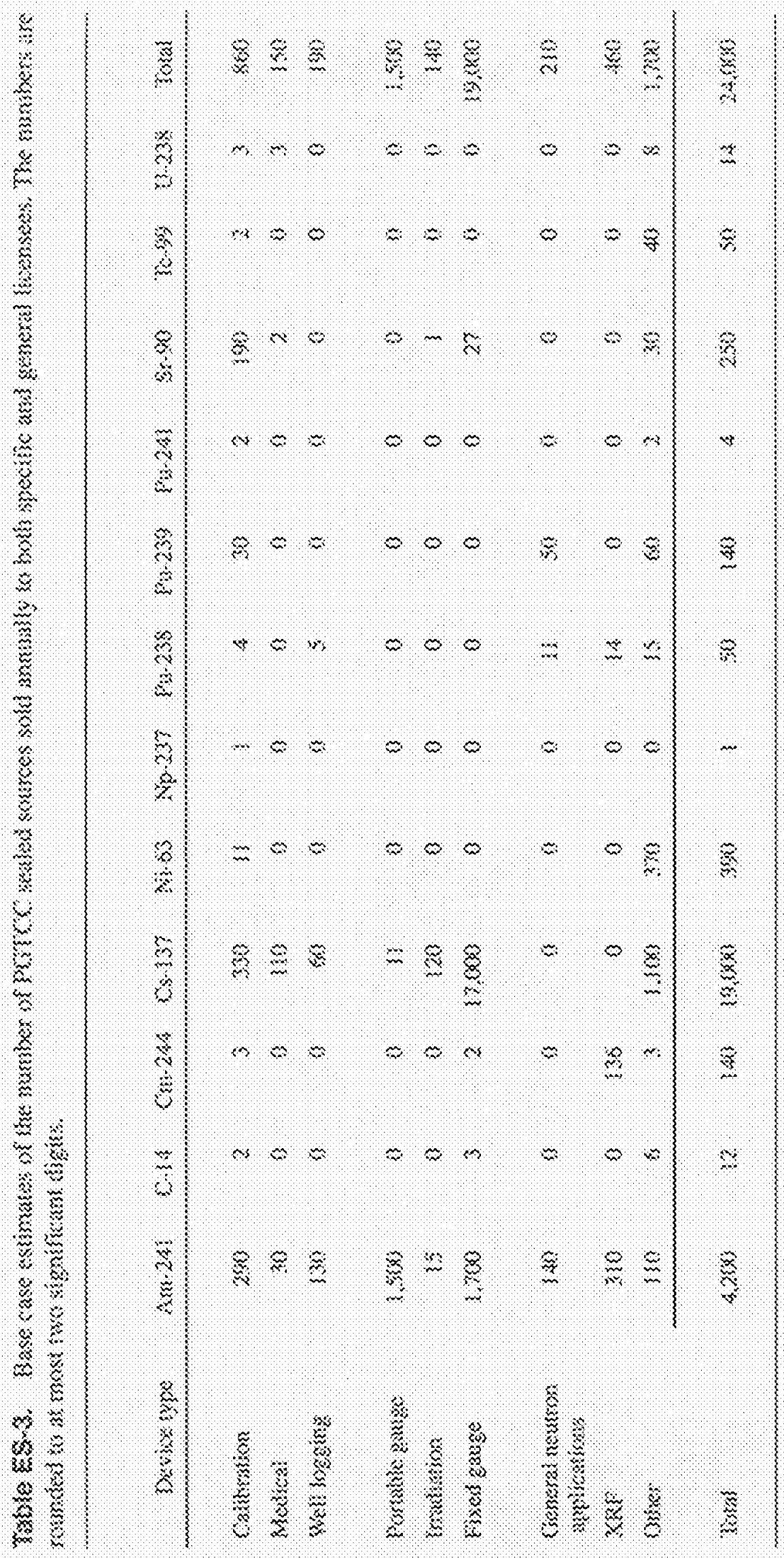




\section{contents}

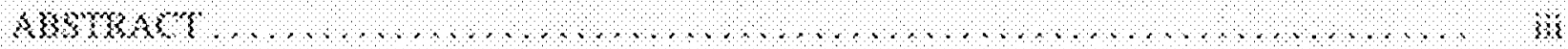

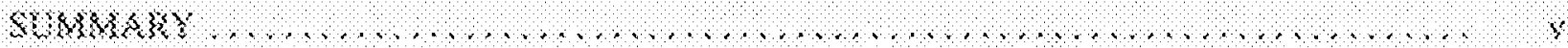

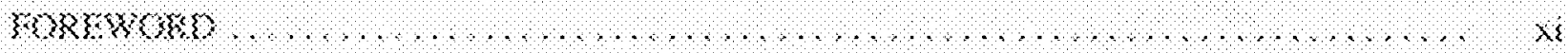

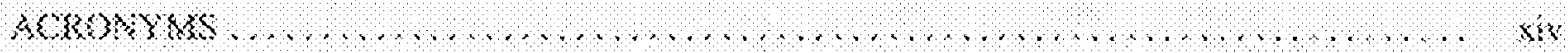

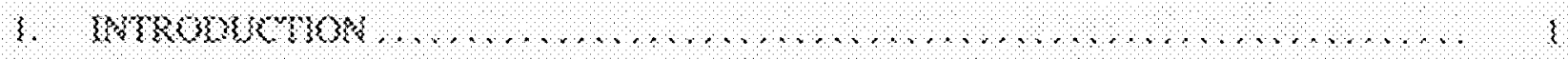

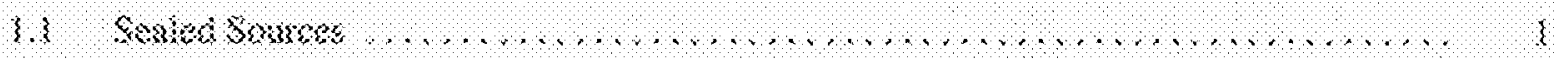

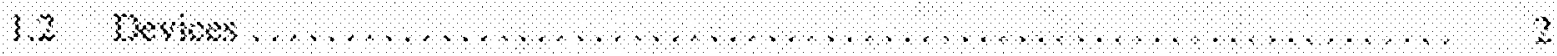

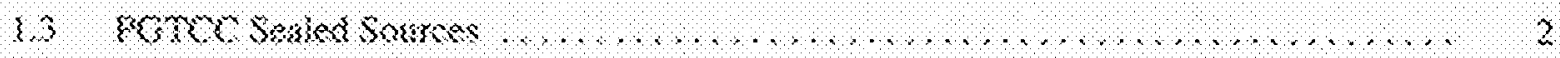

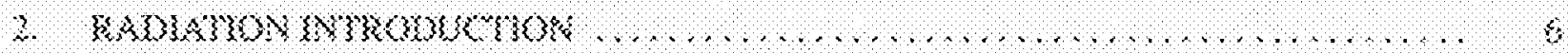

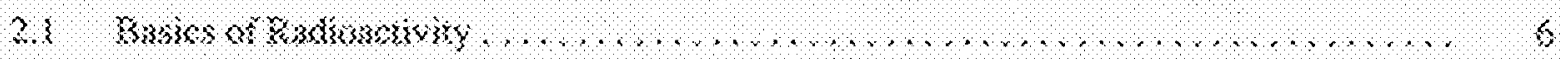

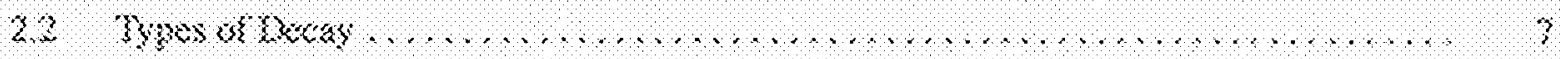

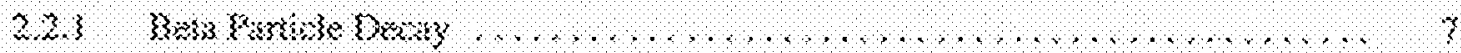

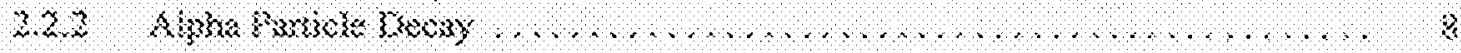

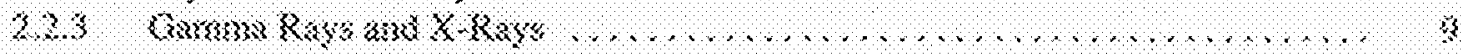

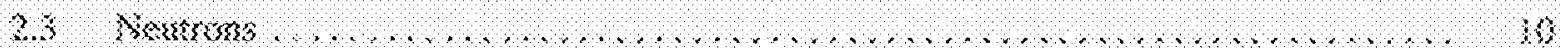

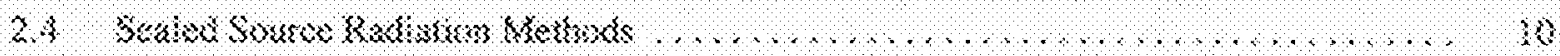

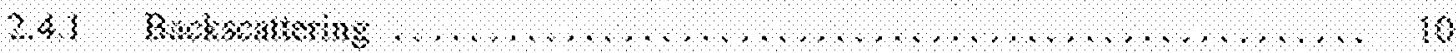

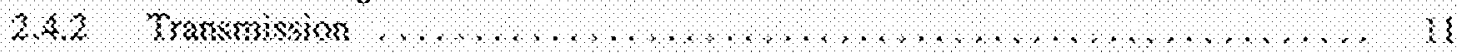

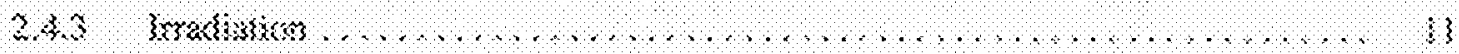

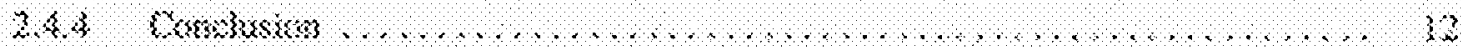

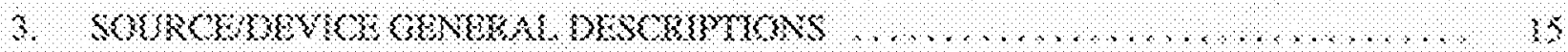

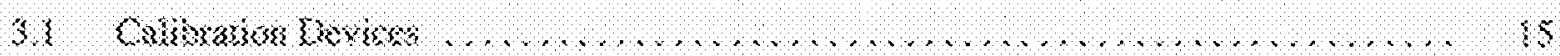

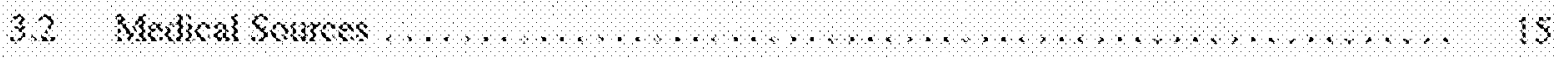

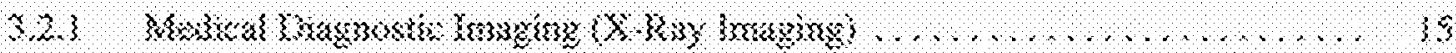

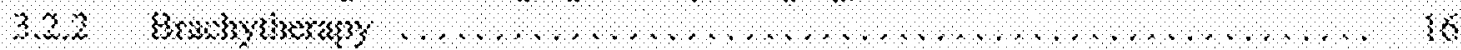

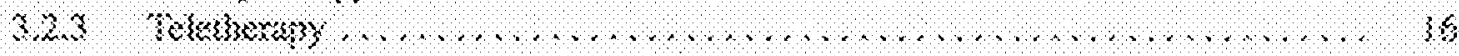

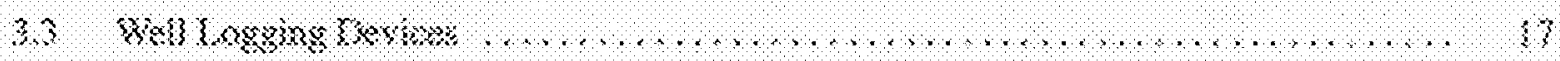

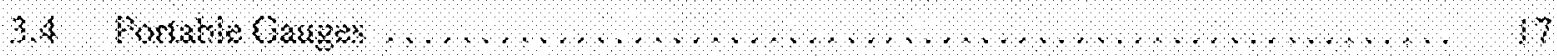




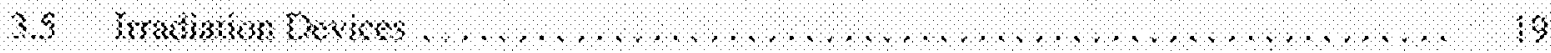

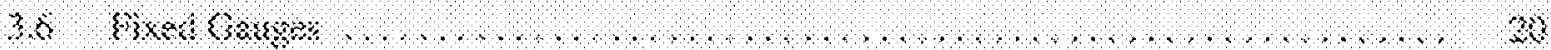

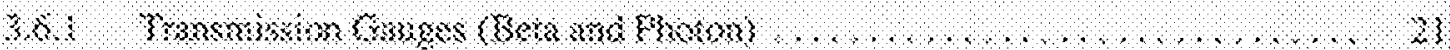

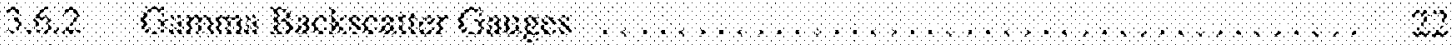

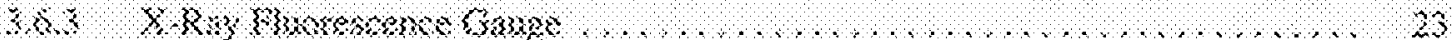

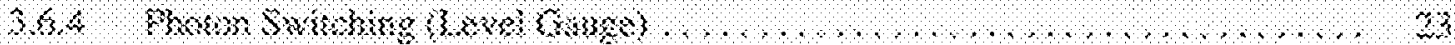

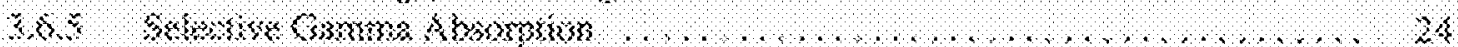

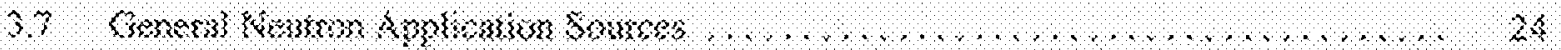

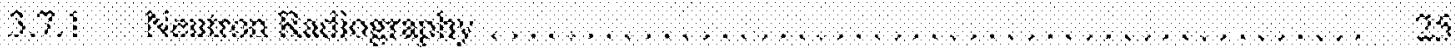

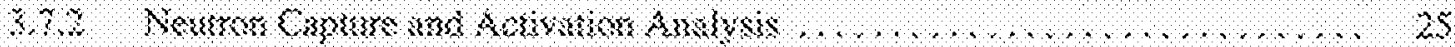

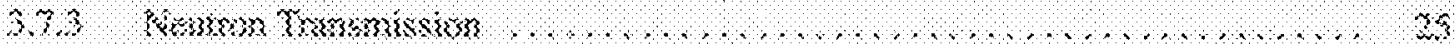

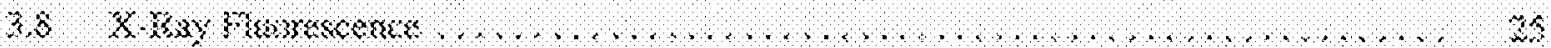

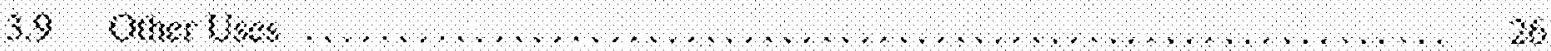

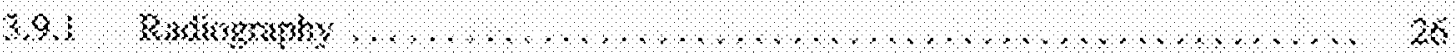

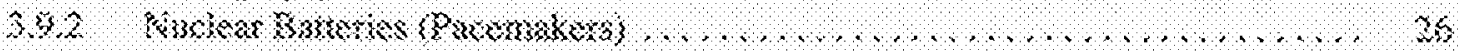

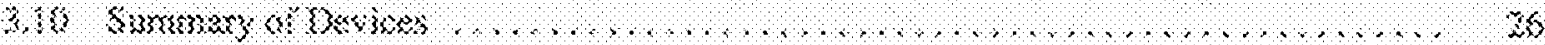

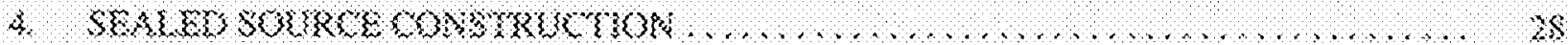

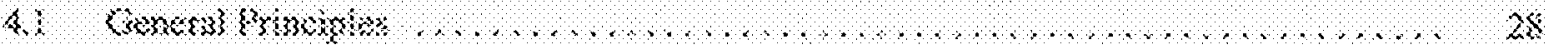

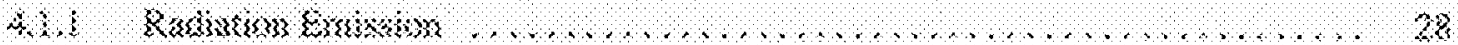

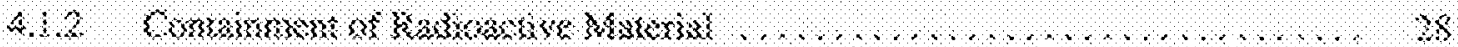

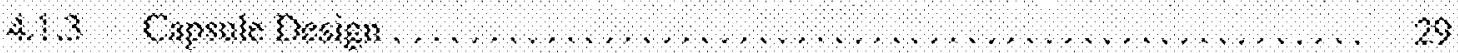

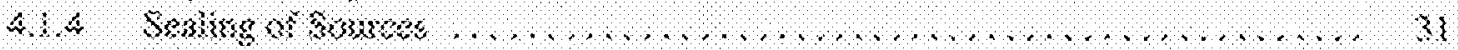

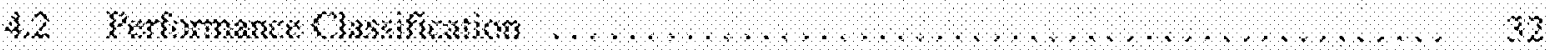

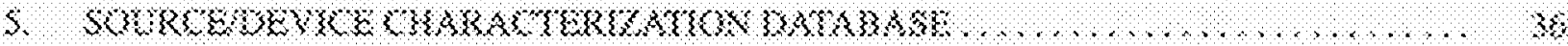

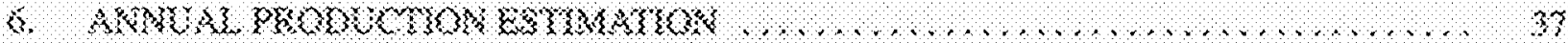

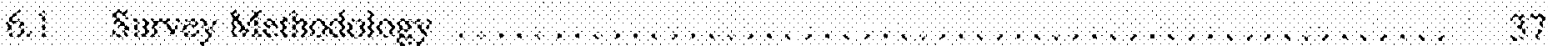

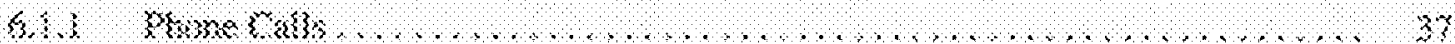

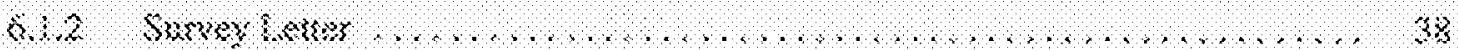

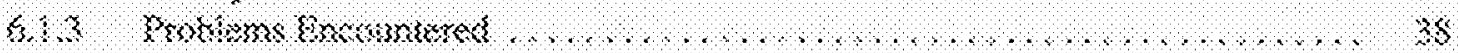

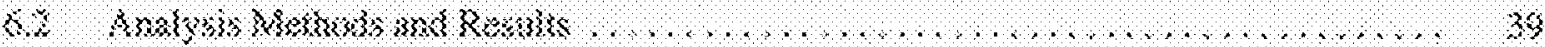

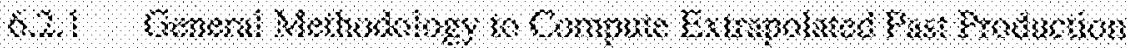

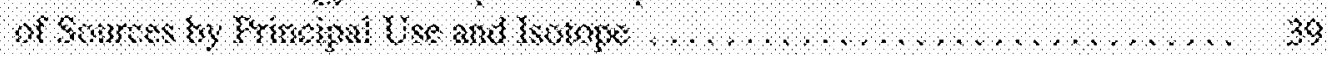

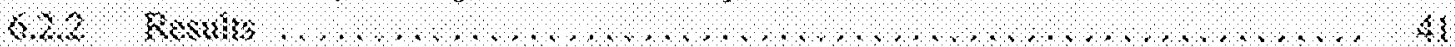




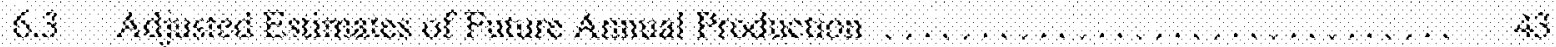

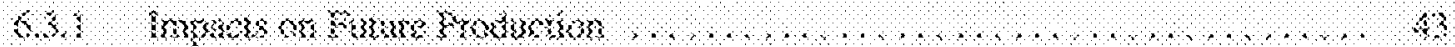

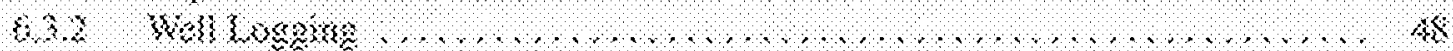

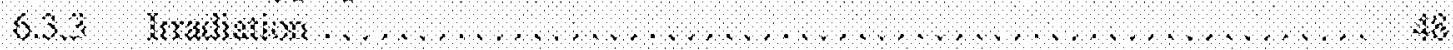

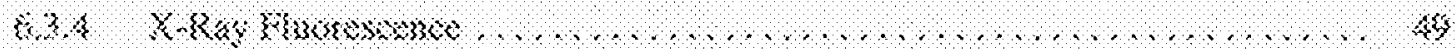

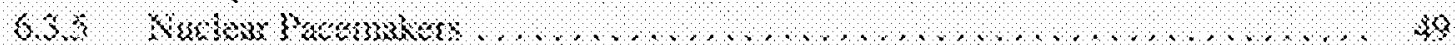

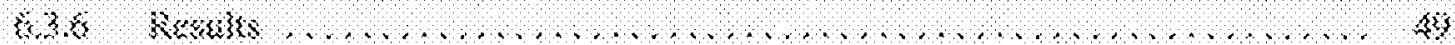

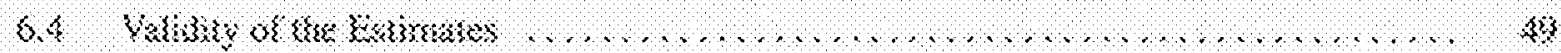

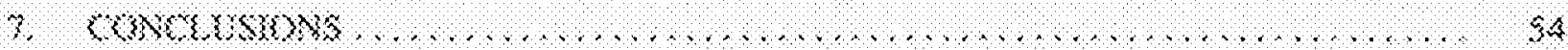

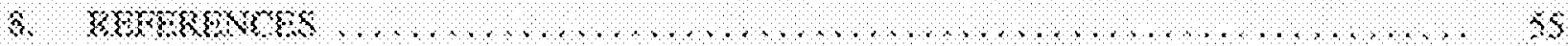

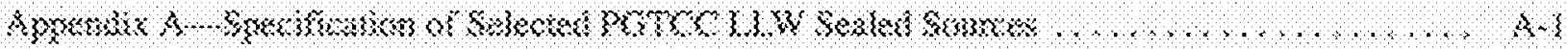

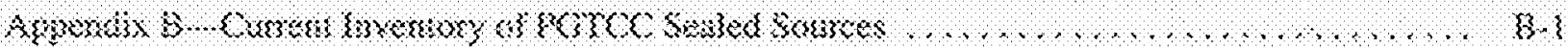

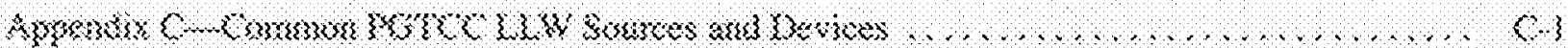

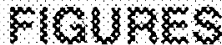

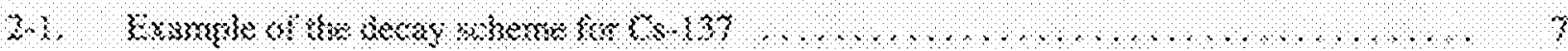

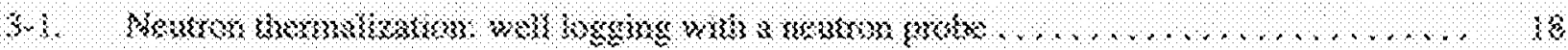

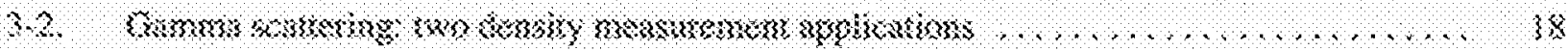

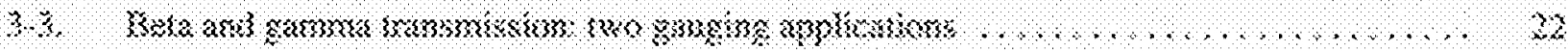

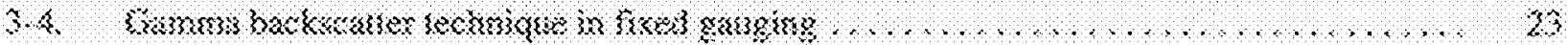

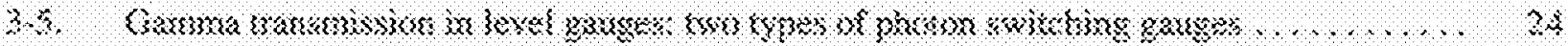

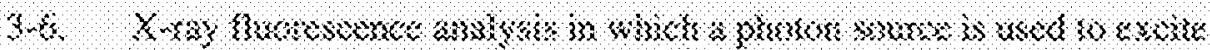

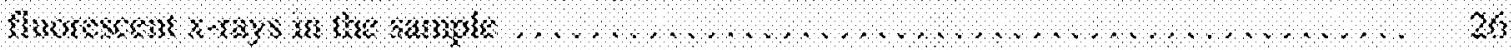

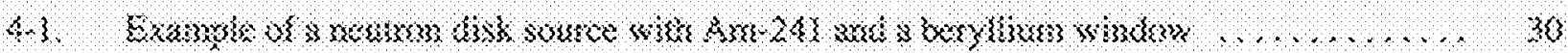

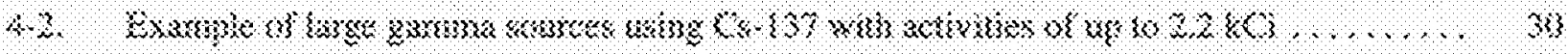

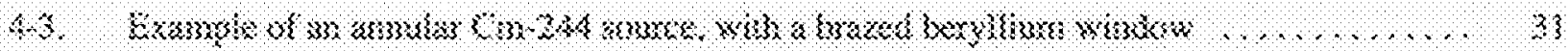

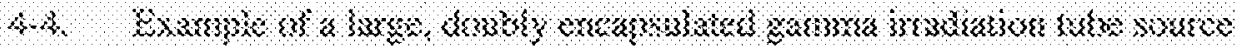

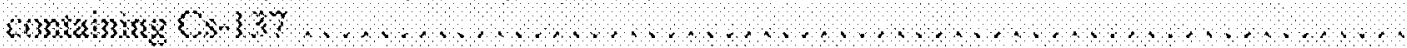




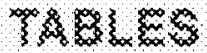

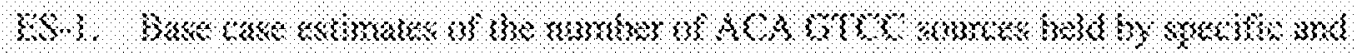

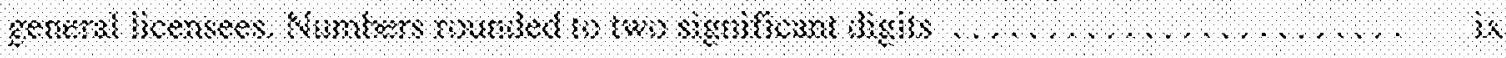

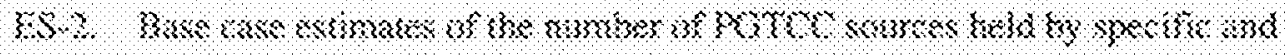

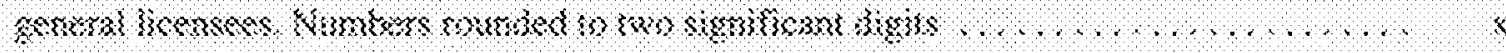

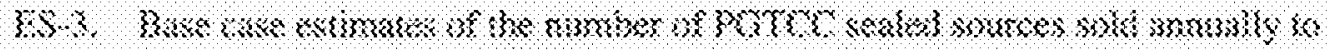

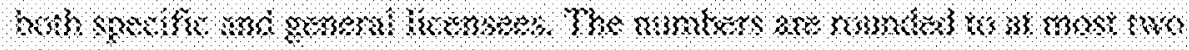

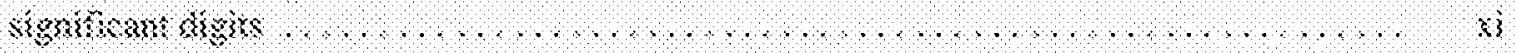

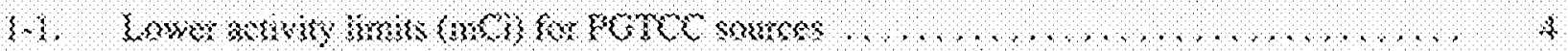

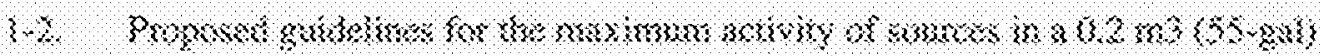

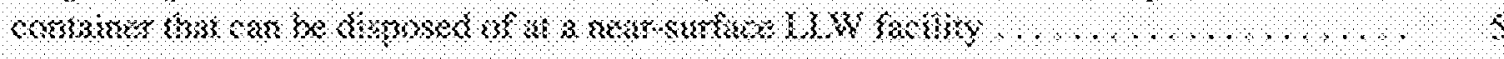

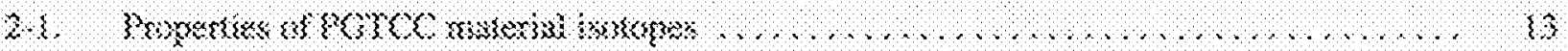

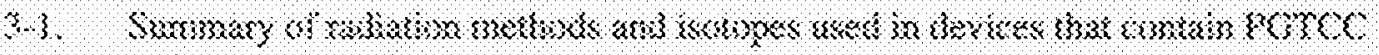

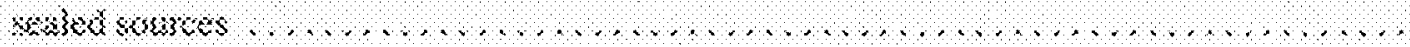

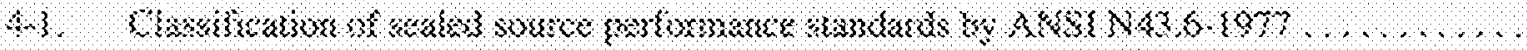

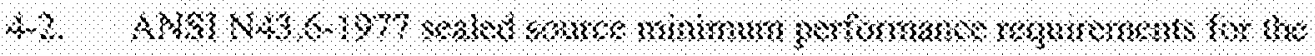

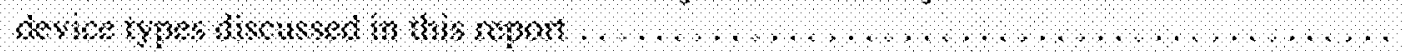

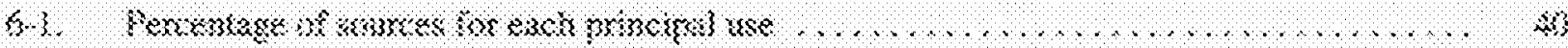

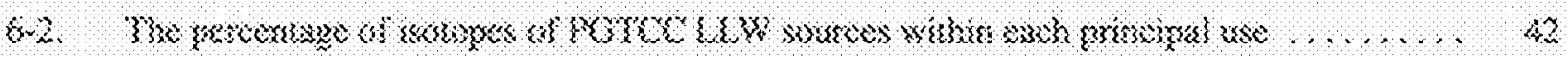

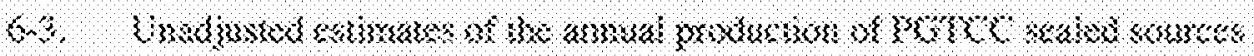

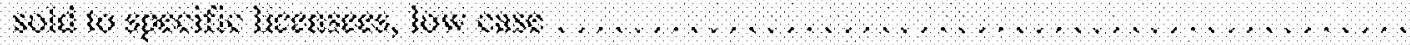

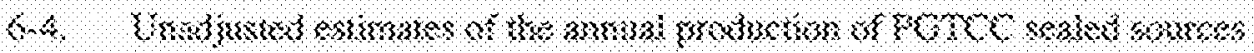

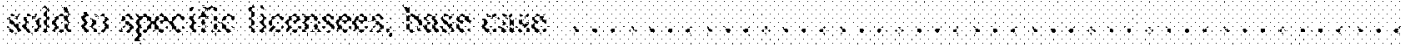

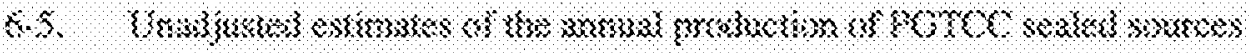

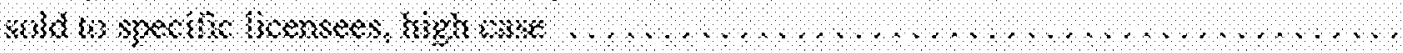

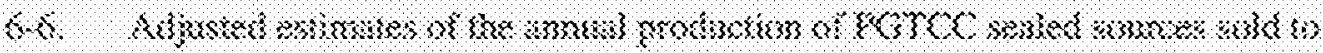

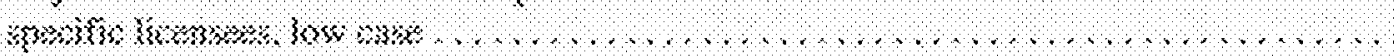

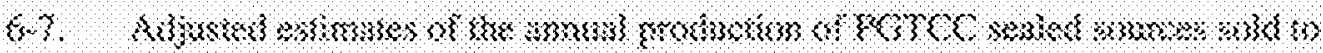

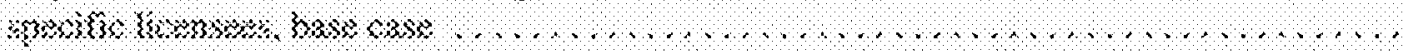

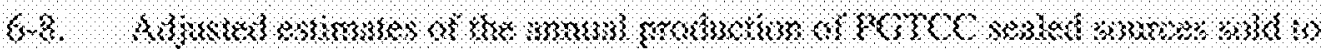

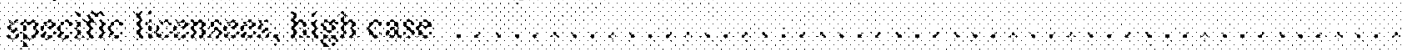




\section{mongons}

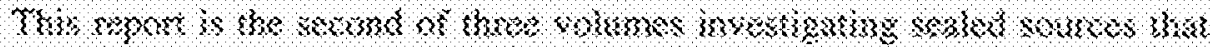

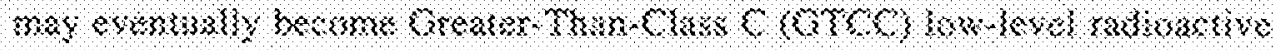

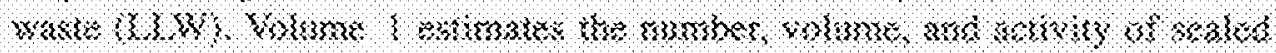

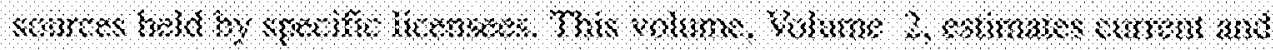

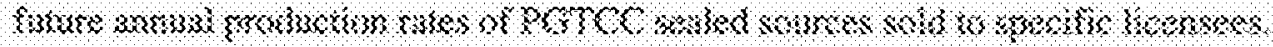

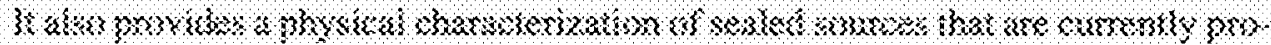

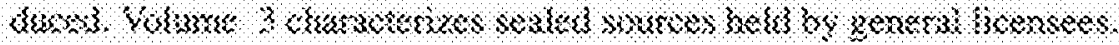




\section{AOXONYW}

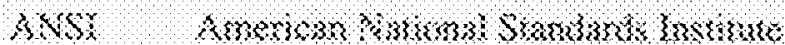

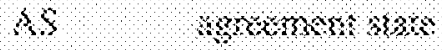

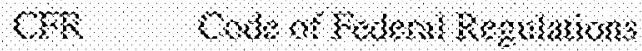

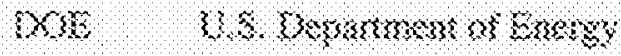

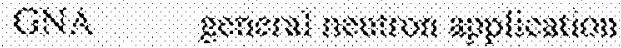

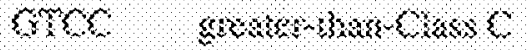

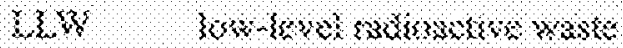

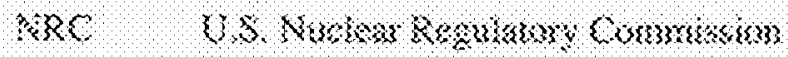

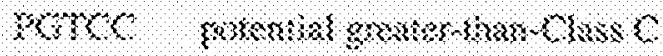

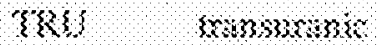

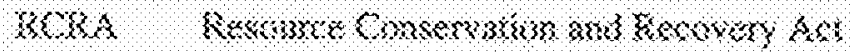

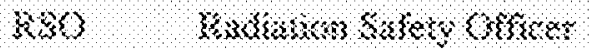

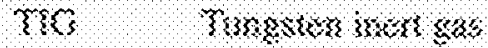

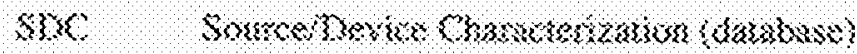

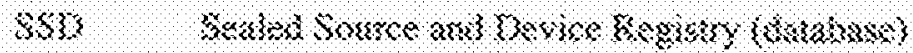

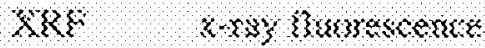




\section{Characterization of Greater-Than-Class C Sealed Sources Volume $2 \times$ Sealed Source Characterization and Future Production}

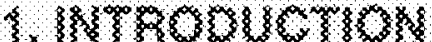

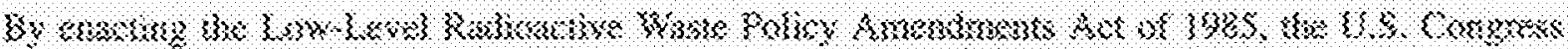

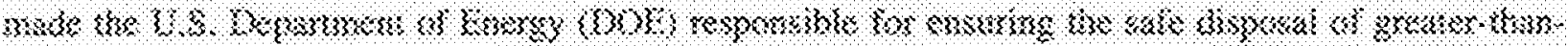

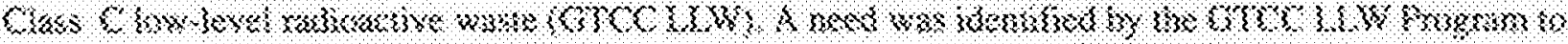

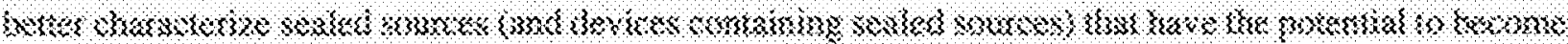

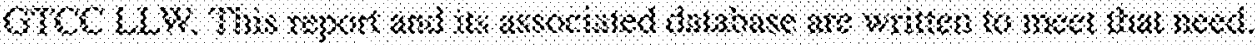

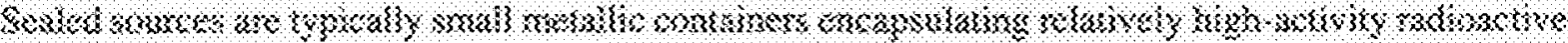

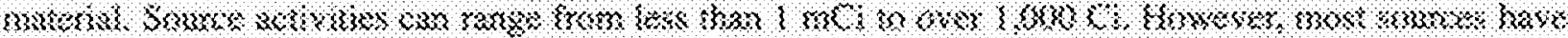

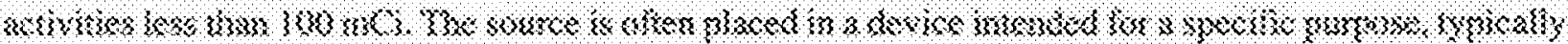

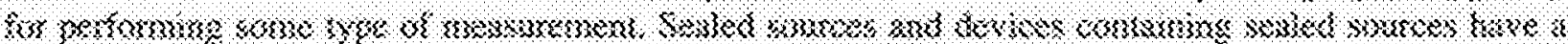

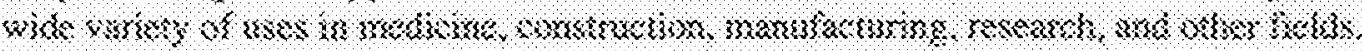

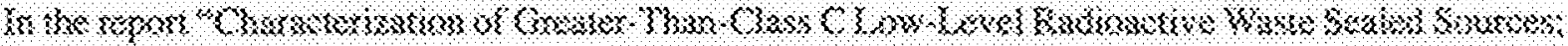

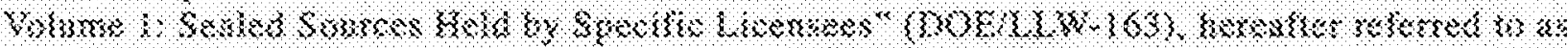

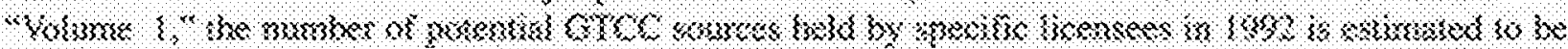

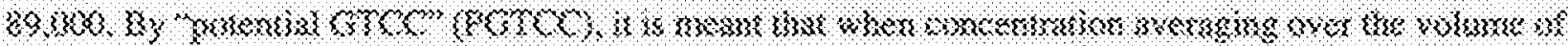

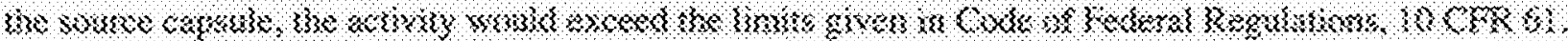

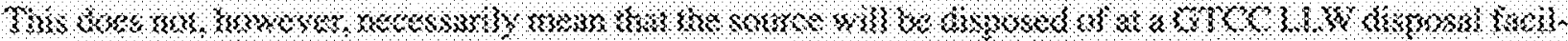

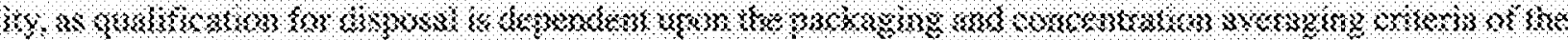
kimosis site.

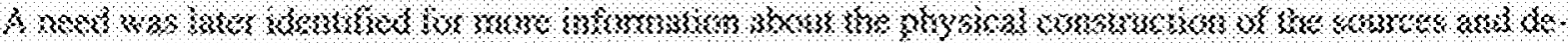

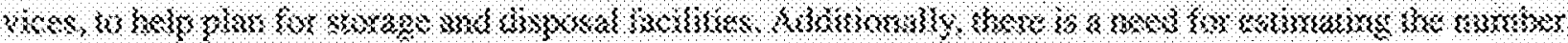

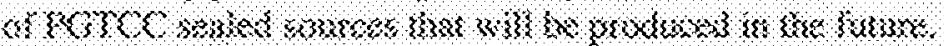

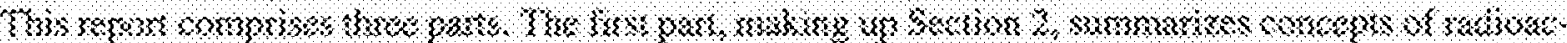

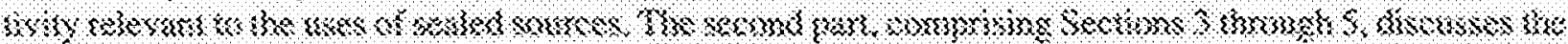

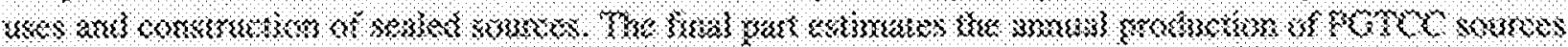

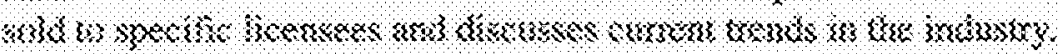

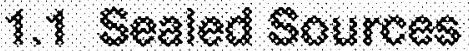

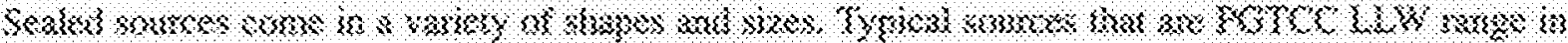

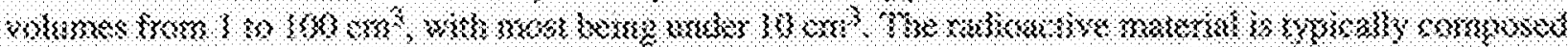

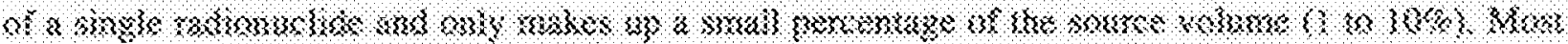

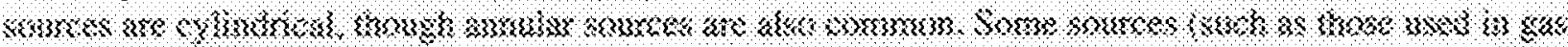

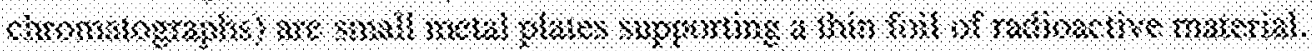

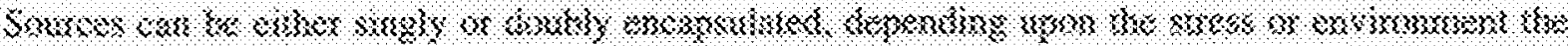

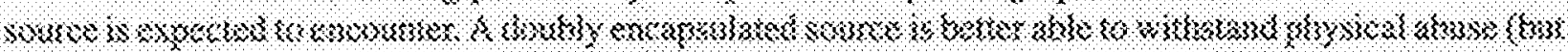

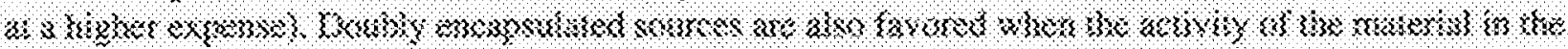




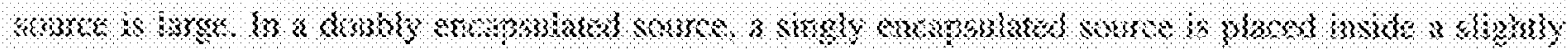

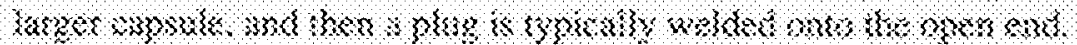

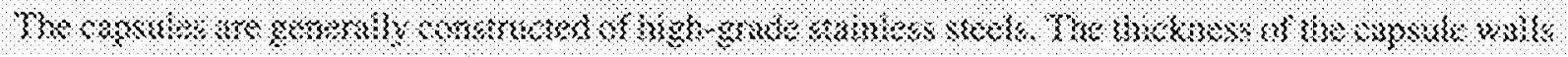

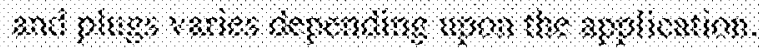

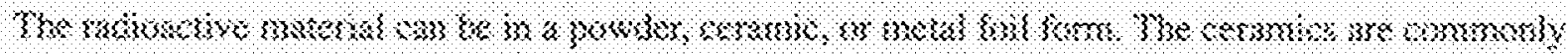

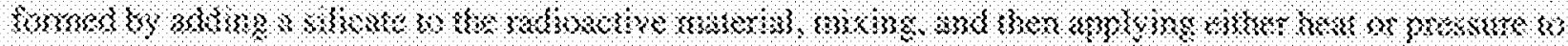

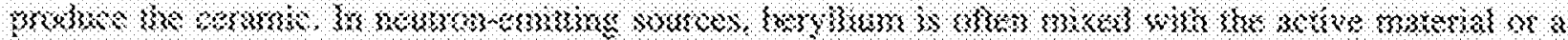

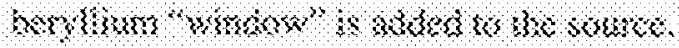

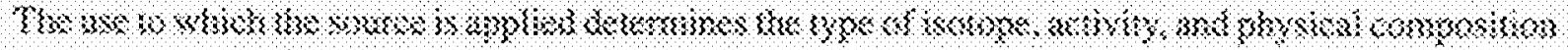

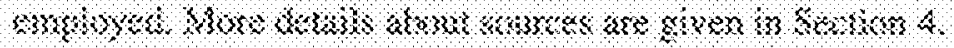

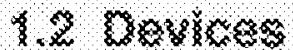

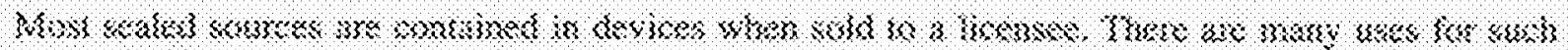

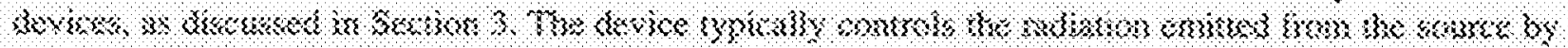

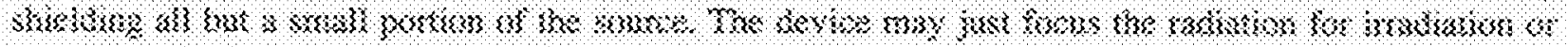

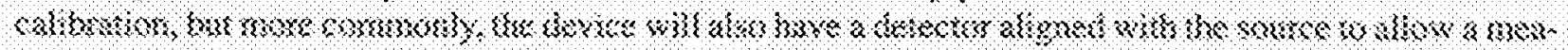

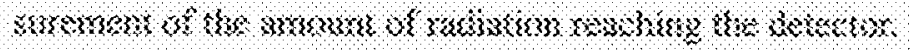

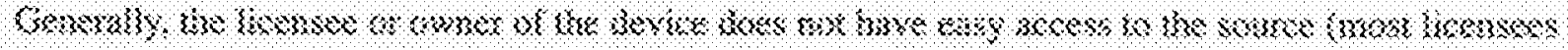

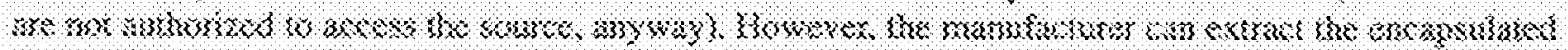

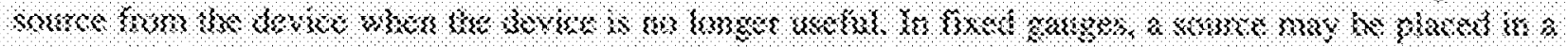

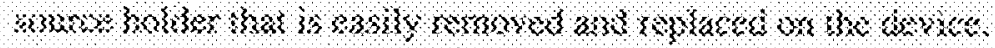

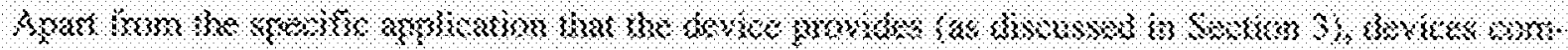

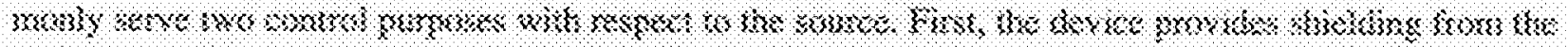

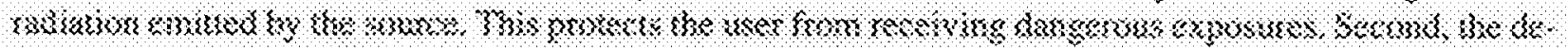

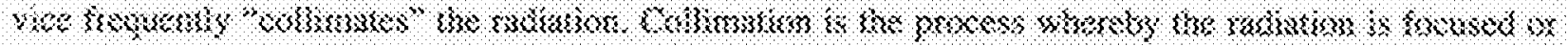

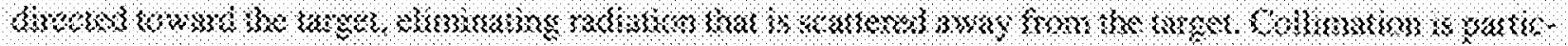

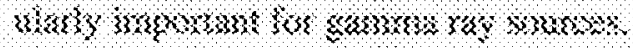

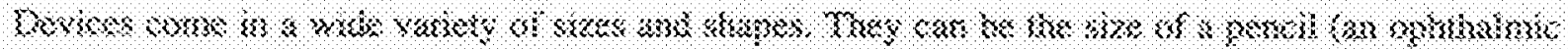

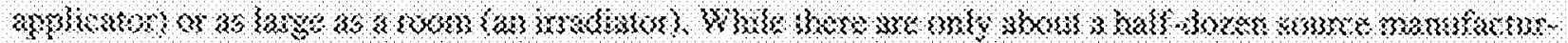

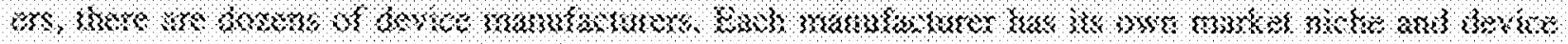

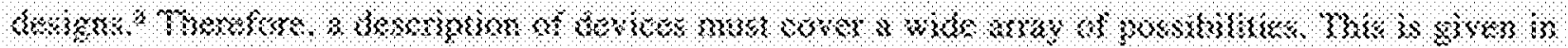
Sactism?

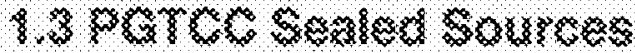

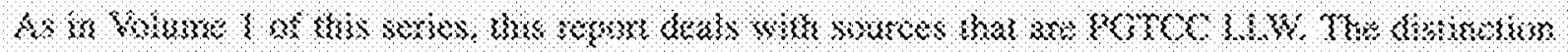

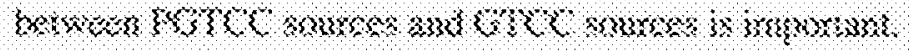

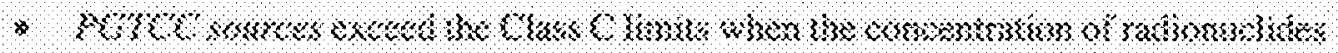

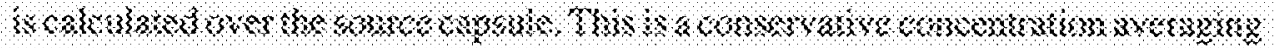

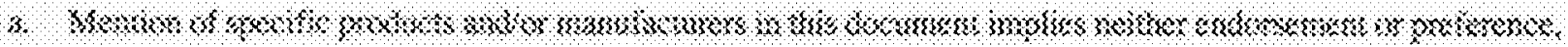

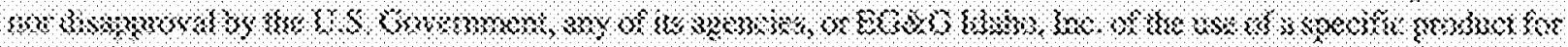

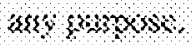




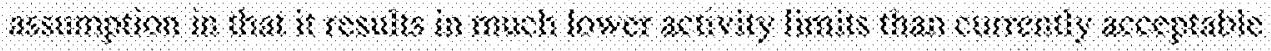

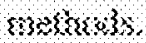

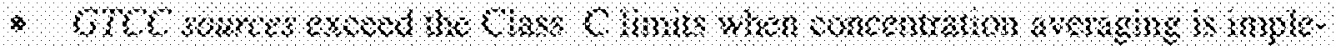

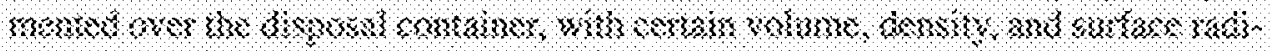

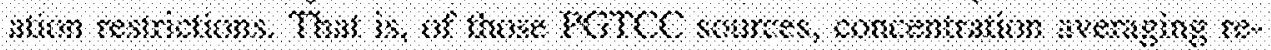

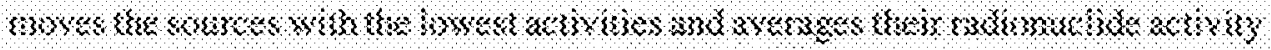

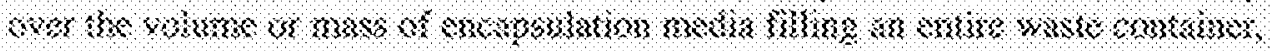

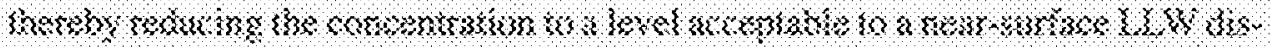

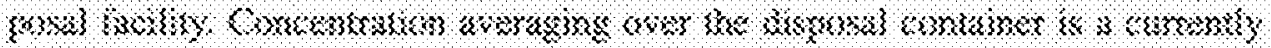
secopes pookse

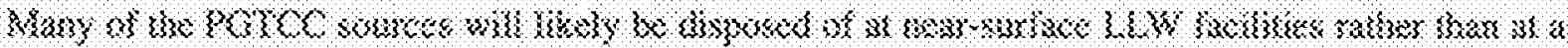

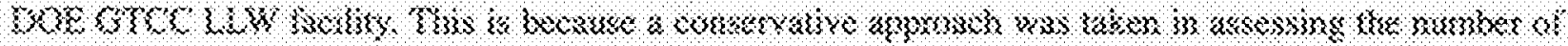

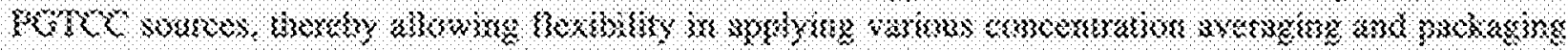

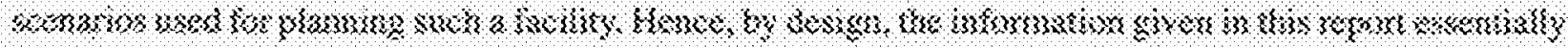

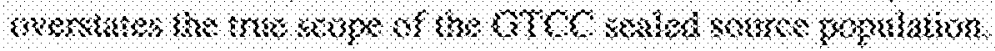

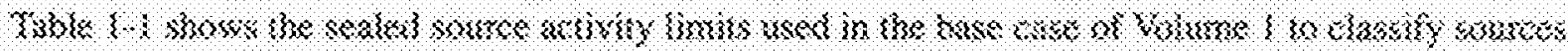

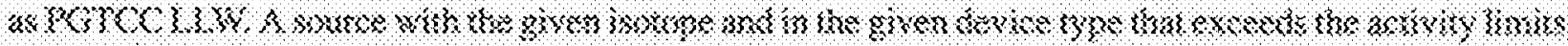

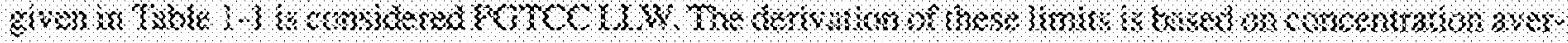

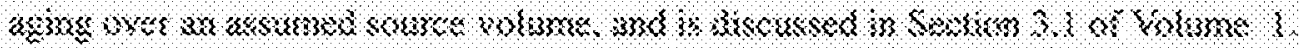

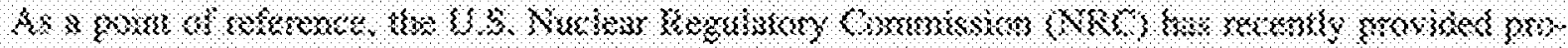

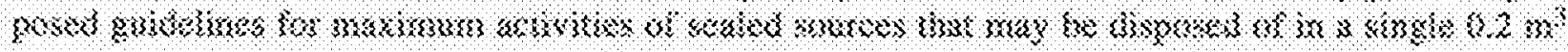

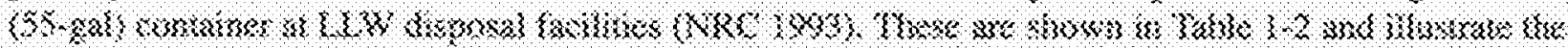

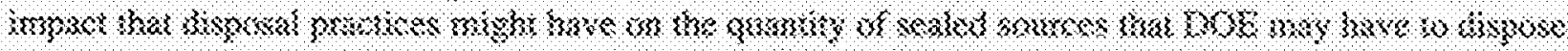

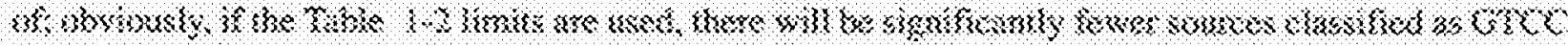

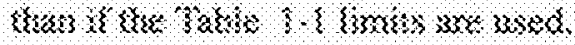

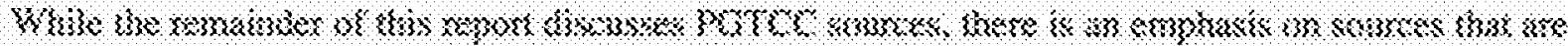

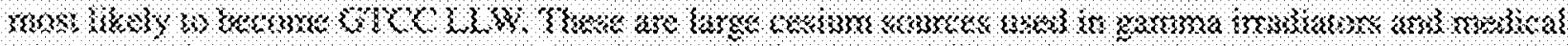

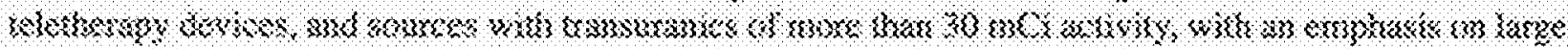
steurom soumzes. 


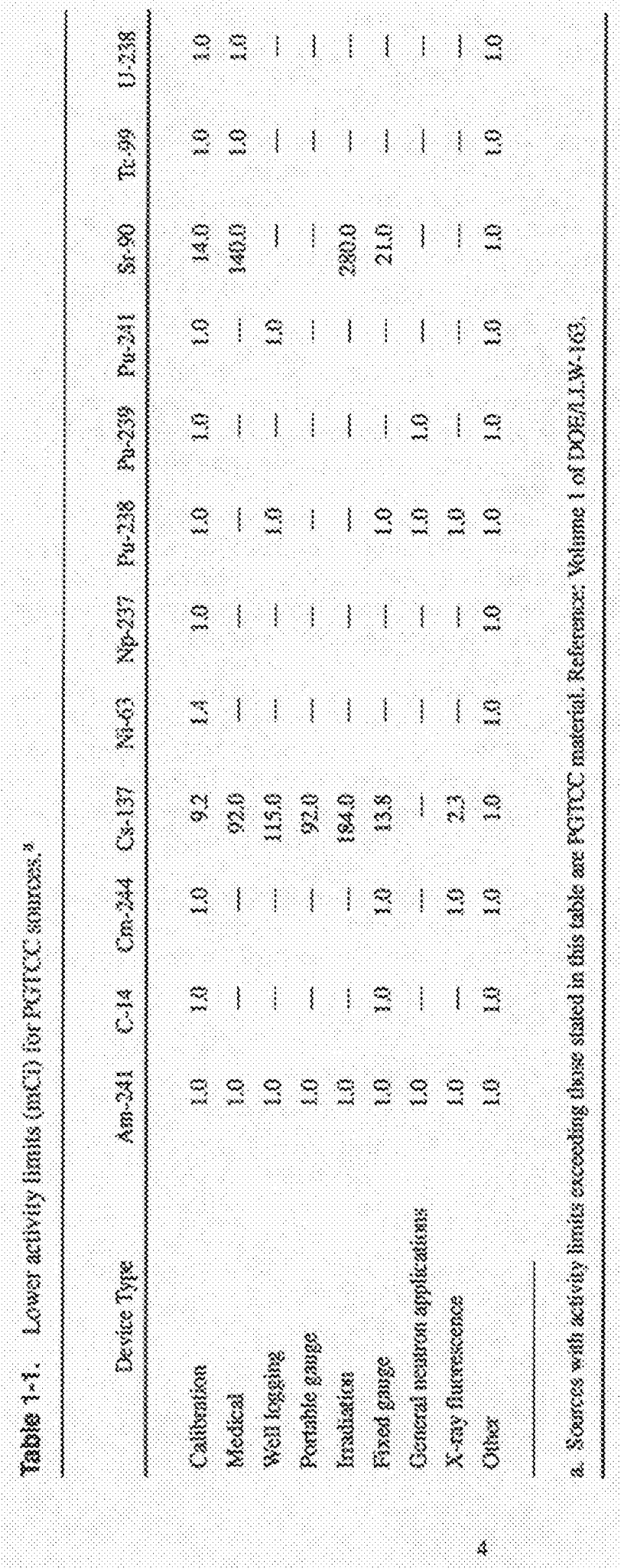




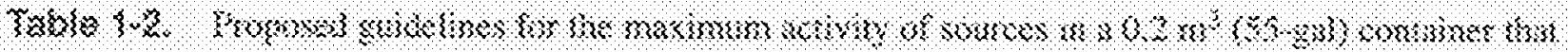

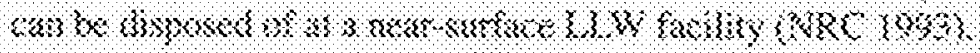

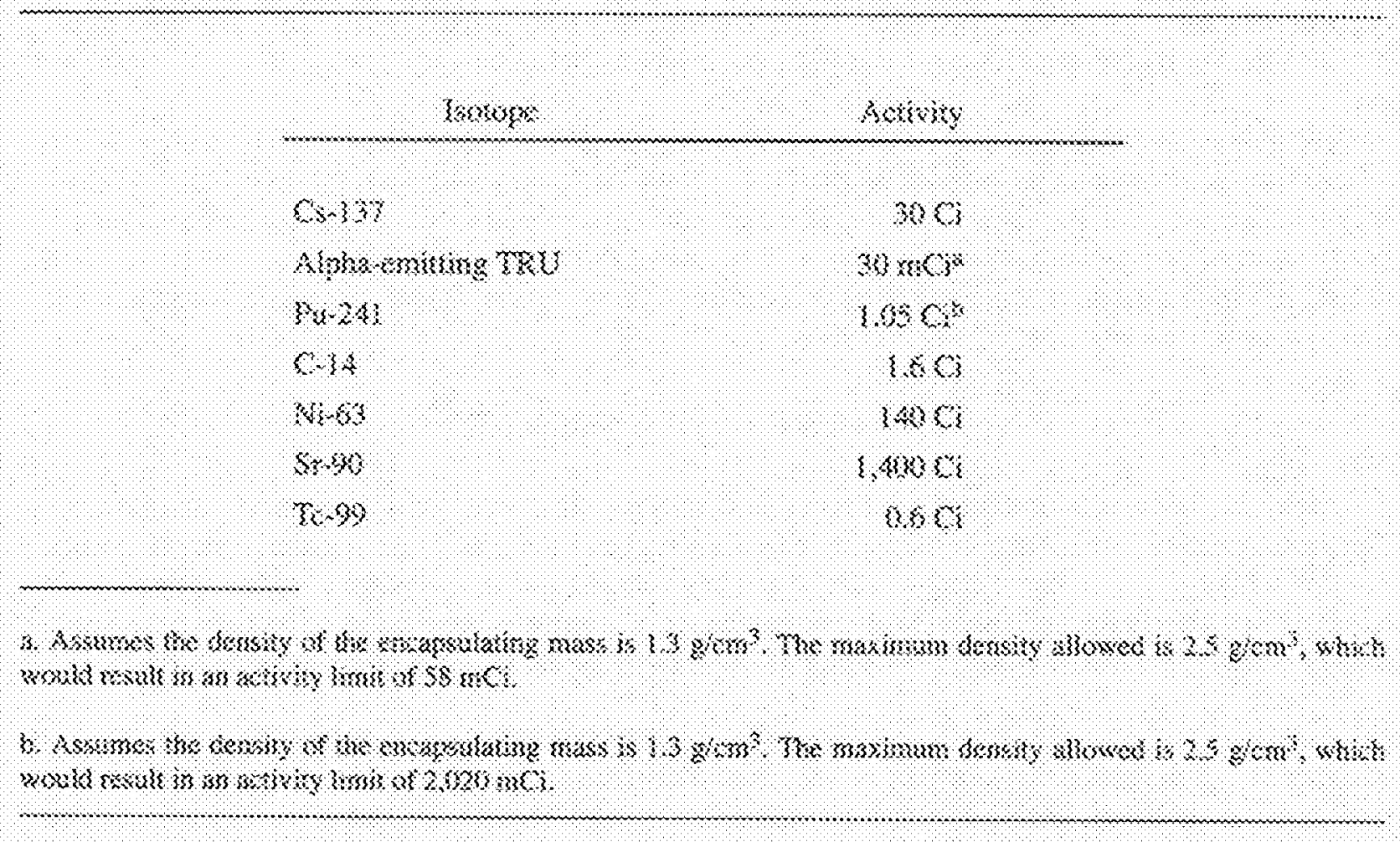




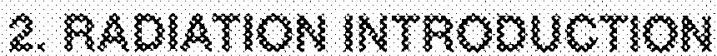

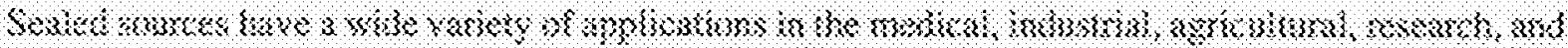

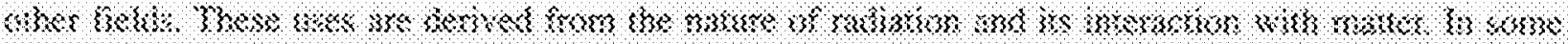

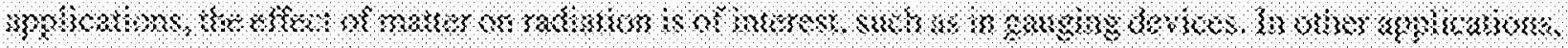

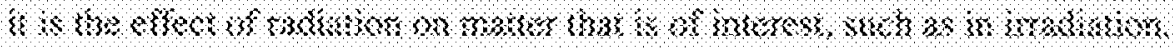

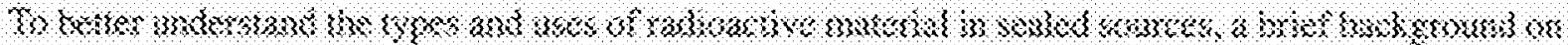

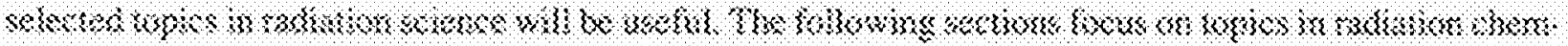

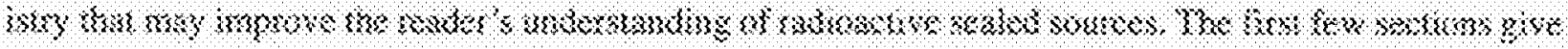

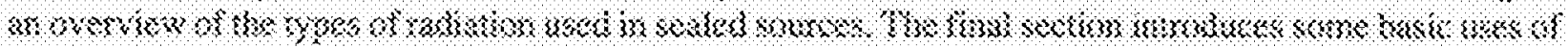

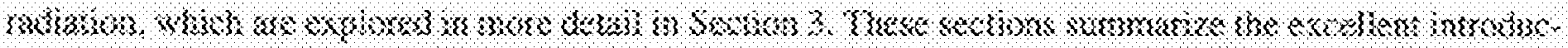

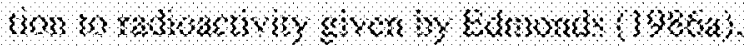

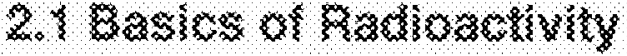

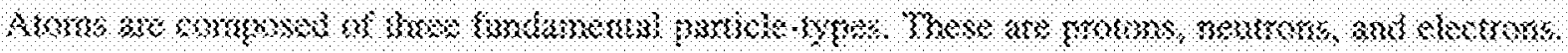

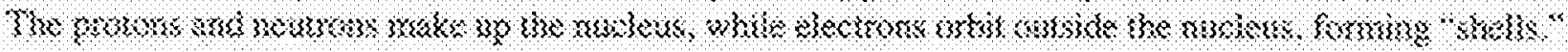

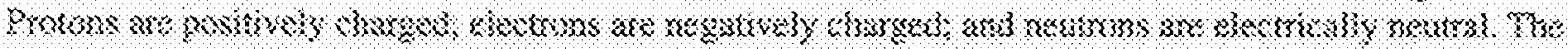

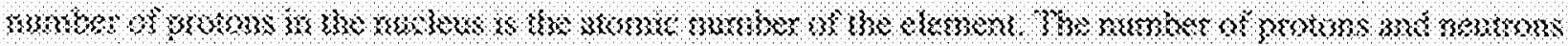

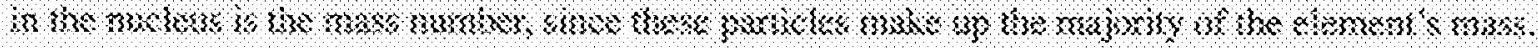

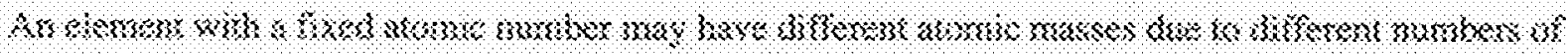

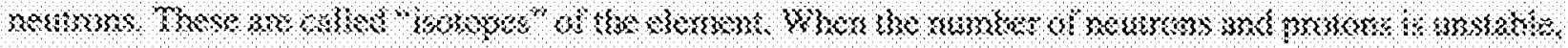

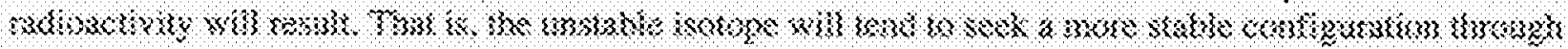

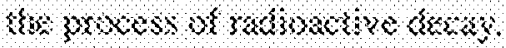

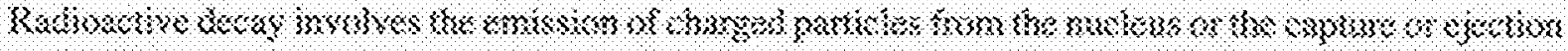

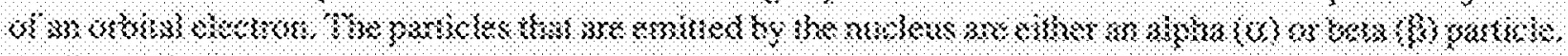

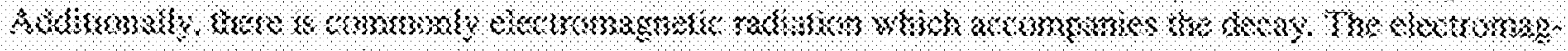

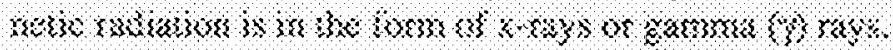

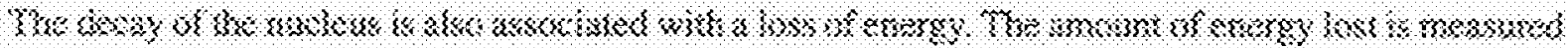

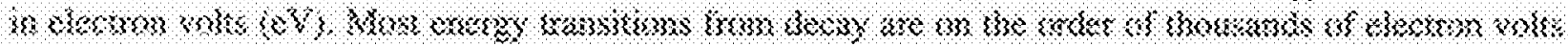

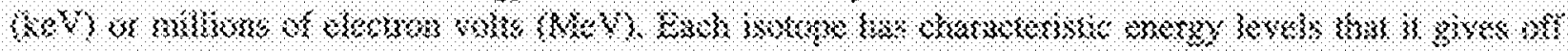

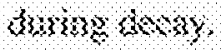

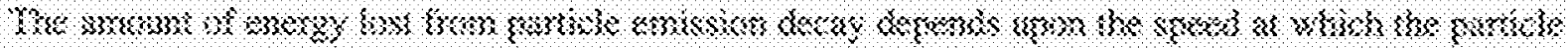

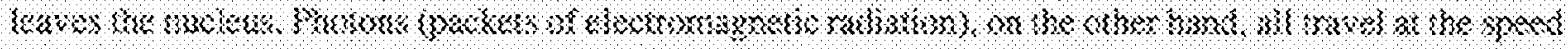

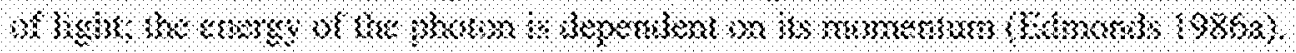

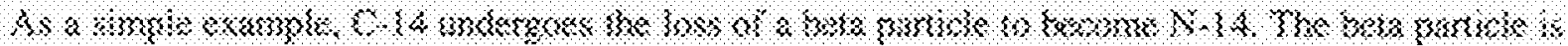

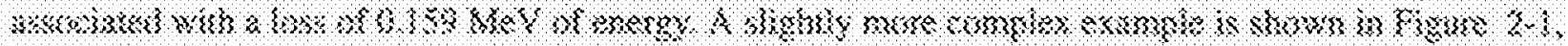

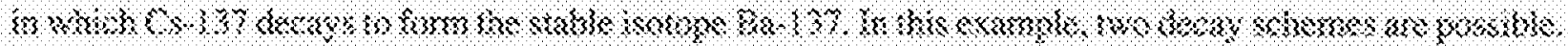

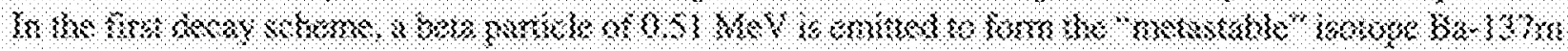

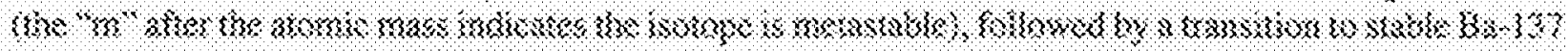

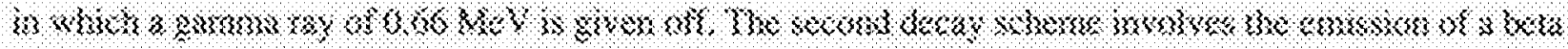

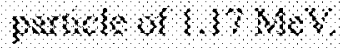




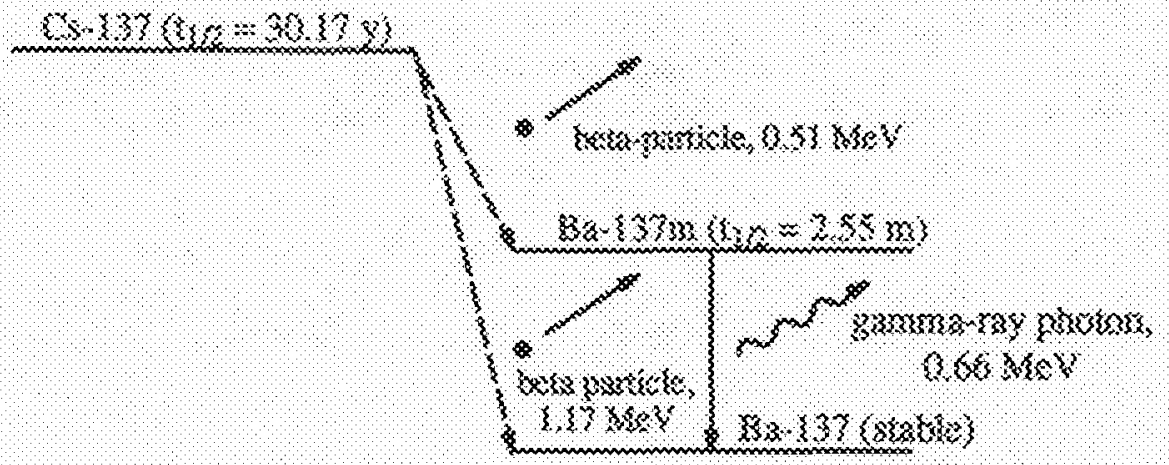

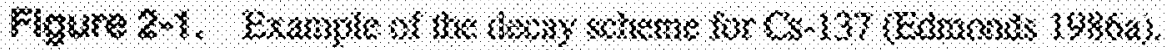

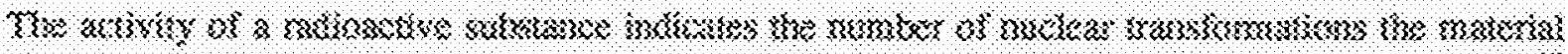

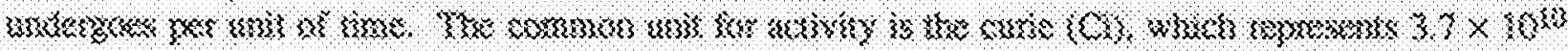

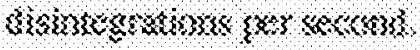

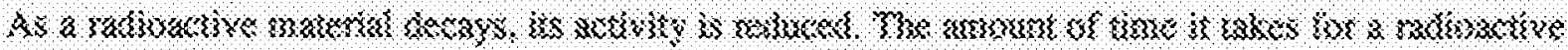

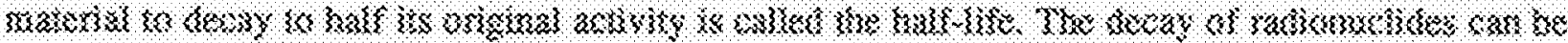

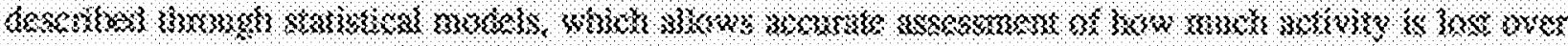

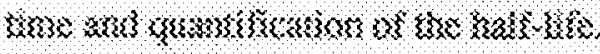

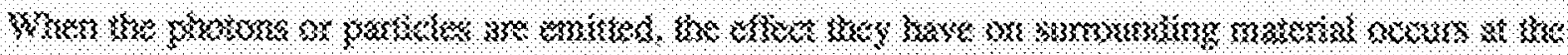

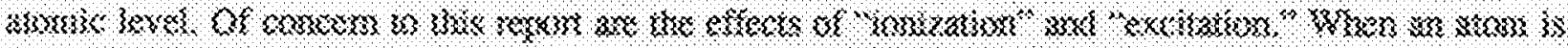

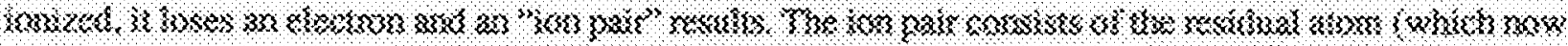

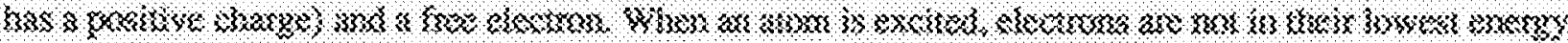

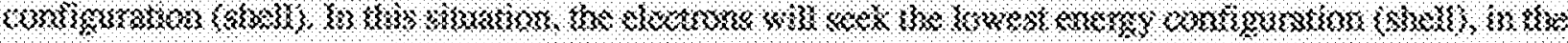

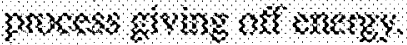

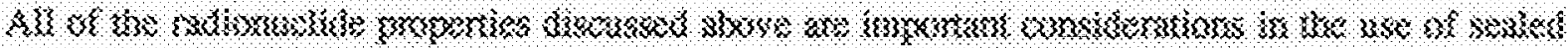

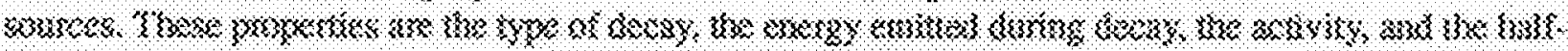

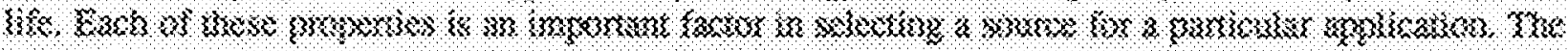

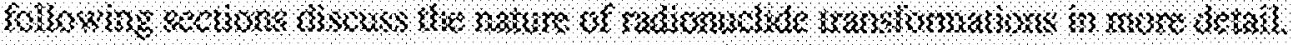

\subsection{3.}

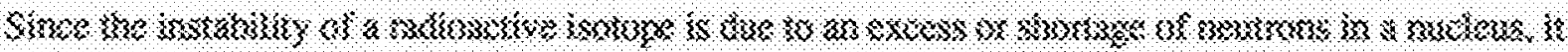

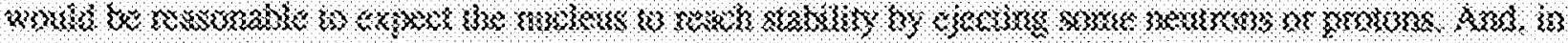

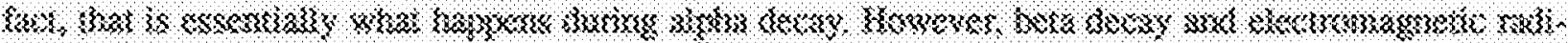

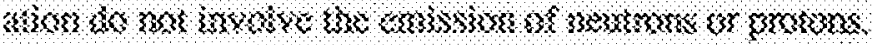

\section{ㄱ..2.8}

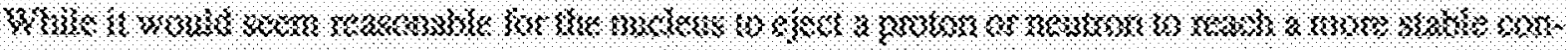

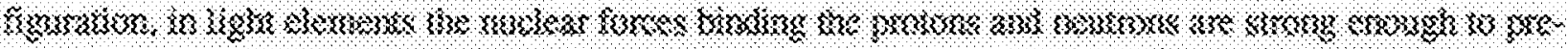

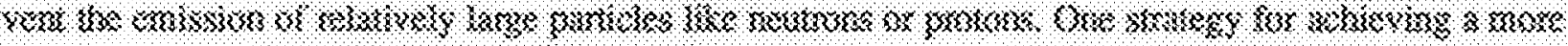

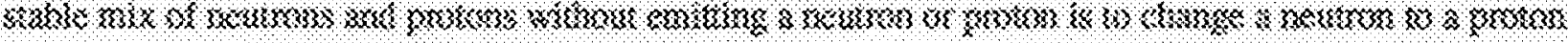
or river vera. 


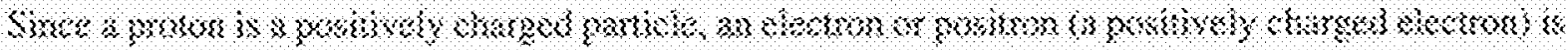

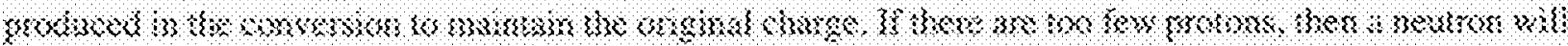

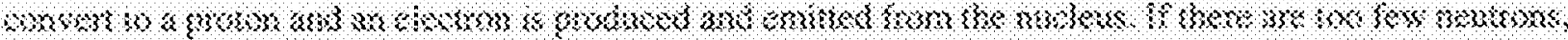

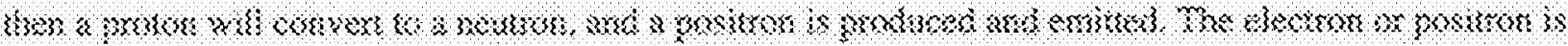
ins bera gastisise.

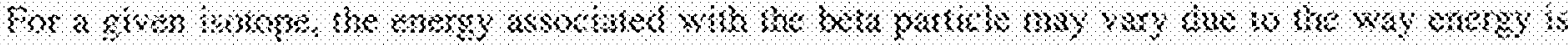

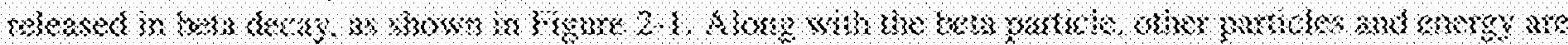

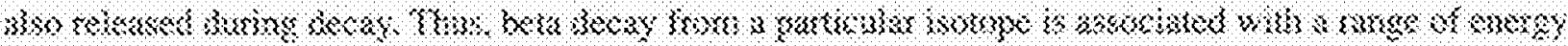
Sexsis.

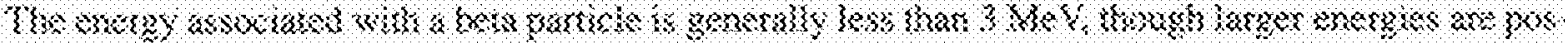

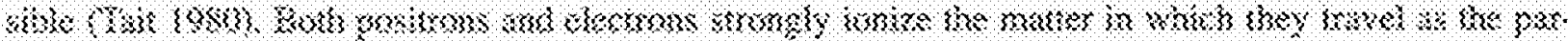

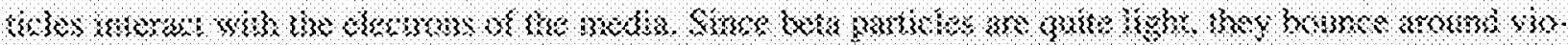

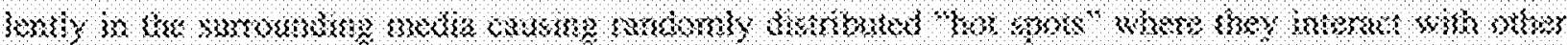

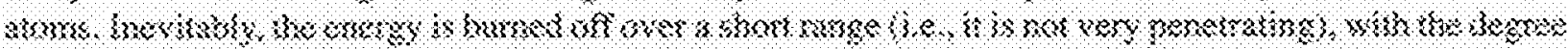

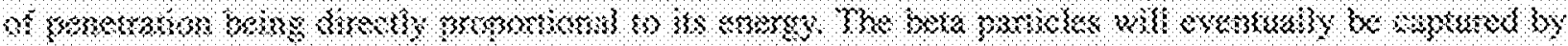

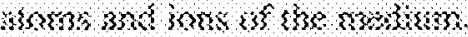

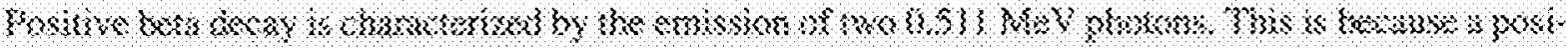

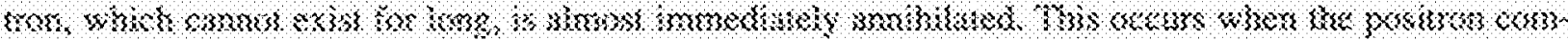
brros veik an oleskon.

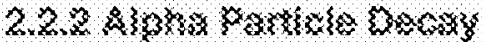

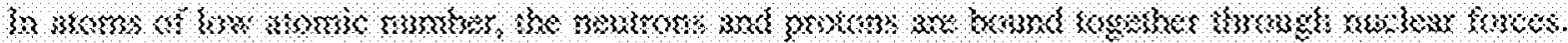

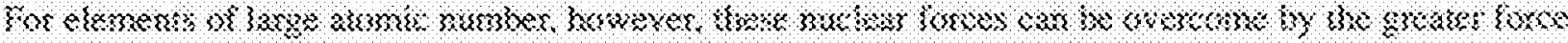

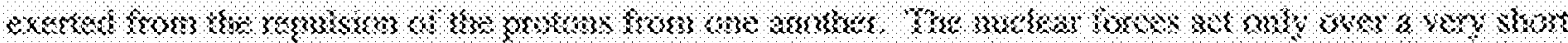

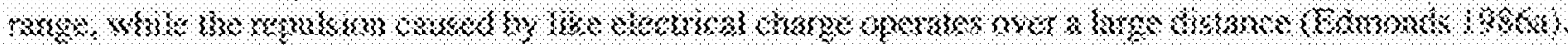

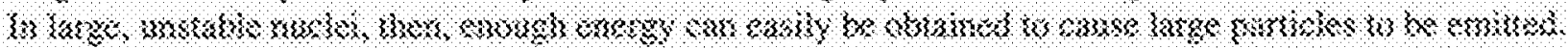

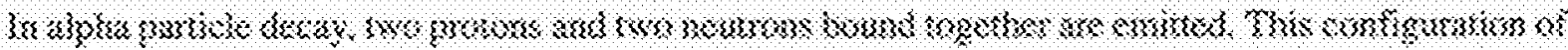

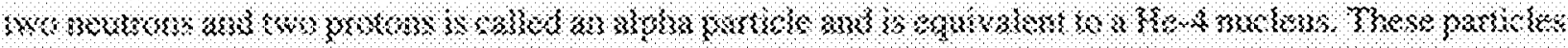

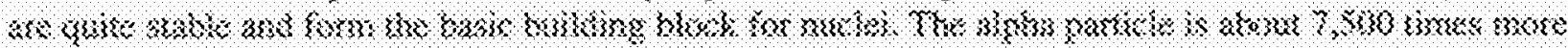

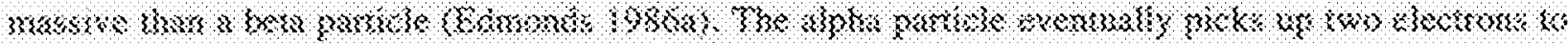
gocoms kowums

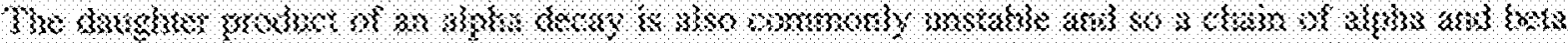

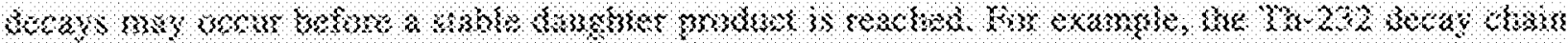

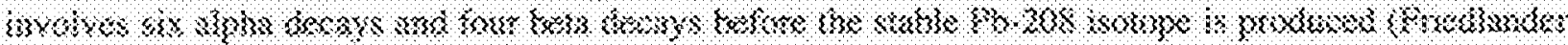
(4) 03.3983$)$.

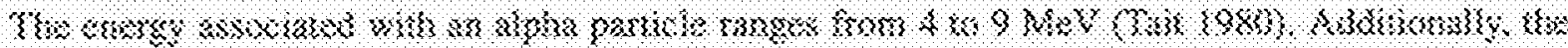

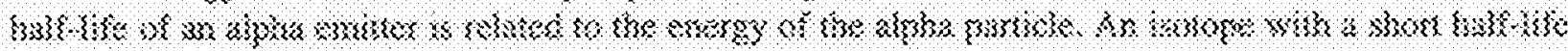

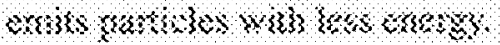

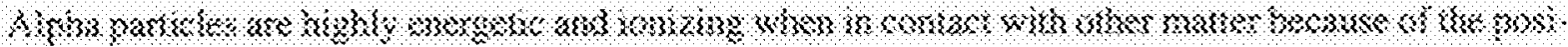

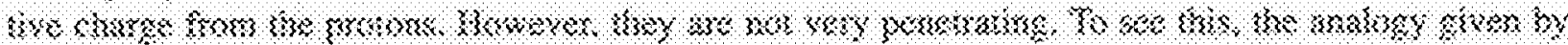

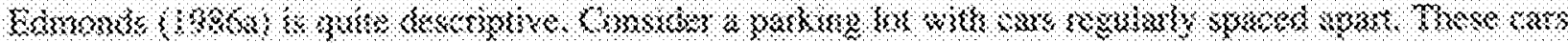

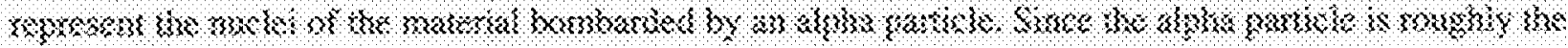

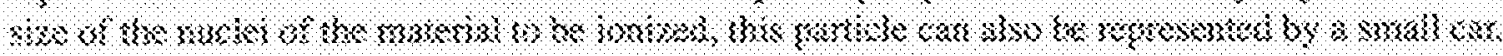




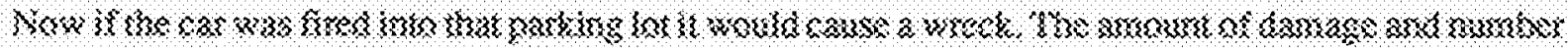

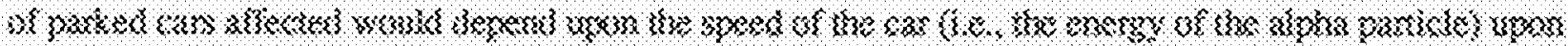

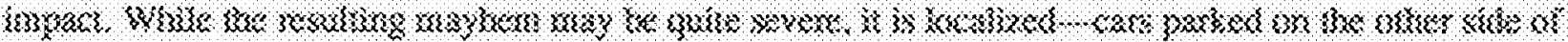

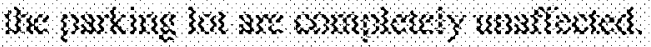

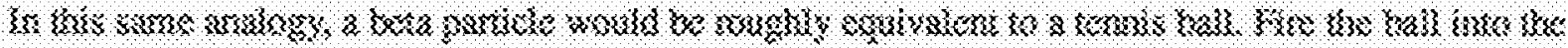

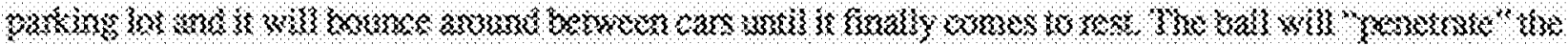

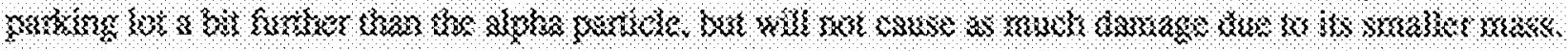

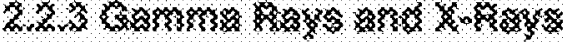

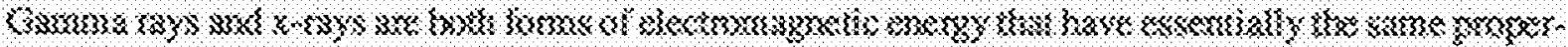

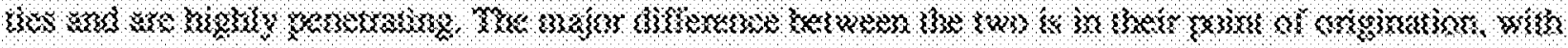

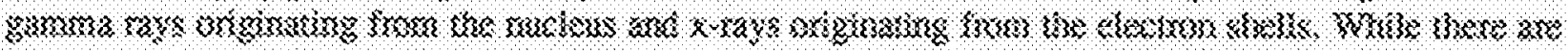

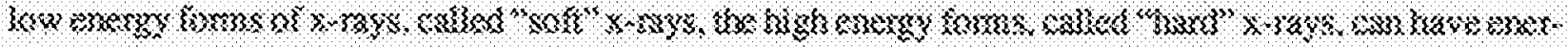

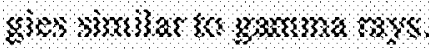

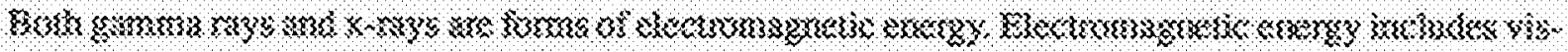

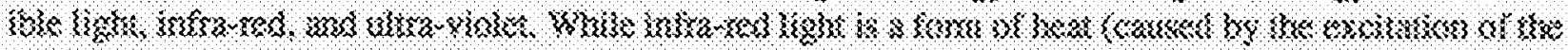

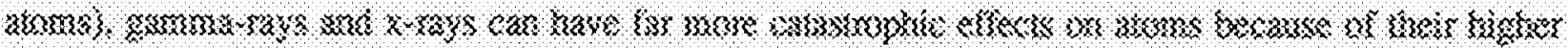

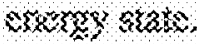

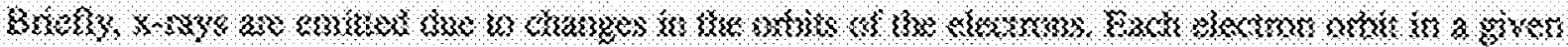

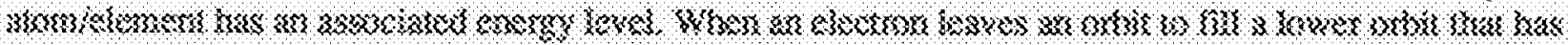

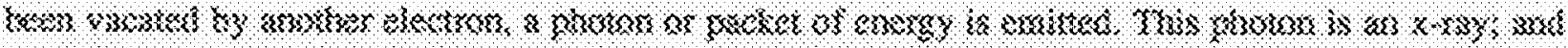

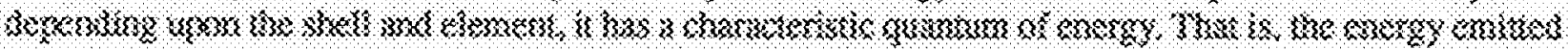

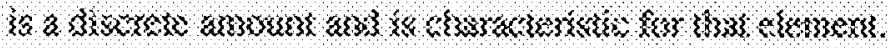

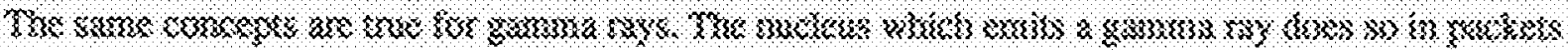

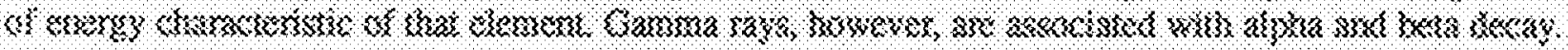

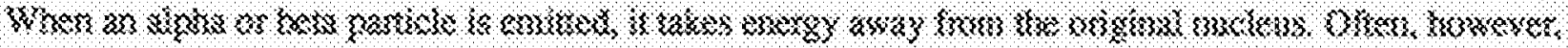

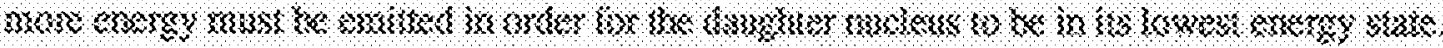

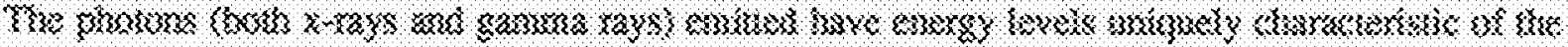

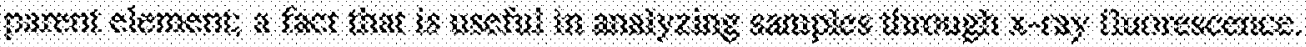

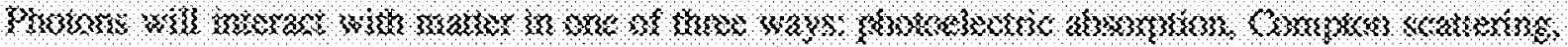

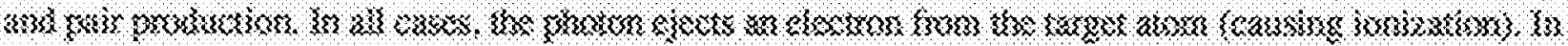

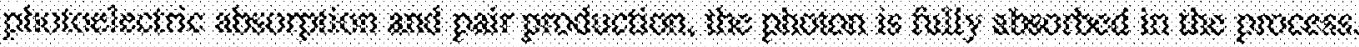

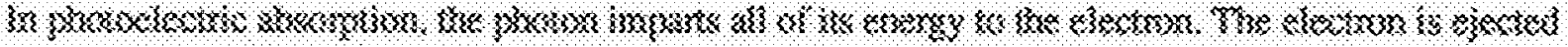

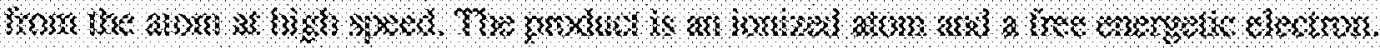

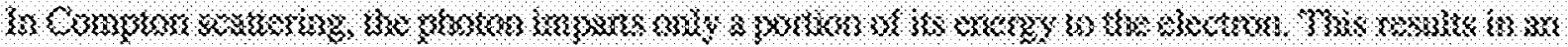

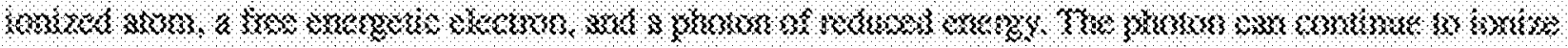
muter answi.

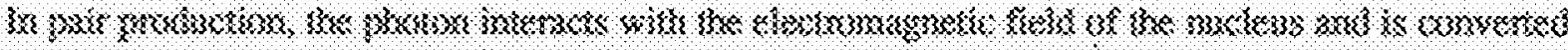

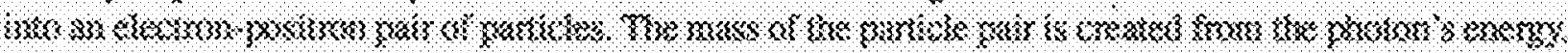

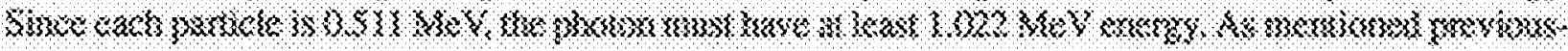

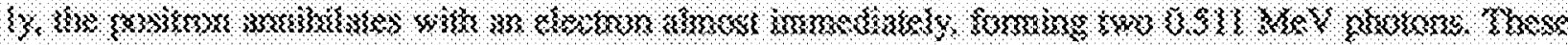

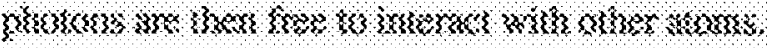




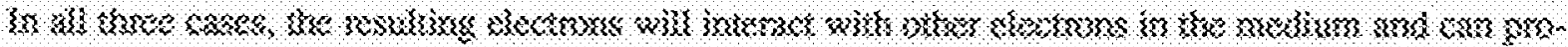

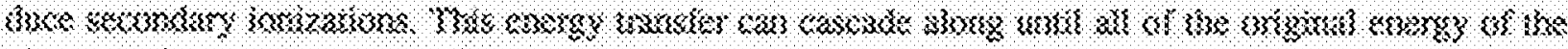

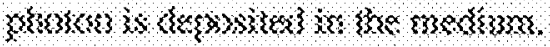

\section{3}

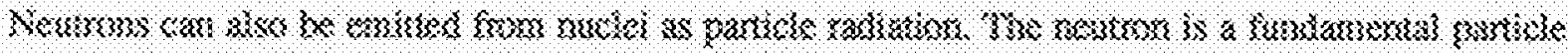

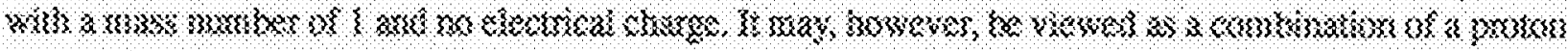

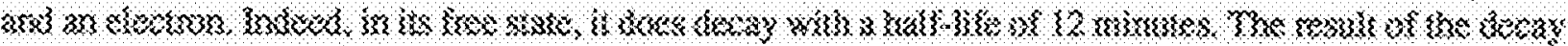

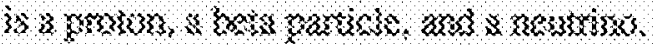

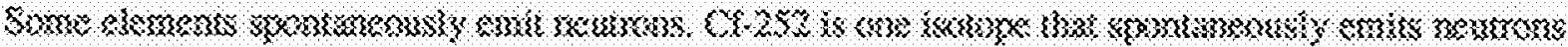

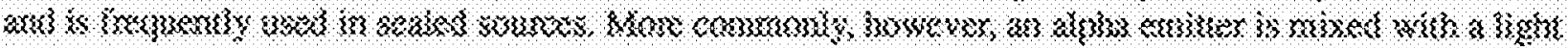

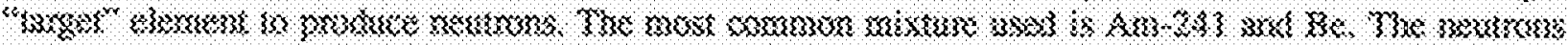

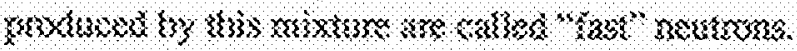

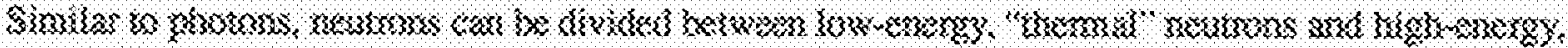

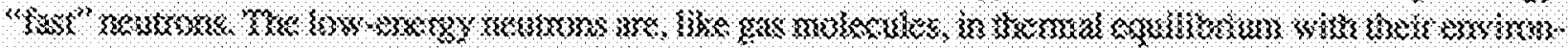

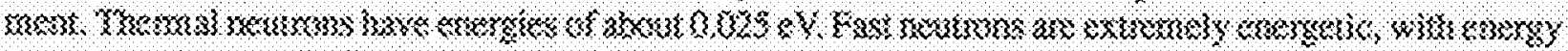

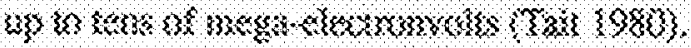

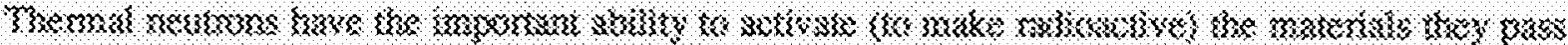

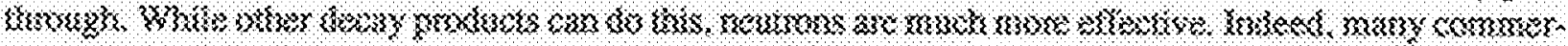

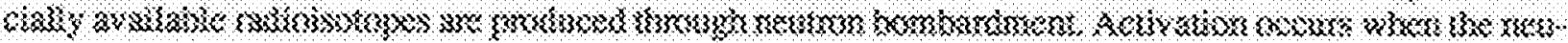

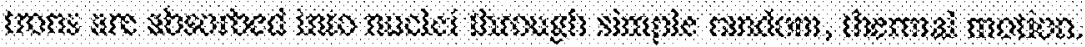

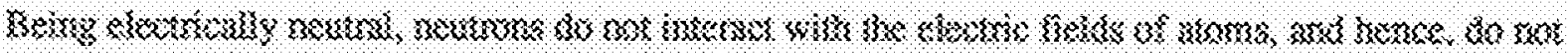

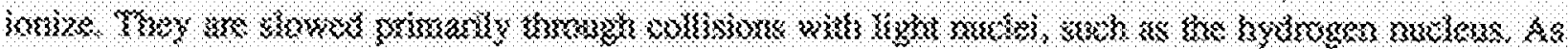

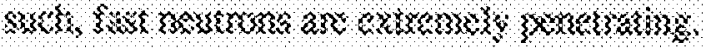

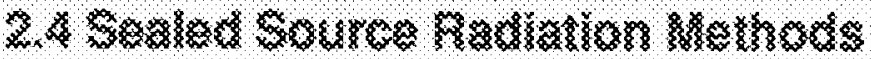

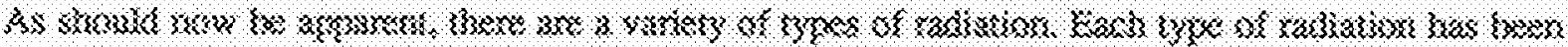

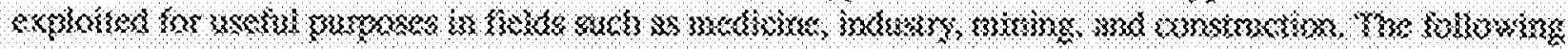

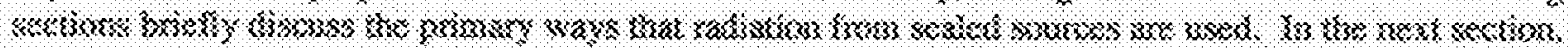

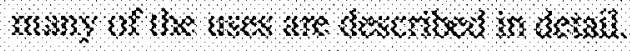

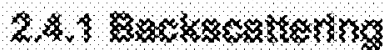

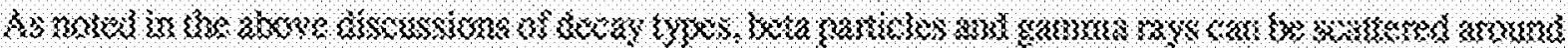

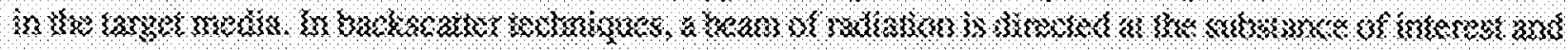

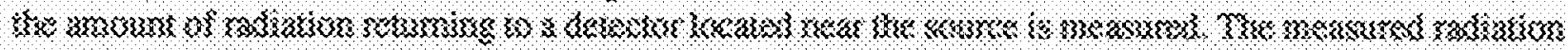

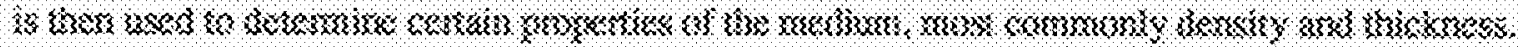

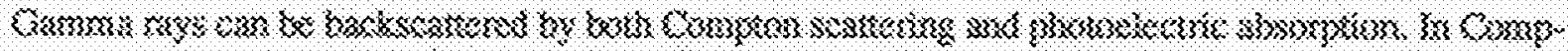

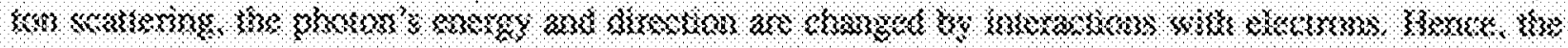

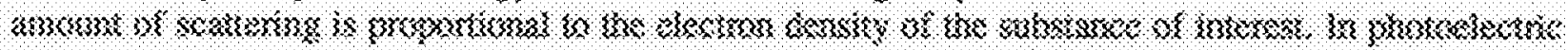

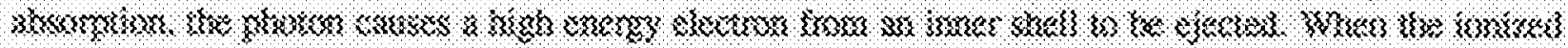

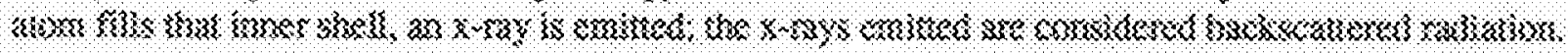




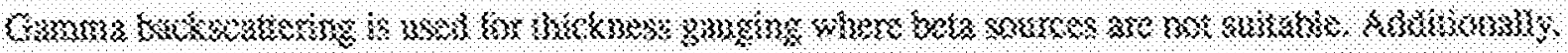

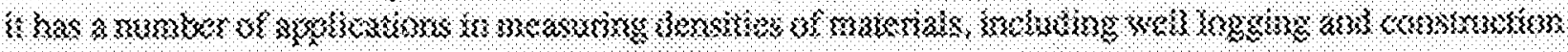

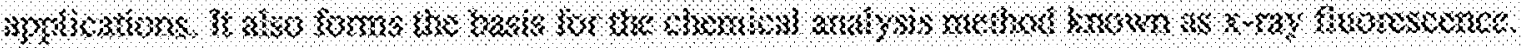

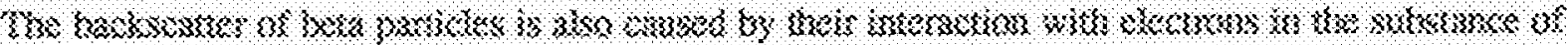

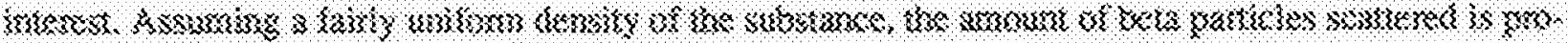

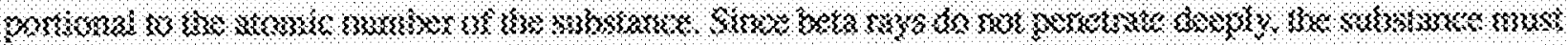

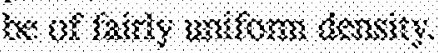

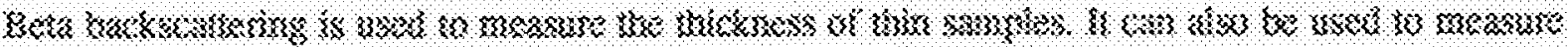

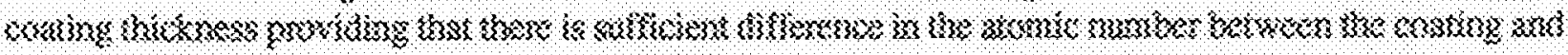

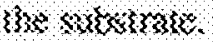

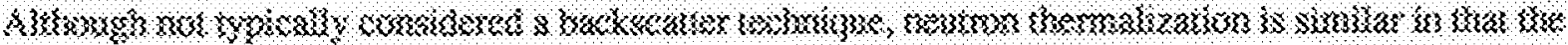

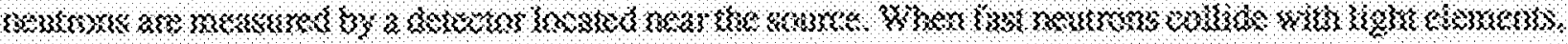

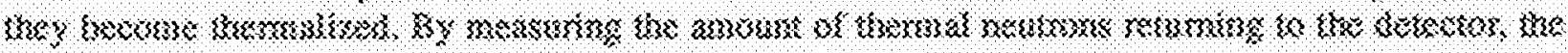

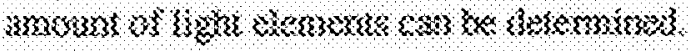

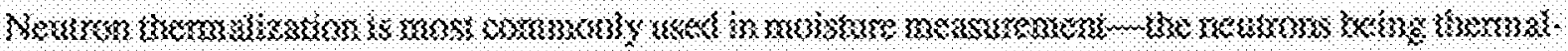

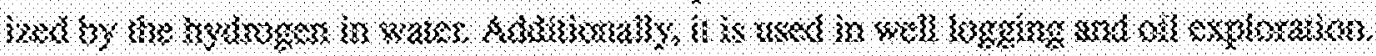

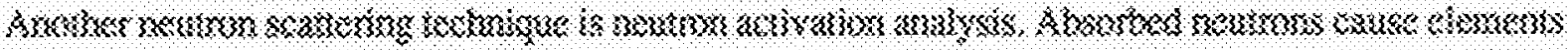

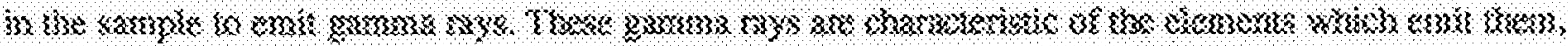

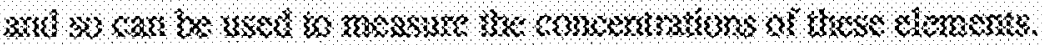

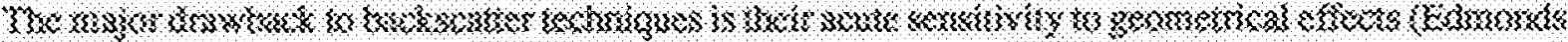

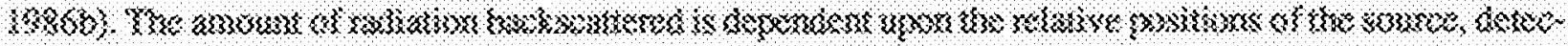
kni, akt simmpls.

\section{$2,2,2,823$}

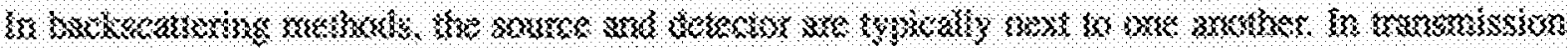

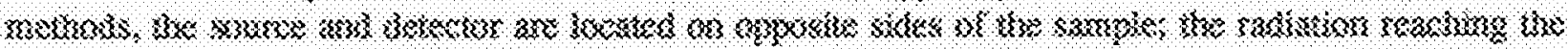

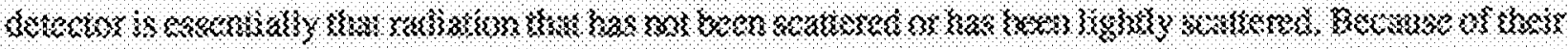

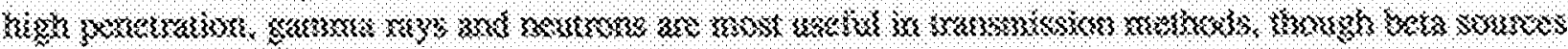

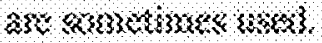

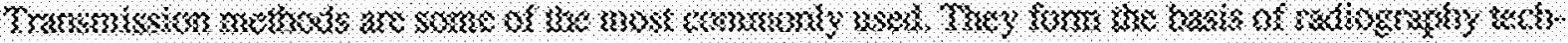

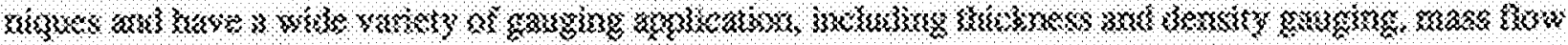

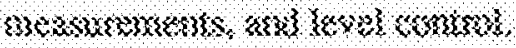

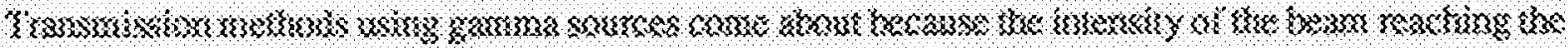

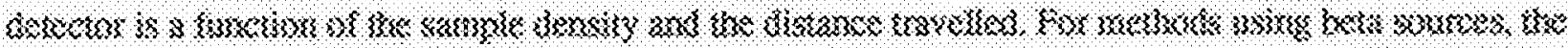

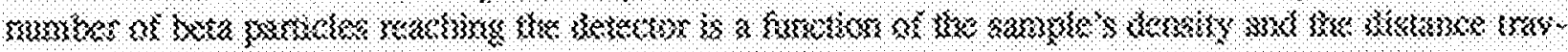

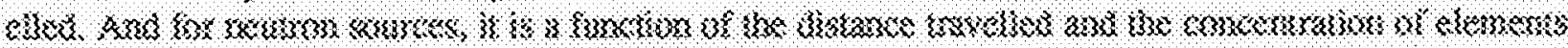

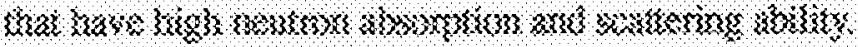

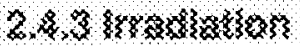

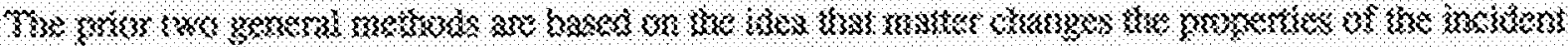

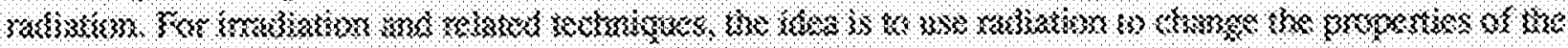




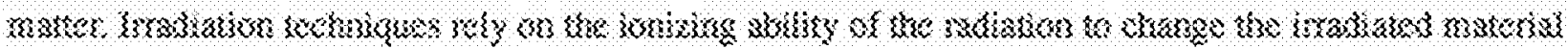
ist sombs sway.

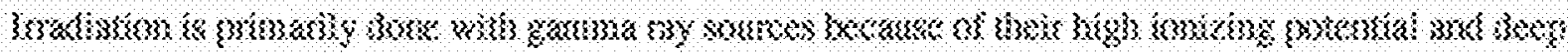

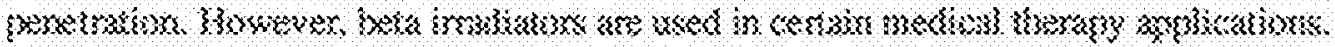

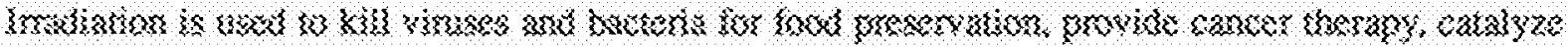

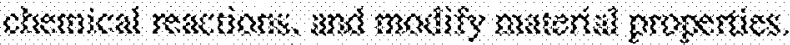

\section{2.}

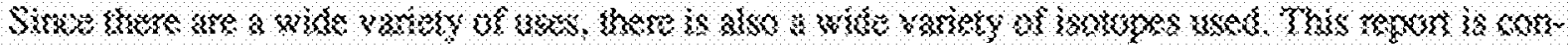

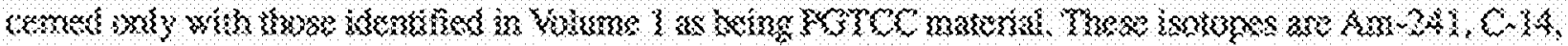

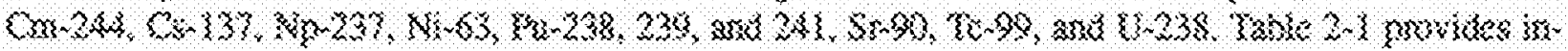

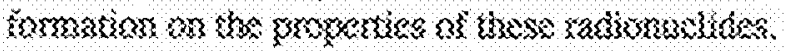

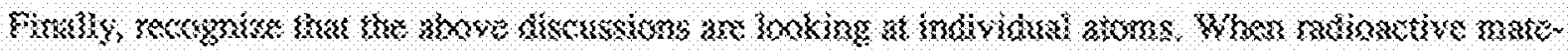

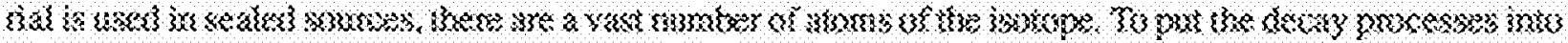

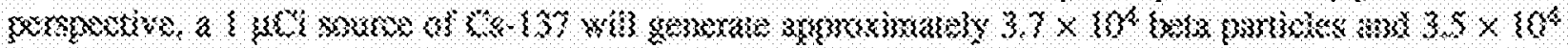

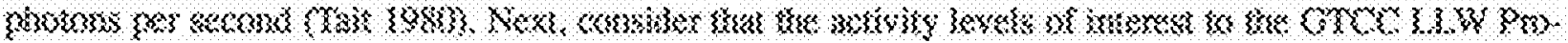

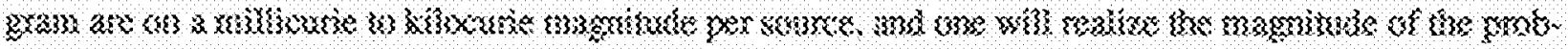

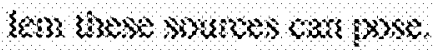




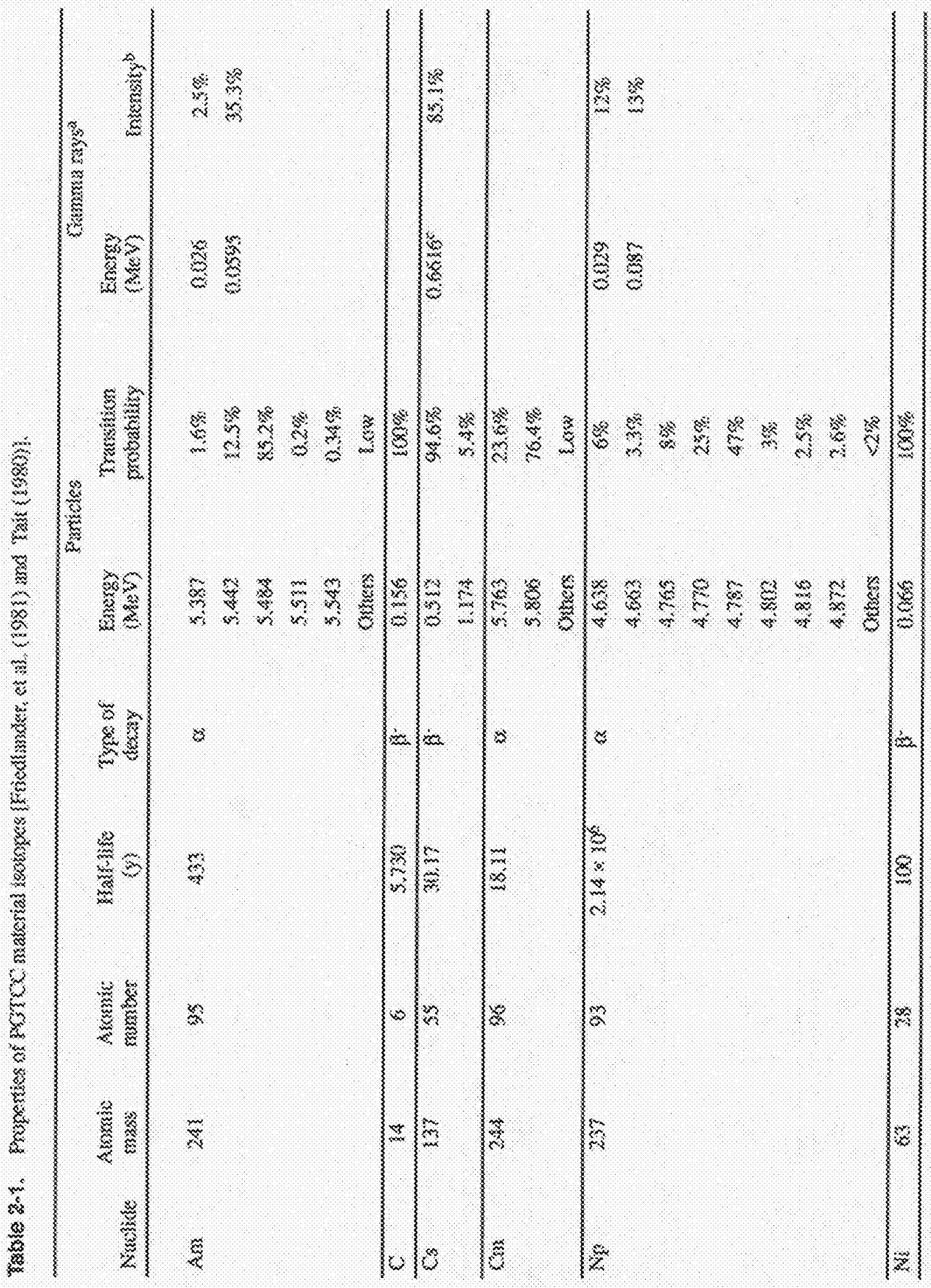




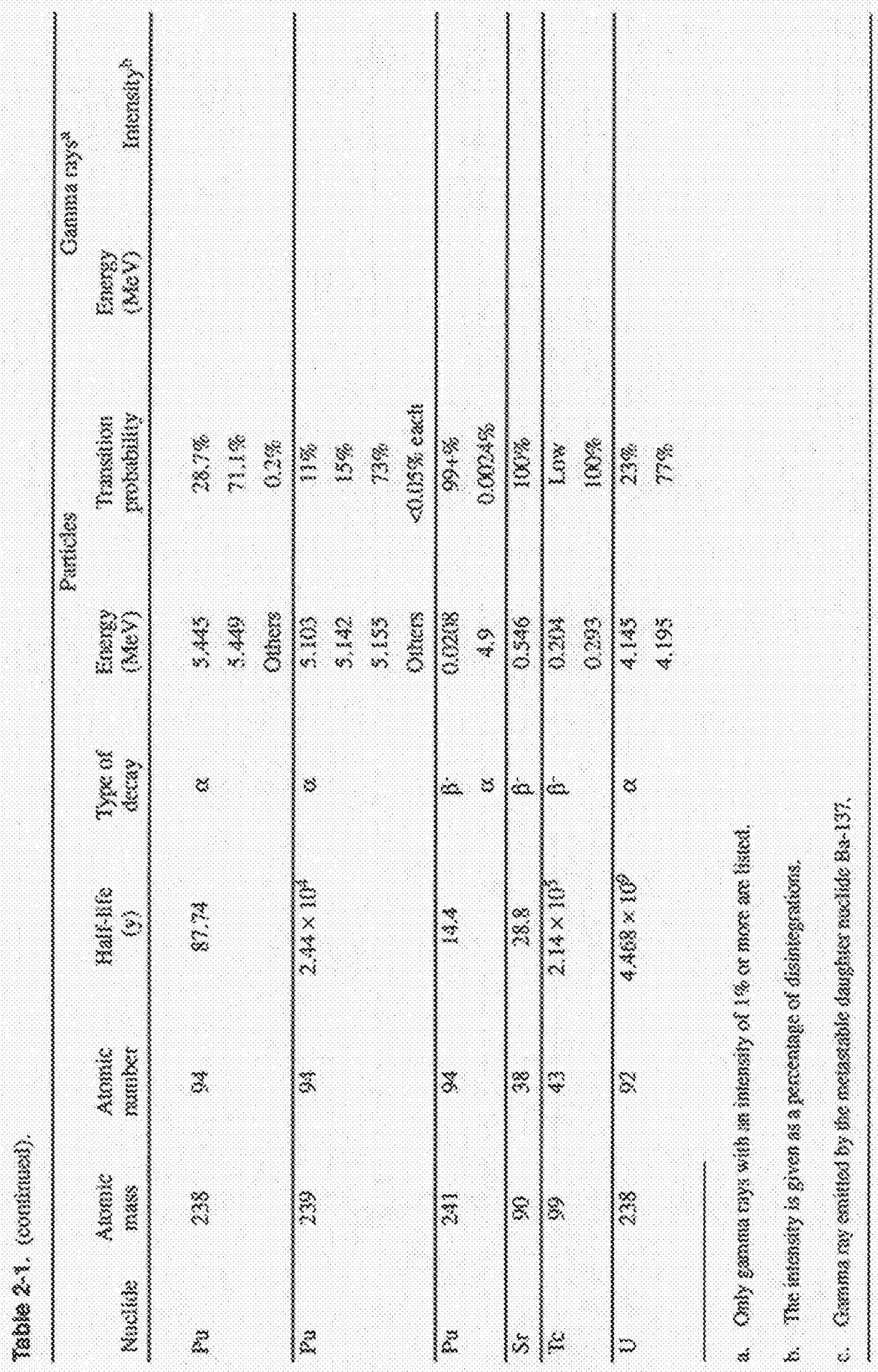




\section{SOURCE/DEVICE GENERAL DESCRIPTIONS}

The following sections give a brief overview of the various device and source types that have the potential to be GTCC material. Each section describes the function of the device/source, the isotopes and activities of the sources, and the major manufacturers. The descriptions ignore cobalt and other sources that cannot be GTCC material. Much of the information presented in this section is taken from IAEA (1990).

\subsection{Calibration Devices}

Calibration sources and devices are generally used to calibrate various radiation measuring and monitoring instruments. The source is constructed to emit a specified amount of radioactivity within a small degree of error. In this sense, a calibration device is very similar to an irradiation device as far as its method of application is concerned. Calibration sources are often traceable to some standard, such as from the National Institute of Standards and Technology (formerly the National Bureau of Standards).

There are a wide variety of isotopes and activities available for calibration sources. The primary PGTCC isotopes are Am-241, Cs-137, and Sr-90. Most of the source activities are under $1 \mathrm{Ci}$. The largest activity calibration source in the NRC Sealed Source and Device (SSD) Registry is a 5,500 Ci Cs-137 source produced by Oak Ridge National Laboratory. The remaining PGTCC calibration sources in the Registry are all less than $250 \mathrm{Ci}$.

The major manufacturers of calibration sources and devices that are PGTCC material are Monsanto (who is no longer producing sealed sources) and Amersham. GNI, 3M, and ABB Process Automation have also been significant sellers of calibration sources or devices.

\subsection{Medical Sources}

Sealed sources are used for both diagnosis and treatment of diseases. Uses include $\mathrm{x}$-ray imaging, brachytherapy, and teletherapy. The latter two uses involve irradiating damaged tissue. Medical teletherapy devices treat disease with gamma radiation from a controlled source of radiation located at a distance from the patient. Additionally, there are numerous medical reference sources used as instrument check sources and spot markers. Radioactive materials in unsealed form also have a variety of uses in medicine, including tracer studies and therapeutic applications; however, these unsealed sources generally do not use PGTCC isotopes and are not discussed here.

The isotopes most likely to be found in PGTCC sources or devices are Am-241 and Cs-137, though there are a few high-activity Sr-90 sources also. In the past, Ra-226 sources were extensively used in brachytherapy. Cobalt and iridium sources are probably the most common but are not PGTCC material. Most medical sources have activities well below the PGTCC limits. The majority of medical sources are well below $100 \mathrm{mCi}$, though there are some sources in the kiloCurie range-used in medical teletherapy devices.

The major manufacturer of medical sources that are PGTCC material was 3M. Since 3M no longer produces sealed sources, other companies such as Amersham and Isotope Products Laboratories will have increasing shares of this market. Nuclear Associates also has a significant market share, specializing in medical reference sources.

\subsubsection{Medical Diagnostic Imaging (X-Ray Imaging)}

Diagnostic imaging includes a range of radiographic and fluoroscopic techniques, with new techniques still being developed. In general, a beam of radiation is directed through the part of a patient's body under 


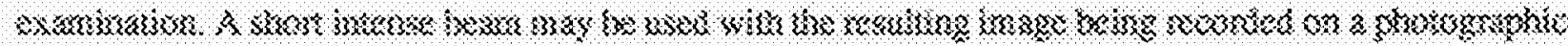

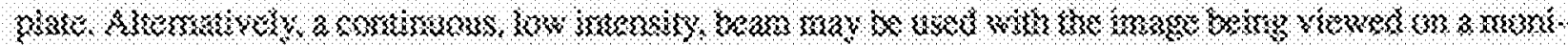

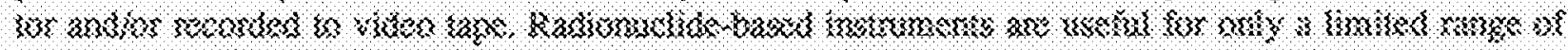

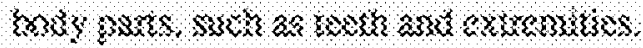

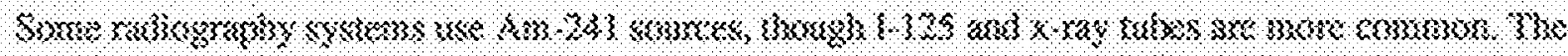

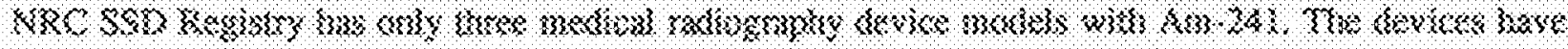

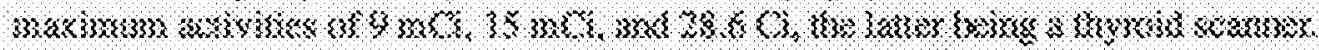

\section{2.}

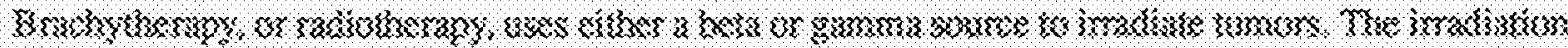

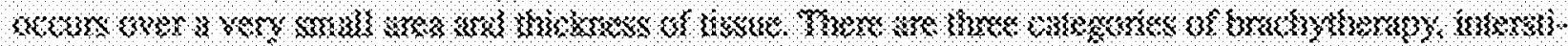

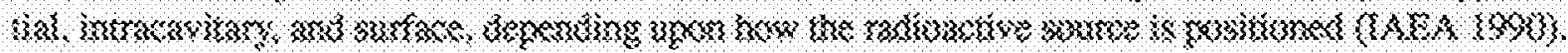

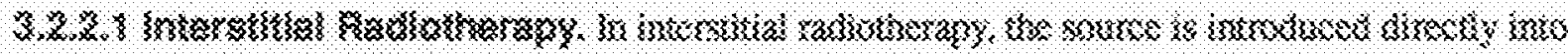

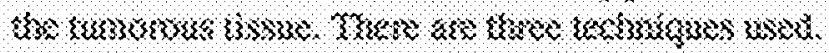

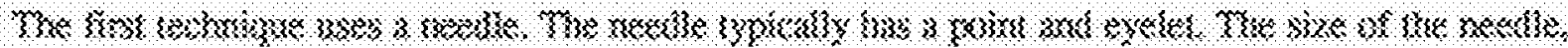

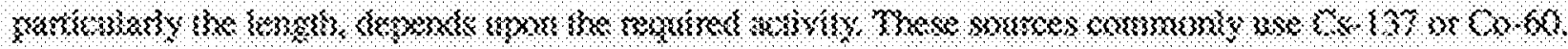

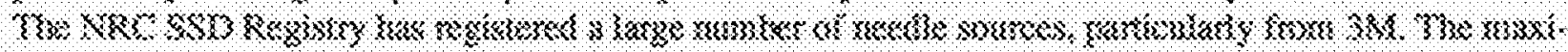

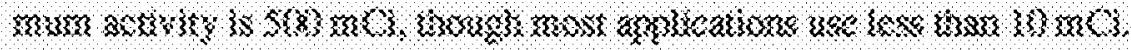

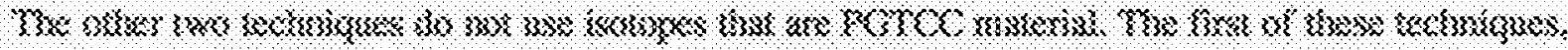

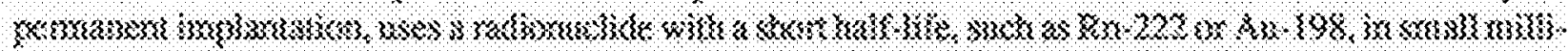

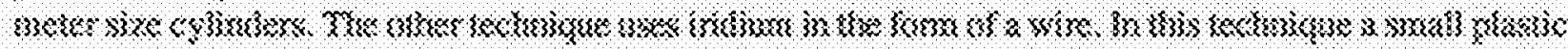

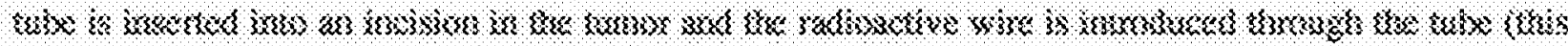

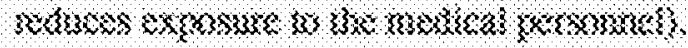

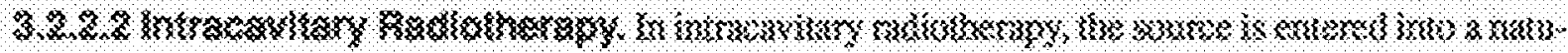

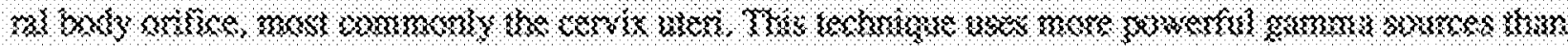

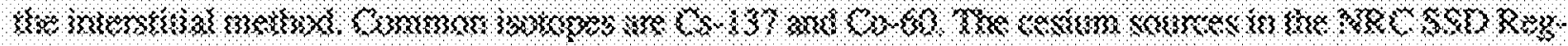

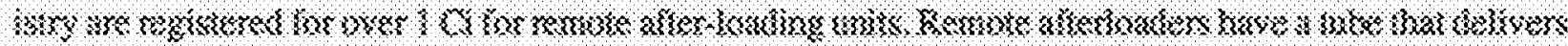

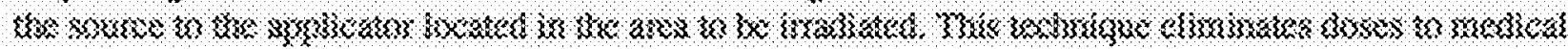

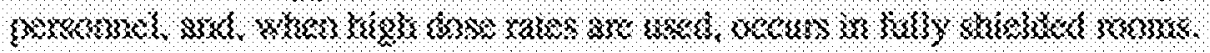

3.2,2 \%

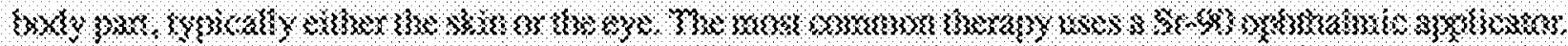

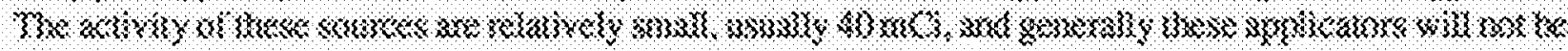

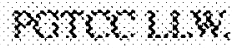

\section{$3.2 .3 \%\}$}

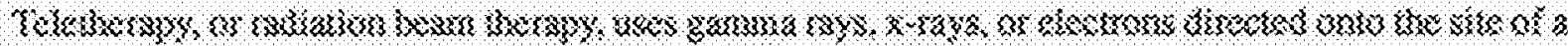

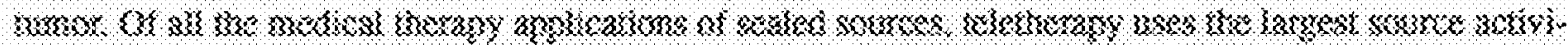

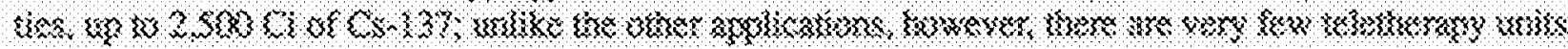

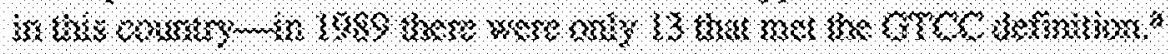

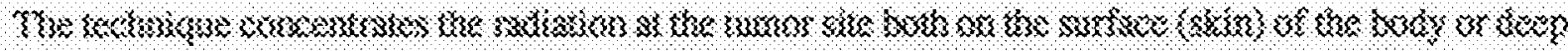

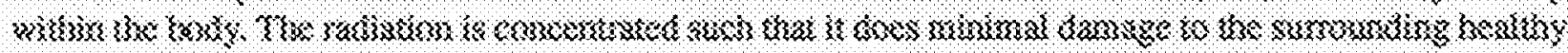

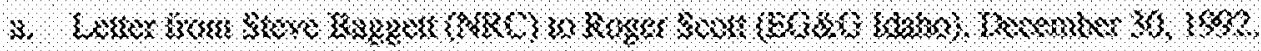


tissue, but kills the tumor. The patient is located on a table in a shielded room that the medical personnel cannot access during the irradiation.

\subsection{Well Logging Devices}

Well logging sources are used to do geophysical surveys. They are most commonly associated with oil and mineral exploration but are also used by others interested in characterizing subsurface properties, such as matrix density and percent moisture. The source is commonly placed in a pressure vessel before being lowered into the well. This vessel protects the source from the well environment, which can have extremely high pressures and temperatures.

There are generally two techniques used in well logging-neutron thermalization and gamma scattering. Neutron thermalization is used for moisture measurement and oil prospecting. Figure 3-1 shows an example neutron probe. Gamma scattering in well logging has a variety of uses based on density measurements. This use is illustrated in Figure 3-2.

Well logging sources are typically neutron emitters, though gamma sources (typically Cs-137) are also used. The neutron emitters use either Am-241 or Pu-238 mixed with beryllium or other light elements (lithium, boron, or fluorine). The americium or plutonium is typically present as an oxide $\left(\mathrm{AmO}_{2}, \mathrm{PuO}_{2}\right)$ in a powder and mixed with the target light element (also in powder form). The resulting powder is pressed into the inner capsule and plugged. Virtually all well logging sources are doubly encapsulated. The activities range from $100 \mathrm{mCi}$ to $20 \mathrm{Ci}$, with the larger activities associated with neutron sources; the cesium sources can have activities up to $5 \mathrm{Ci}$.

The source, pressure vessel, and detector are placed in a borehole or well. The detector is typically wired to instruments on the surface that record or display results. For neutron logging, the alpha particles from the americium or plutonium interact with the target material, causing the target material to emit neutrons. The neutrons travel at a high speed, but are slowed down by interacting with certain elements, particularly hydrogen. The intensity of the slowed down neutrons give a measure of the concentration of the interacting element. Hence, in oil well logging, the neutron source measures the hydrogen content of oil deposits.

The cesium sources are used to determine matrix density. This application of gamma rays, called "gamma scattering" is discussed in Section 3.4, Portable Gauges, and shown in Figure 3-2. The cesium sources are typically around $500 \mathrm{mCi}$.

In the past, the major well logging source manufacturers were Gulf Nuclear, Inc., Monsanto, and 3M, all of which have since stopped source production. Amersham has recently become more involved in manufacturing cesium and americium sources for well logging applications. Other manufacturers include Tuboscope Inc., Gammatron (also known as Nuclear Sources and Services, Inc.), and Gearhart-Owen Industries, Inc.

\subsection{Portable Gauges}

Portable gauges or, more specifically, moisture/density gauges, are used in the field at construction sites and on farms. The gauges are typically used to determine the moisture or density of a material such as soil or asphalt. The gauges are relatively small and light so they can be carried to the site (in a transport case similar to luggage). The gauge usually has a long cylindrical probe that is placed into the matrix of interest. The probe most commonly contains the detector, though it may contain the source. 


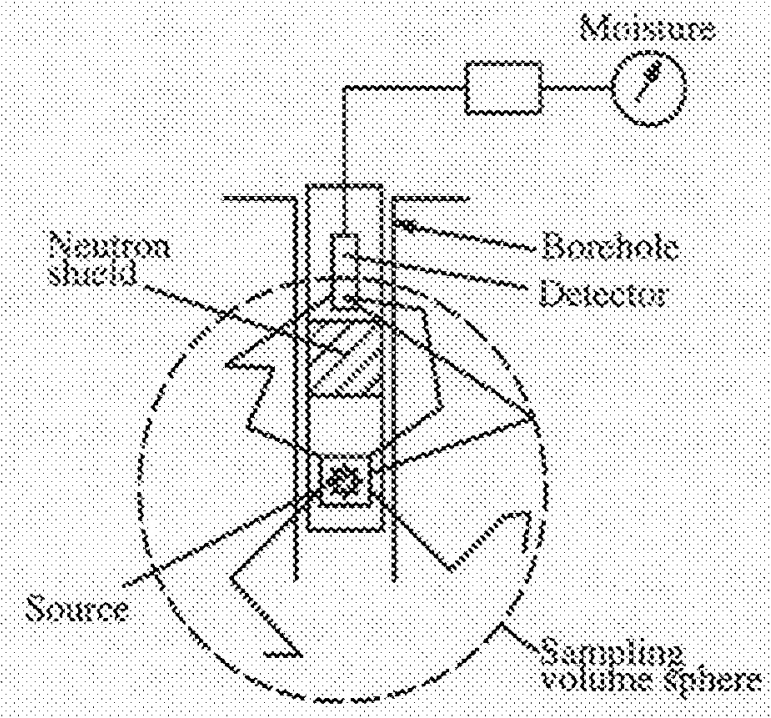

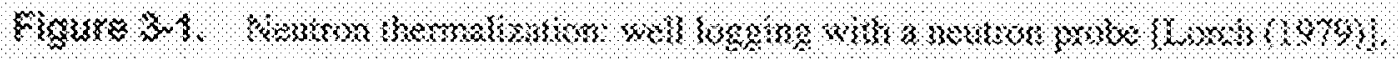
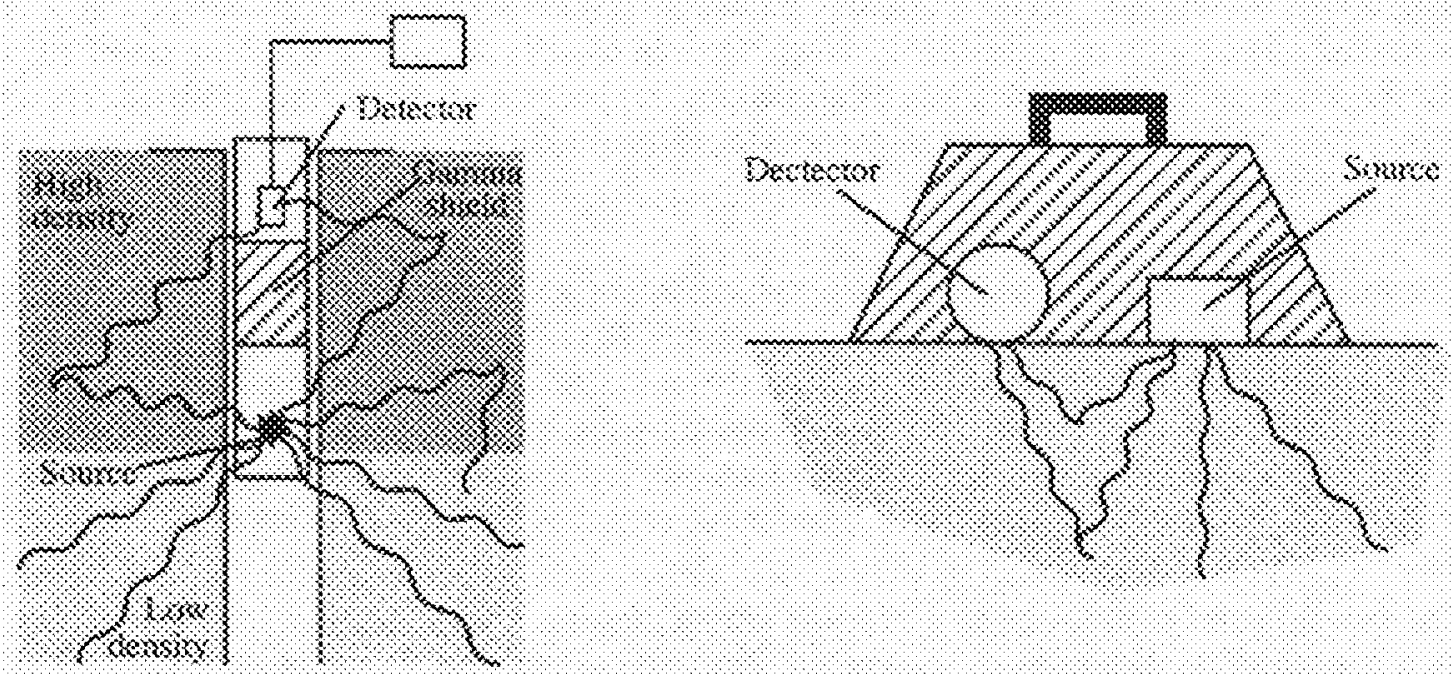

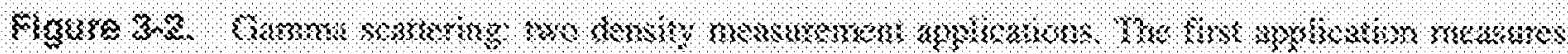

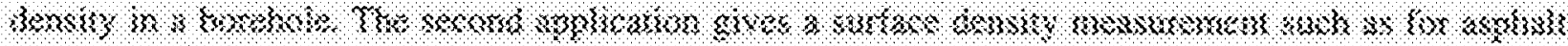

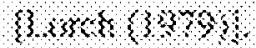

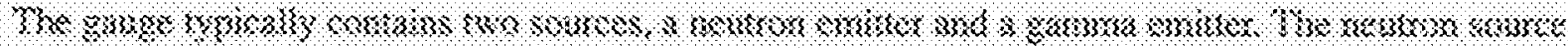

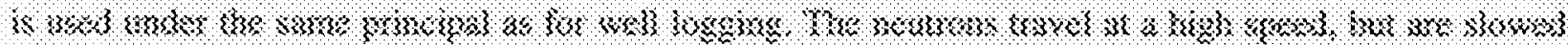

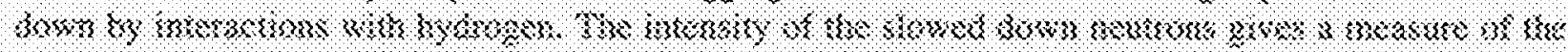

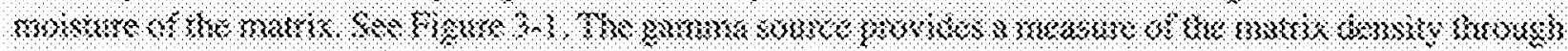

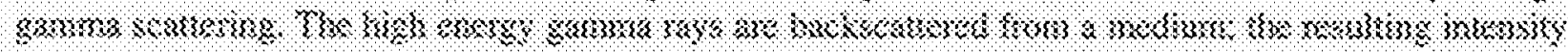

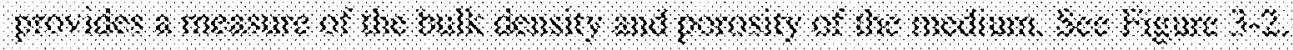

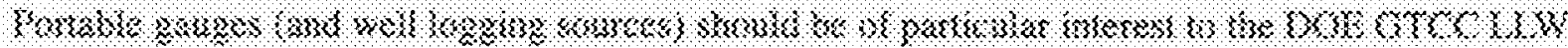

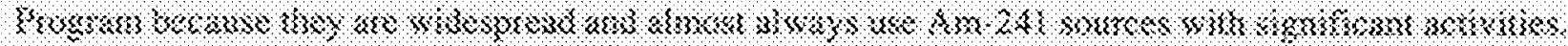

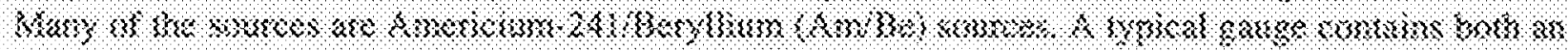




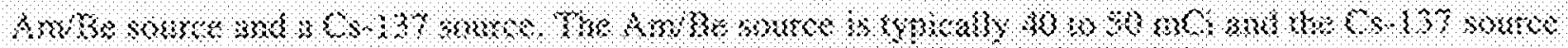

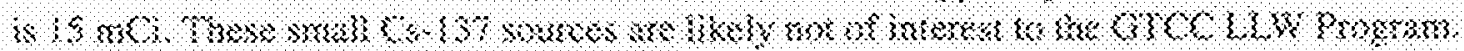

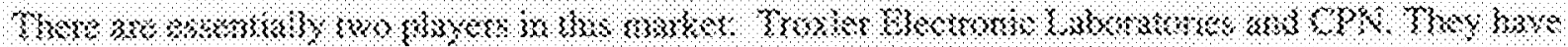

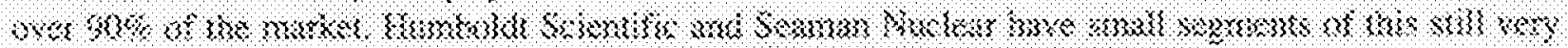
setive sisiskt:

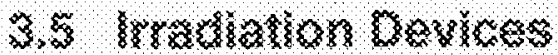

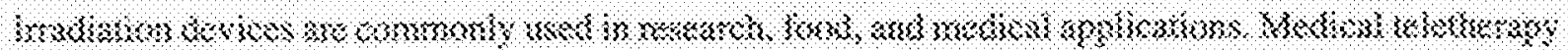

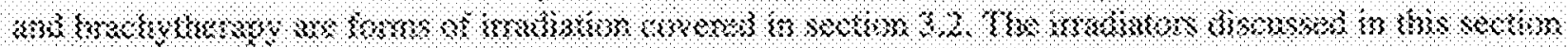

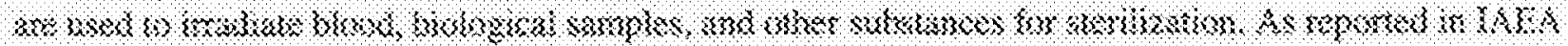

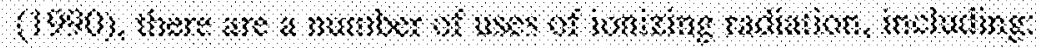

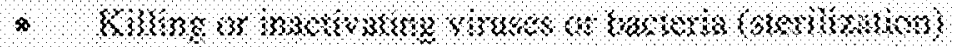

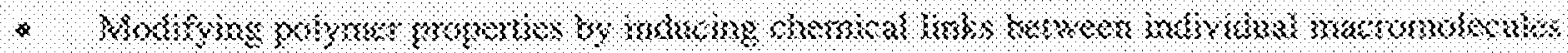

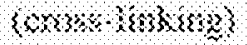

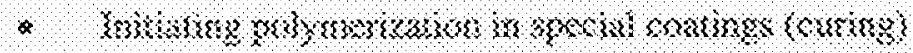

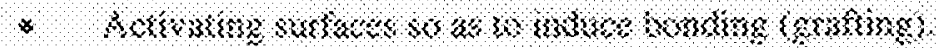

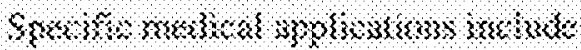

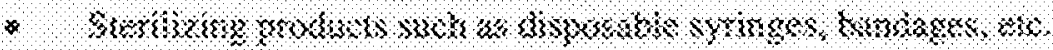

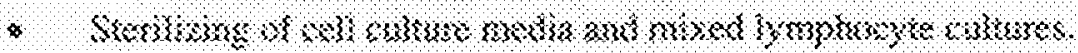

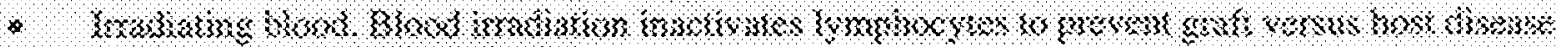

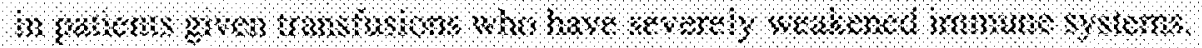

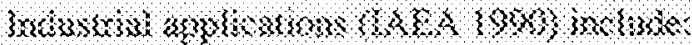

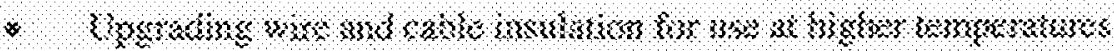

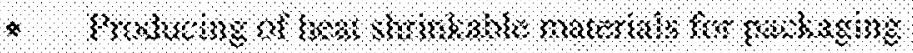

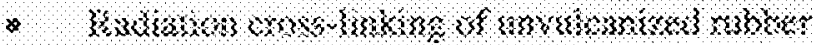

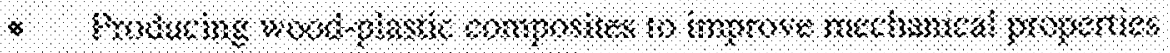

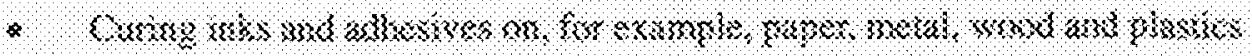

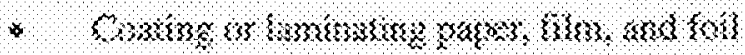

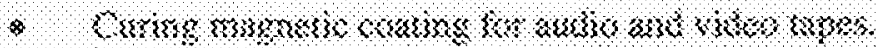

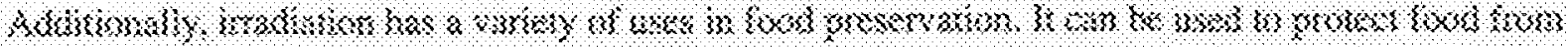

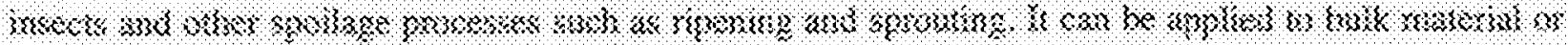

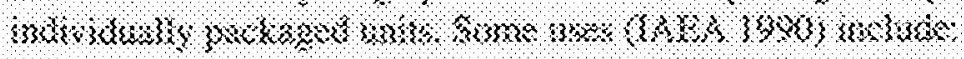

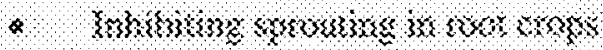

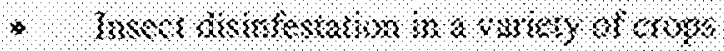




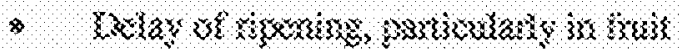

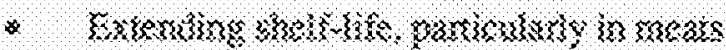

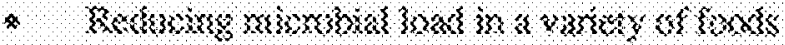

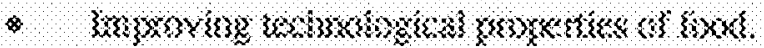

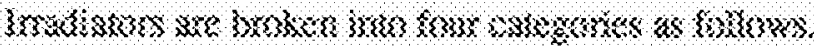

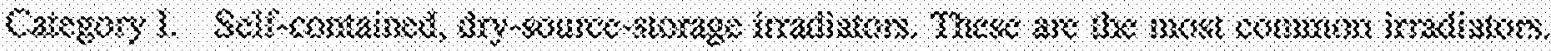

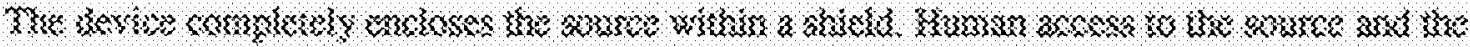

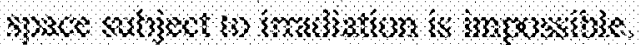

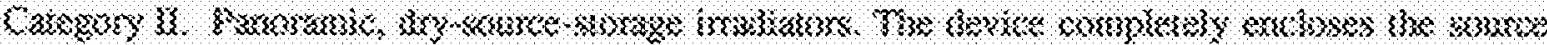

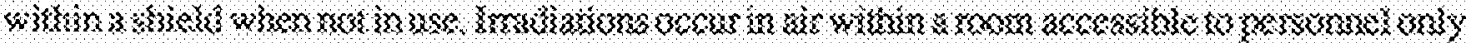

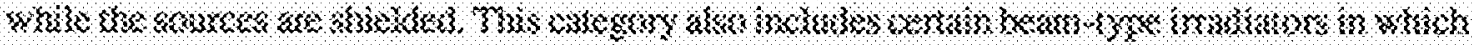

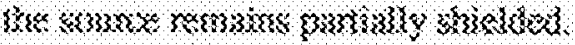

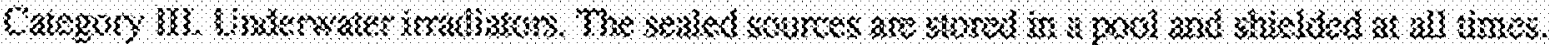

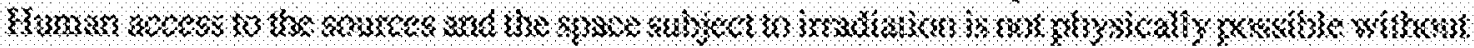

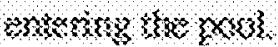

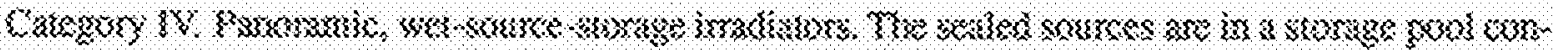

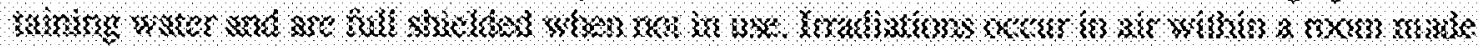

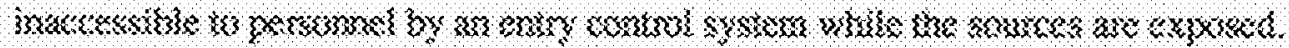

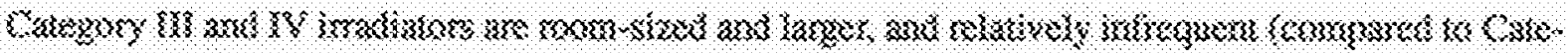

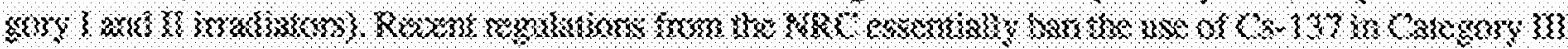

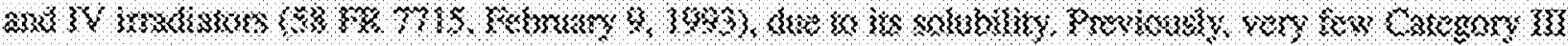

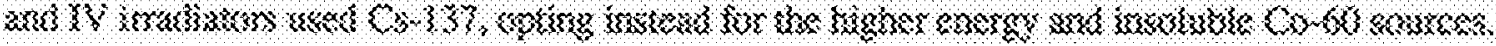

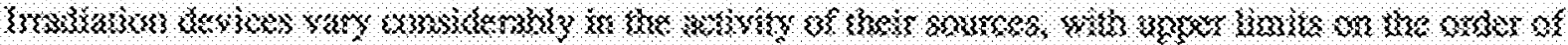

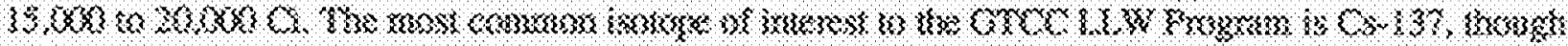

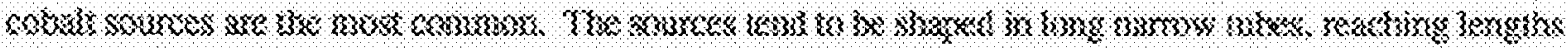

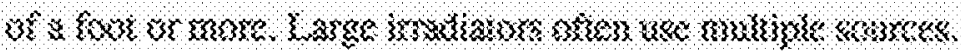

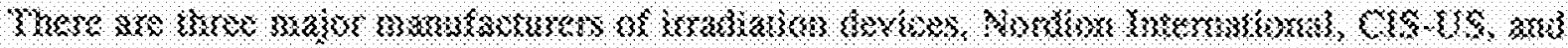

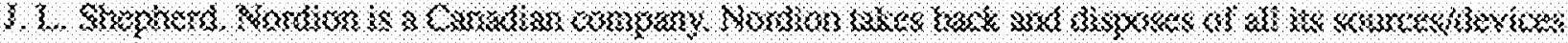

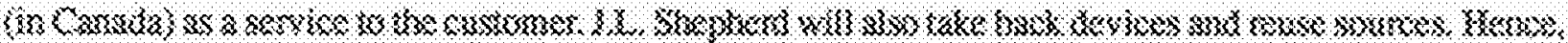

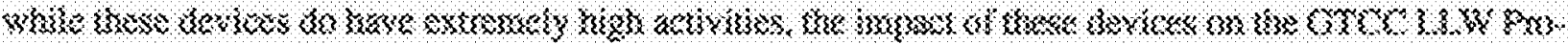

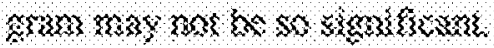

\subsection{0}

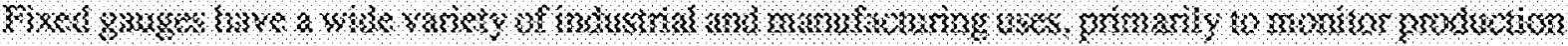

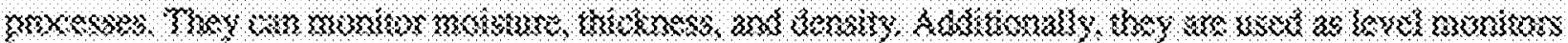

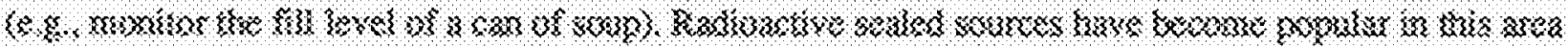

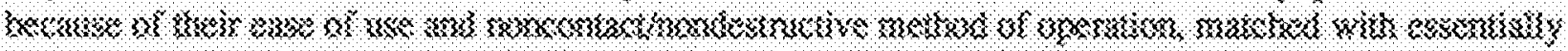

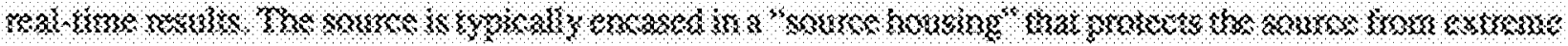

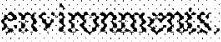




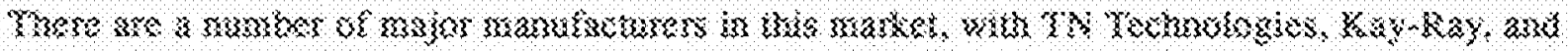

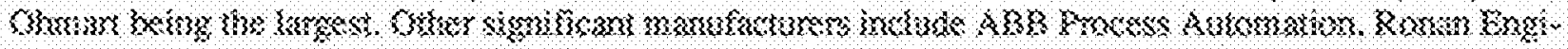

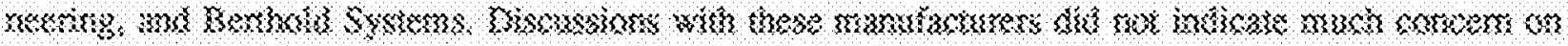

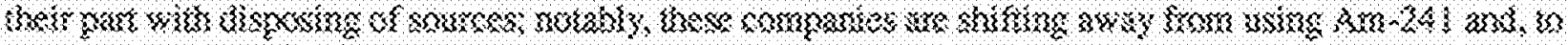

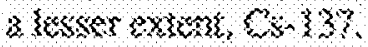

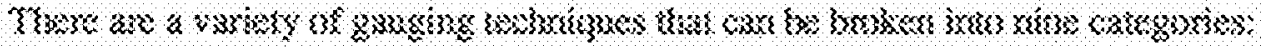

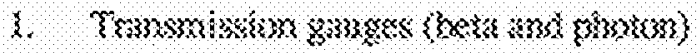

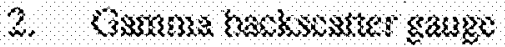

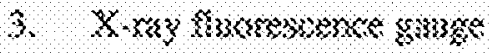

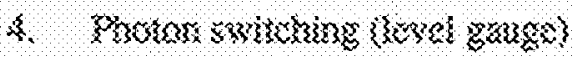

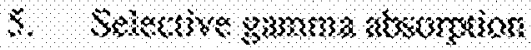

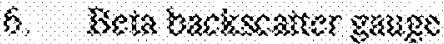

7. Qanuma ratserixss

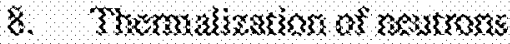

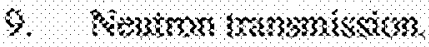

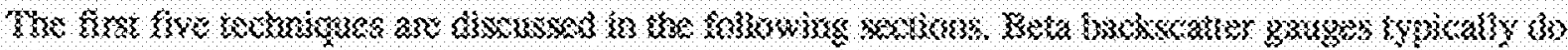

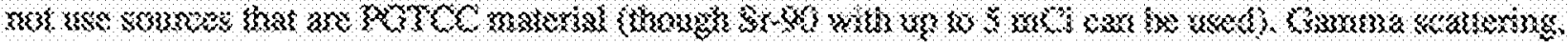

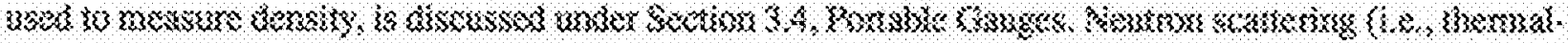

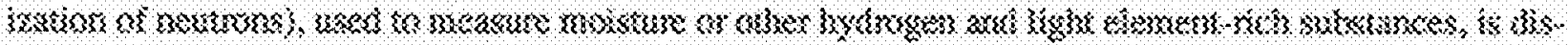

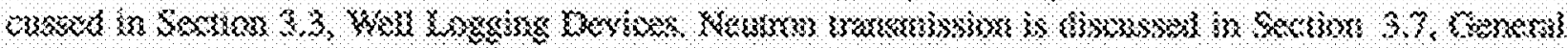

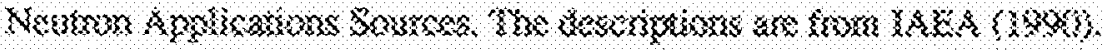

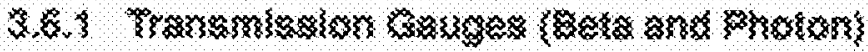

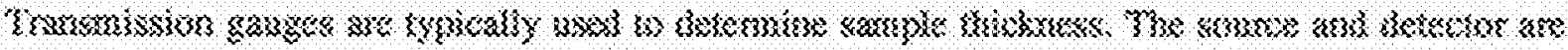

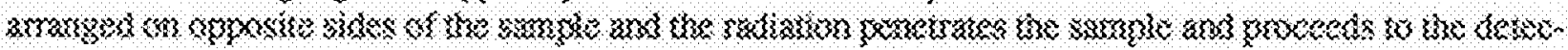

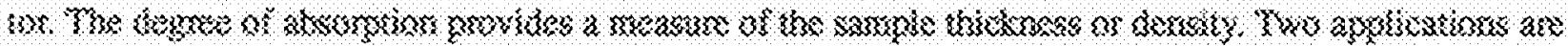

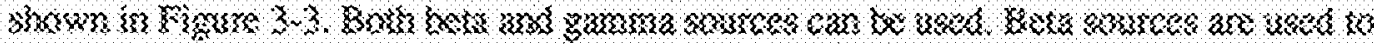

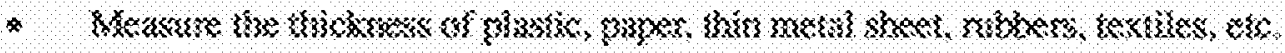

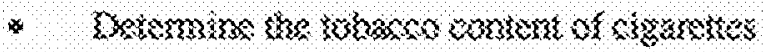

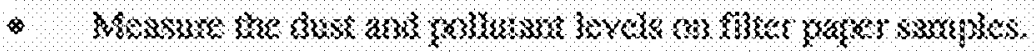

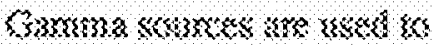

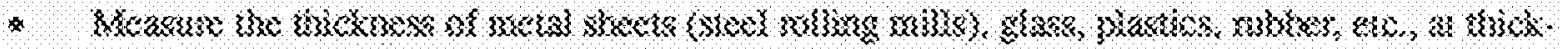

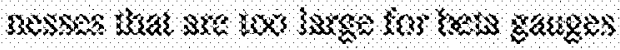

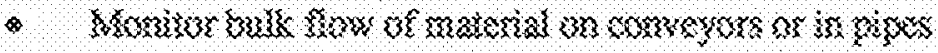

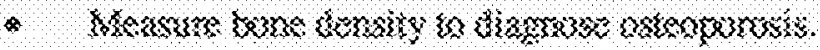



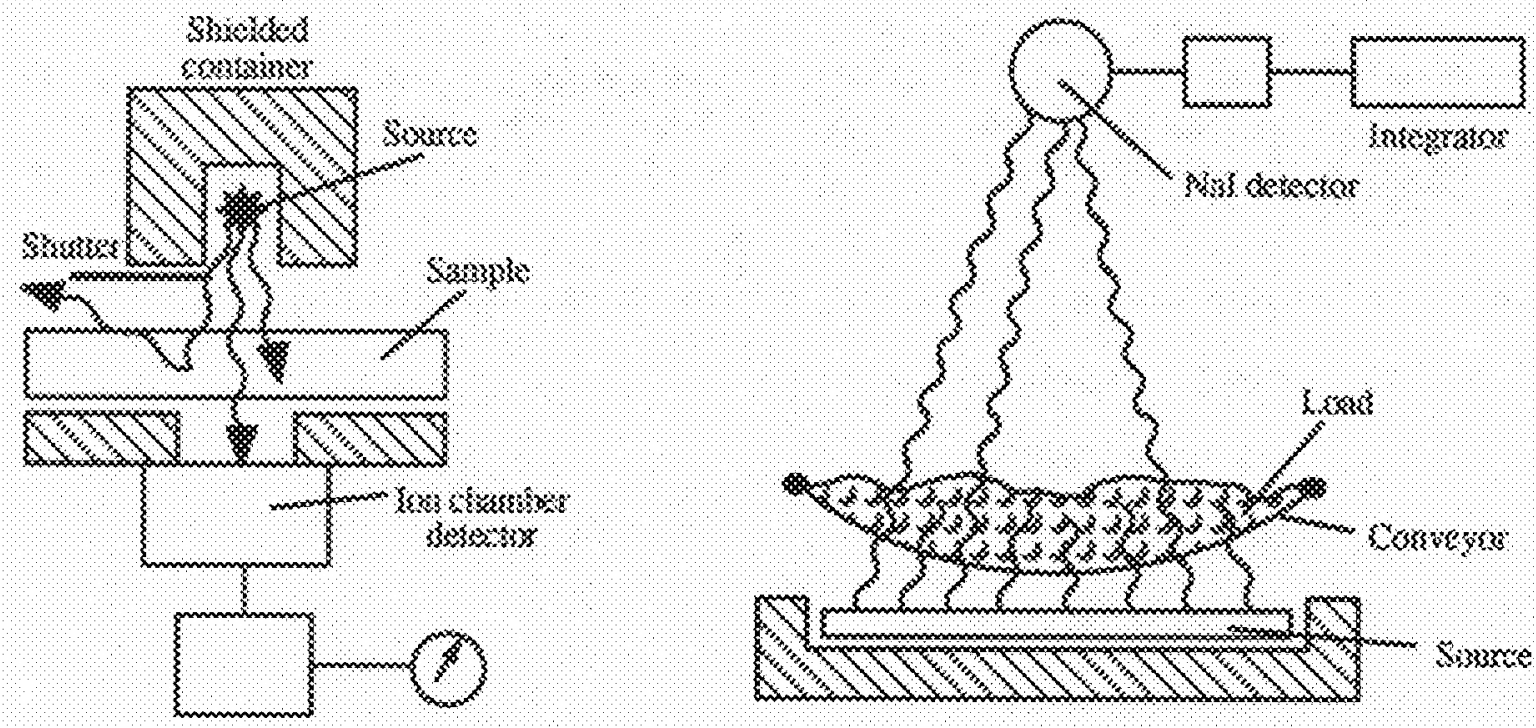

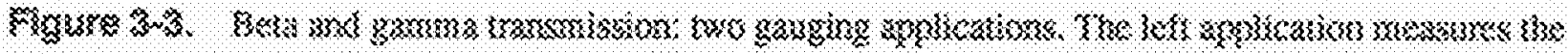

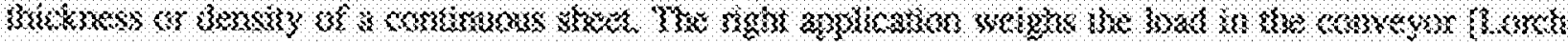
$\{13>3\}\}$,

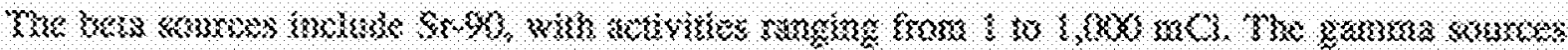

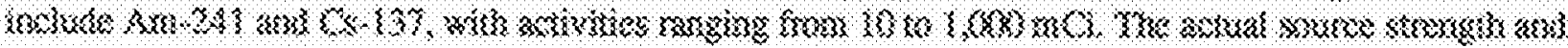

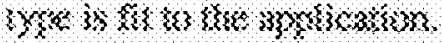

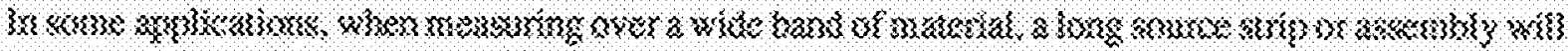

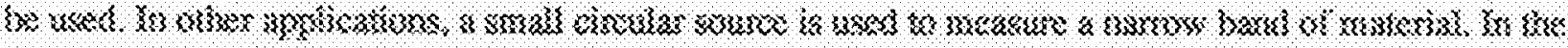

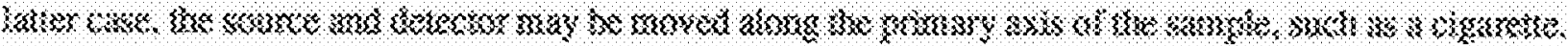

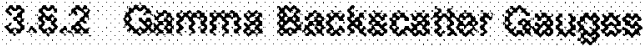

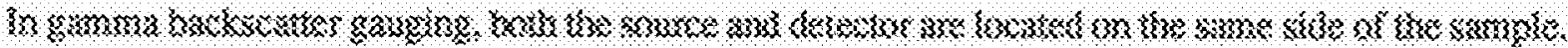

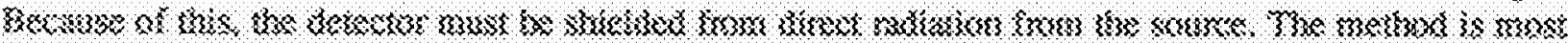

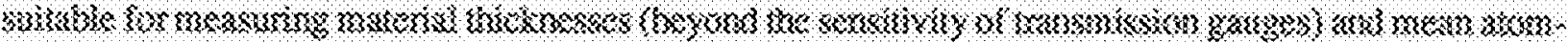

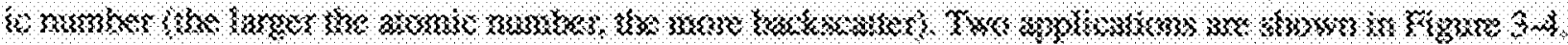

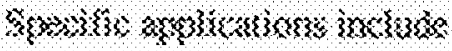

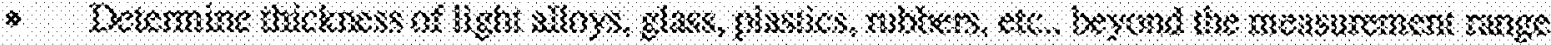

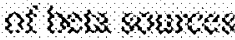

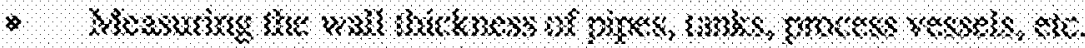

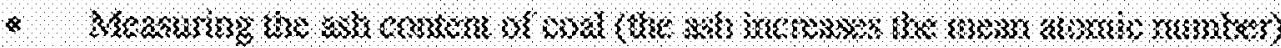

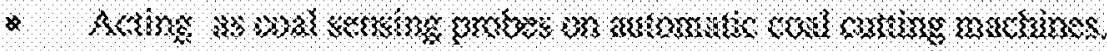

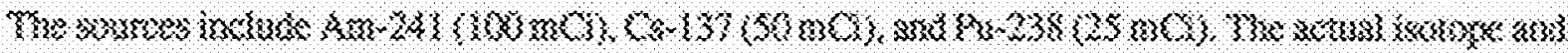

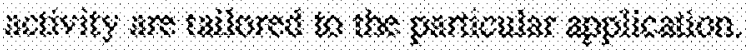




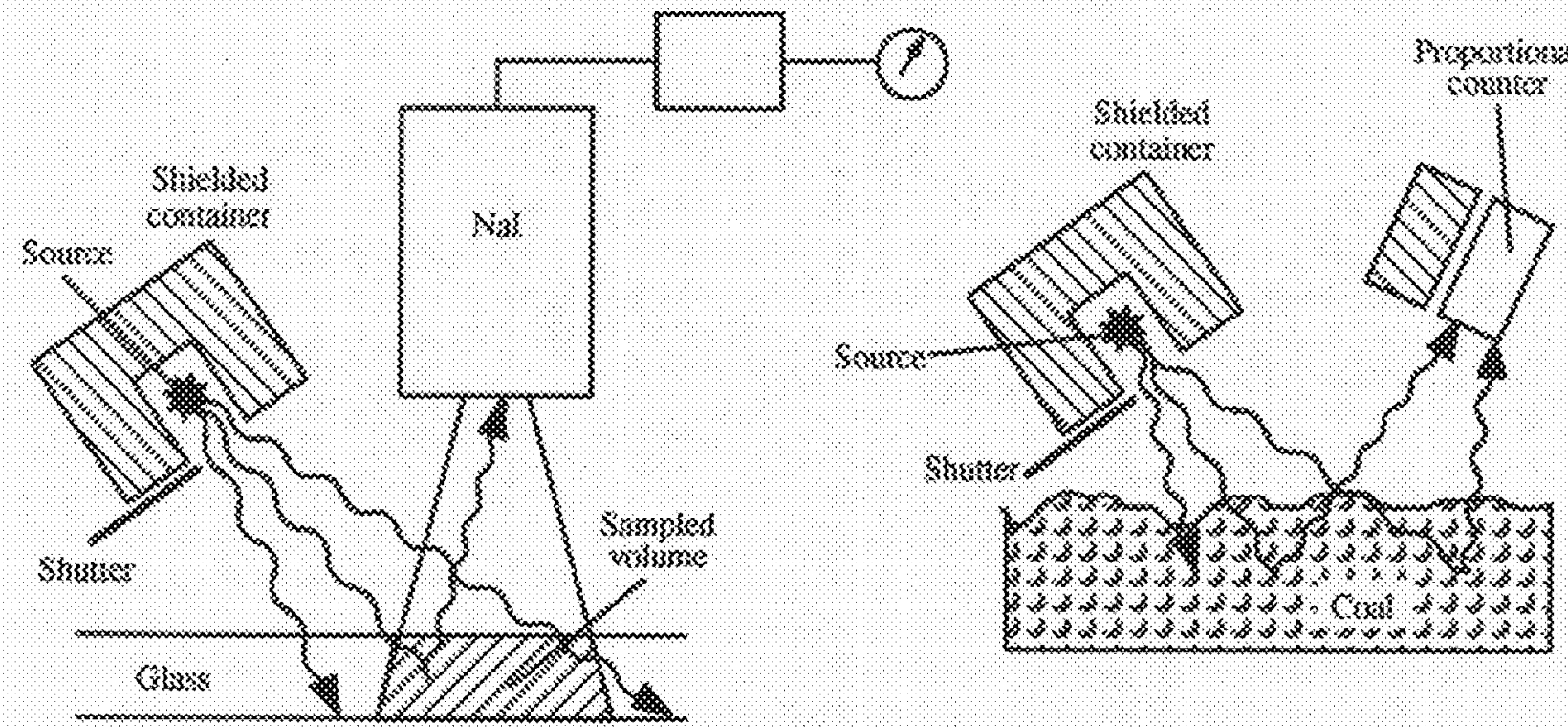

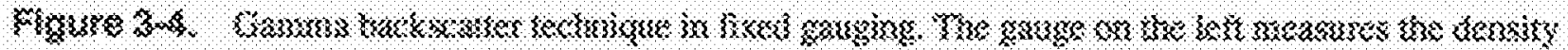

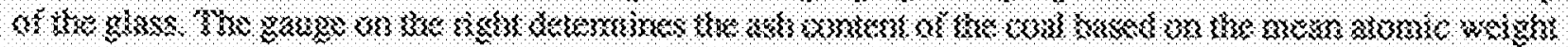
\{sosos $\{0 \% 8\}\}$.

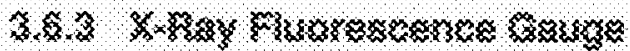

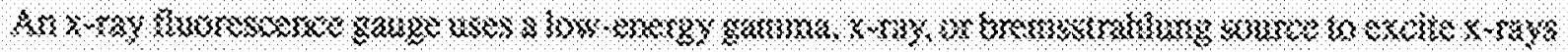

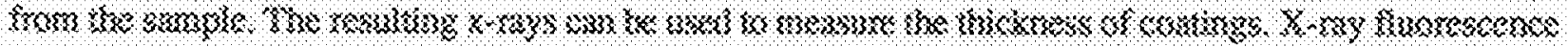

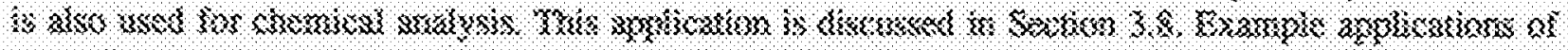

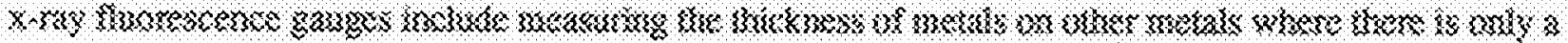

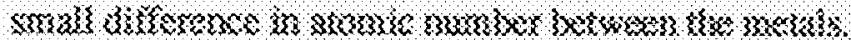

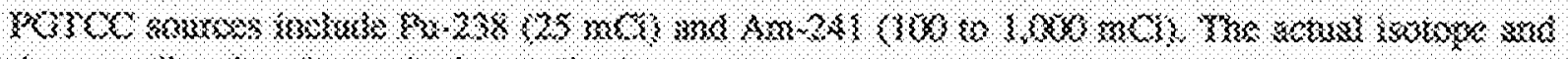

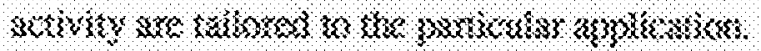

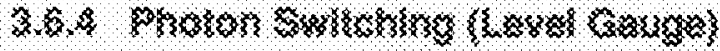

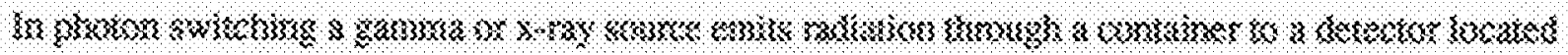

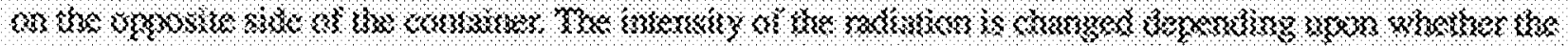

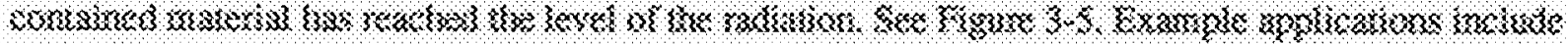

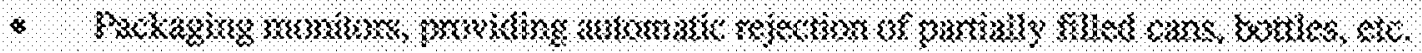

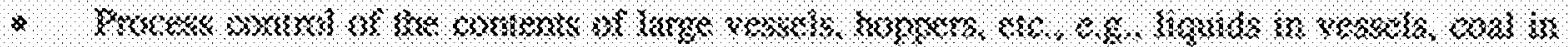
kom

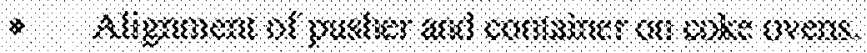

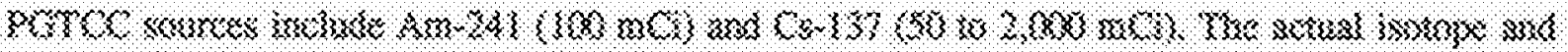

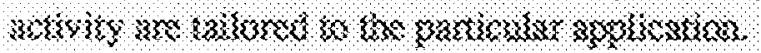



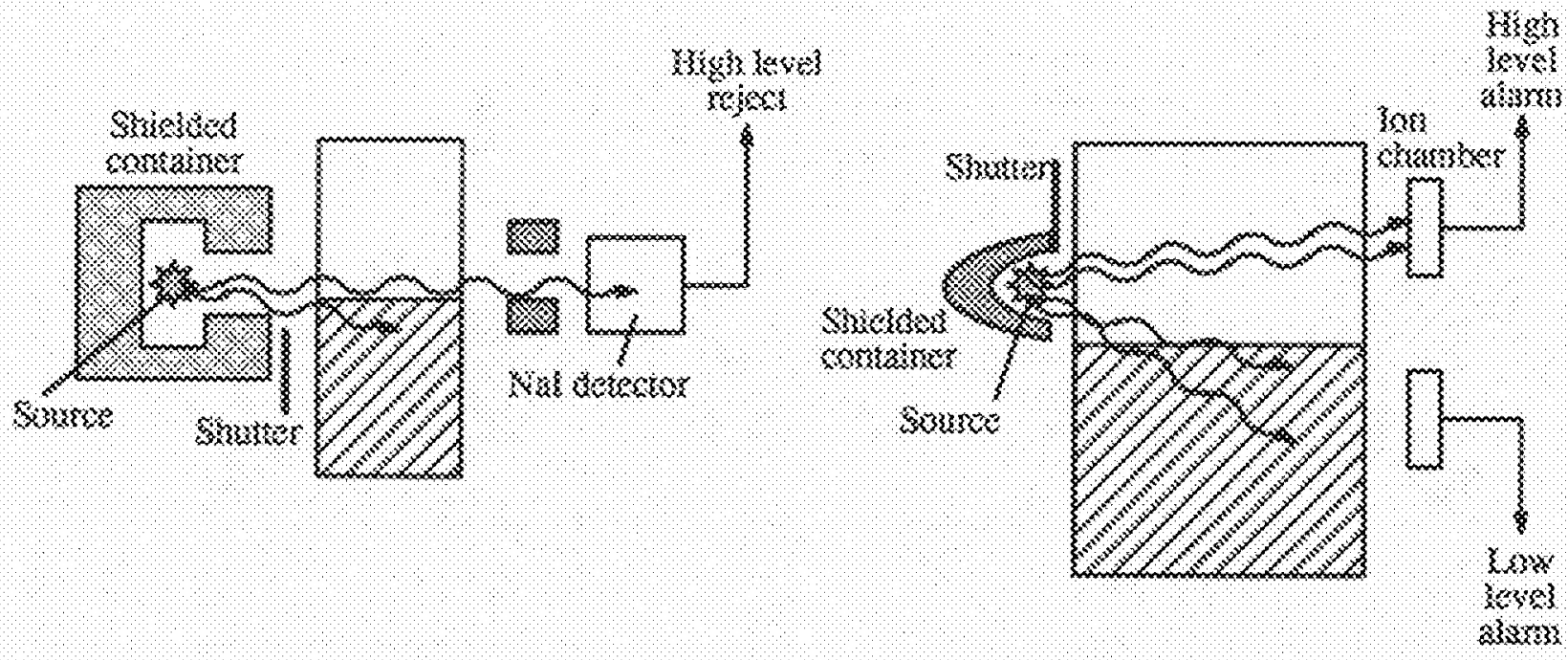

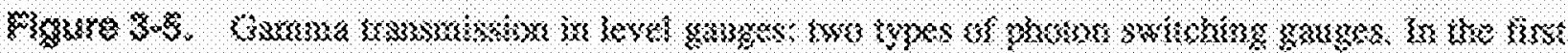

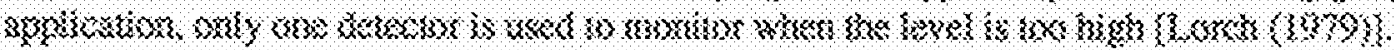

\section{$3.5 \%$}

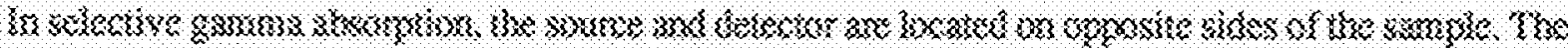

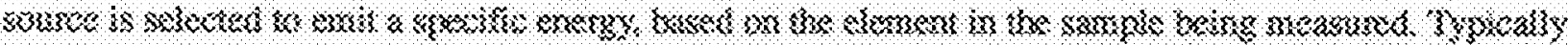

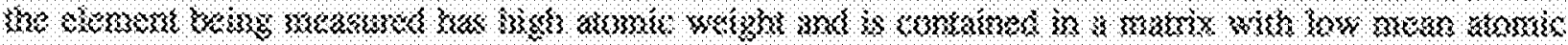

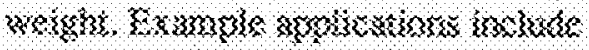

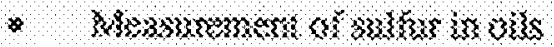

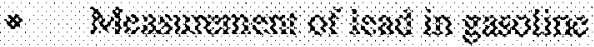

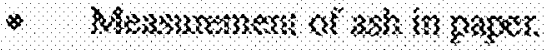

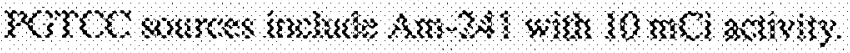

\section{7}

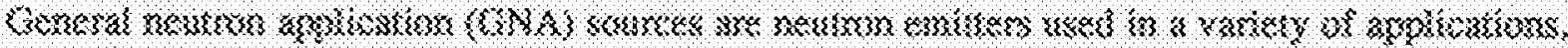

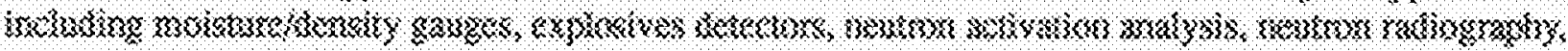

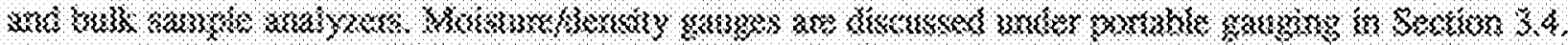

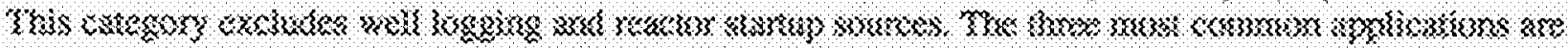
Wronsond bulow:

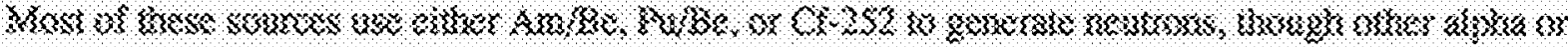

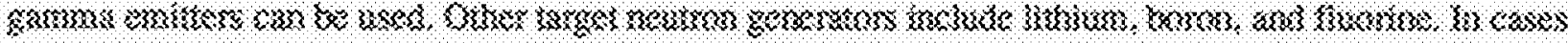

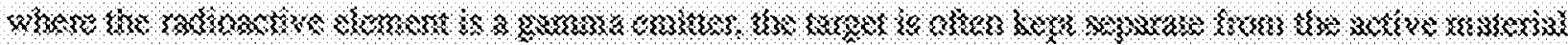

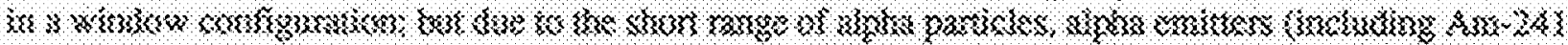

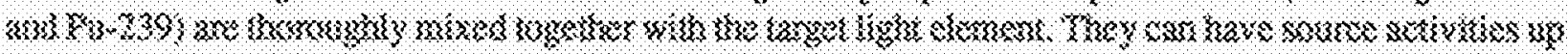

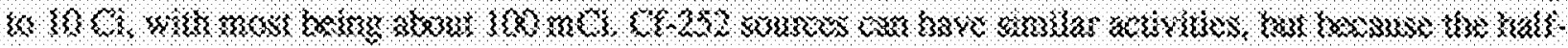

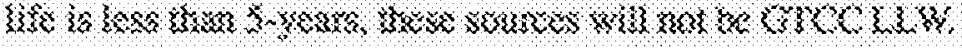




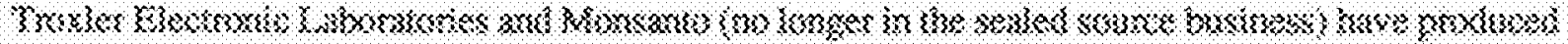

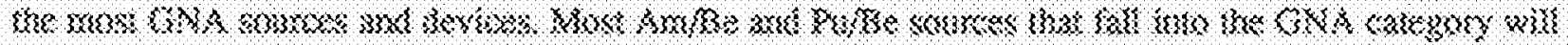

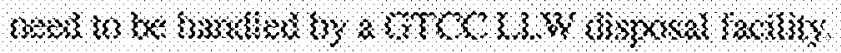

\section{7.}

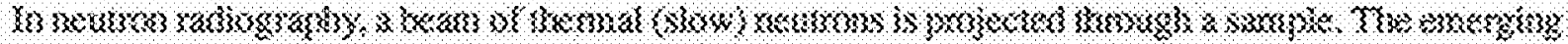

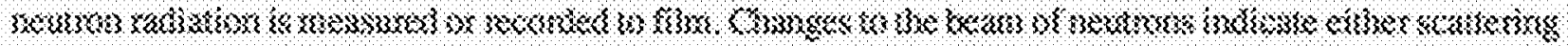

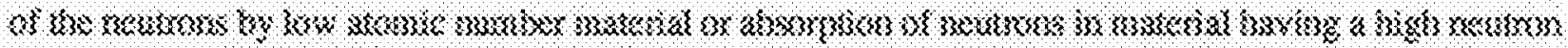

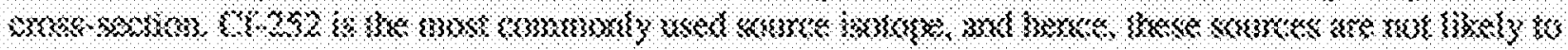

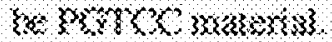

\subsection{2.}

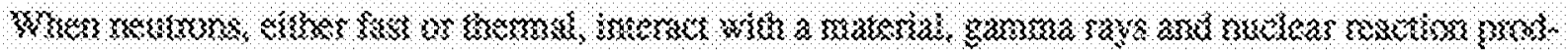

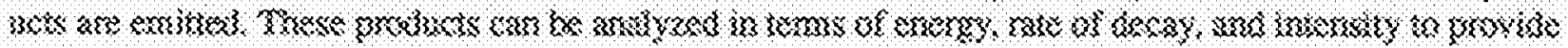

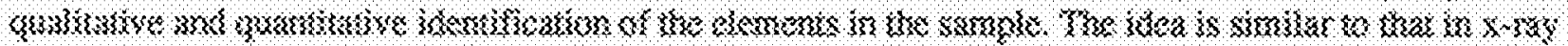

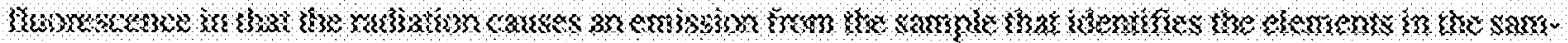

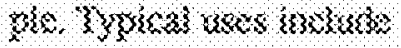

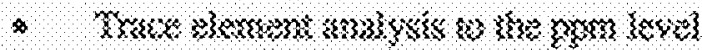

- Golkution aratusais

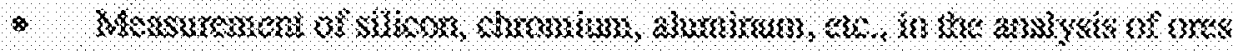

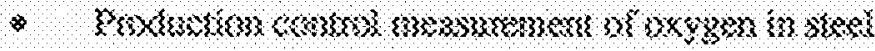

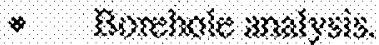

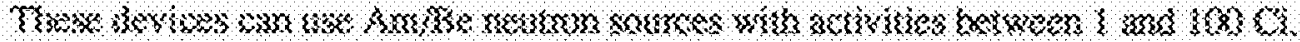

\section{3.}

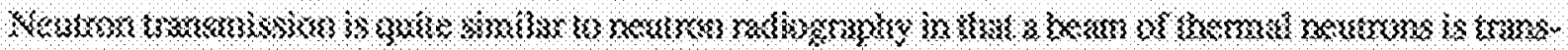

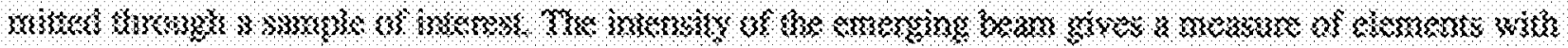

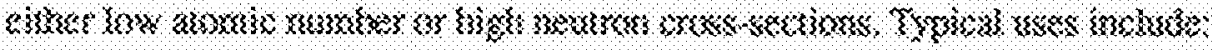

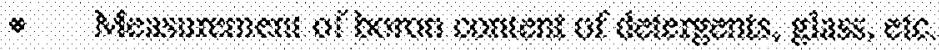

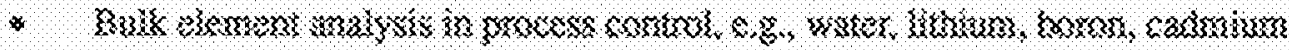

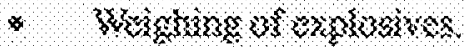

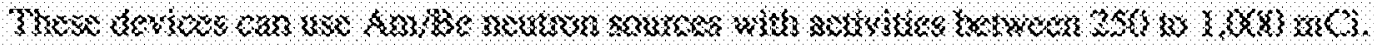

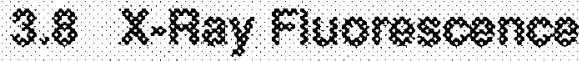

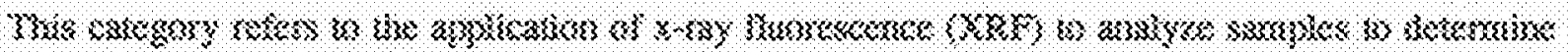

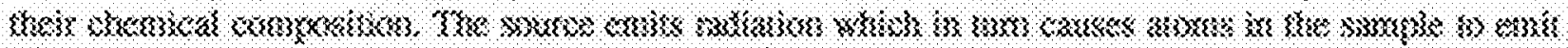

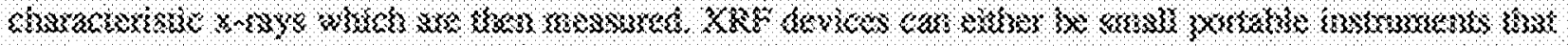

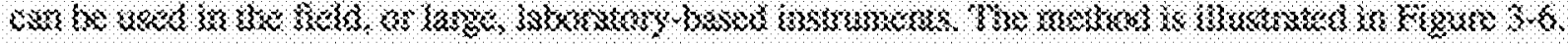

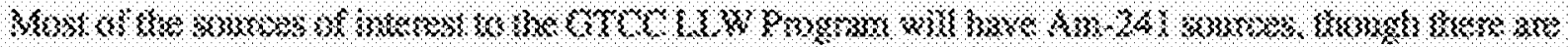

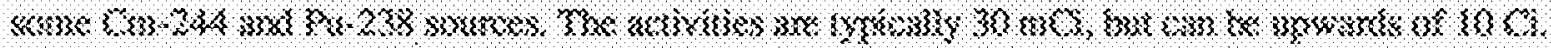

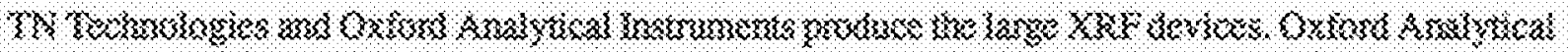

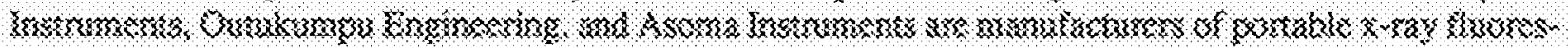
sectionserion. 


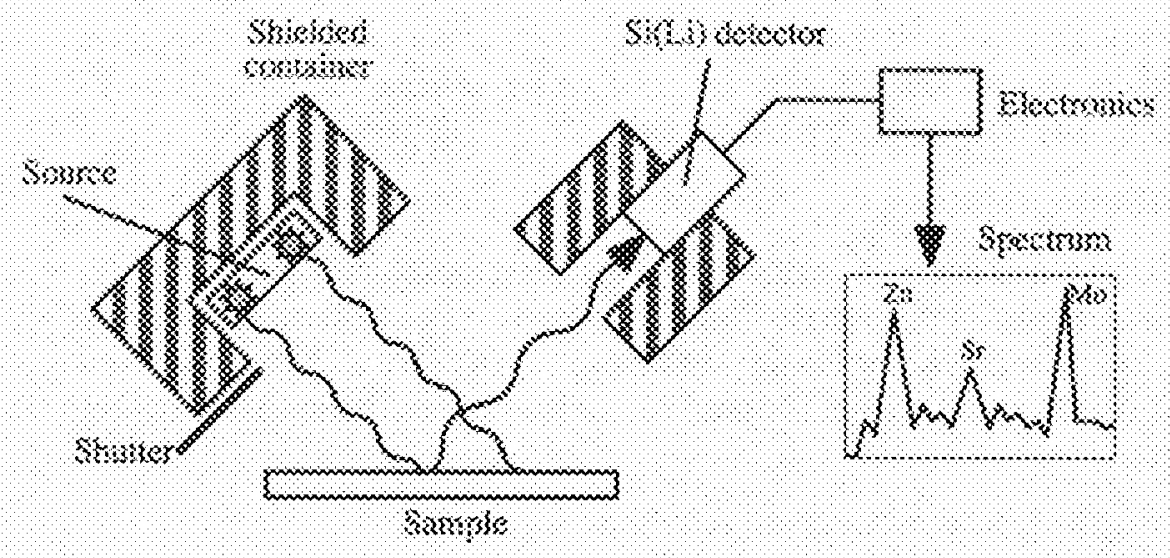

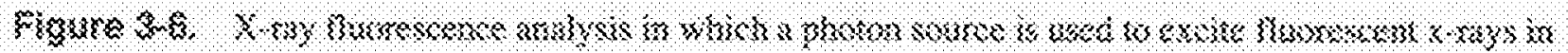

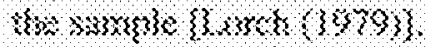

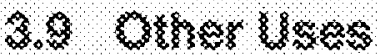

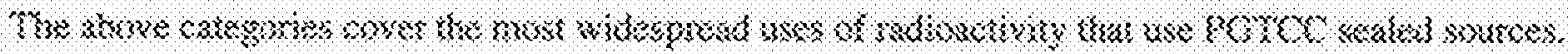

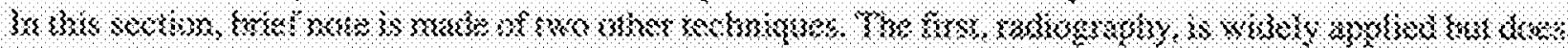

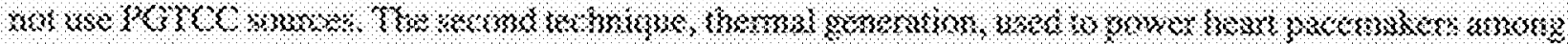

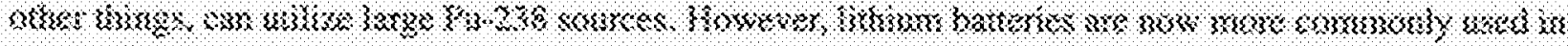
rasens $k 0 \mathrm{~s}$.

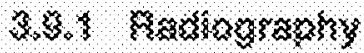

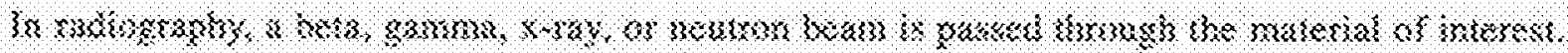

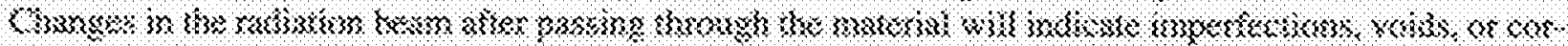

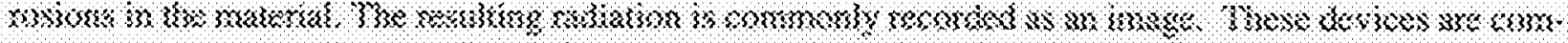

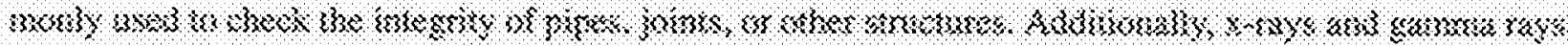

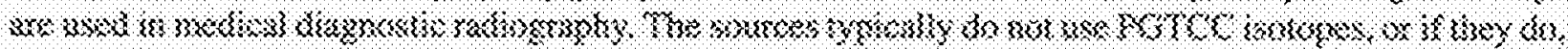

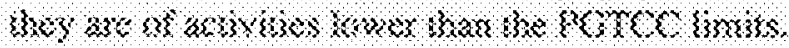

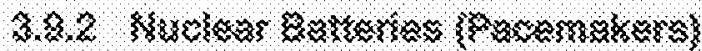

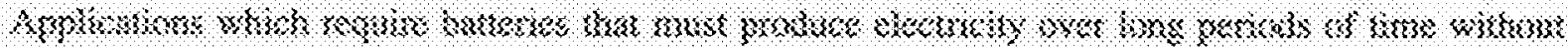

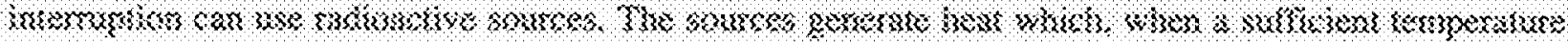

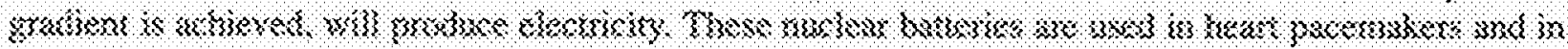

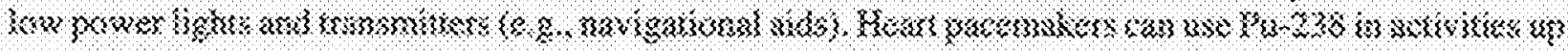

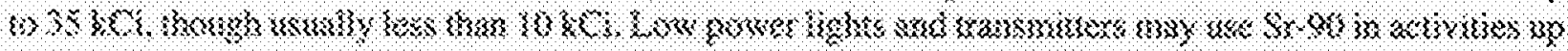
$\$ 20 \leqslant 8$.

\subsection{0}

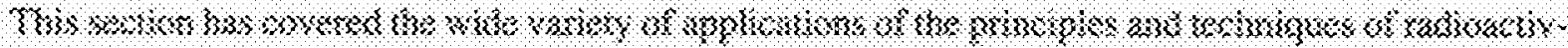

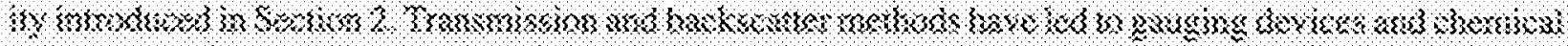

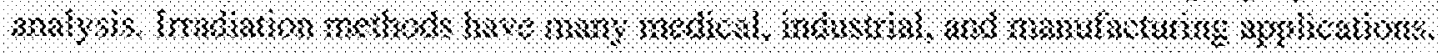

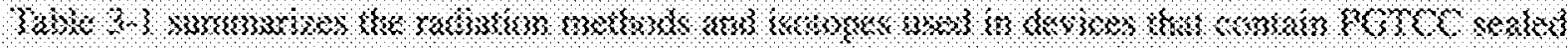

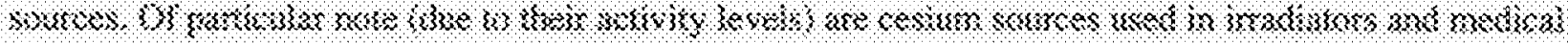

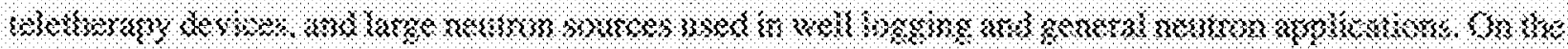




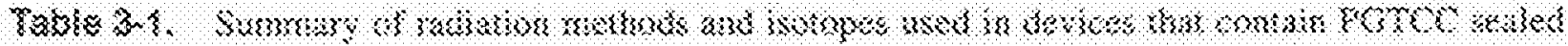

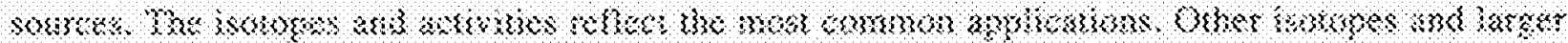

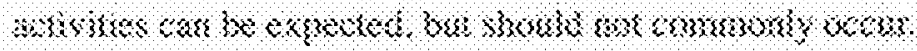

\begin{tabular}{|c|c|c|c|c|}
\hline $\mathrm{Mexh}, y 3 \mathrm{k}$ & Rinbiston Mastor & $38 \times 803 n=$ & 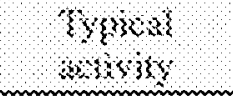 & 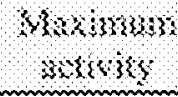 \\
\hline Qubismbon & $\times 8$ & $\begin{array}{l}\mathrm{n}, 24 \\
\mathrm{n}, \mathrm{P}\end{array}$ & $\begin{array}{l}5,808 \mathrm{~m} \times \mathrm{r} \\
\times, 0 \%\end{array}$ & 383 \\
\hline \multirow[t]{3}{*}{ Medirsl } & 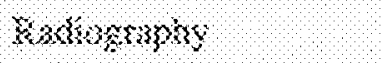 & $\operatorname{sm} 24$ & $<100 \mathrm{~ms}$ & $33 \leqslant 6$ \\
\hline & 3enskersns & $5 \times 33$ & 3.3म25KC) & $2 s k<3$ \\
\hline & Brobytherany & 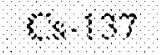 & $316 \mathrm{~mm}$ & 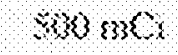 \\
\hline \multirow[t]{3}{*}{$\left.3_{8}\right\}$ \{3880ms } & \multirow[t]{2}{*}{ 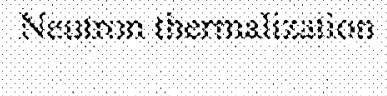 } & $x_{3 \times 3} 243$ & 8,68 & $20 \%$ \\
\hline & & $\mathrm{M}, 2 \mathrm{~S}$ & 6,108 & $20<3$ \\
\hline & 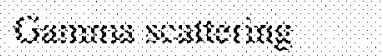 & $(0,3)$ & $<\times B \$ \times 3$ & 38 \\
\hline \multirow{2}{*}{ Sorkmo a rags } & 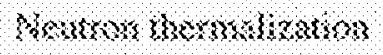 & $4 \sin 24$ & $43.5 \% \mathrm{mC}$ & 58 \\
\hline & Samma kratrerms & $0,13 \%$ & $945 \mathrm{mB}$ & $3<3$ \\
\hline \{rrwsikation & $3 \&$ & $\mathrm{Cs} \cdot \mathrm{s} \mathrm{s}$ & $3,8,8$ & $20 \leqslant<$ \\
\hline \multirow[t]{11}{*}{$\beta x \times 4 x a u s=$} & 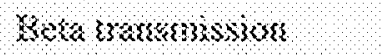 & $\$ 8,30$ & $\$ \$ 030 \leq 33<$ & 3 \\
\hline & \multirow[t]{2}{*}{ 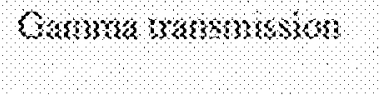 } & $A, B>A$ & 981,050 & 38 \\
\hline & & $\{\} 3\}$, & $801,0 \times<$ & \} \\
\hline & \multirow[t]{3}{*}{ Gmsmms karkansmer } & $3 \mathrm{n} \times 2 \times 1$ & 100 mis & 33 \\
\hline & & $8 \times 33$ & $80 \times 3 \times$ & 30 \\
\hline & & 3,238 & $25, \mathrm{~m}$ & ¿४ \\
\hline & \multirow[t]{2}{*}{ Fhotons swits } & $\sin 2 \times 2$ & $3350 \mathrm{mS}$ & \& \\
\hline & & $3 \times 337$ & $0,13 \times 28$ & 28 \\
\hline & \multirow[t]{2}{*}{$x \ll \beta$} & $\left.A_{3}, 5<2<\right\}$ & $3,3<, 5<3$ & 36 \\
\hline & & 33,230 & $2 \times 5 \times 8$ & $304503 \%$ \\
\hline & Ssamms orsarsmation & $A_{\mathrm{m}} \times 2 \mathrm{Q}$ & $10 \mathrm{mk}$ & NA. \\
\hline \multirow[t]{2}{*}{ 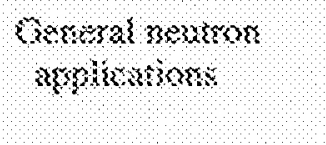 } & 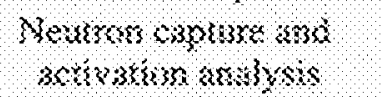 & $\{x 33 \times 28\}$ & 3.1086 & $1000 \%$ \\
\hline & 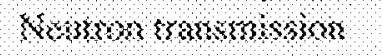 & $63 \times 241$ & 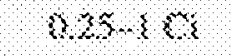 & 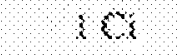 \\
\hline \multirow[t]{2}{*}{ Xray hurrescense } & & $A n, 241$ & $1,1,3 \mathrm{k} \times \mathrm{Bn} \mathrm{K}$ & \& 8 \\
\hline & & $302 \times 3$ & $1,3 \times 603 \times$ & \&) \\
\hline \multirow[t]{2}{*}{ Gkkes } & Phisckerat batrexy & 3,428 & \& $36<$ & 31,3 \\
\hline & & $8, \times 6$ & ?/2 & $20 \times 0$ \\
\hline
\end{tabular}

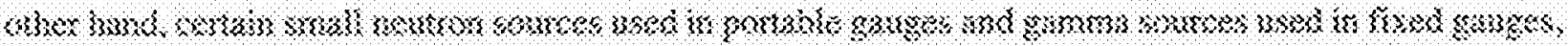

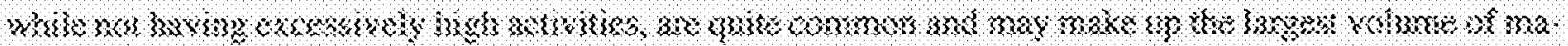

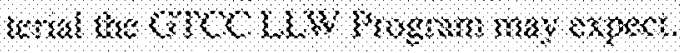

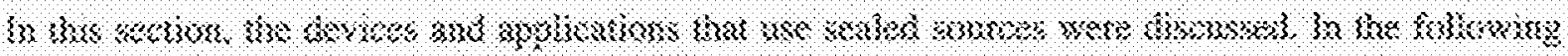

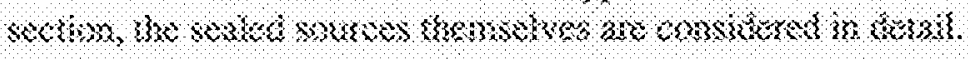




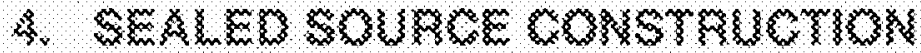

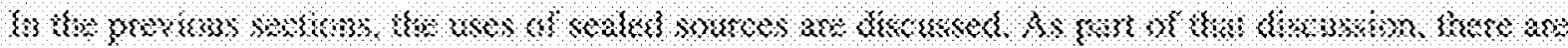

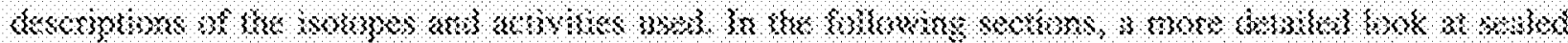

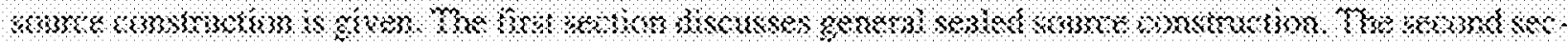

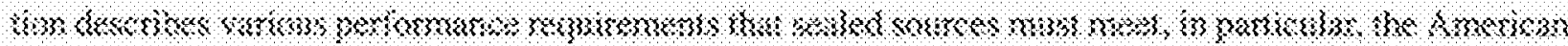

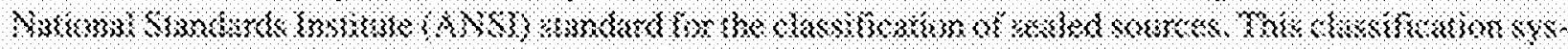

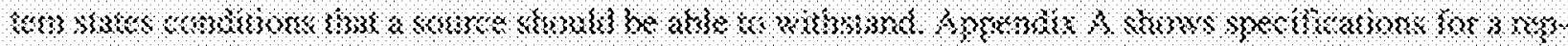

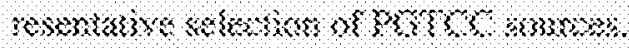

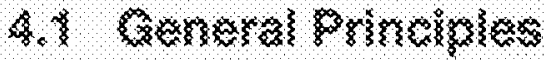

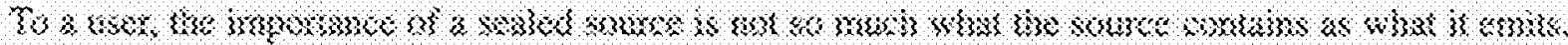

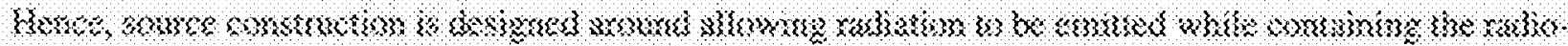

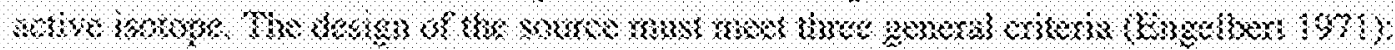

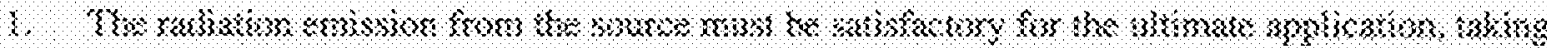

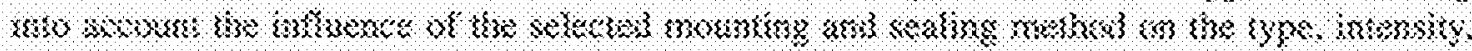

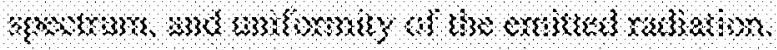

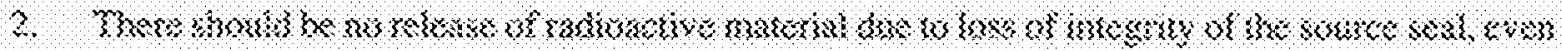

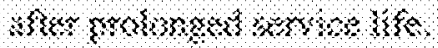

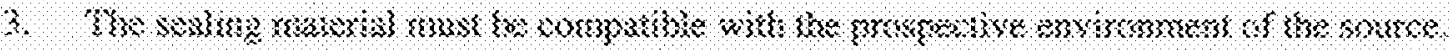

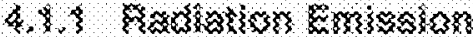

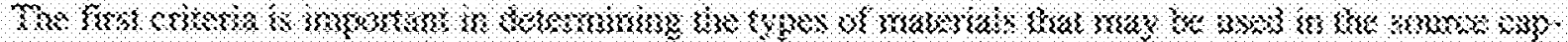

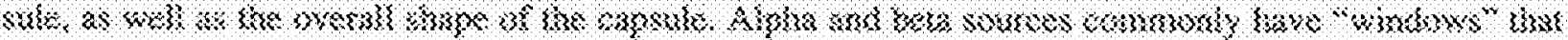

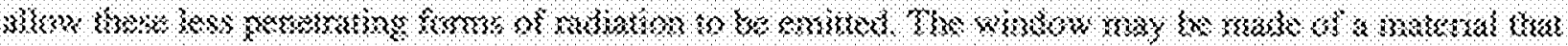

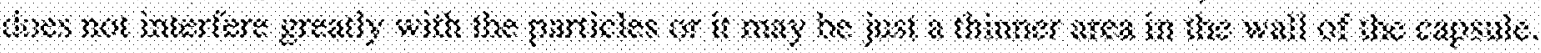

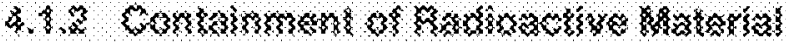

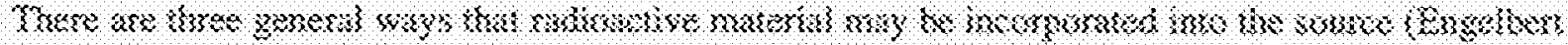
3)3:

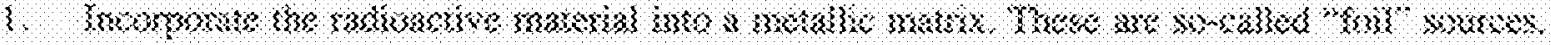

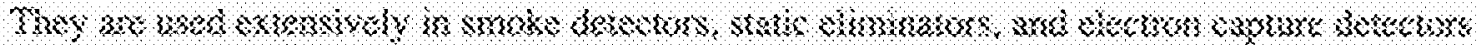

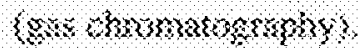

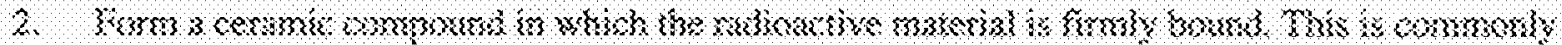

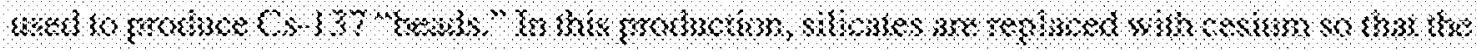

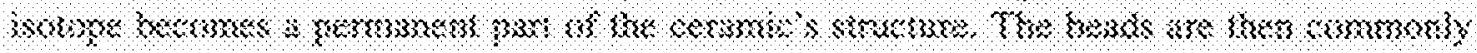

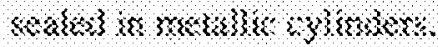

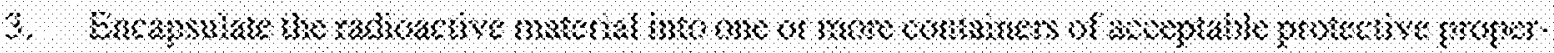

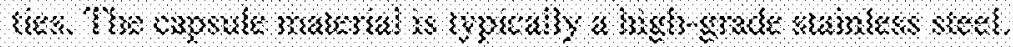

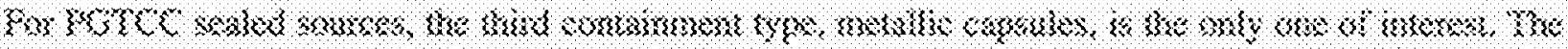

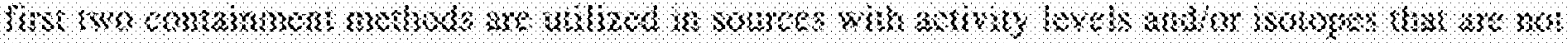

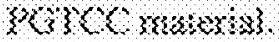




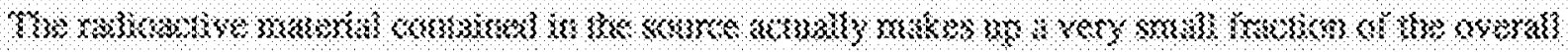

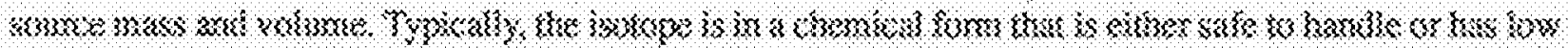

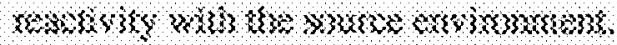

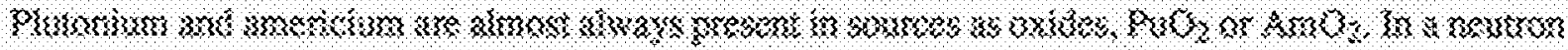

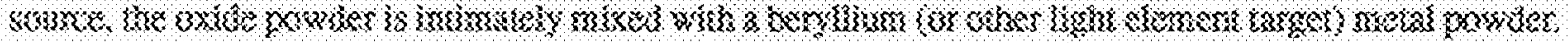

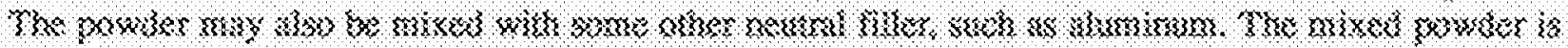

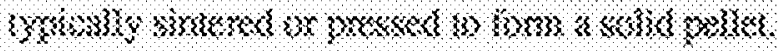

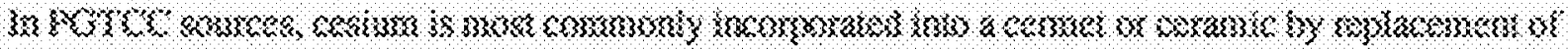

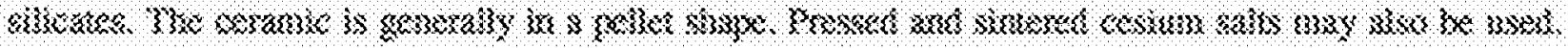

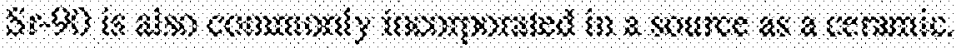

\section{$4.3,3$}

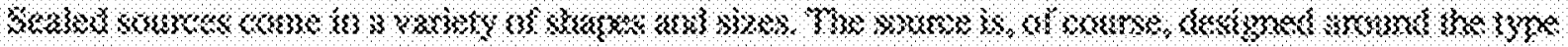

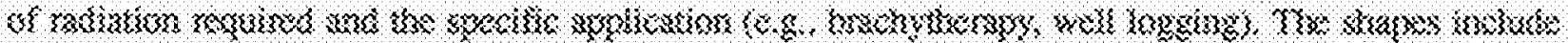

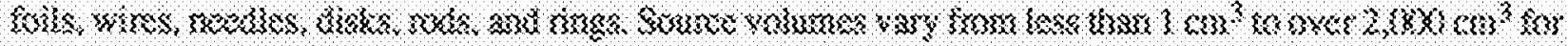

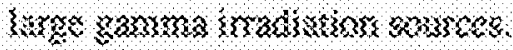

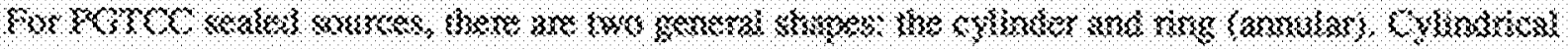

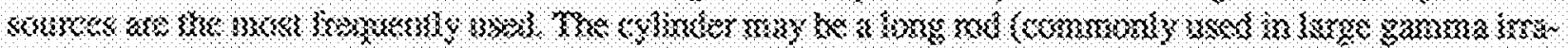

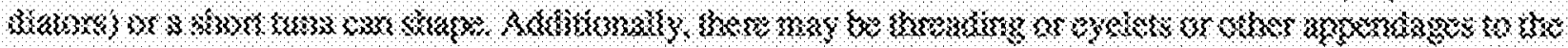

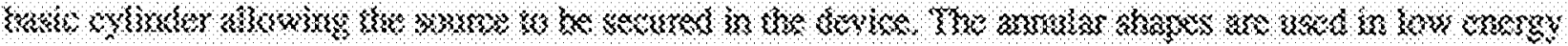

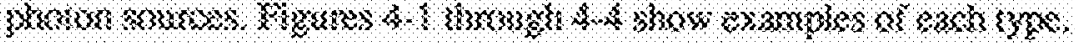

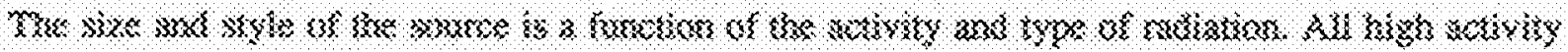

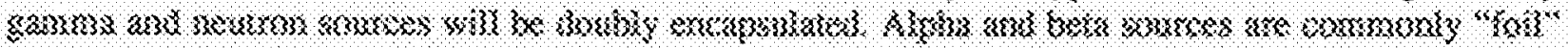

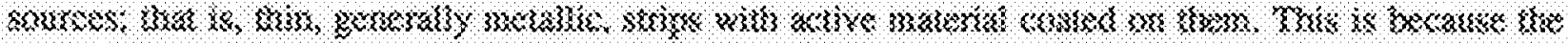

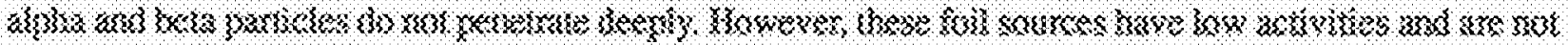

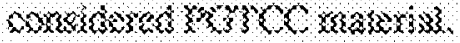

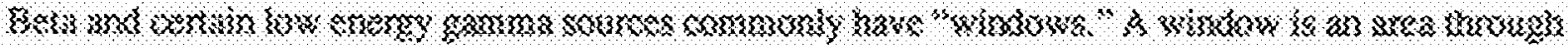

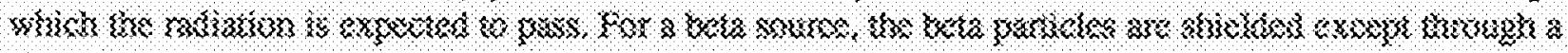

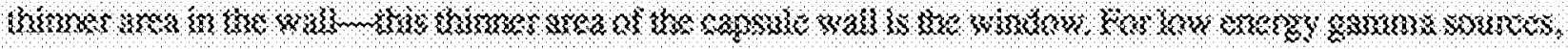

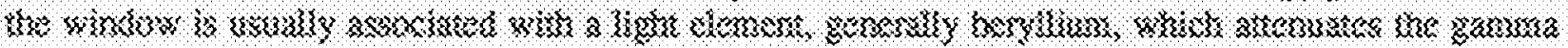

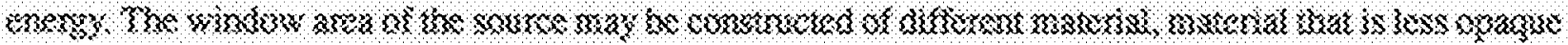

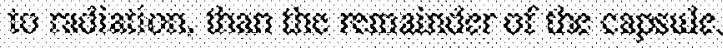

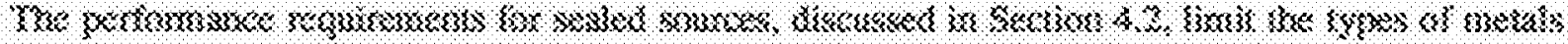

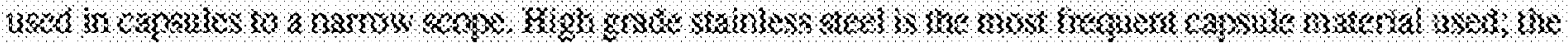

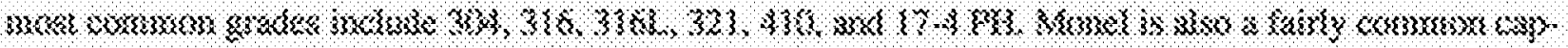

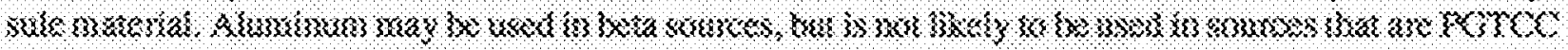

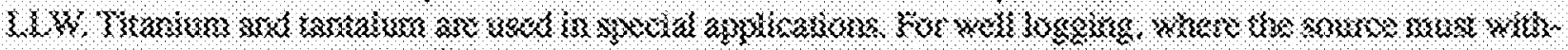

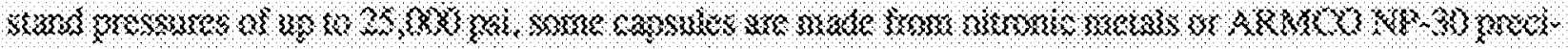

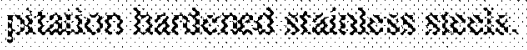

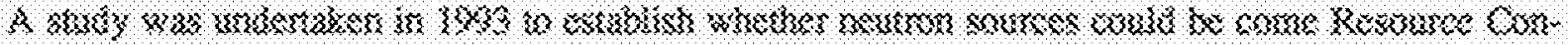

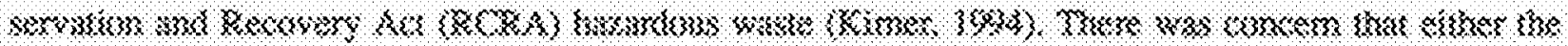

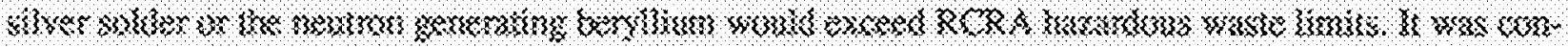

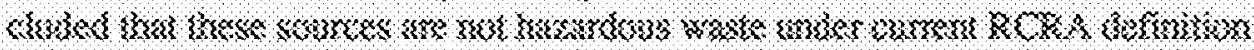




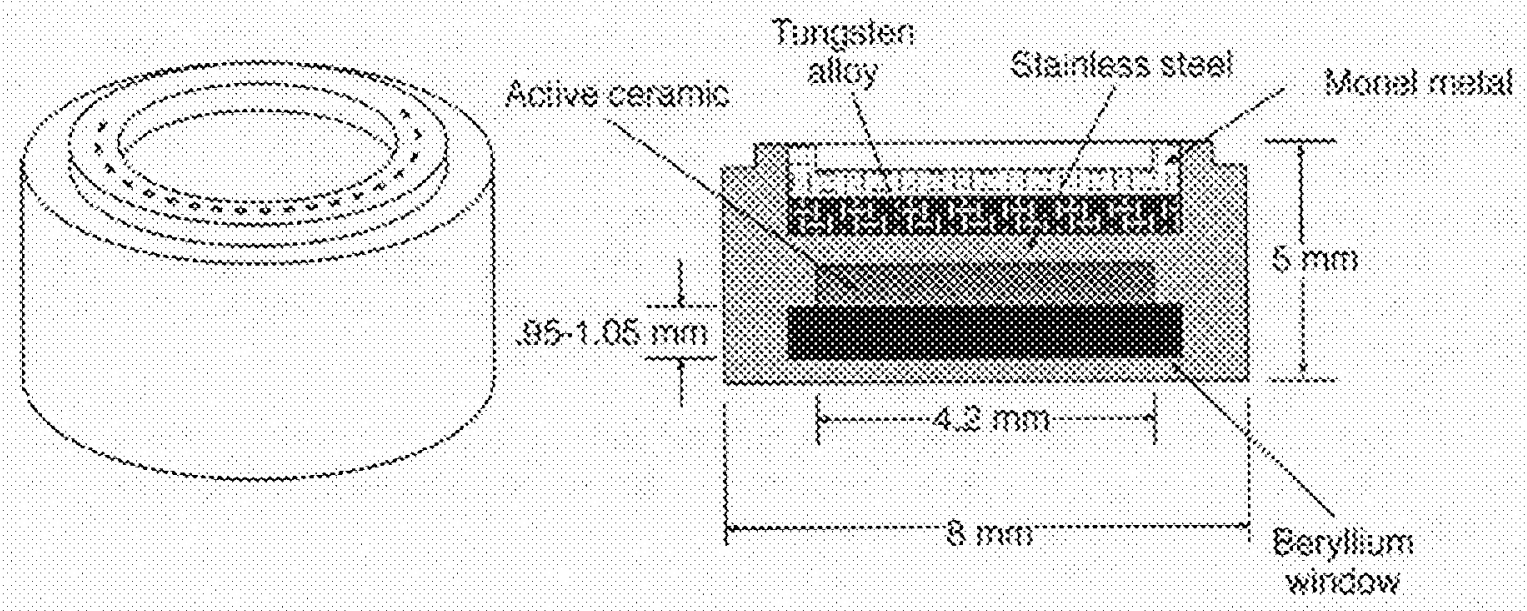

$\$ 304062$

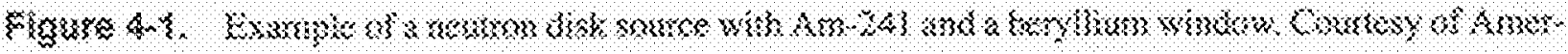

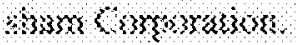
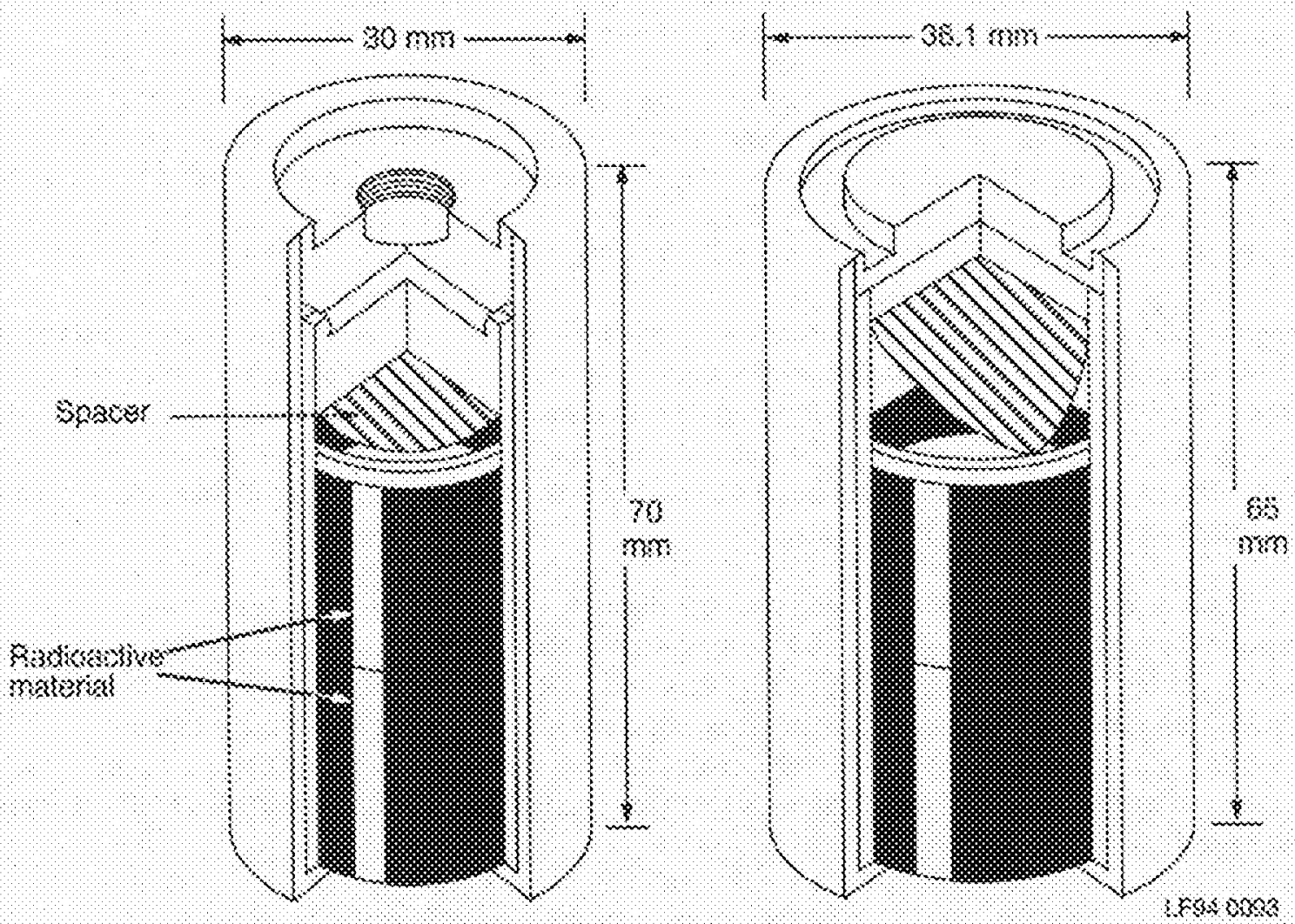

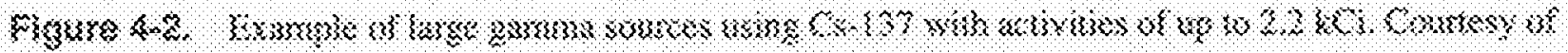

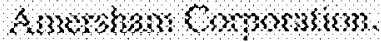



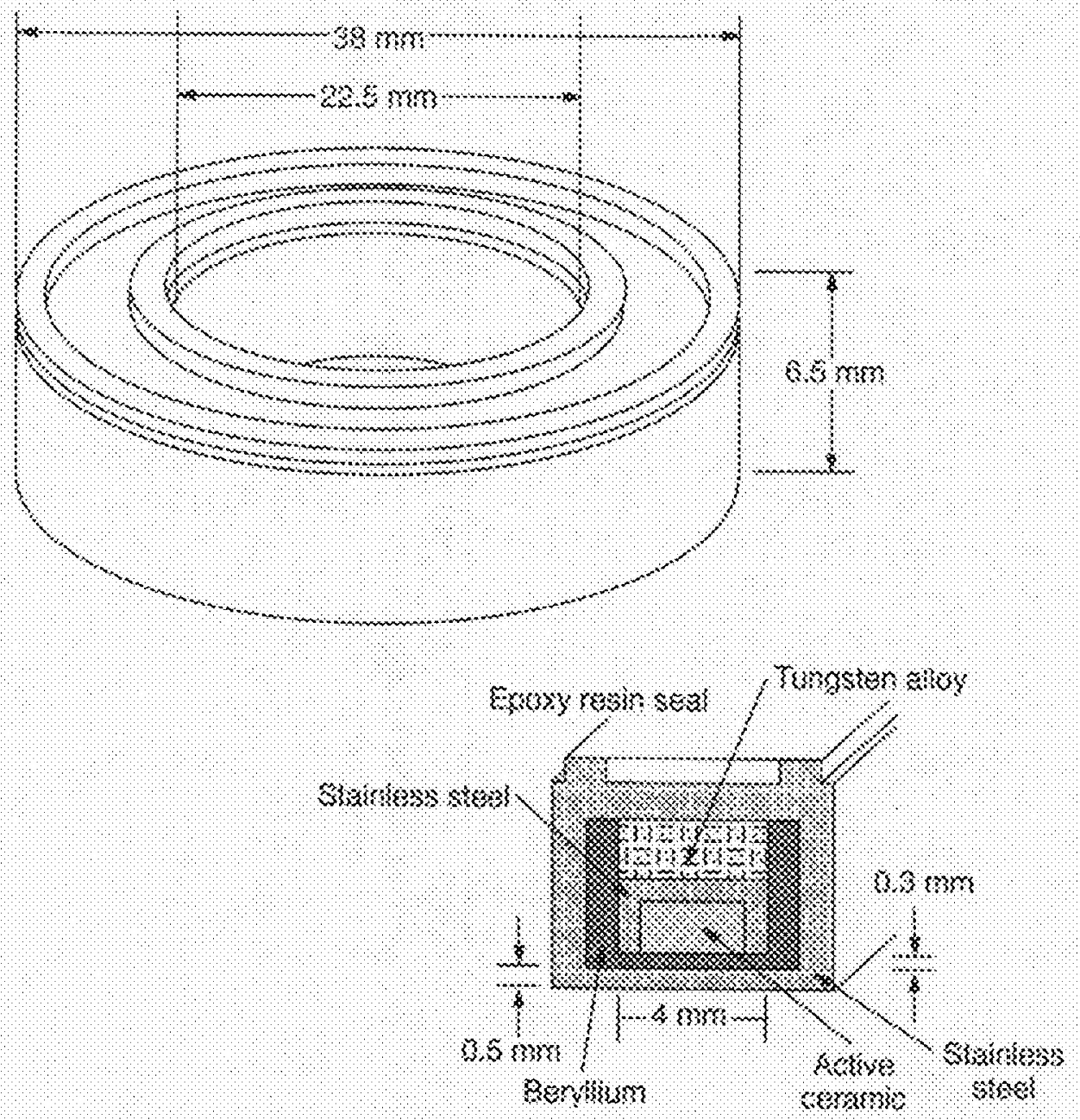

$306 \mathrm{~kg} \pi$

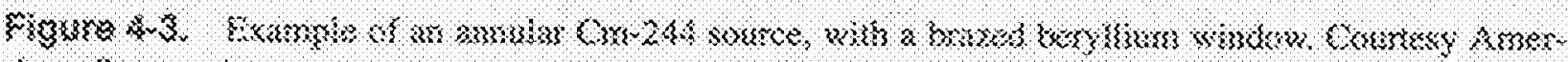

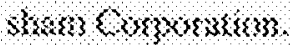

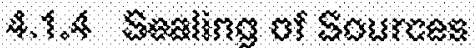

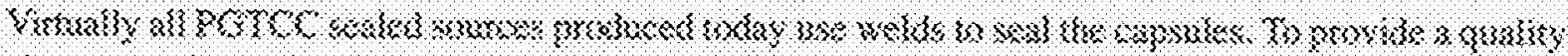

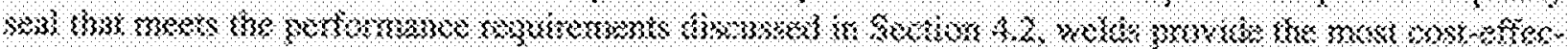

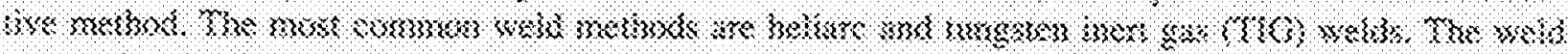

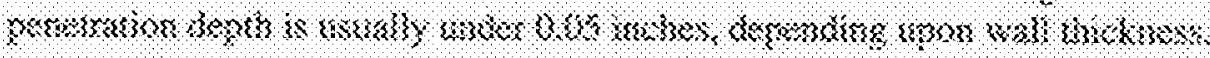

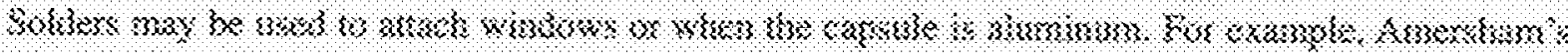

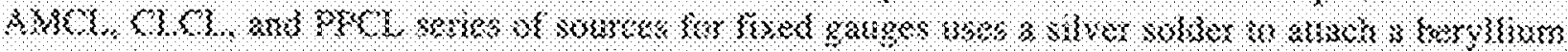

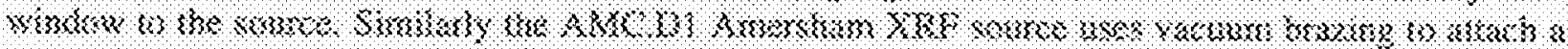

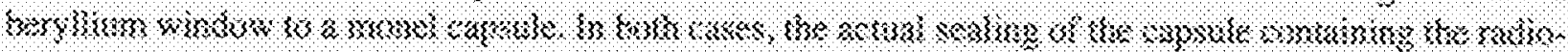

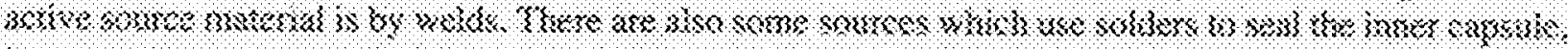

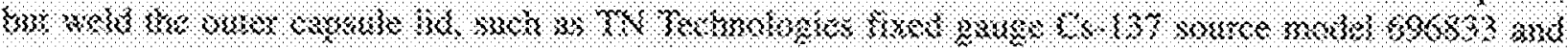

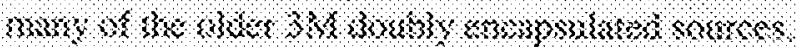




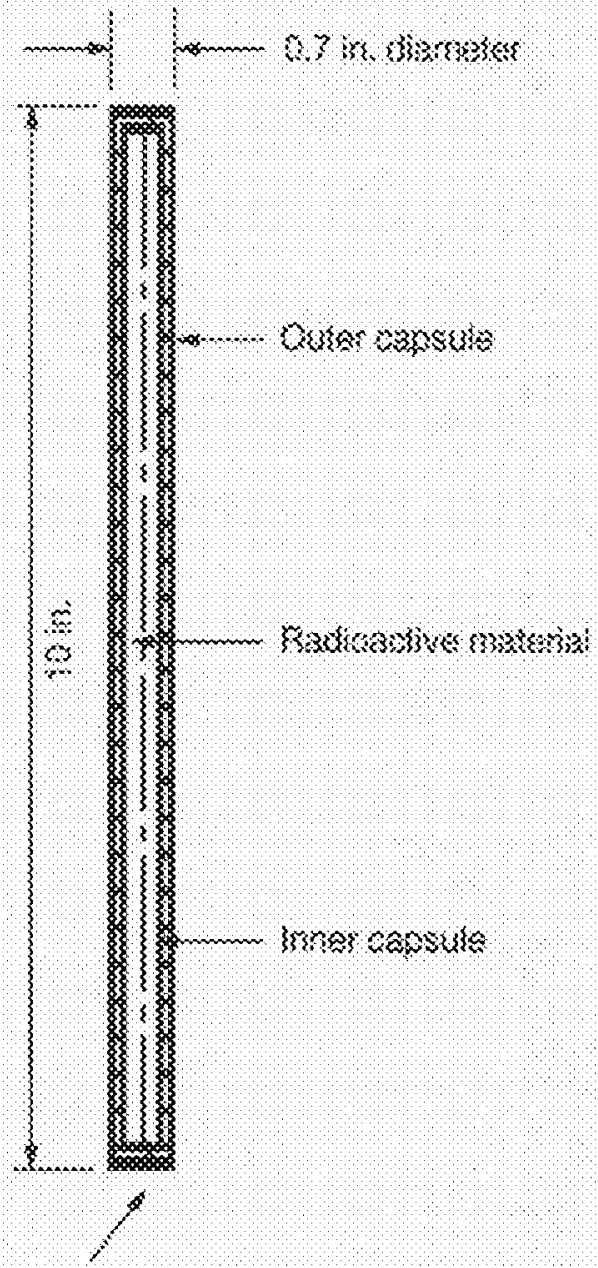

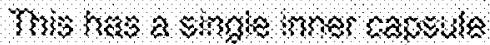

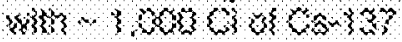

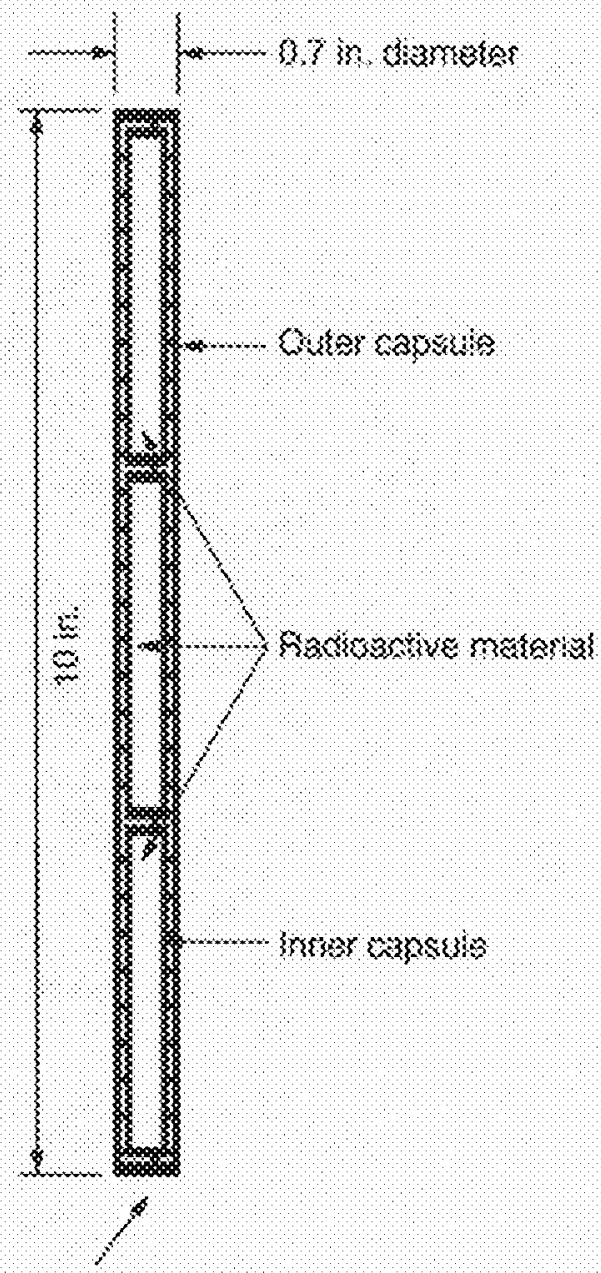

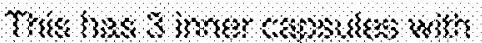

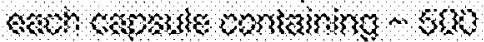

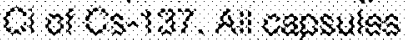

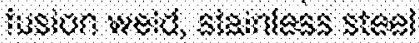
S?

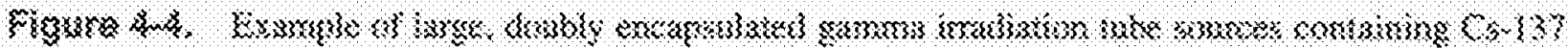

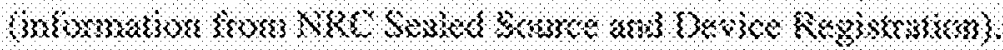

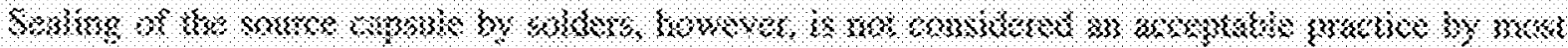

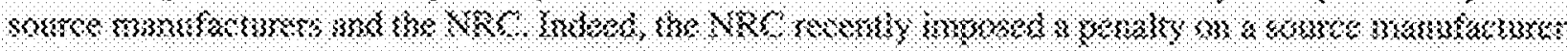

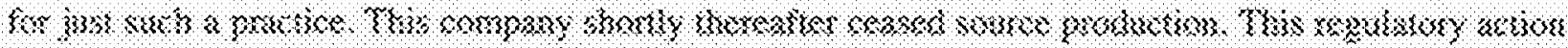

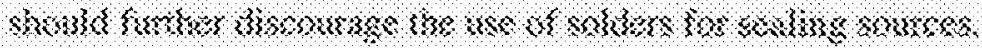

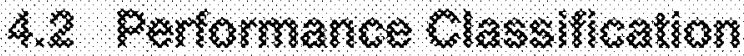

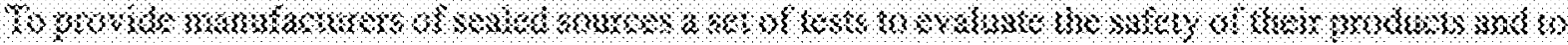

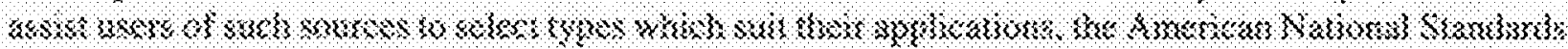

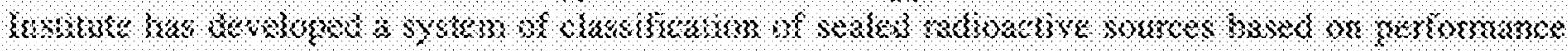




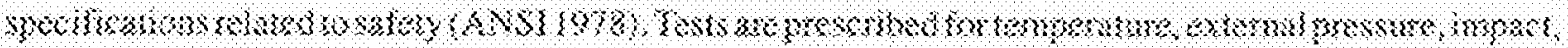

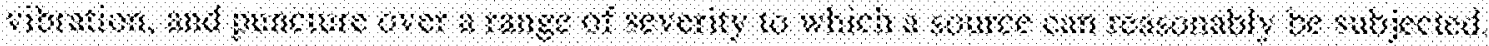

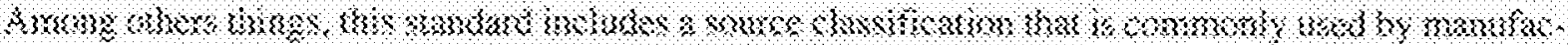

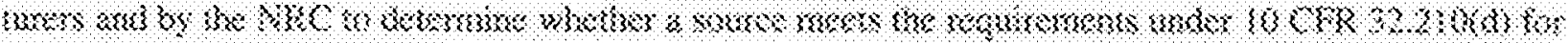

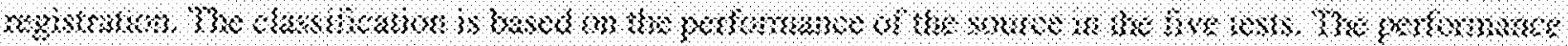

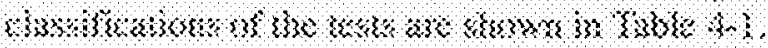

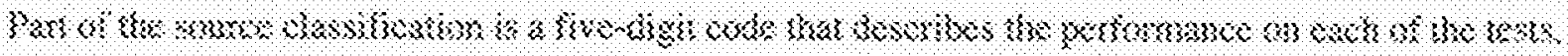

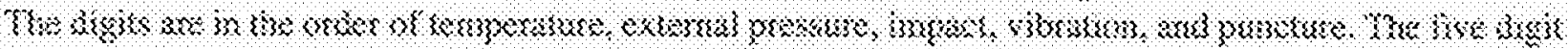

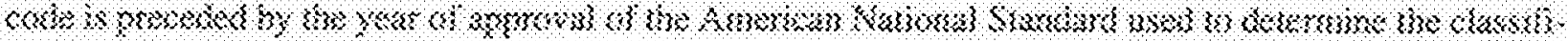

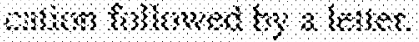

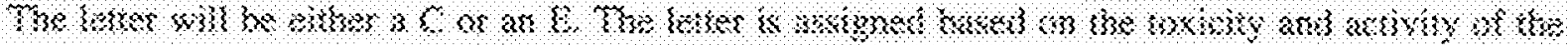

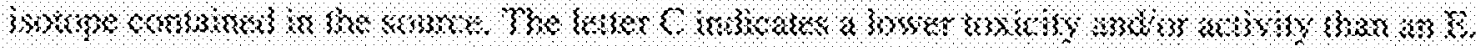

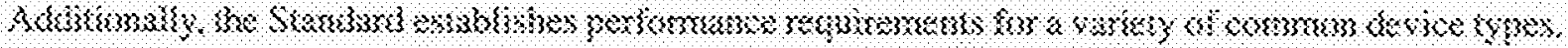

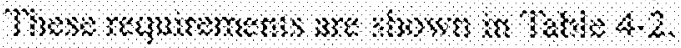

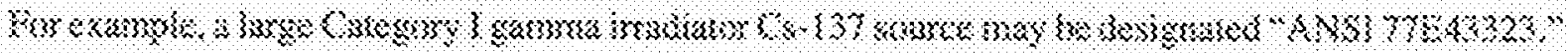

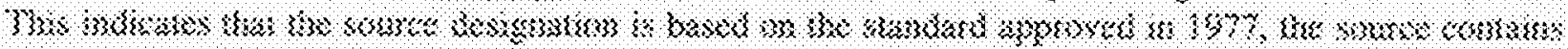

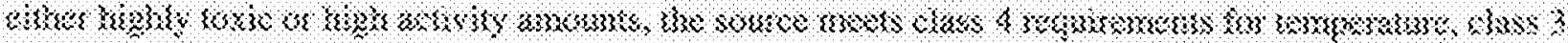

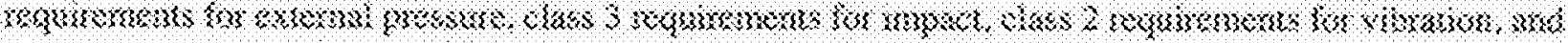

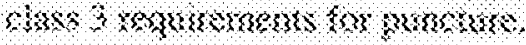

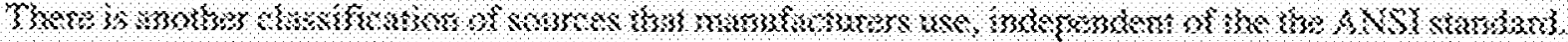

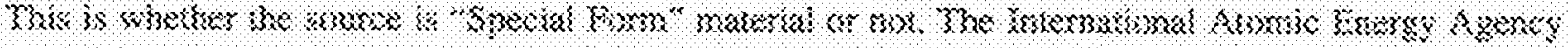

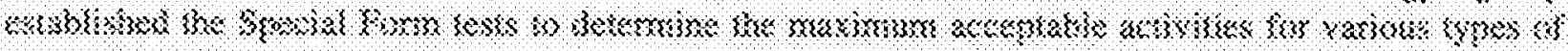

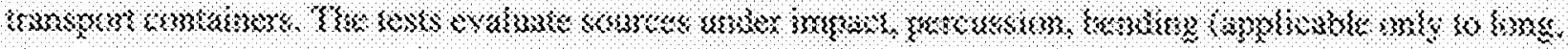

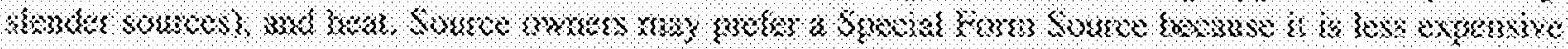

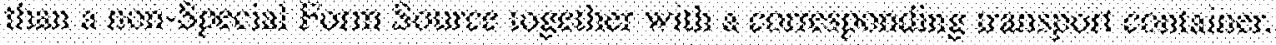

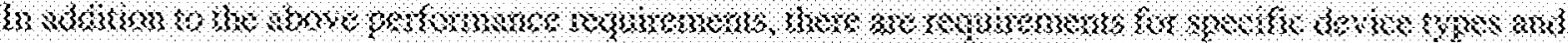

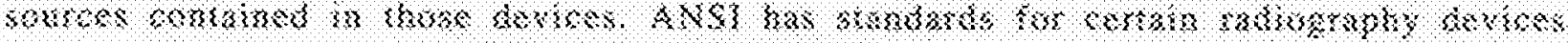

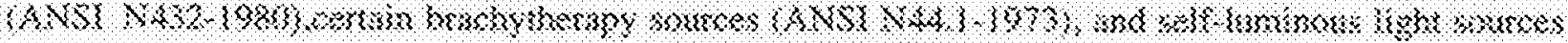

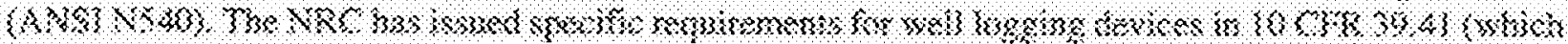

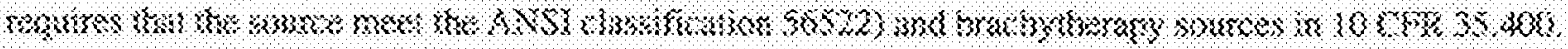

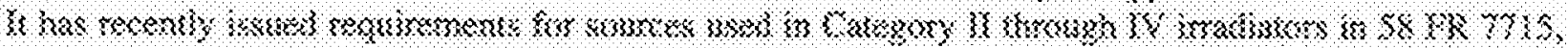

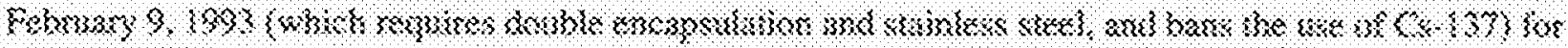

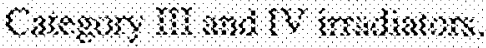




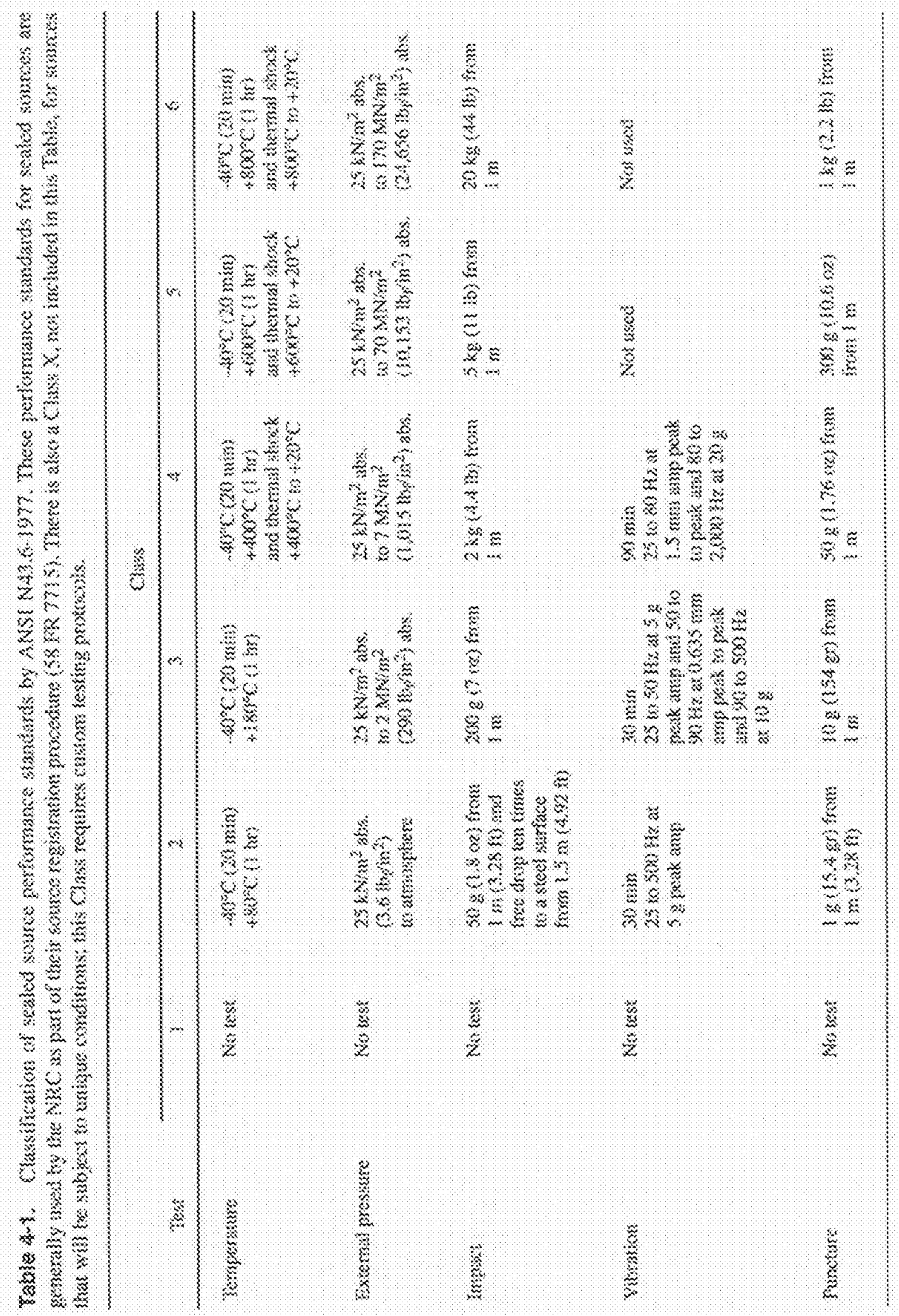




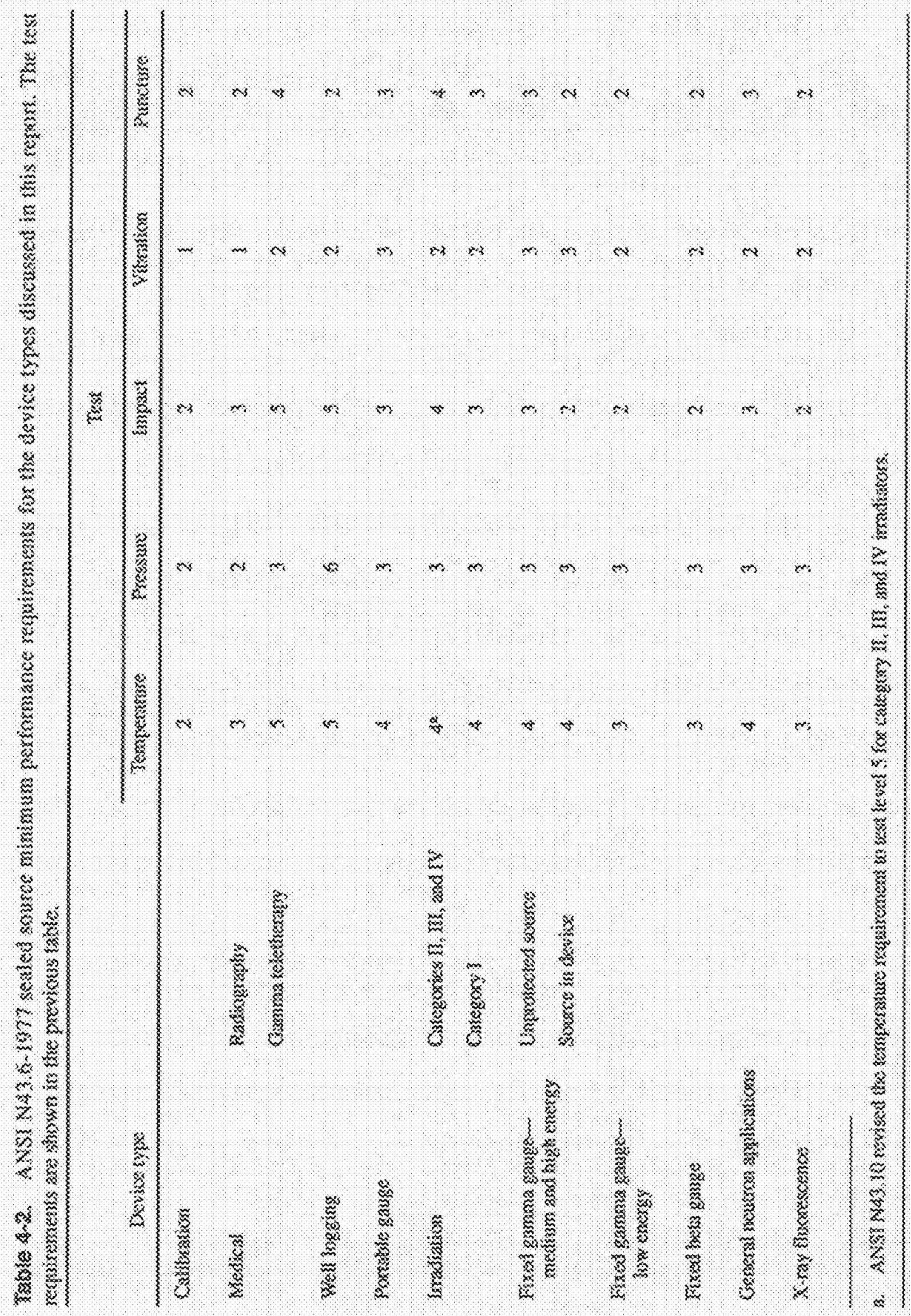




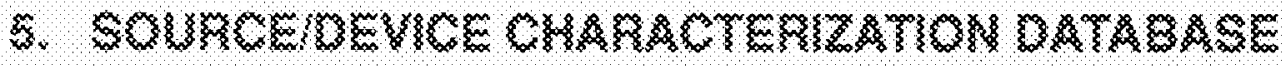

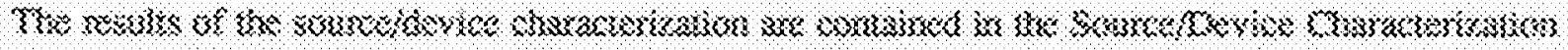

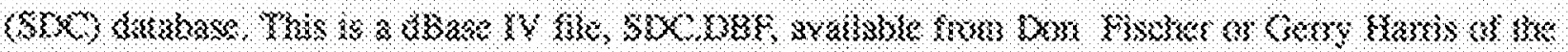

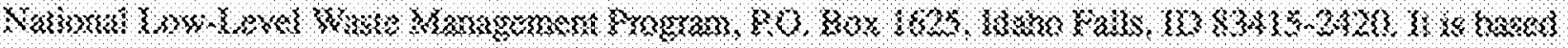

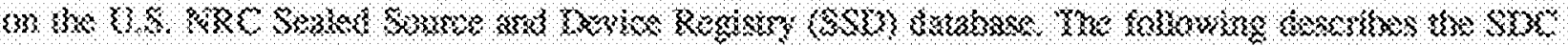
3

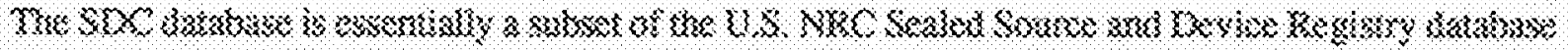

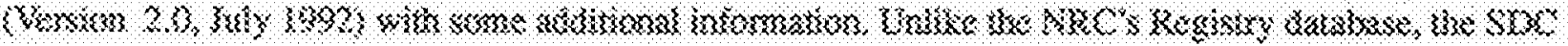

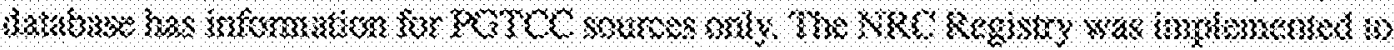

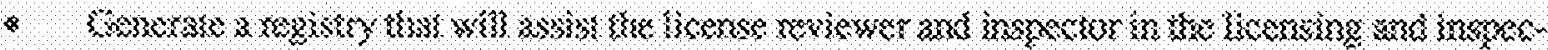

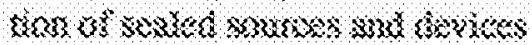

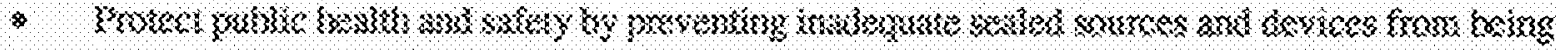

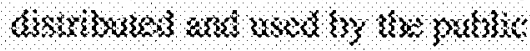

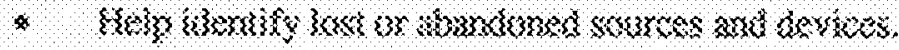

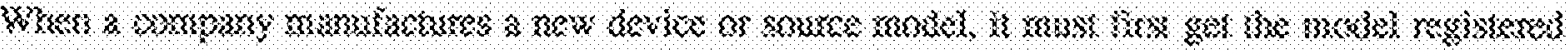

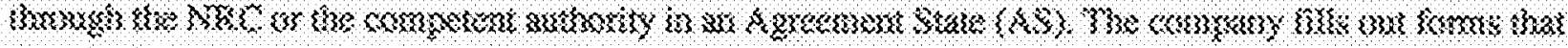

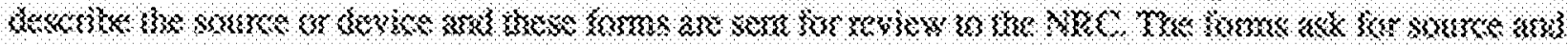

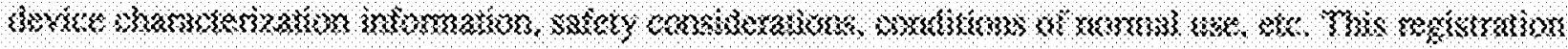

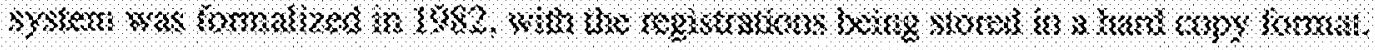

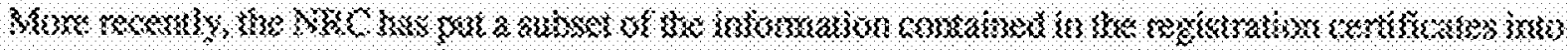

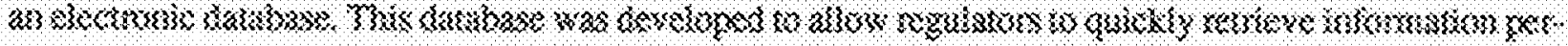

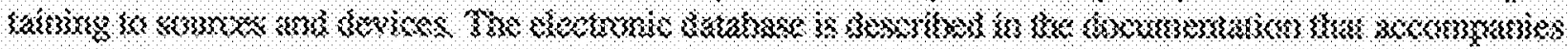

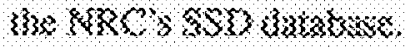

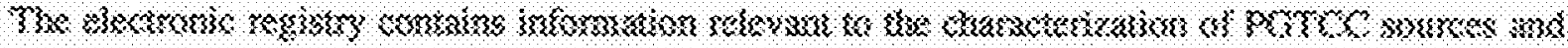

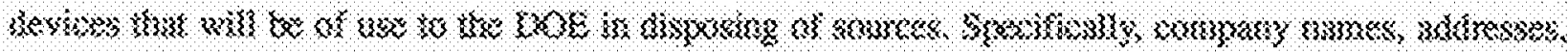

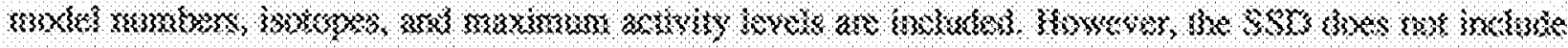

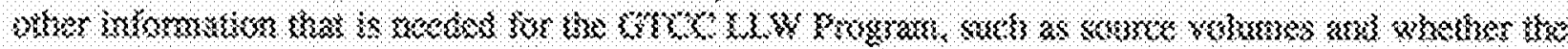

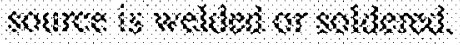

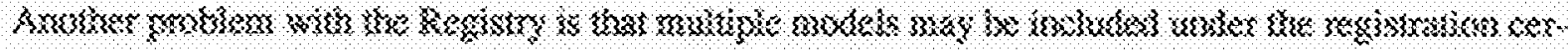

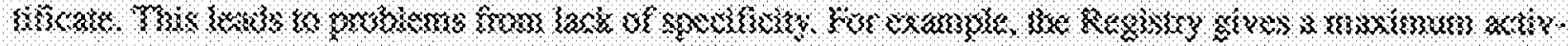

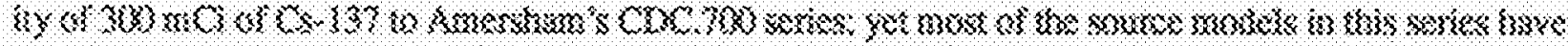

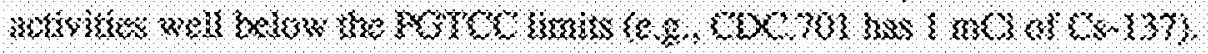

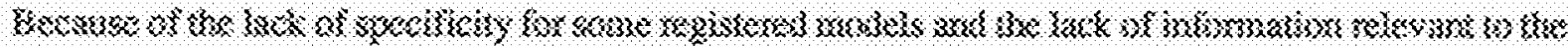

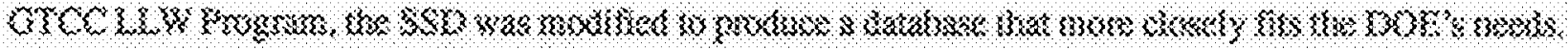

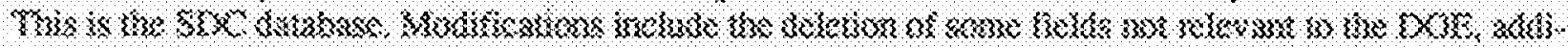

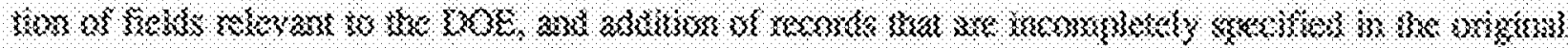

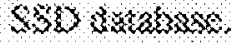

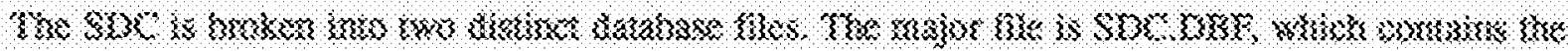

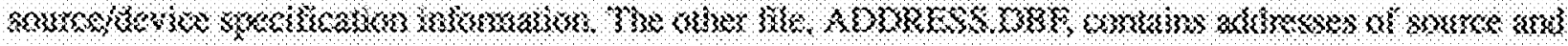

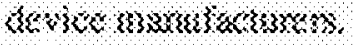




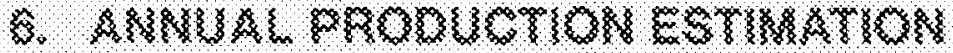

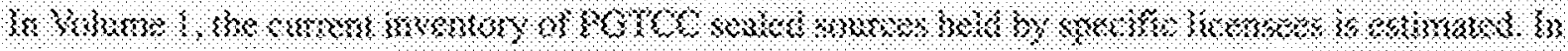

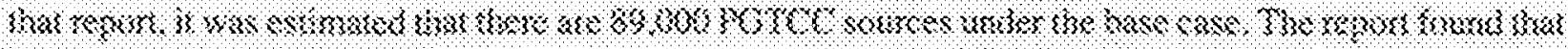

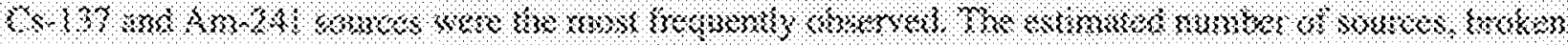

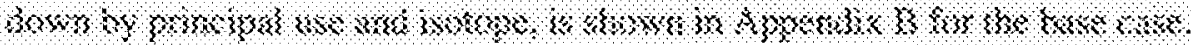

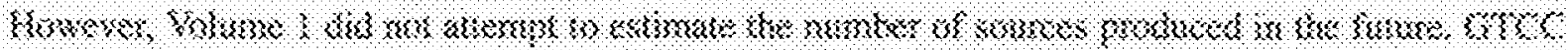

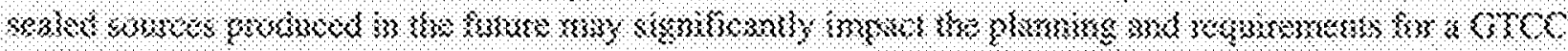

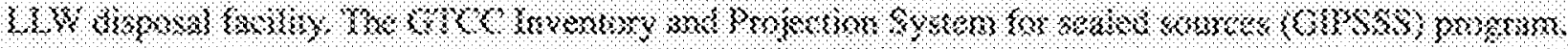

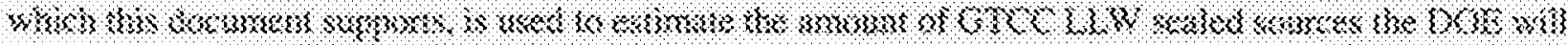

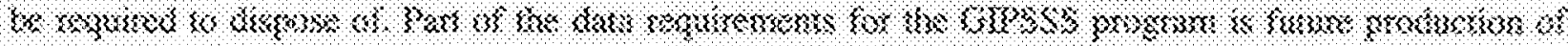

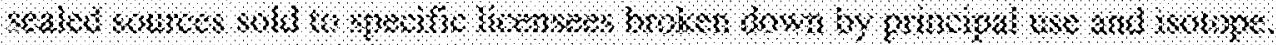

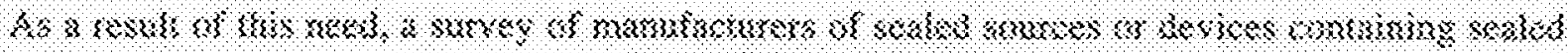

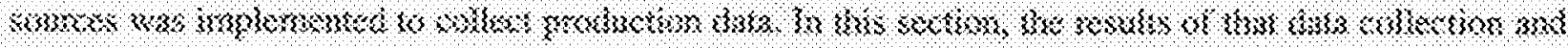
ambisis 3 rivis a s grath.

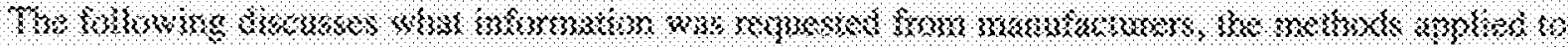

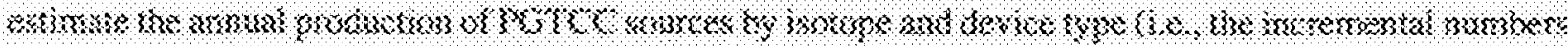

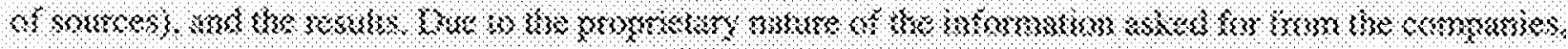

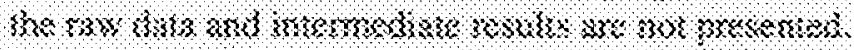

\subsection{Survay Mathonology}

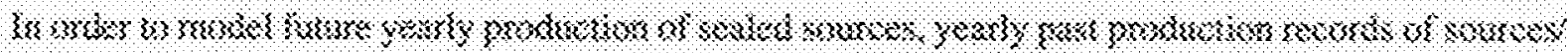

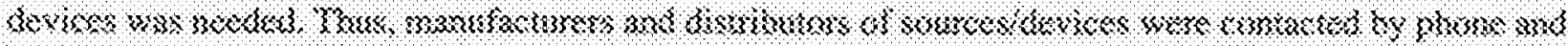

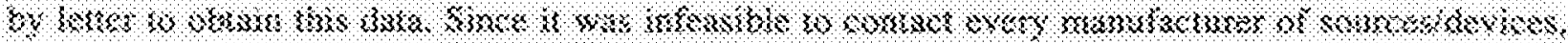

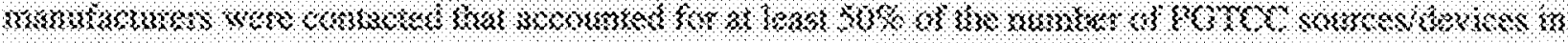

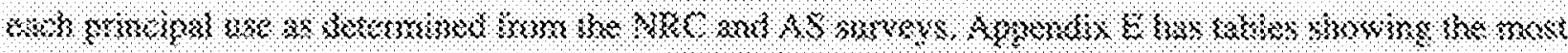

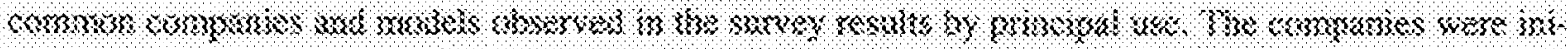

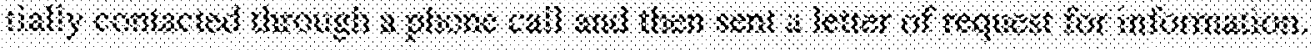

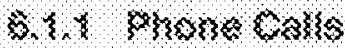

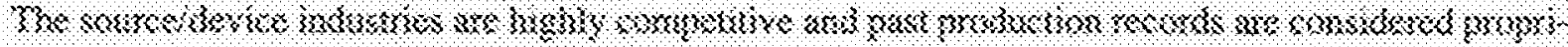

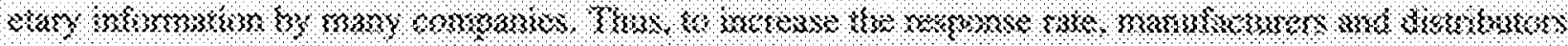

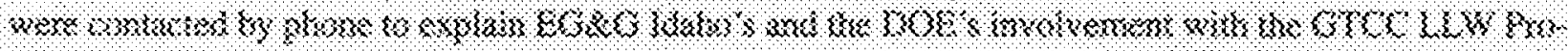

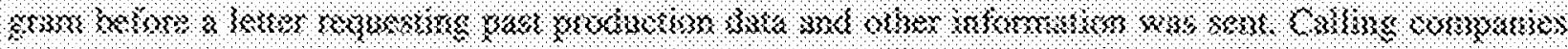

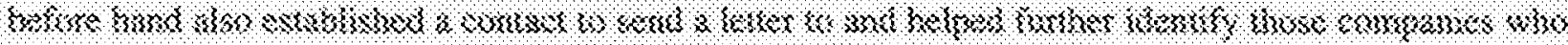

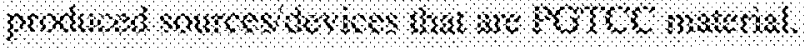

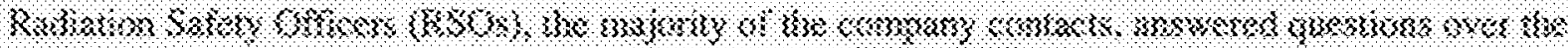

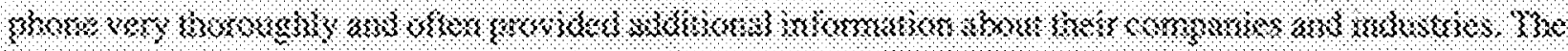

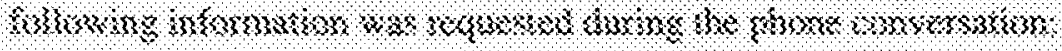

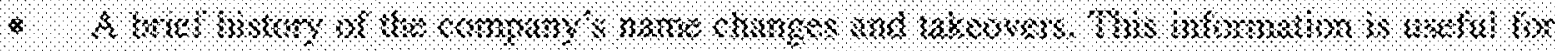

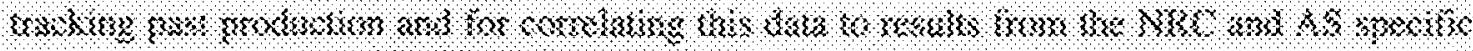

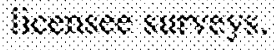




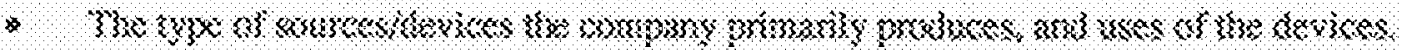

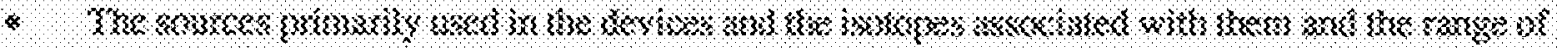

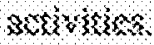

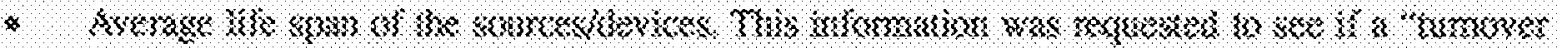

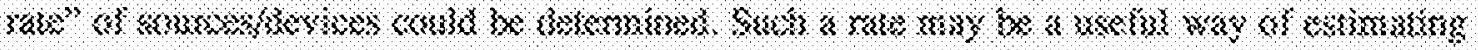

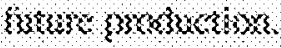

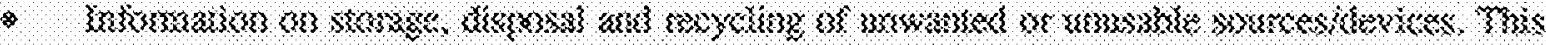

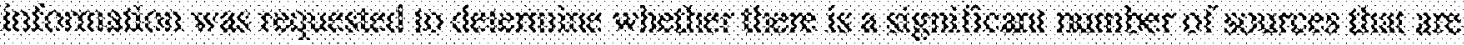

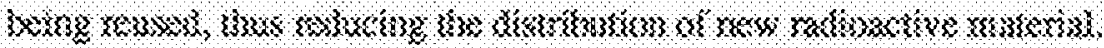

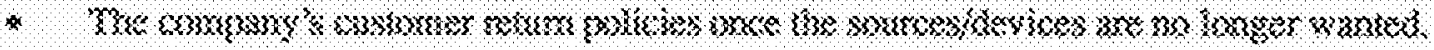

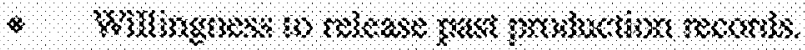

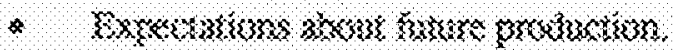

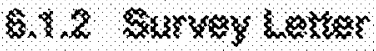

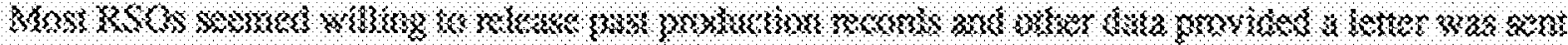

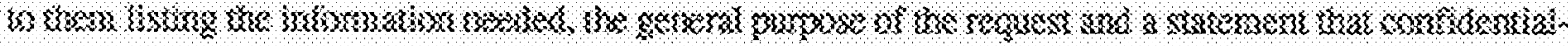

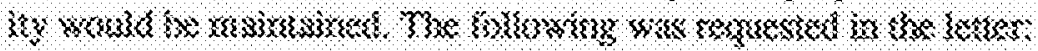

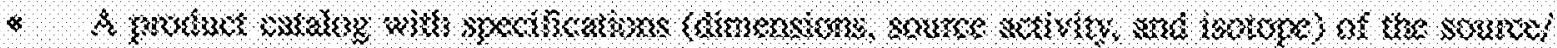

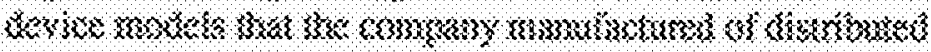

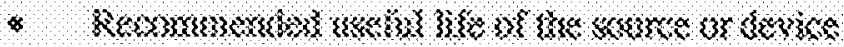

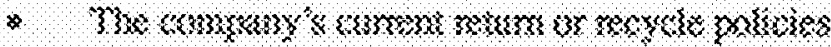

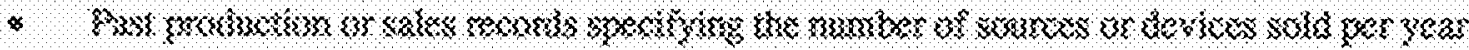

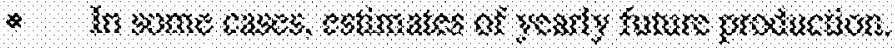

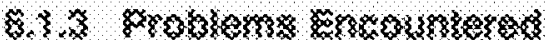

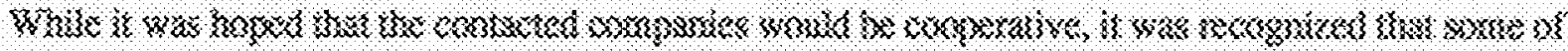

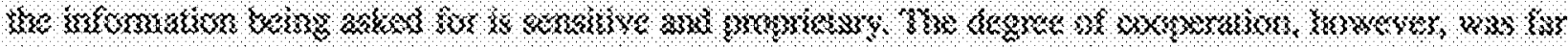

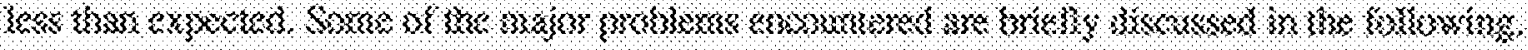

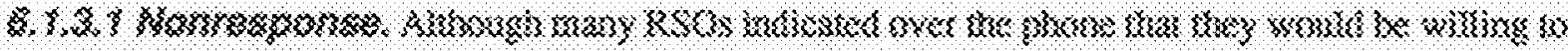

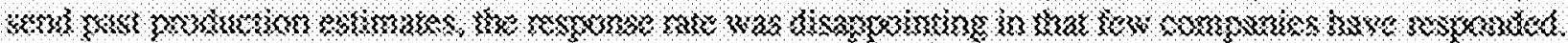

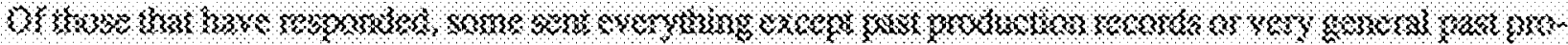

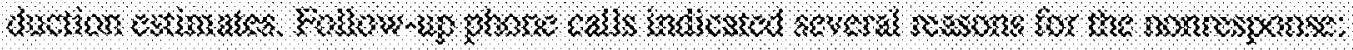

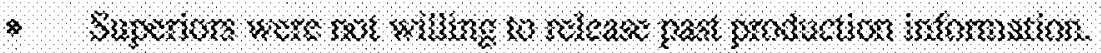

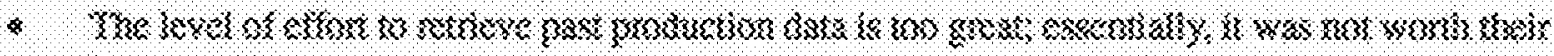
sirste. 


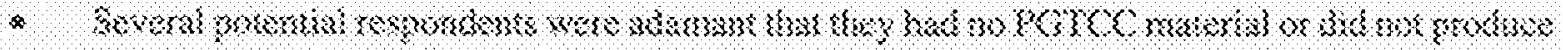

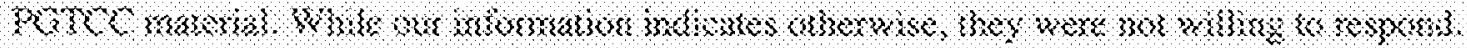

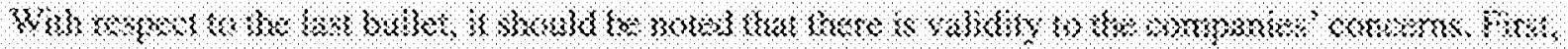

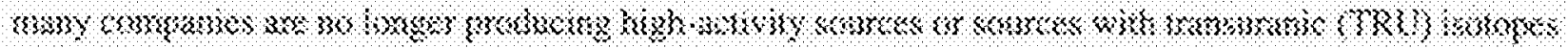

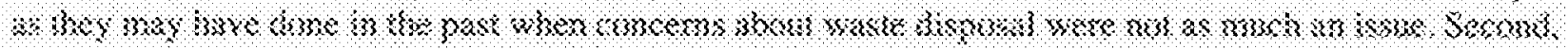

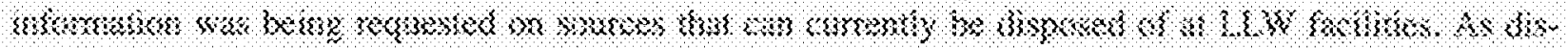

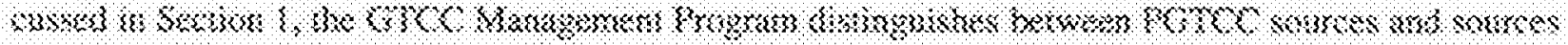

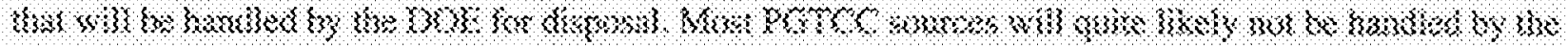

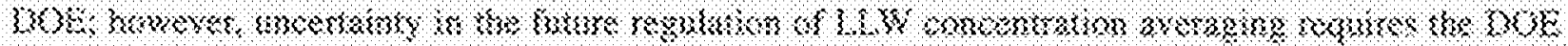

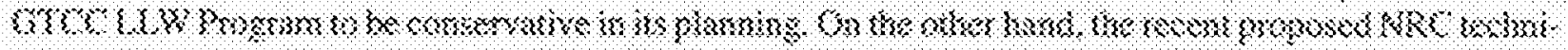

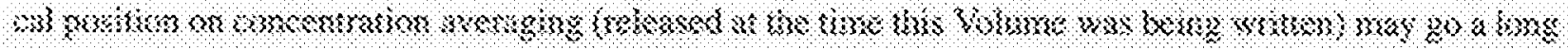

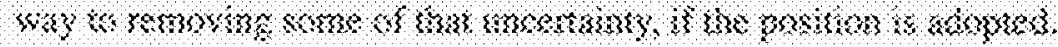

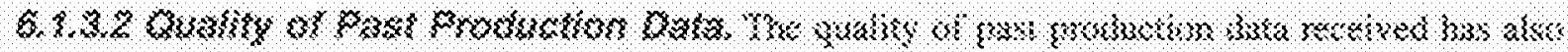

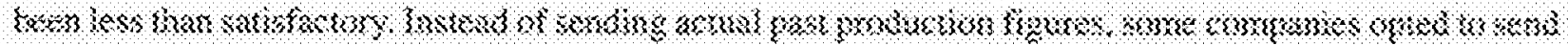

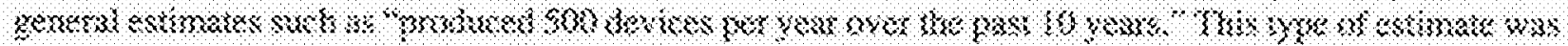

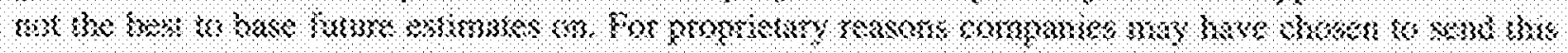
tyge of intorrsaiton:

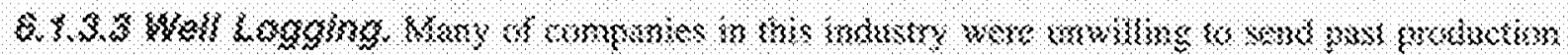

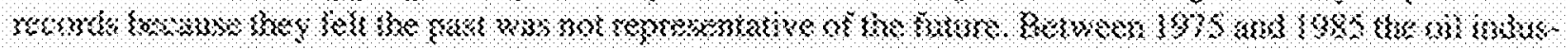

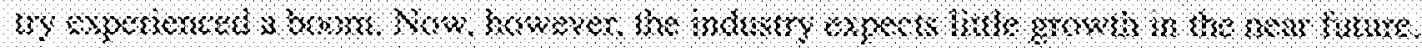

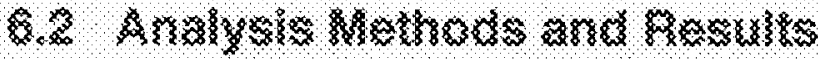

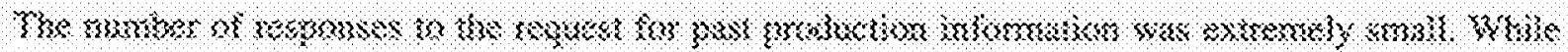

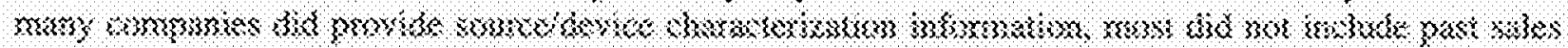

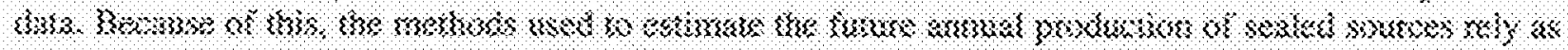

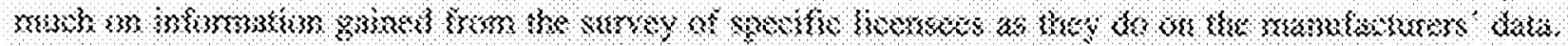

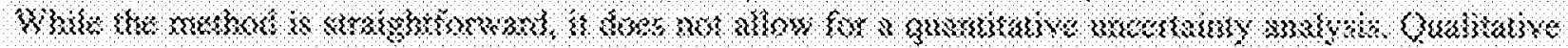

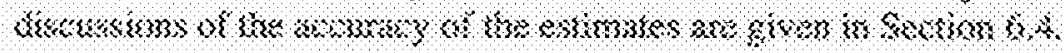

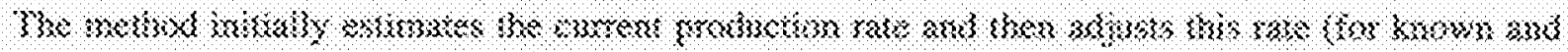

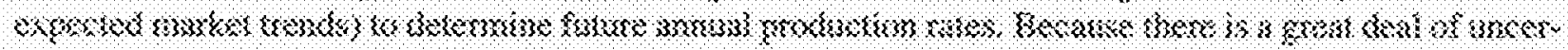

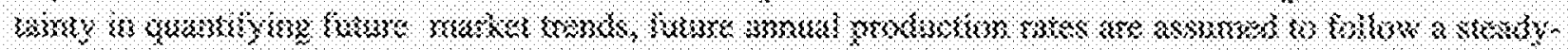

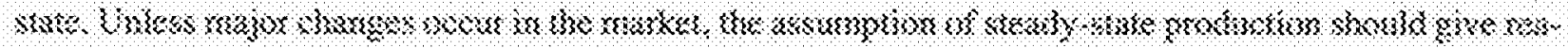

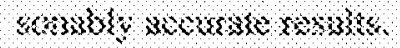

\section{Q.

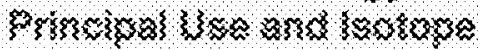

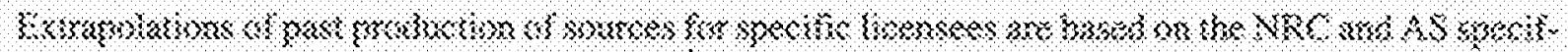

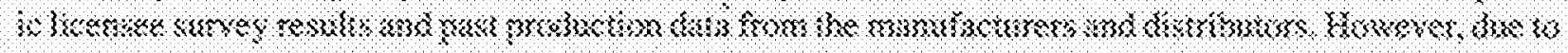

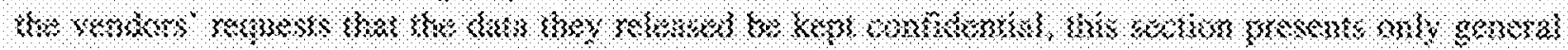

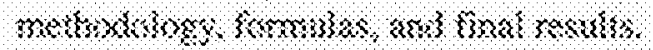

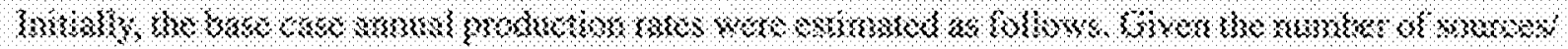

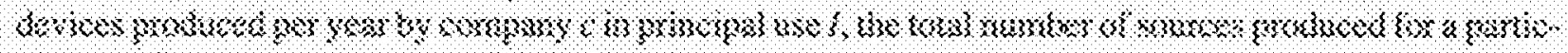

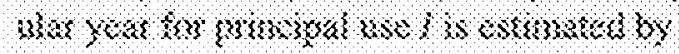




$$
N_{l}=\mathrm{x}_{\mathrm{s}}
$$

was

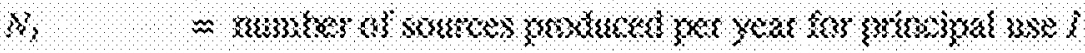

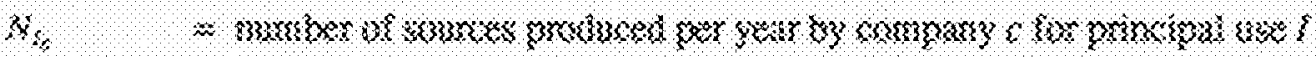

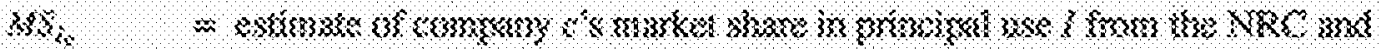

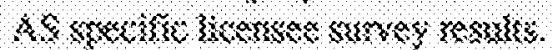

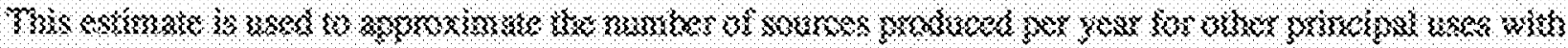

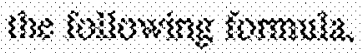

$$
8, \frac{x_{i}}{x_{i}}
$$

shisere

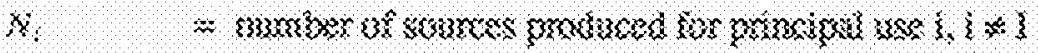

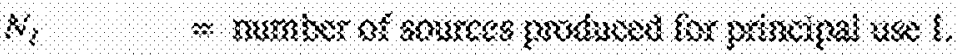

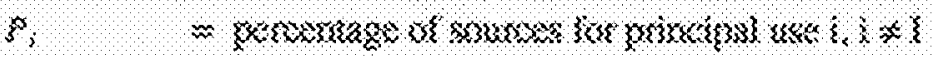

\begin{tabular}{|c|c|}
\hline 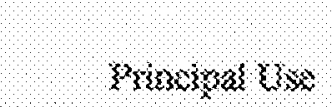 & 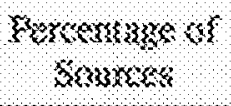 \\
\hline Conicomatizins & 1003 \\
\hline Mrex $2<2$ & $\$ .78$ \\
\hline Ka 3 Y orssing & 346 \\
\hline Burtibsta zankso & 1332 \\
\hline 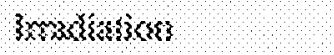 & 2335 \\
\hline 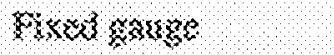 & 3633 \\
\hline 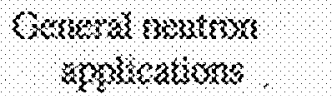 & 238 \\
\hline 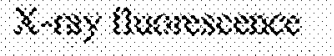 & 3.33 \\
\hline Orsos & 23,65 \\
\hline
\end{tabular}

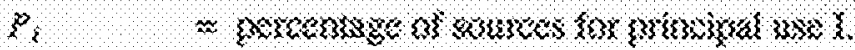

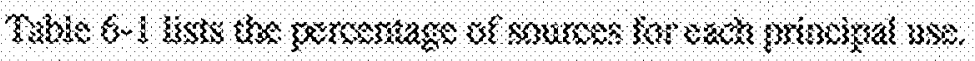

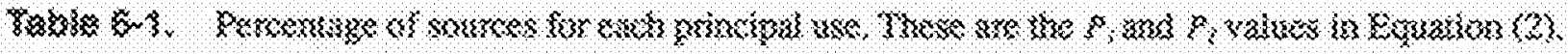




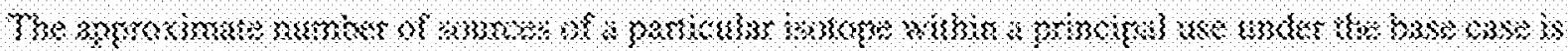
found insing:

$K_{1},=8,8$

when:

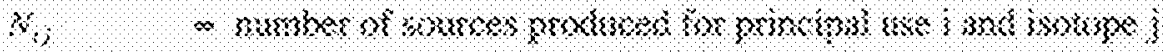

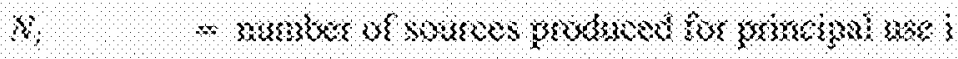

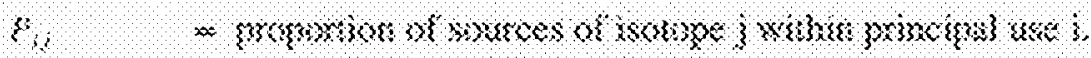

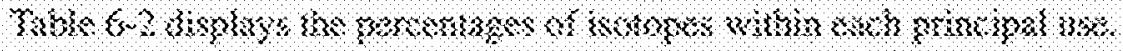

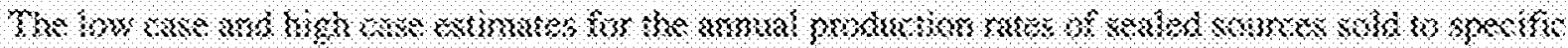

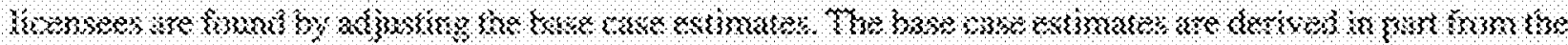

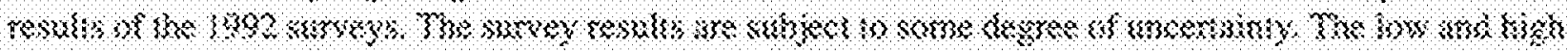

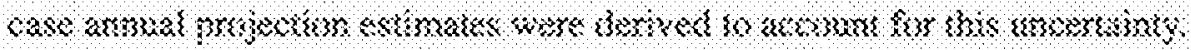

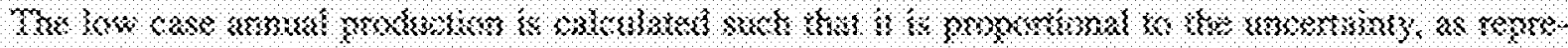

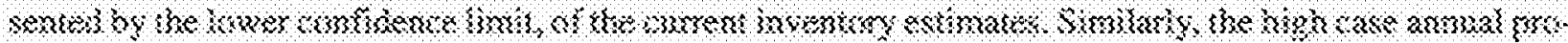

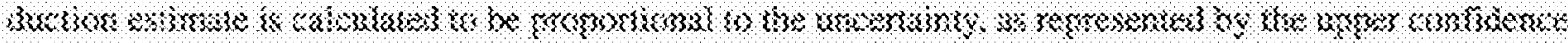

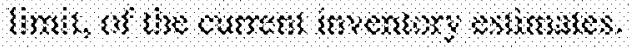

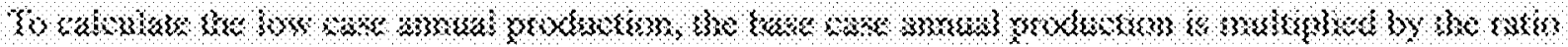

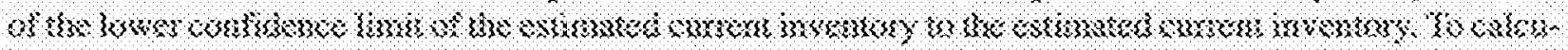

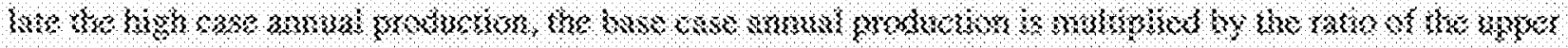

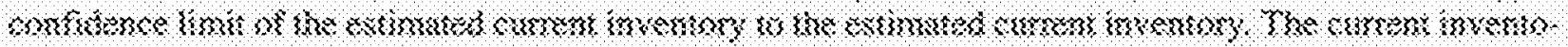

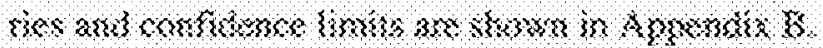

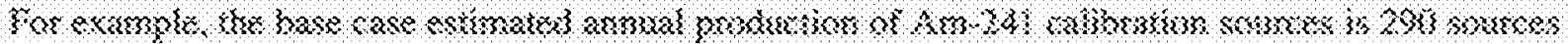

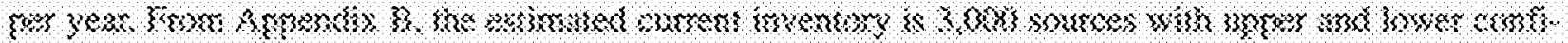

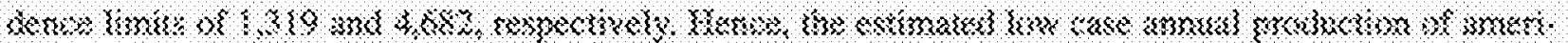

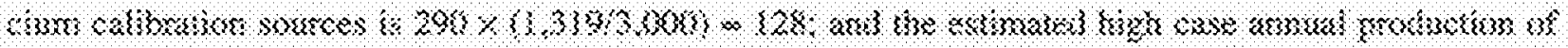

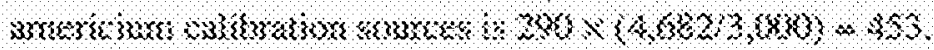

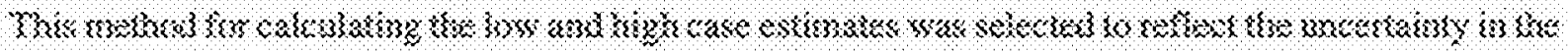

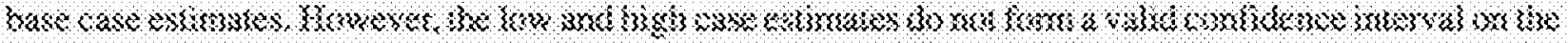

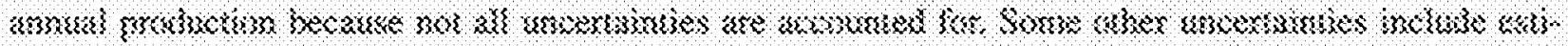

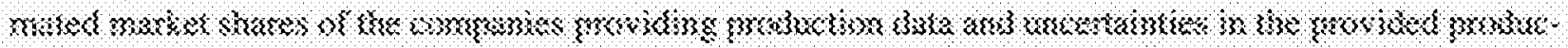
siker saks.

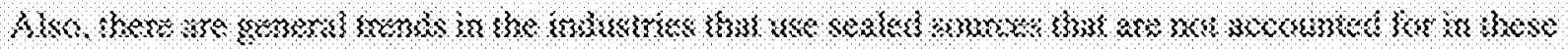

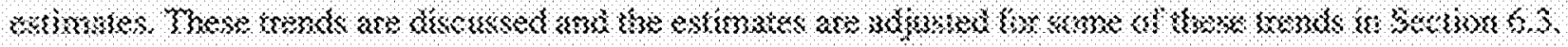

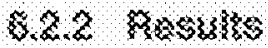

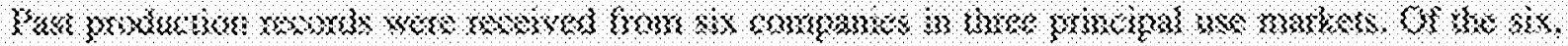

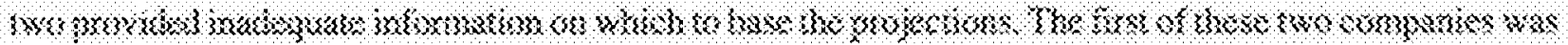

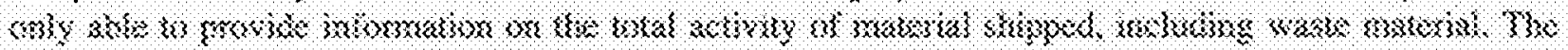




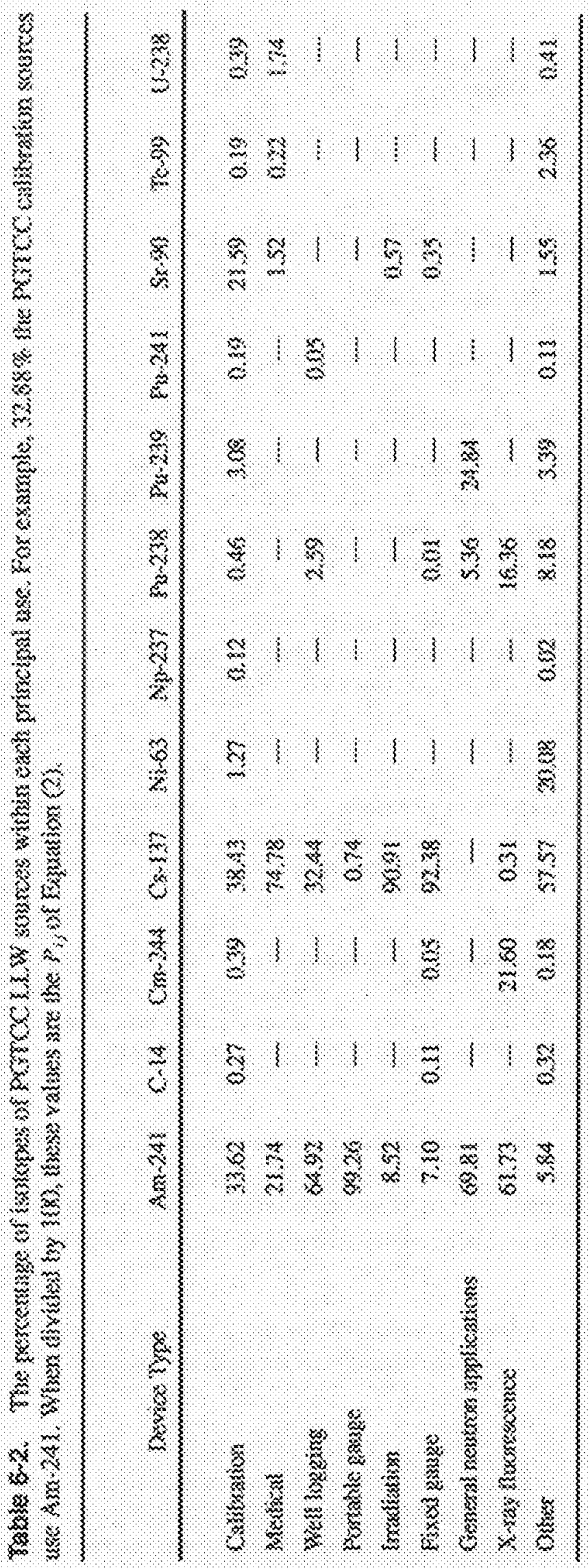




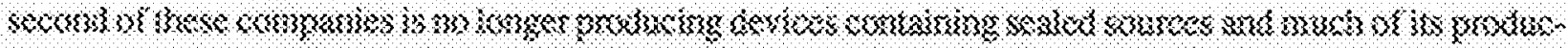

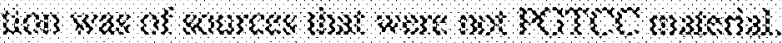

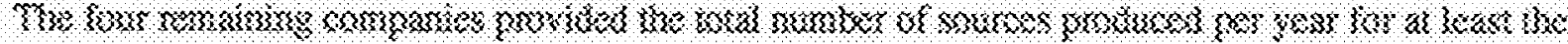

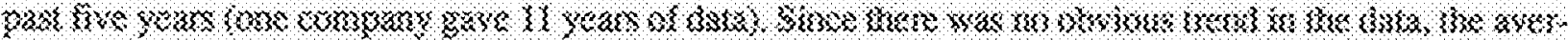

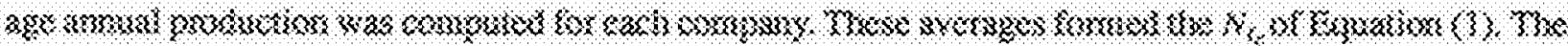

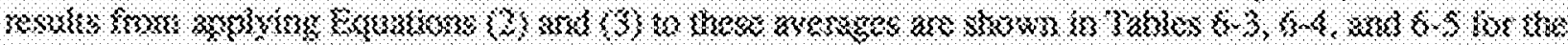

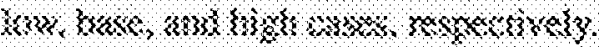

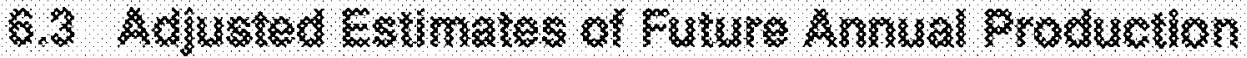

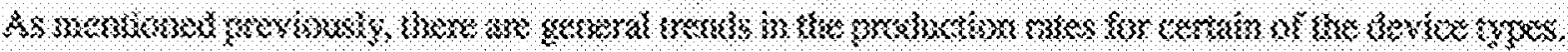

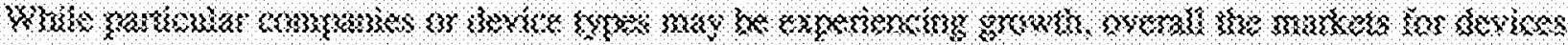

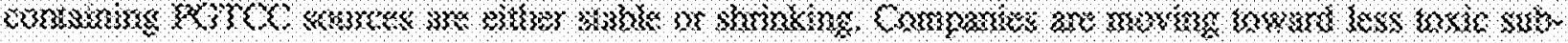

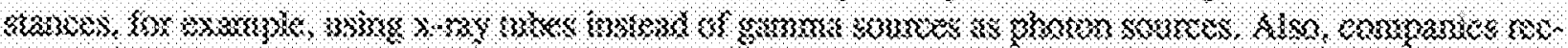

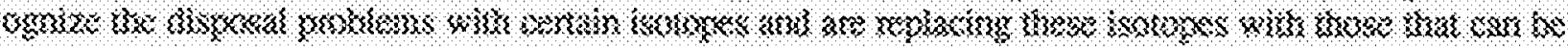

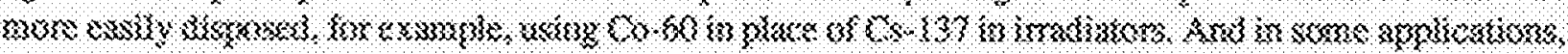

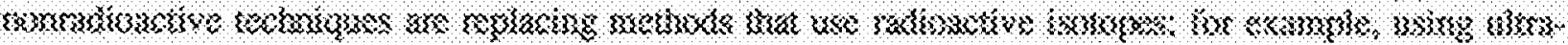

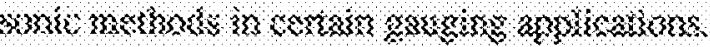

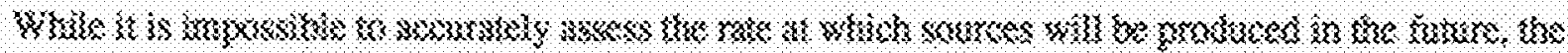

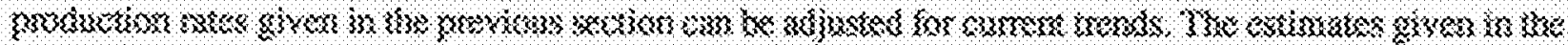

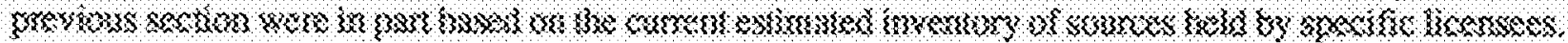

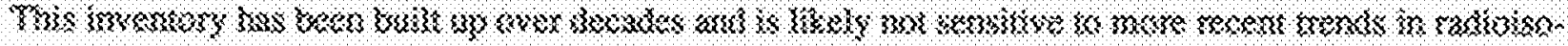
bux groulawines.

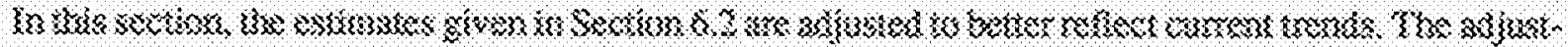

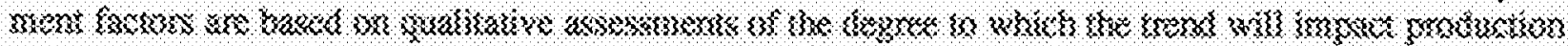

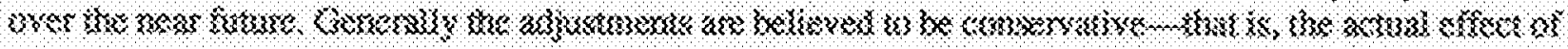

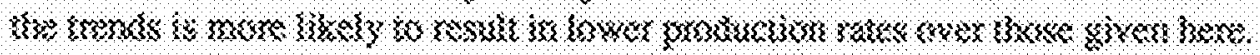

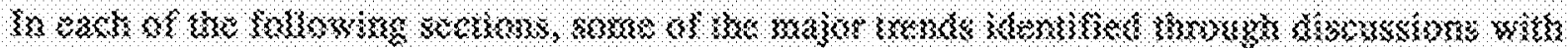

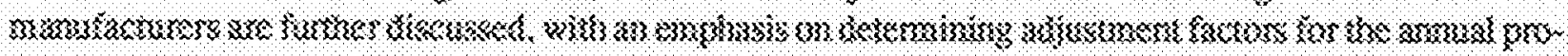

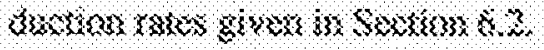

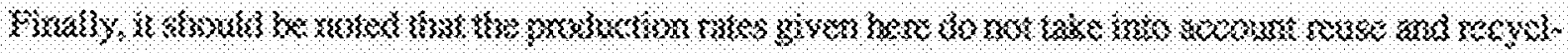

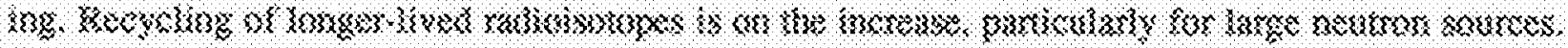

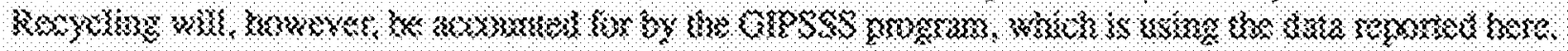

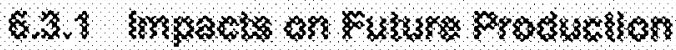

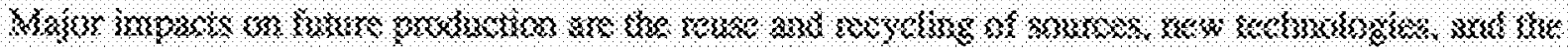

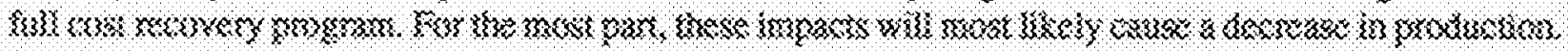

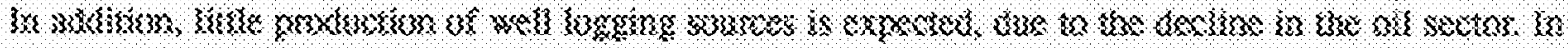

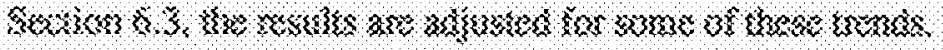

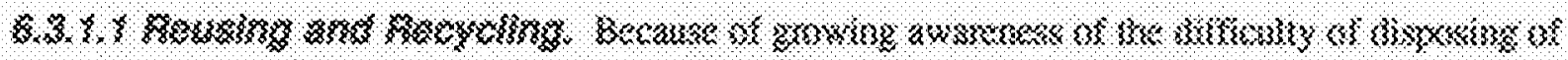

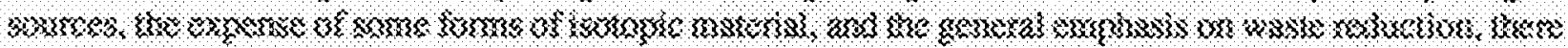

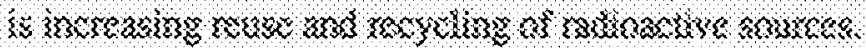

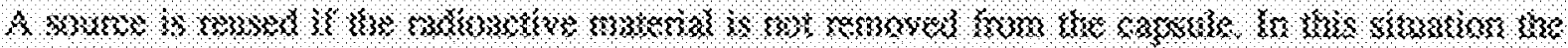

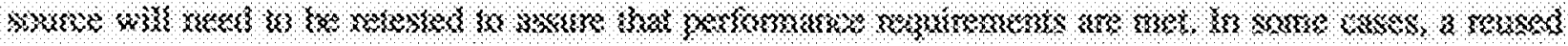




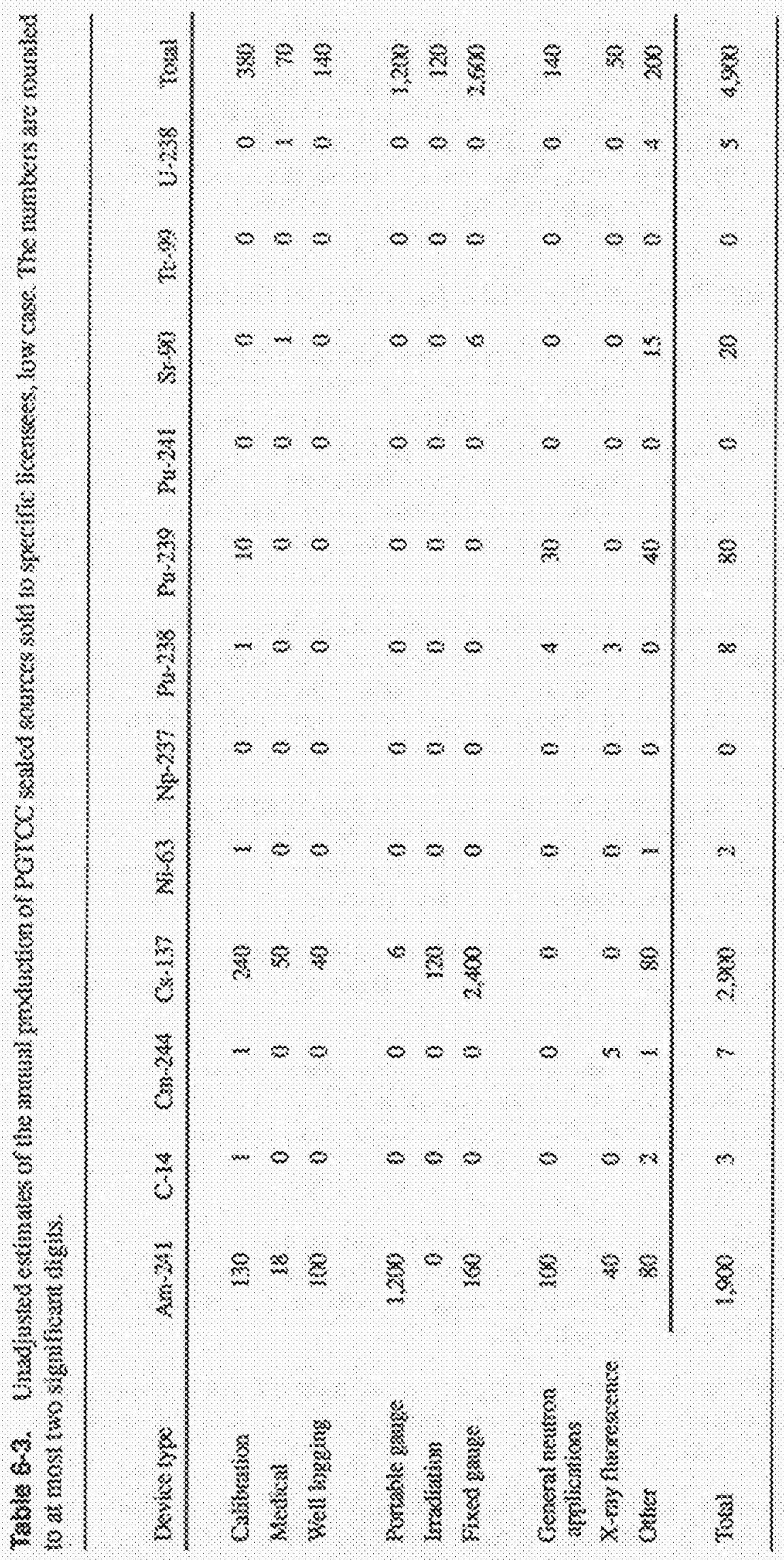




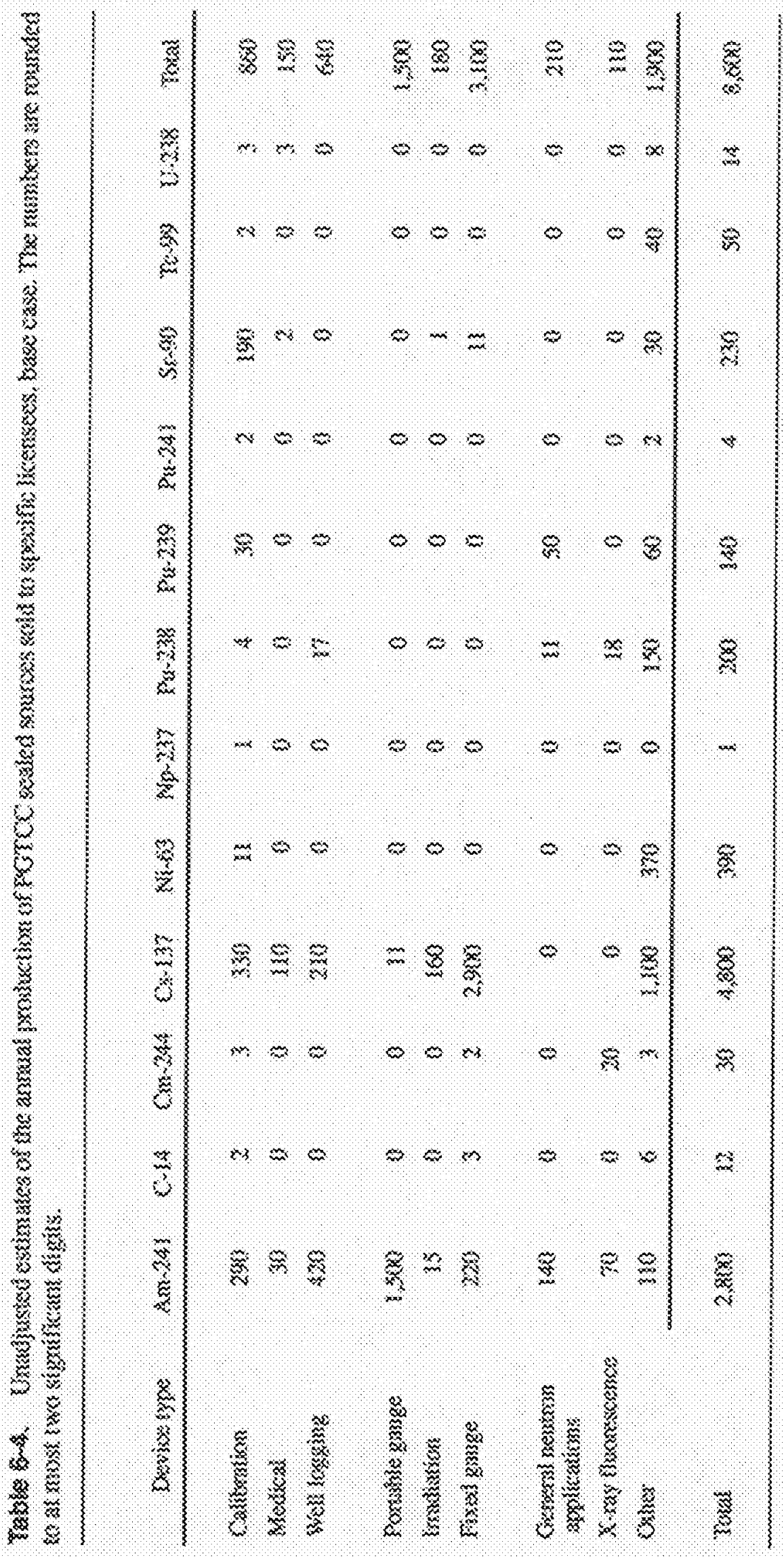




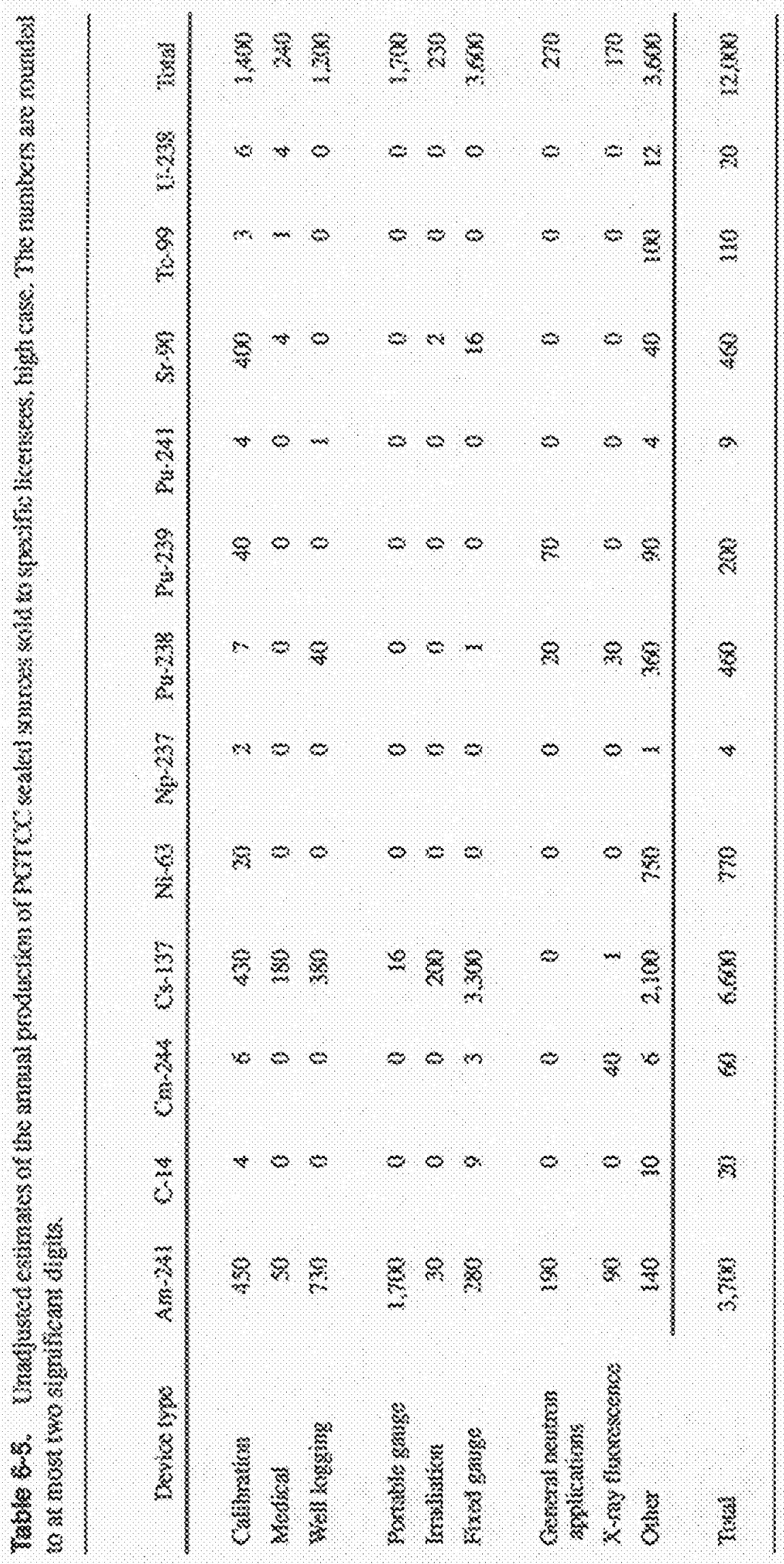




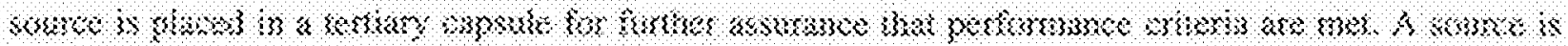

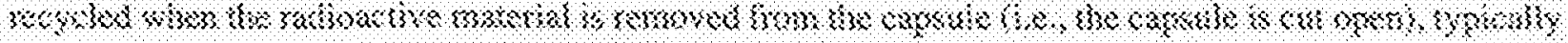

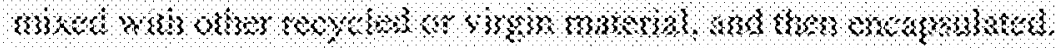

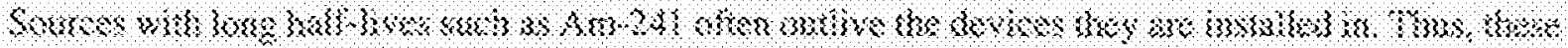

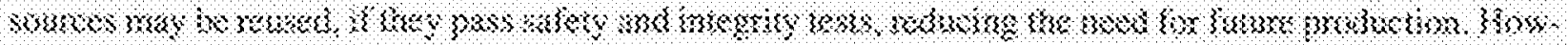

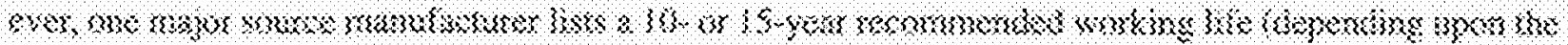

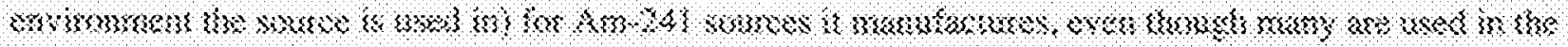

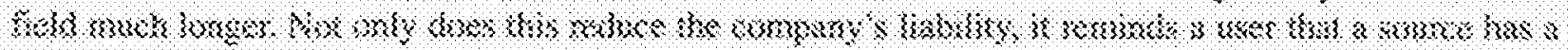

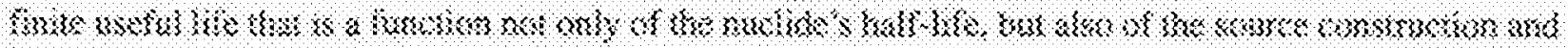

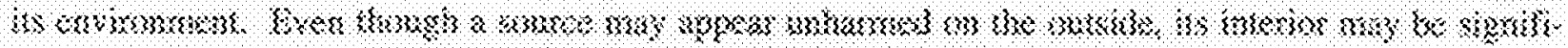

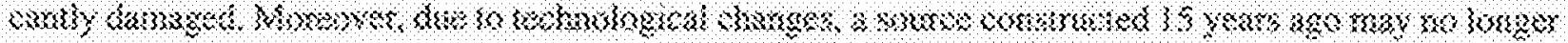

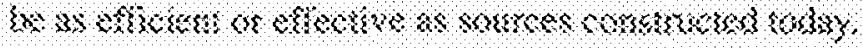

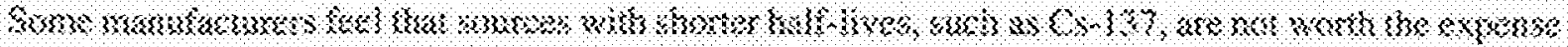

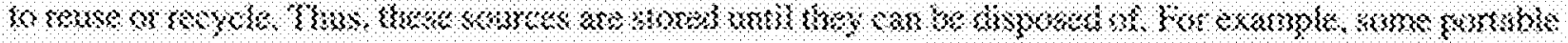

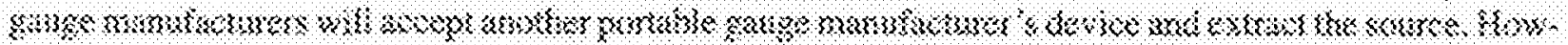

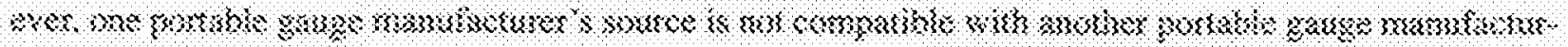

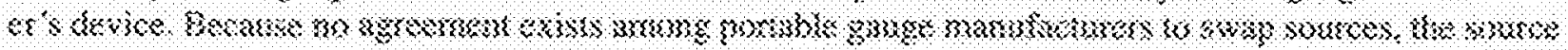

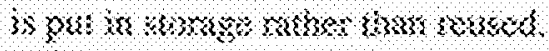

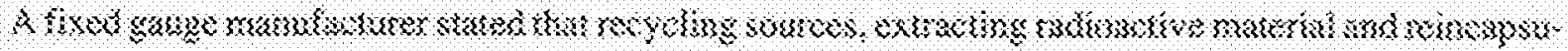

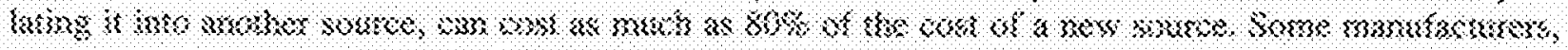

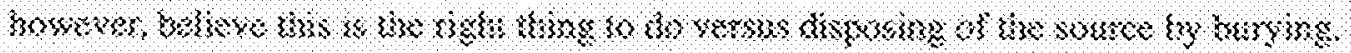

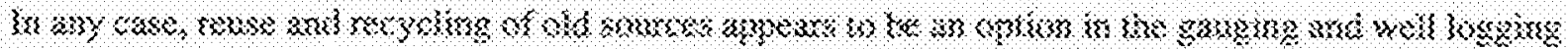

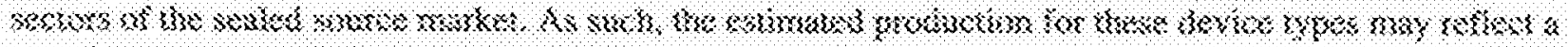

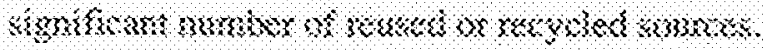

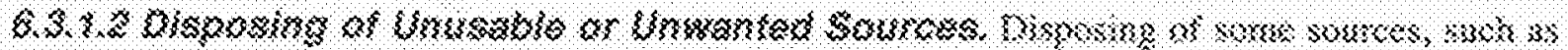

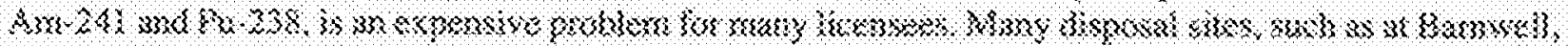

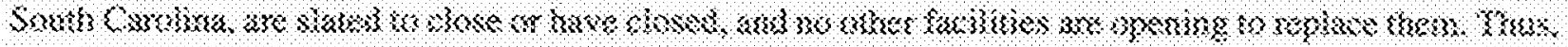

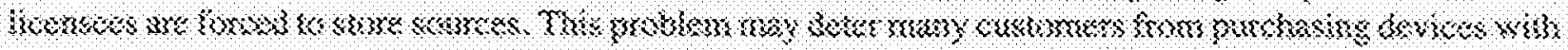
raskintoron sousces.

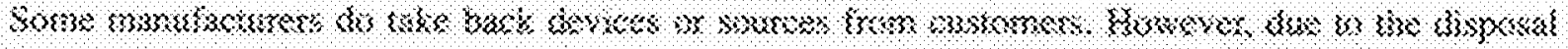

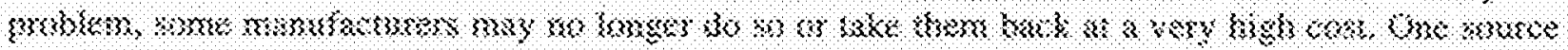

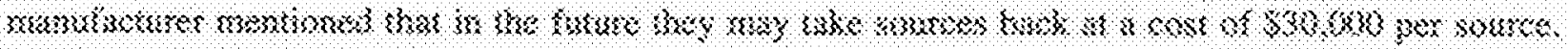

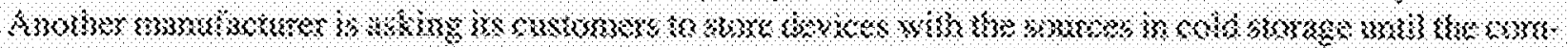

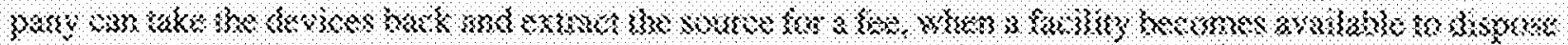
Bi bisere.

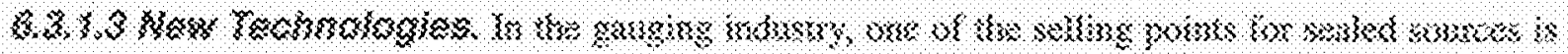

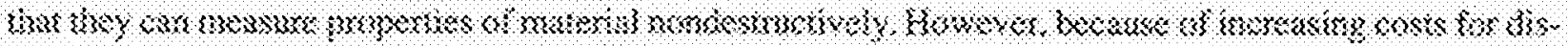

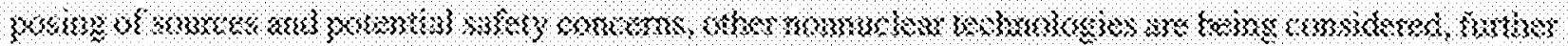

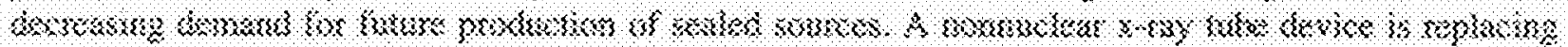

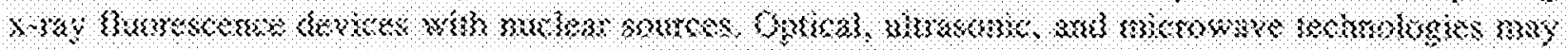

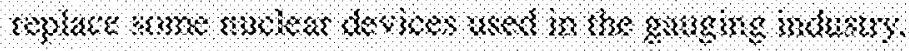

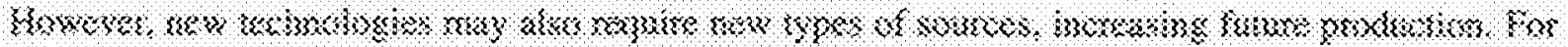

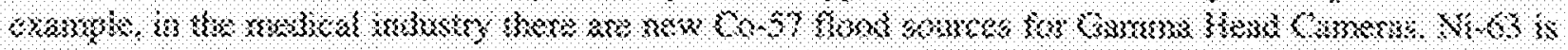

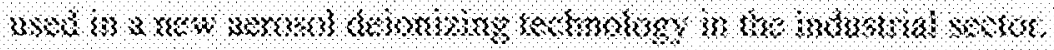




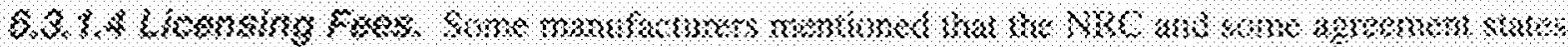

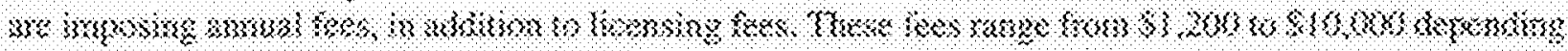

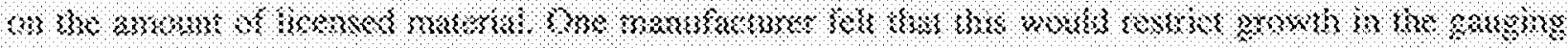

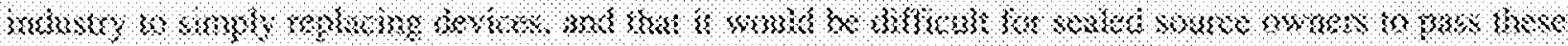

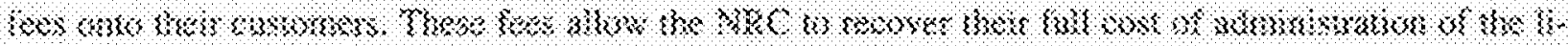

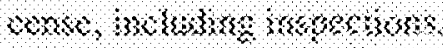

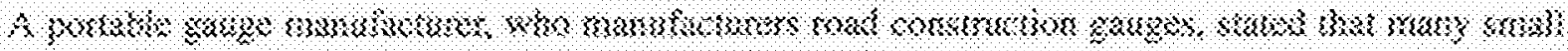

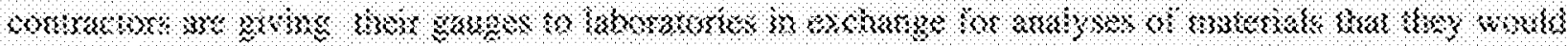

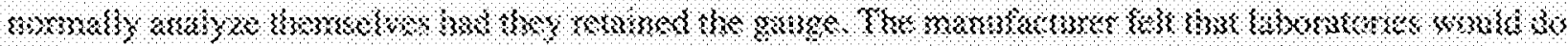

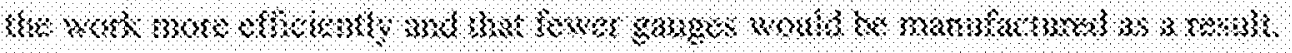

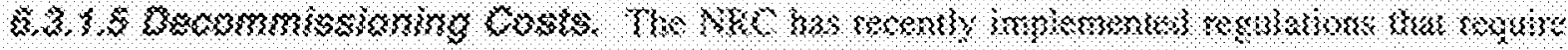

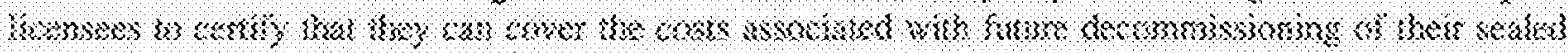

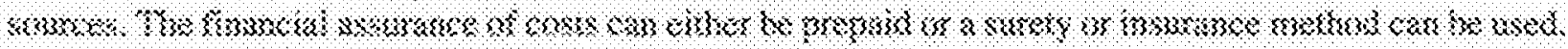

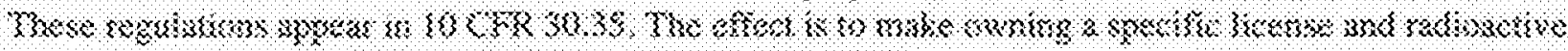

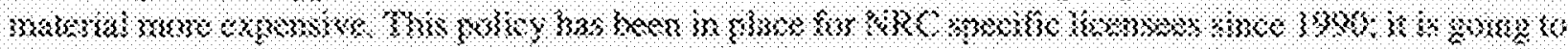

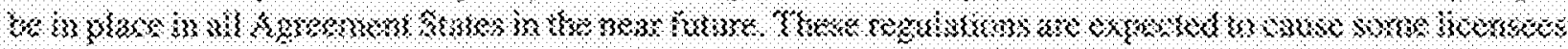

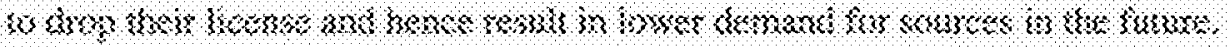

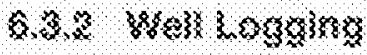

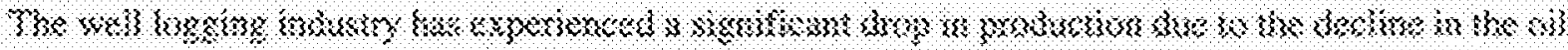

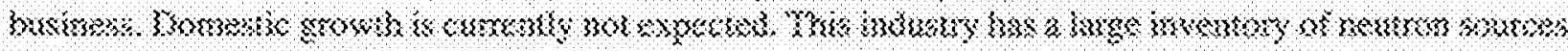

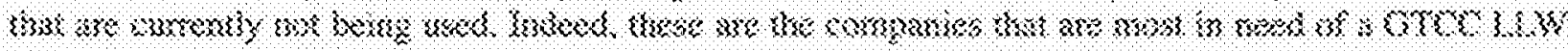

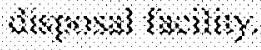

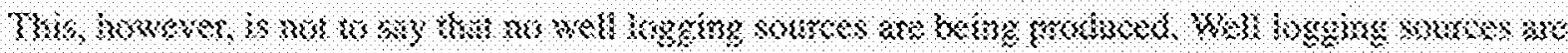

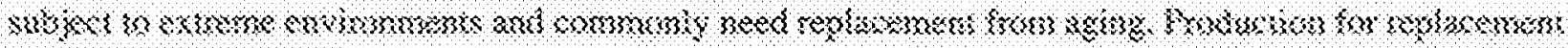

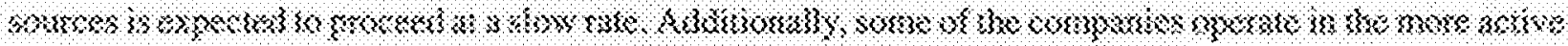

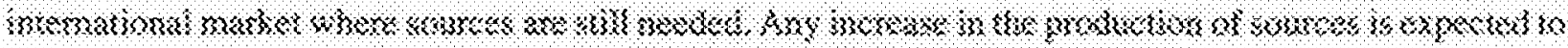

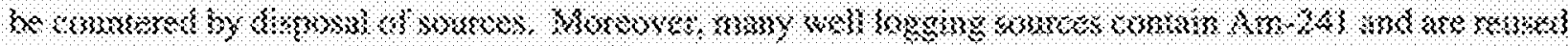
wheren possikis,

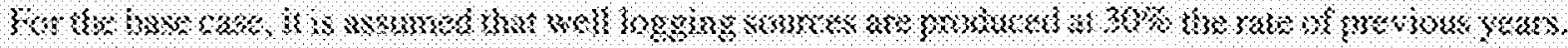

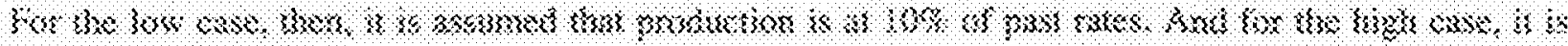

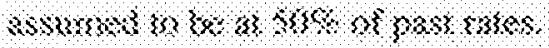

\section{Q}

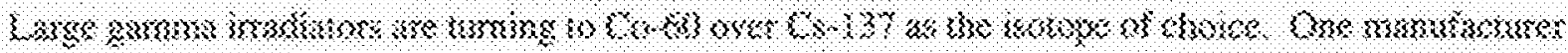

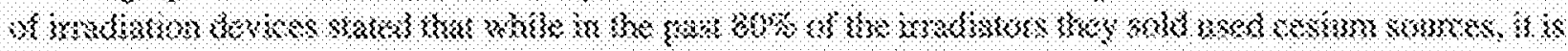

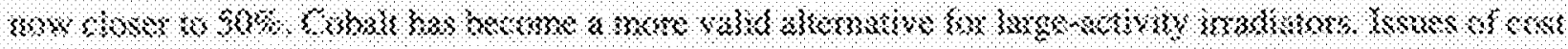

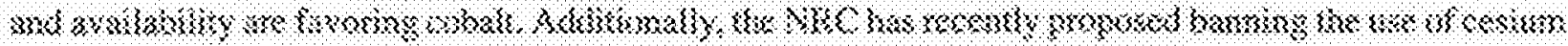

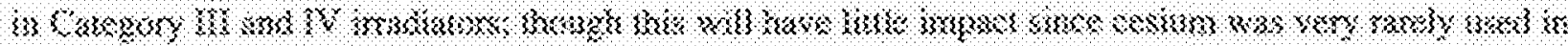

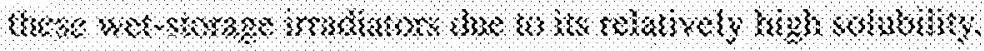

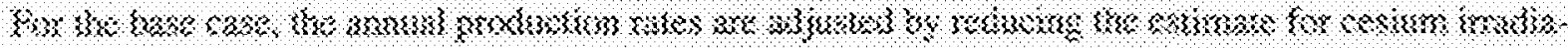

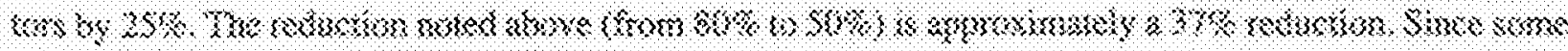

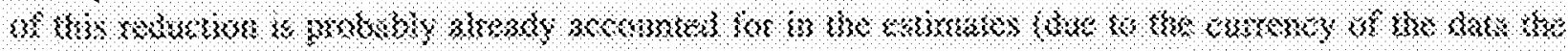

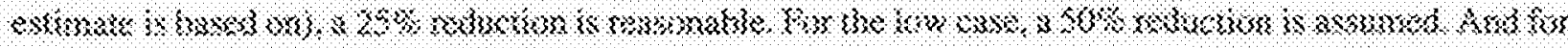

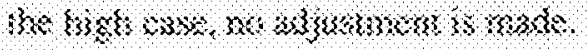




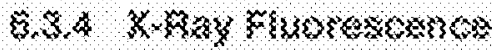

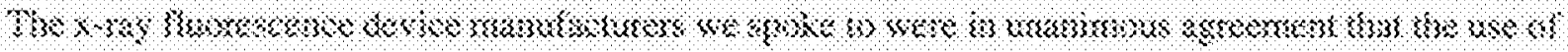

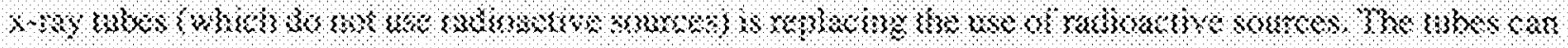

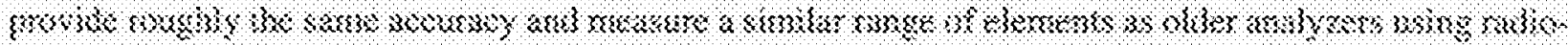

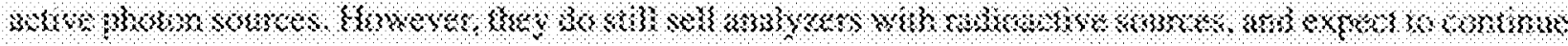

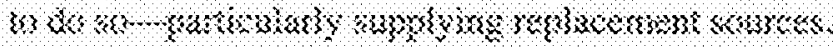

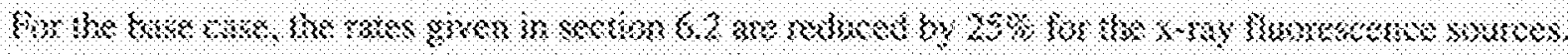

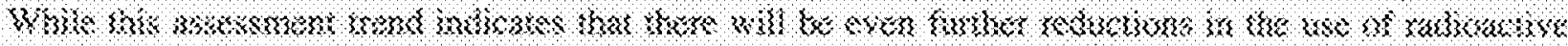

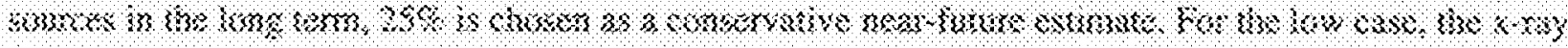

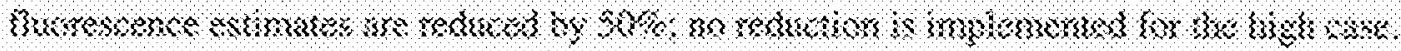

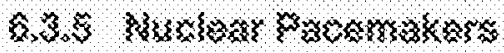

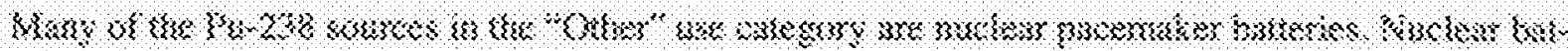

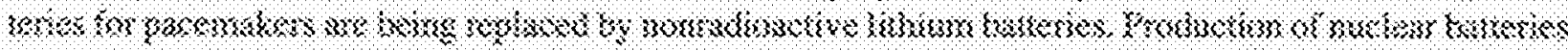

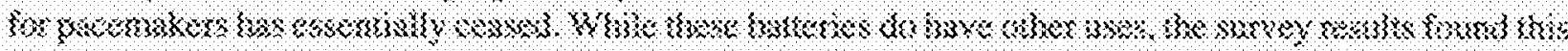

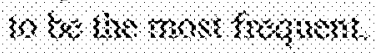

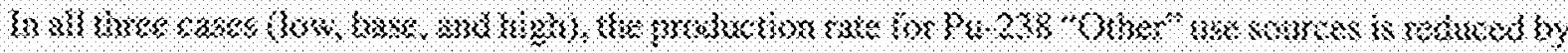

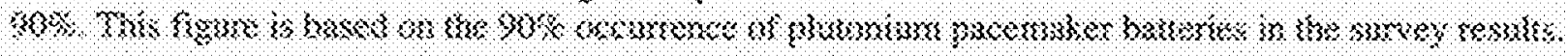

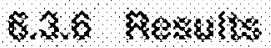

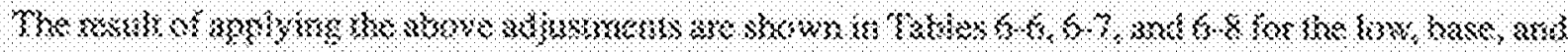

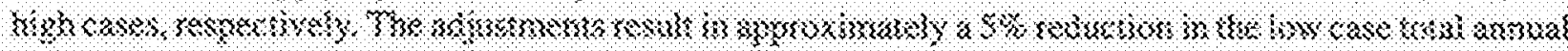

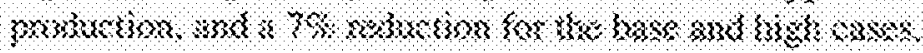

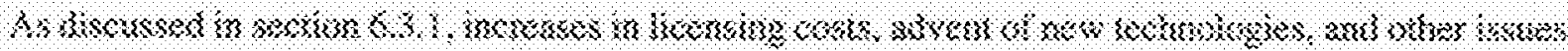

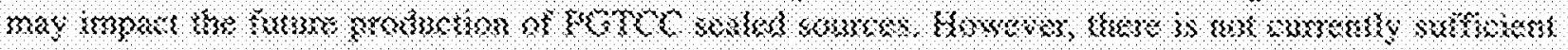

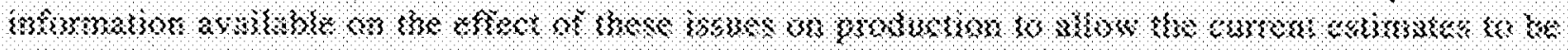

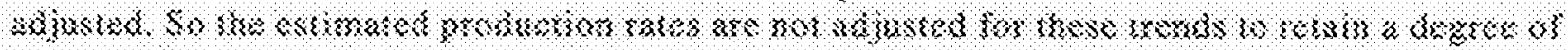
crosencratsisi.

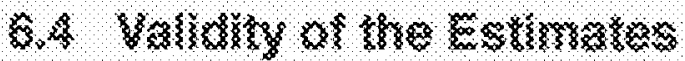

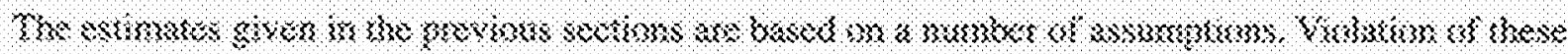

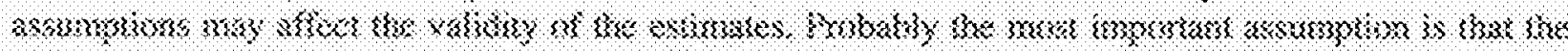

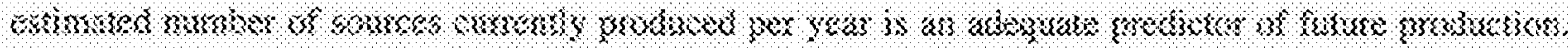

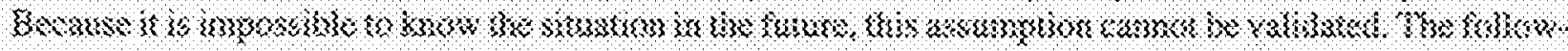

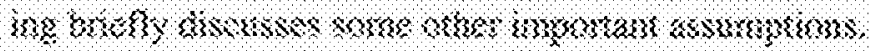

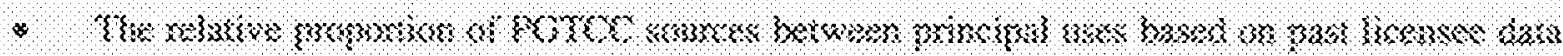

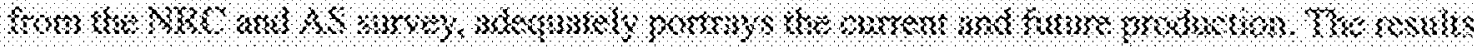

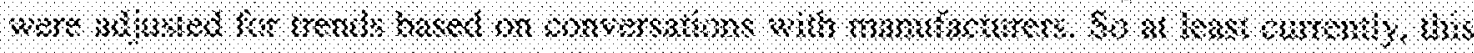

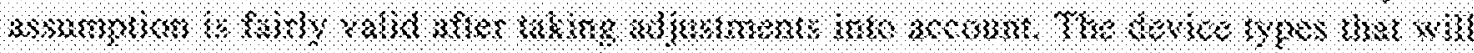

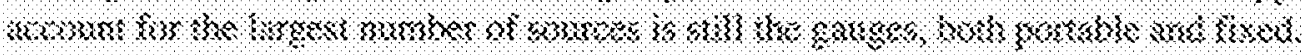




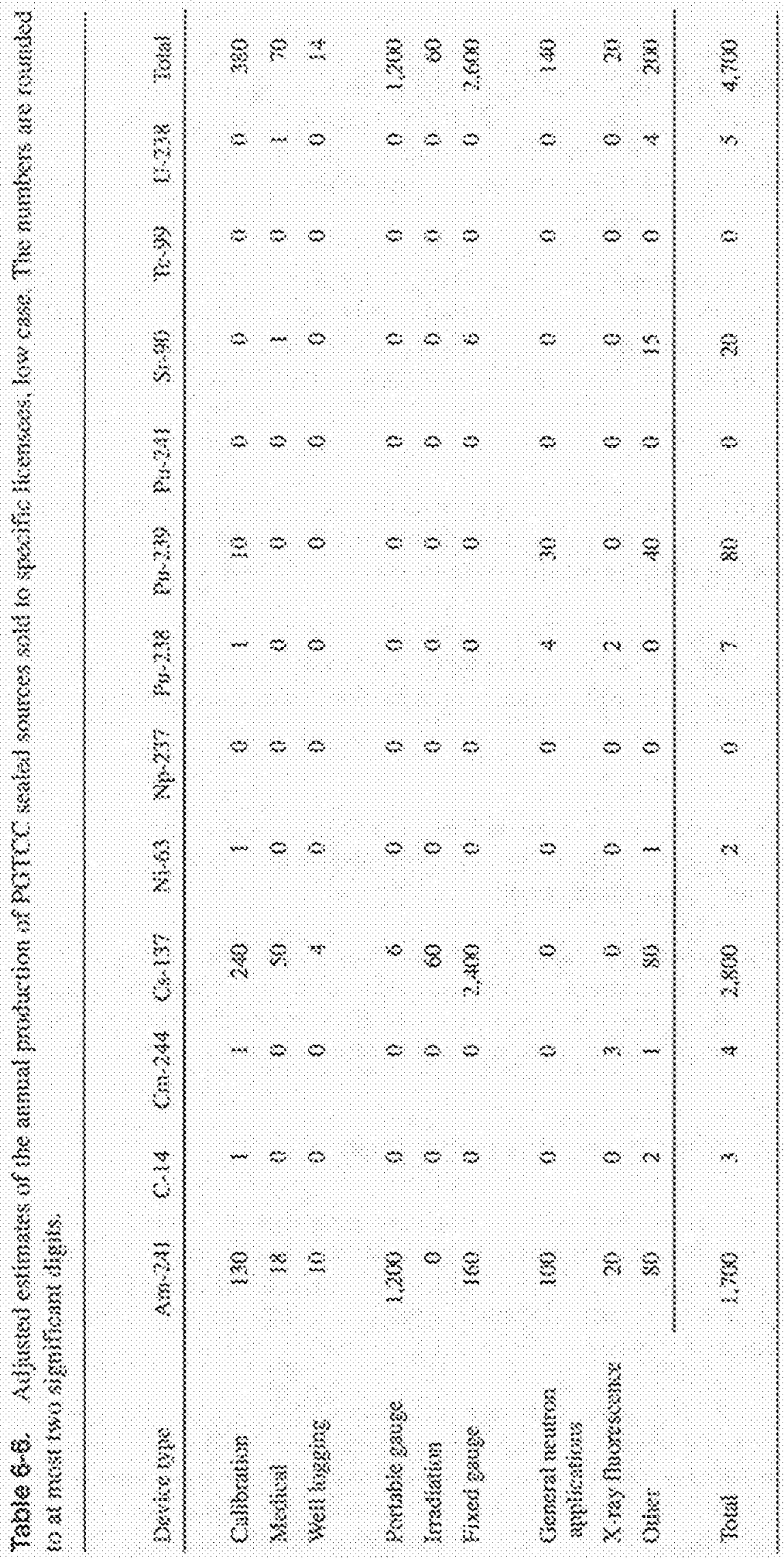




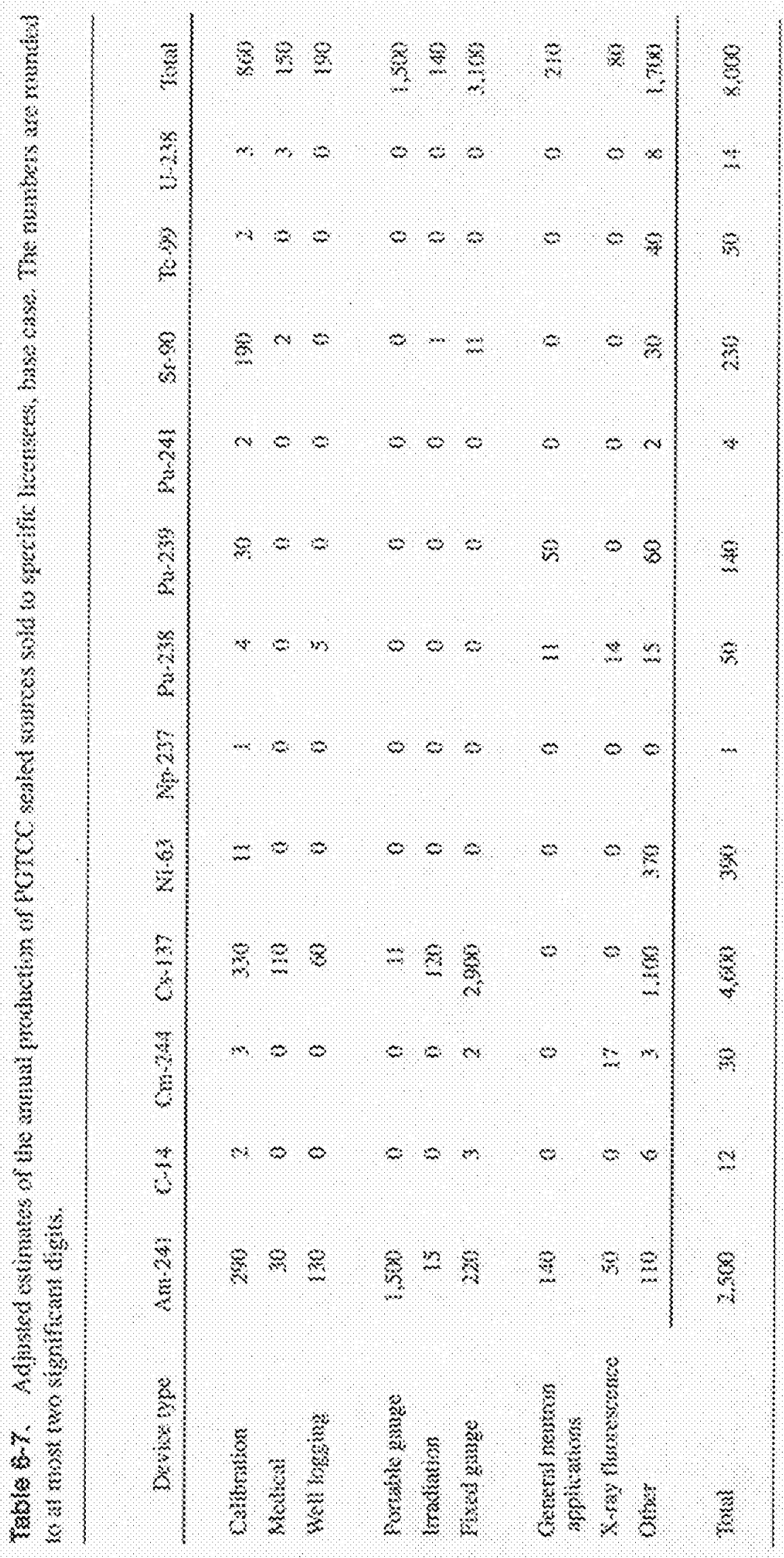




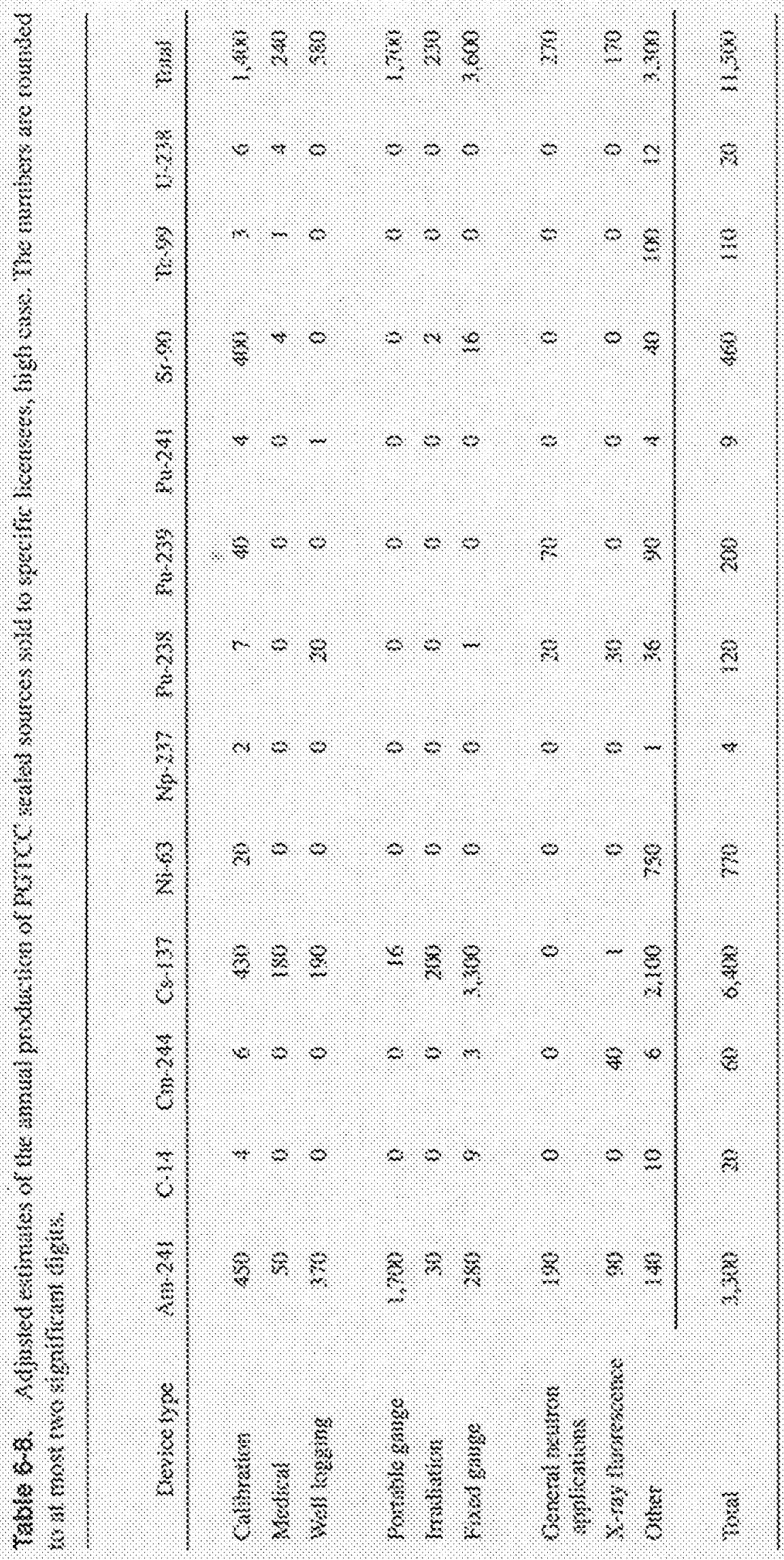




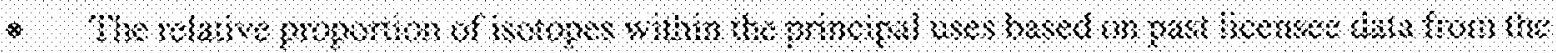

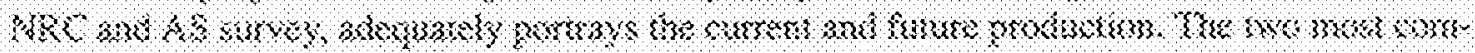

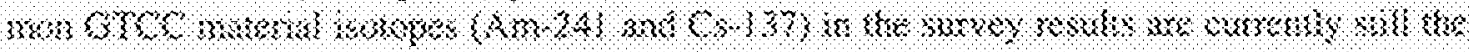

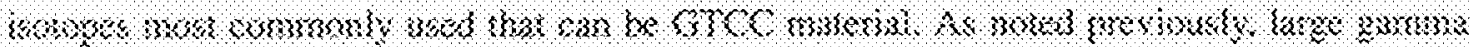

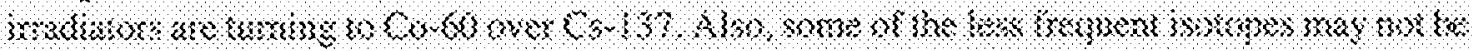

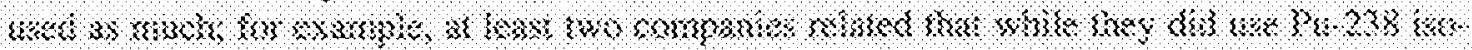

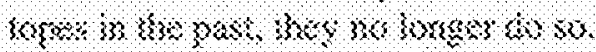

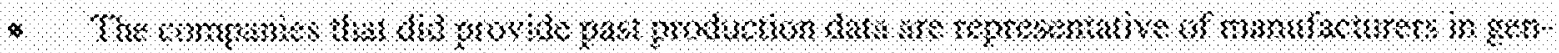

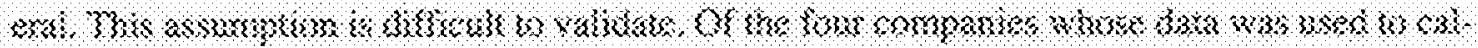

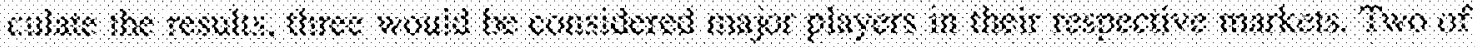

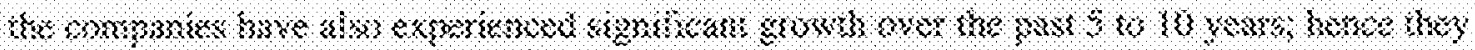

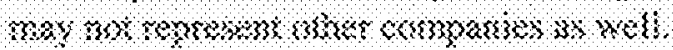

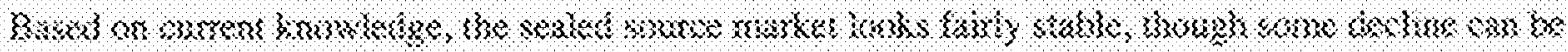

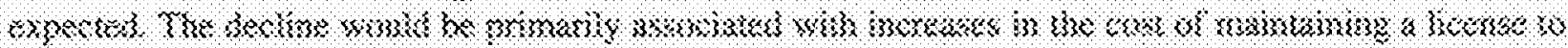

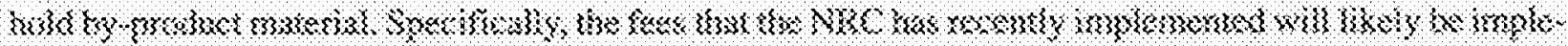

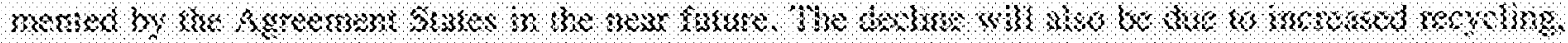

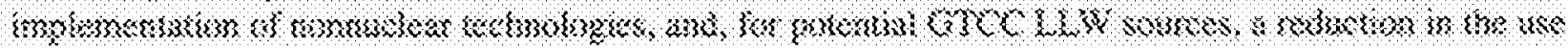

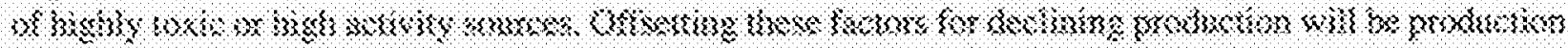

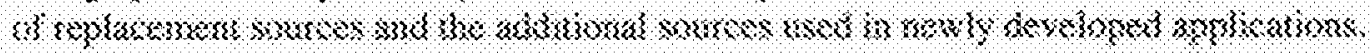

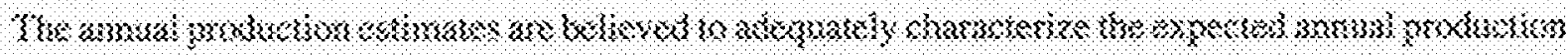

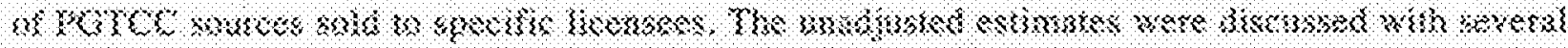

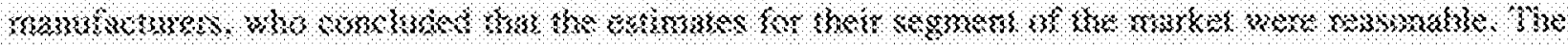

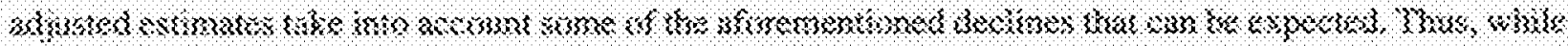

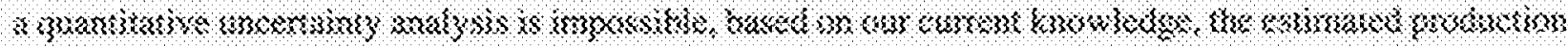

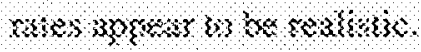




\section{7.}

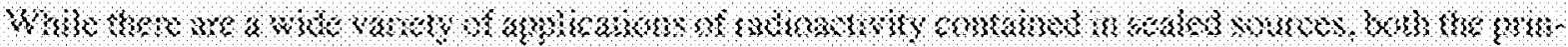

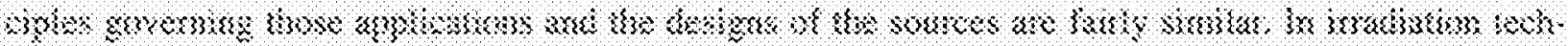

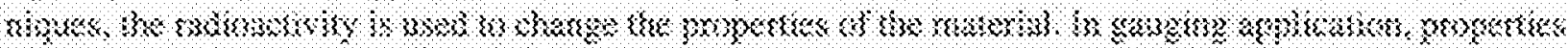

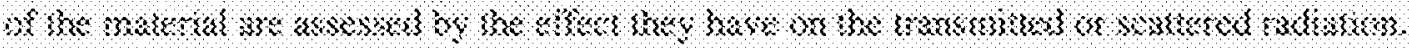

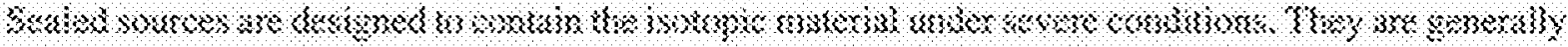

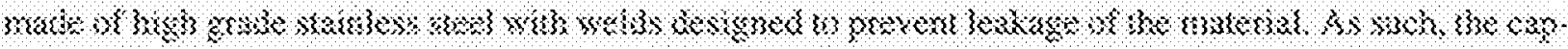

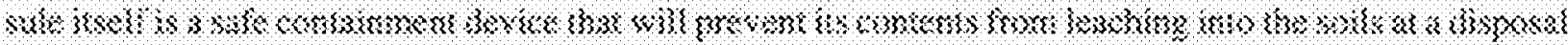

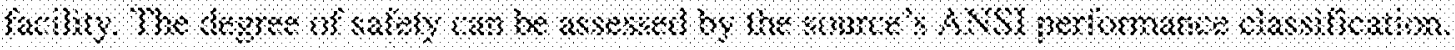

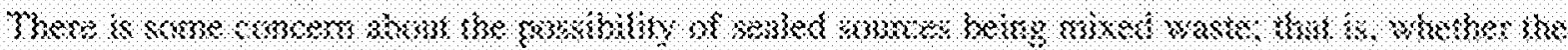

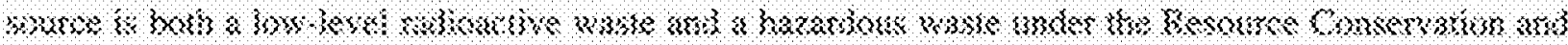

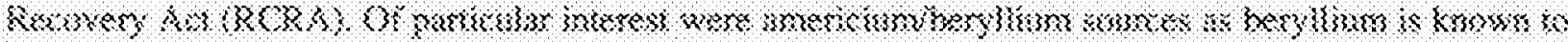

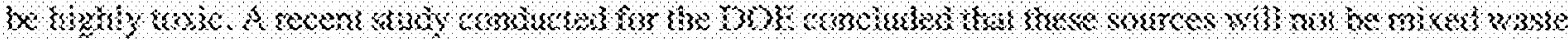

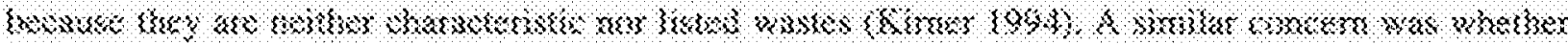

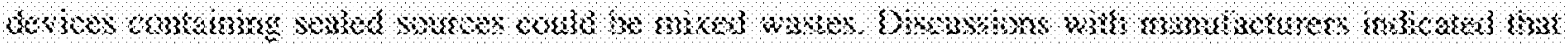

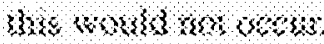

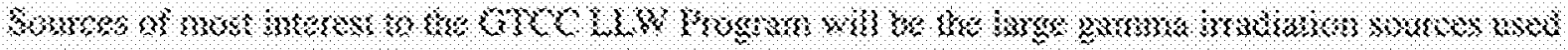

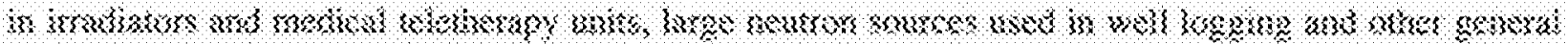

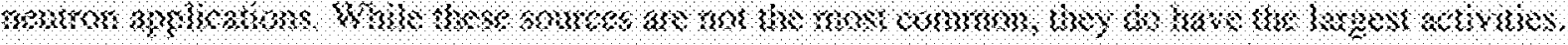

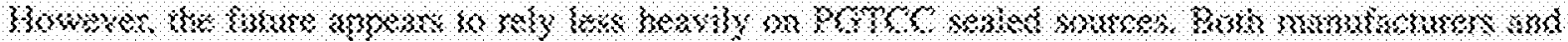

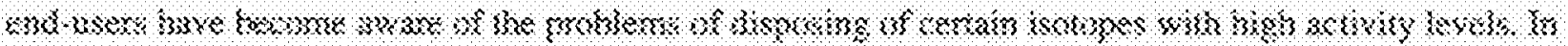

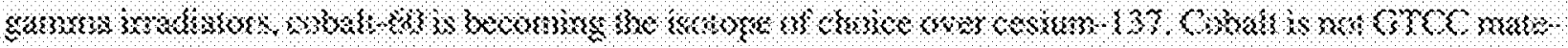

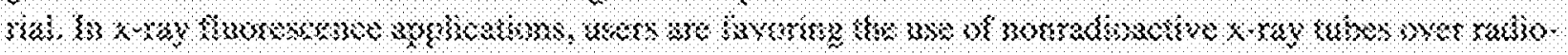

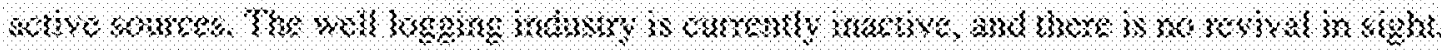

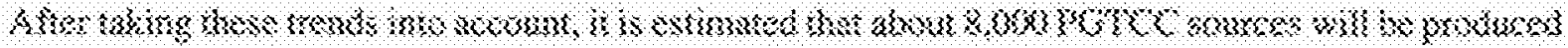

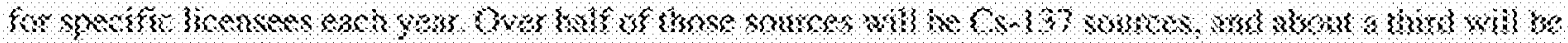

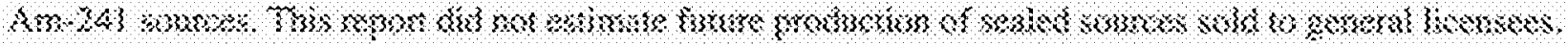

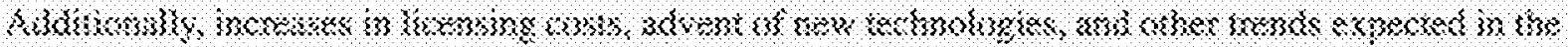

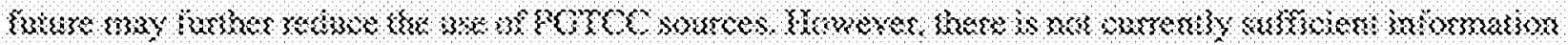

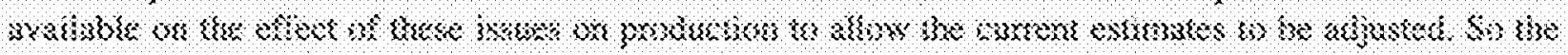

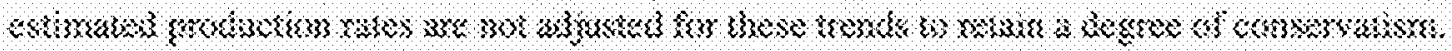




\section{.}

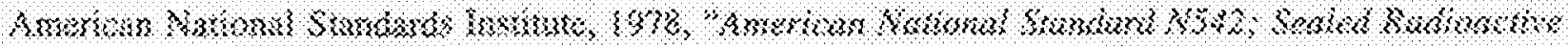

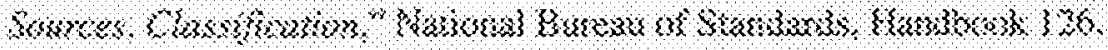

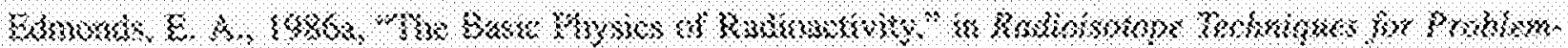

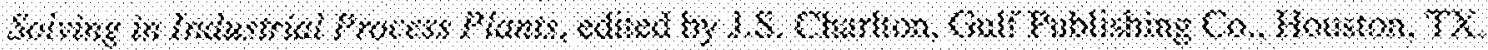

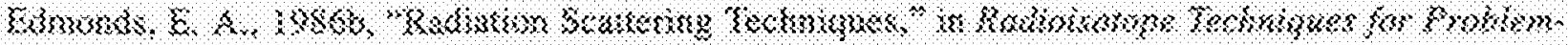

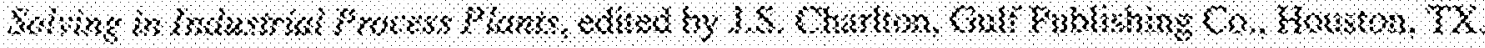

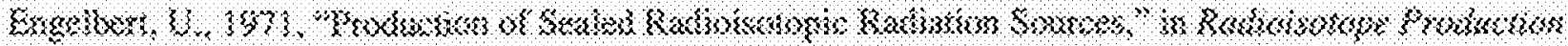

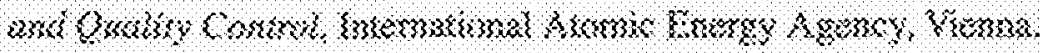

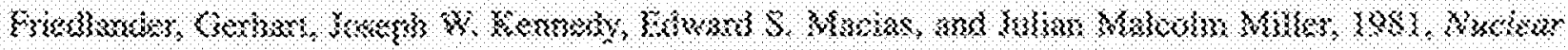

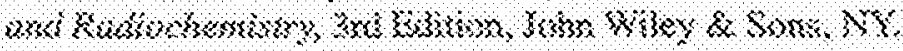

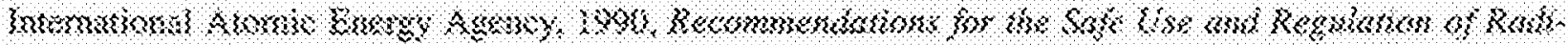

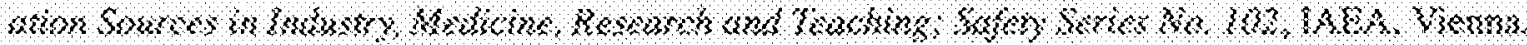

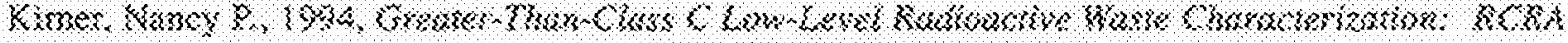

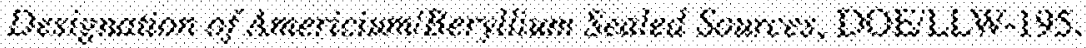

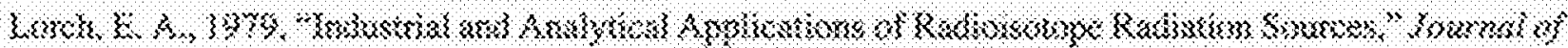

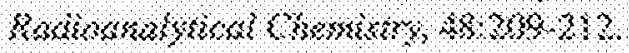

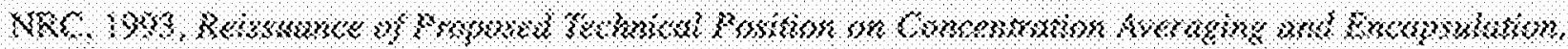

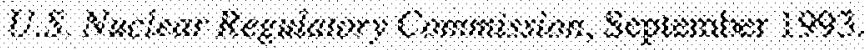

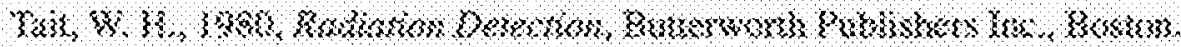

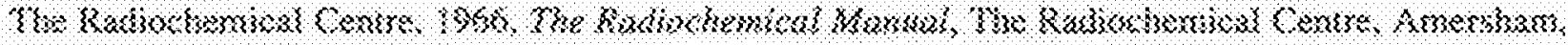

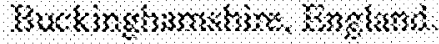


4

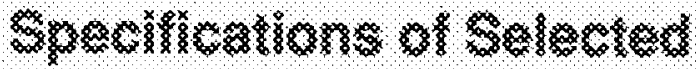

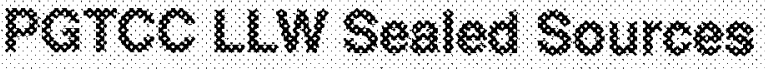




\section{Appendix A \\ Specifications of Selected \\ pGTCE LLW Sealed Sources}

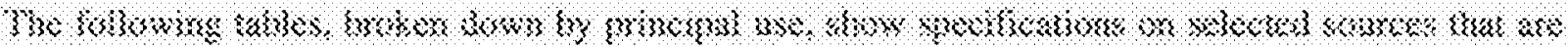

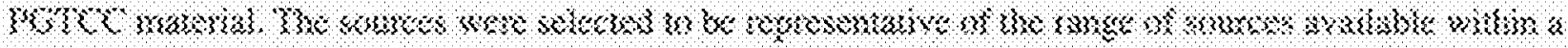

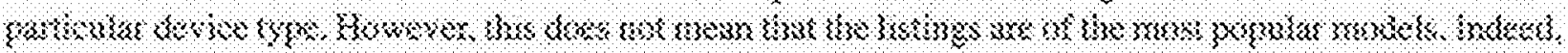

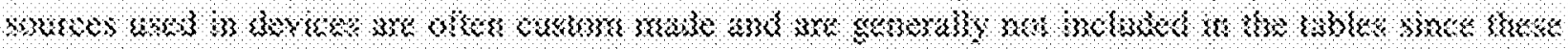

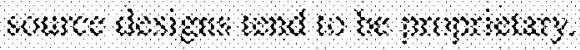

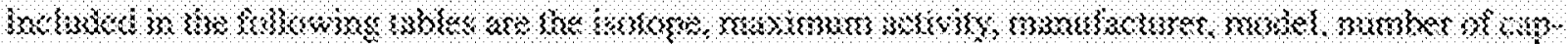

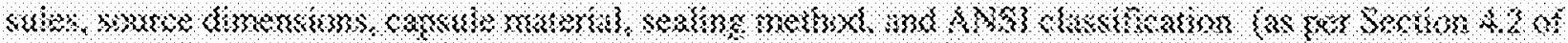

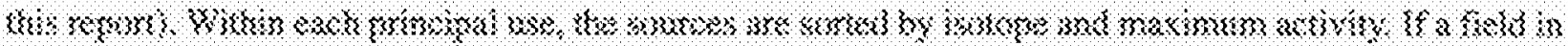

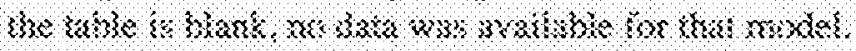

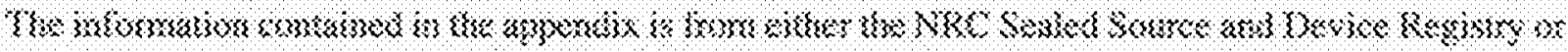

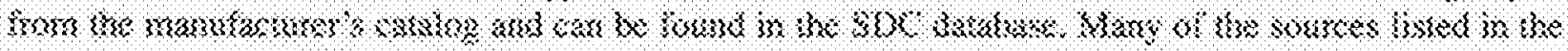

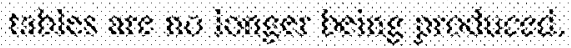

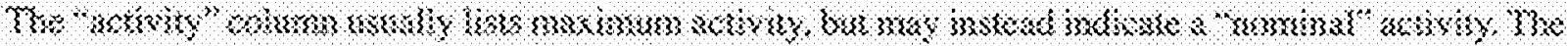

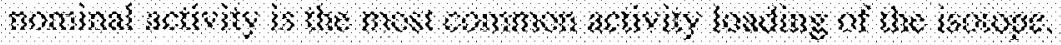

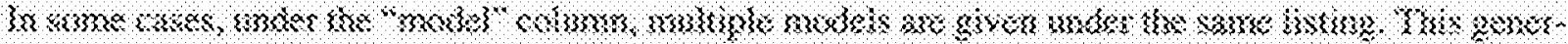

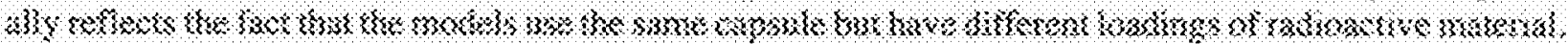

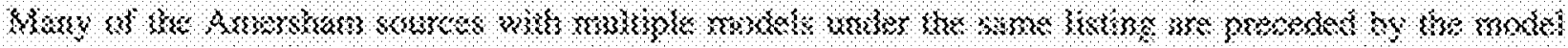

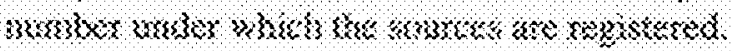

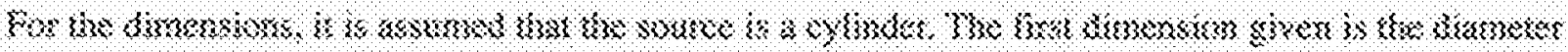

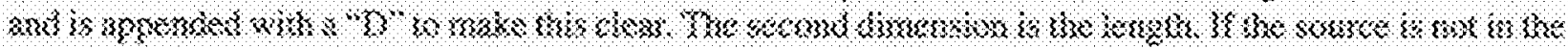

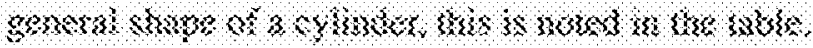

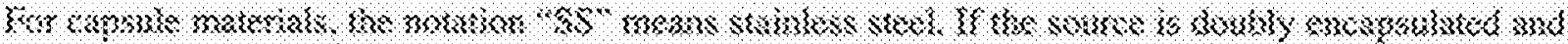

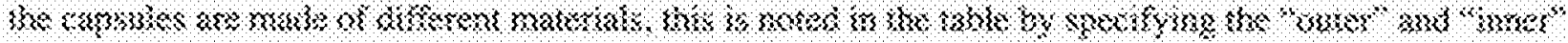
cagknis miskerisk.

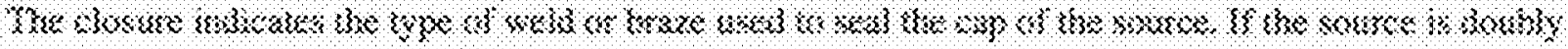

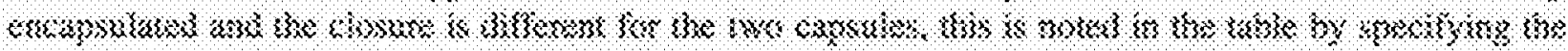

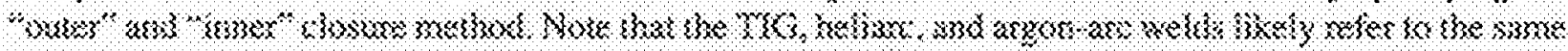

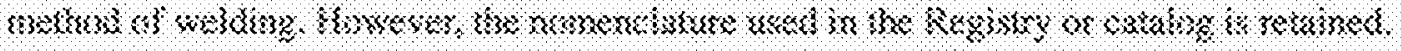




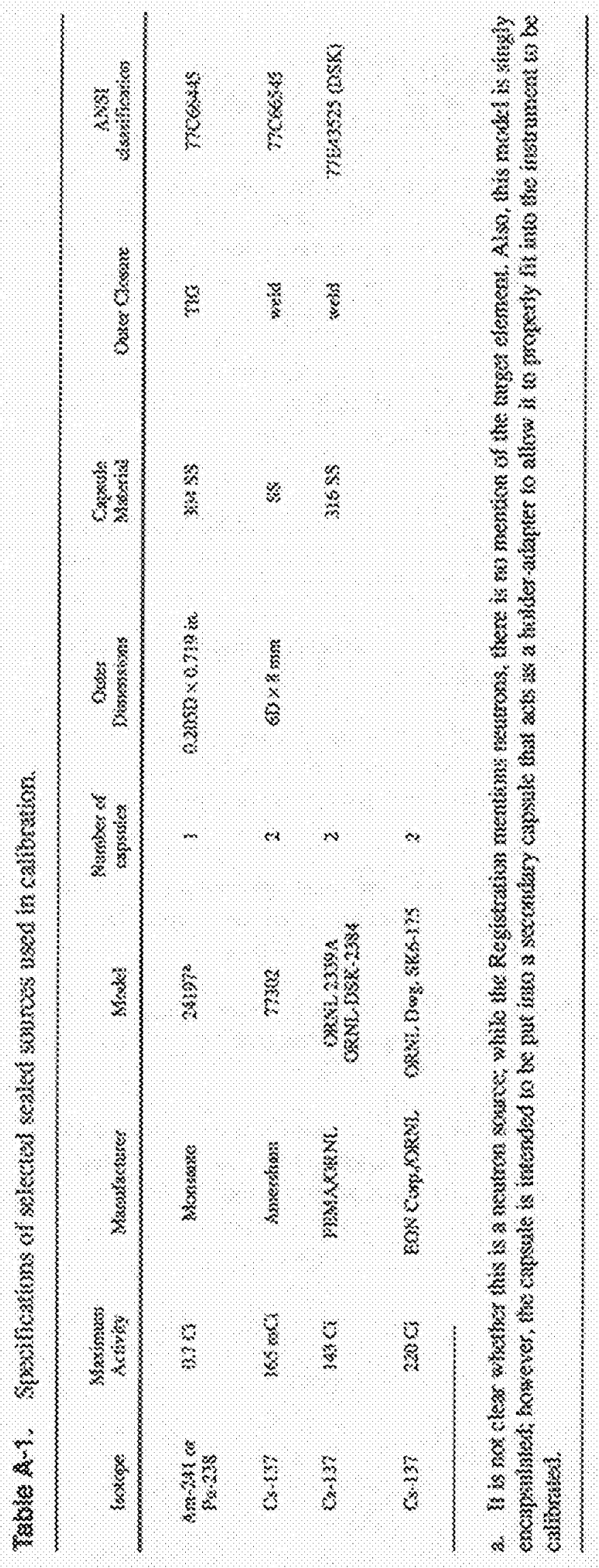




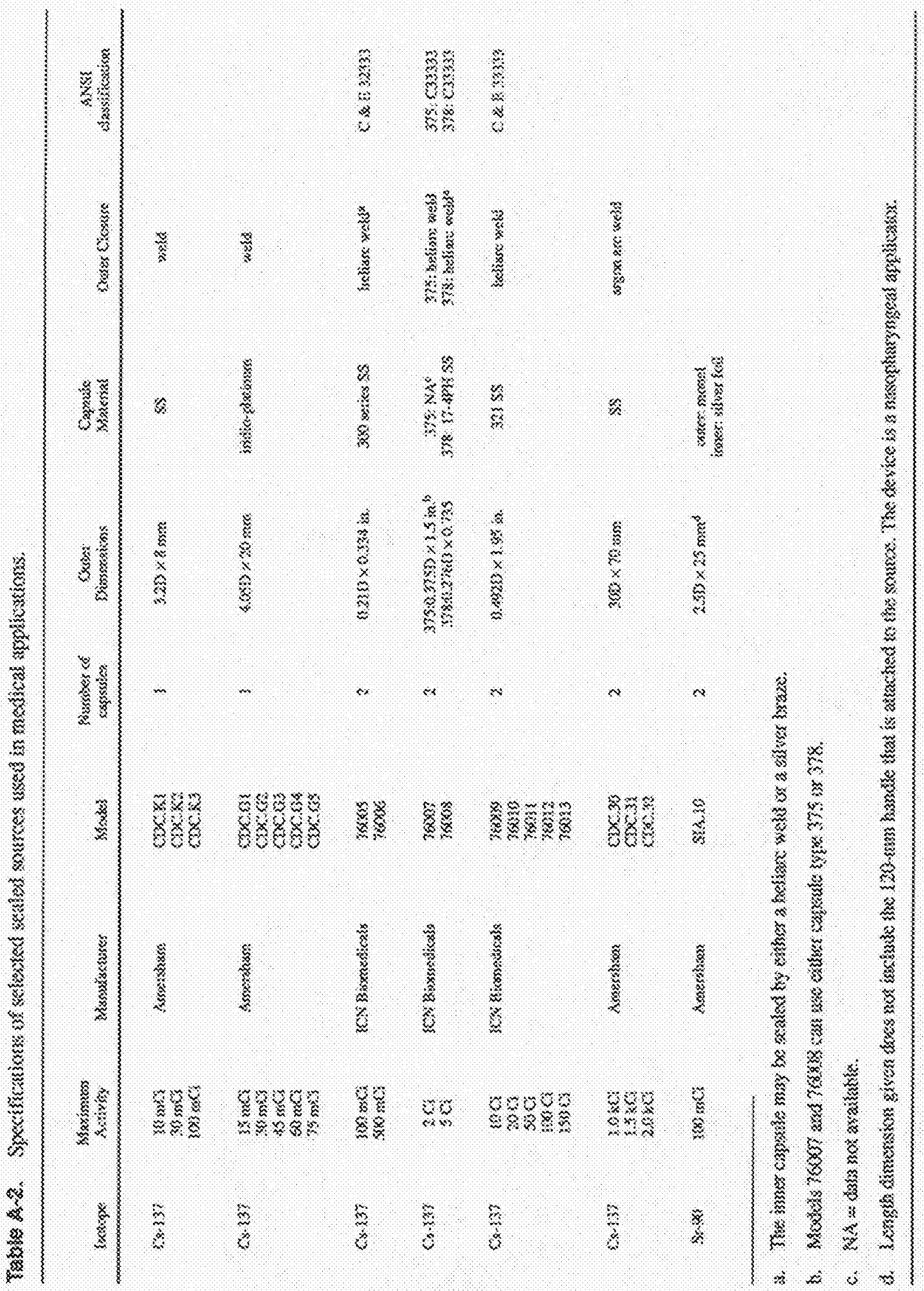




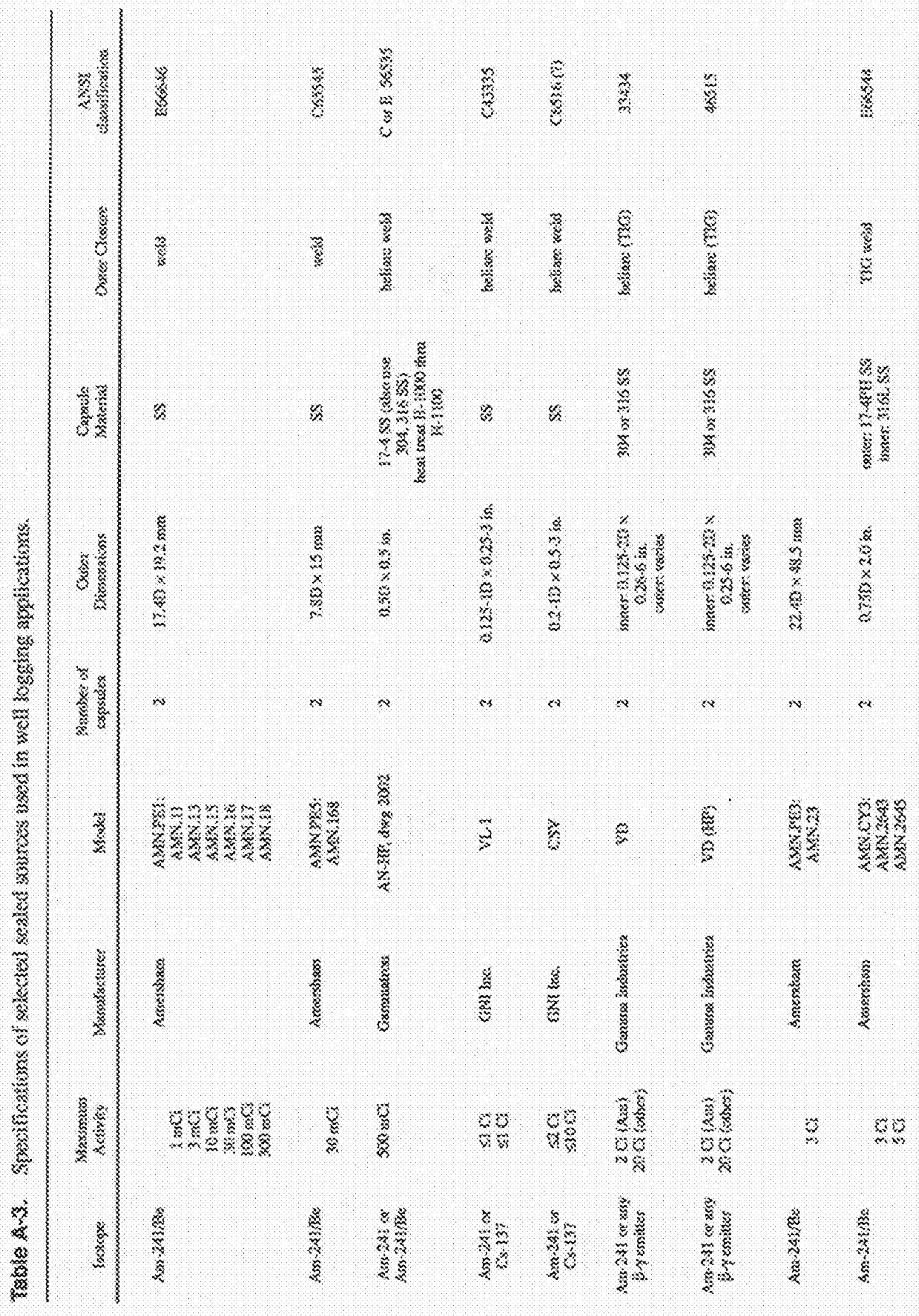




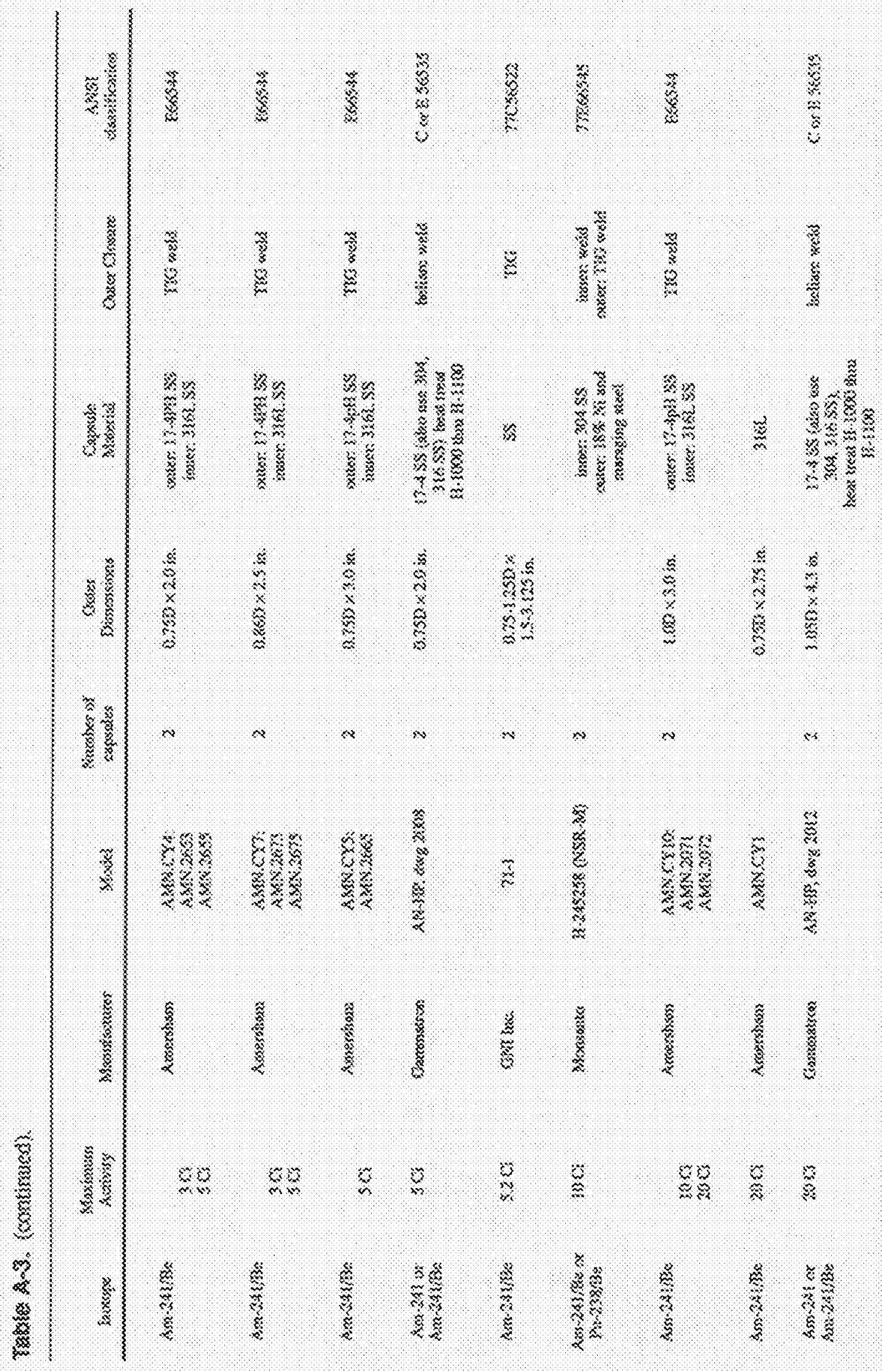




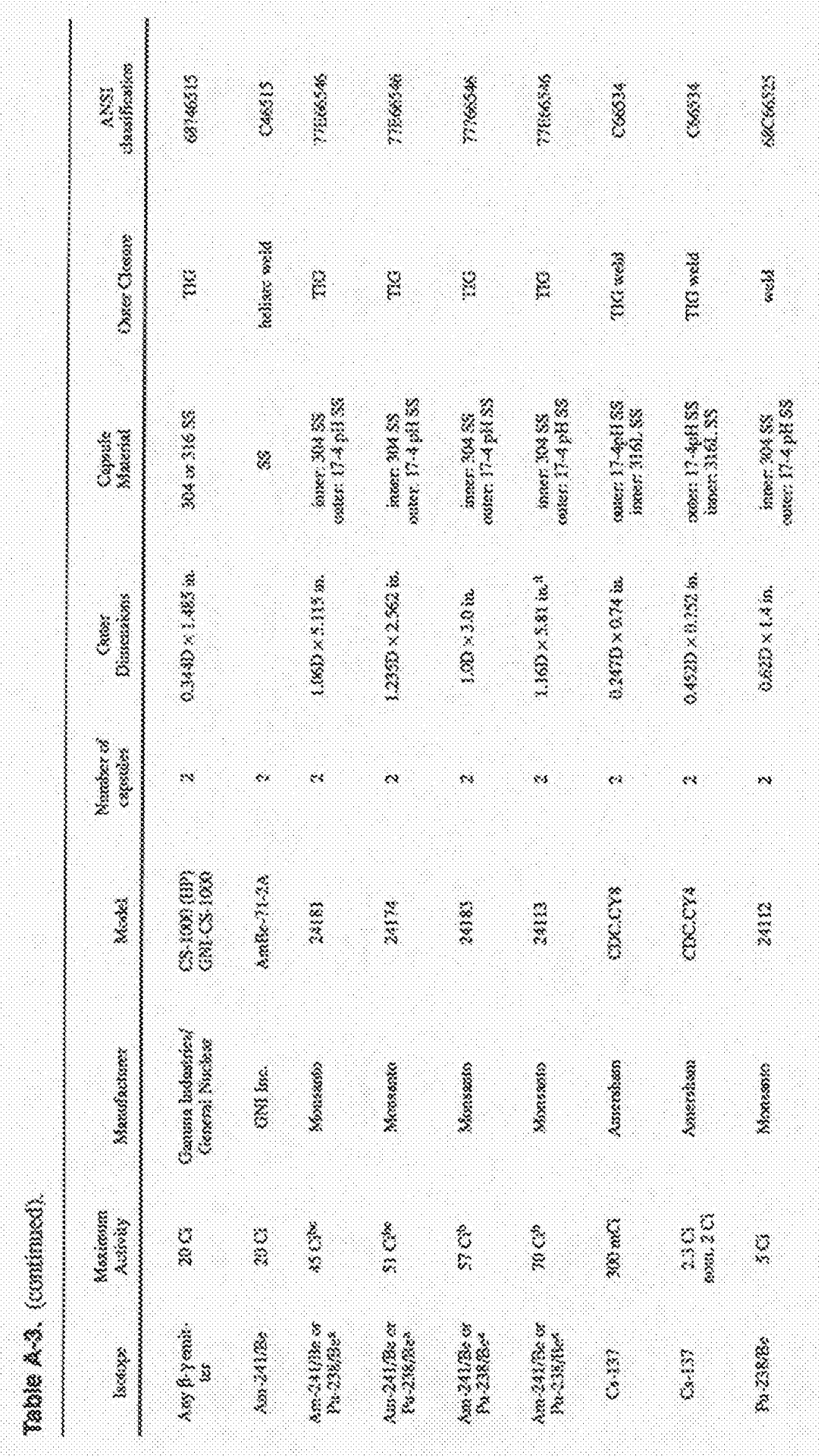




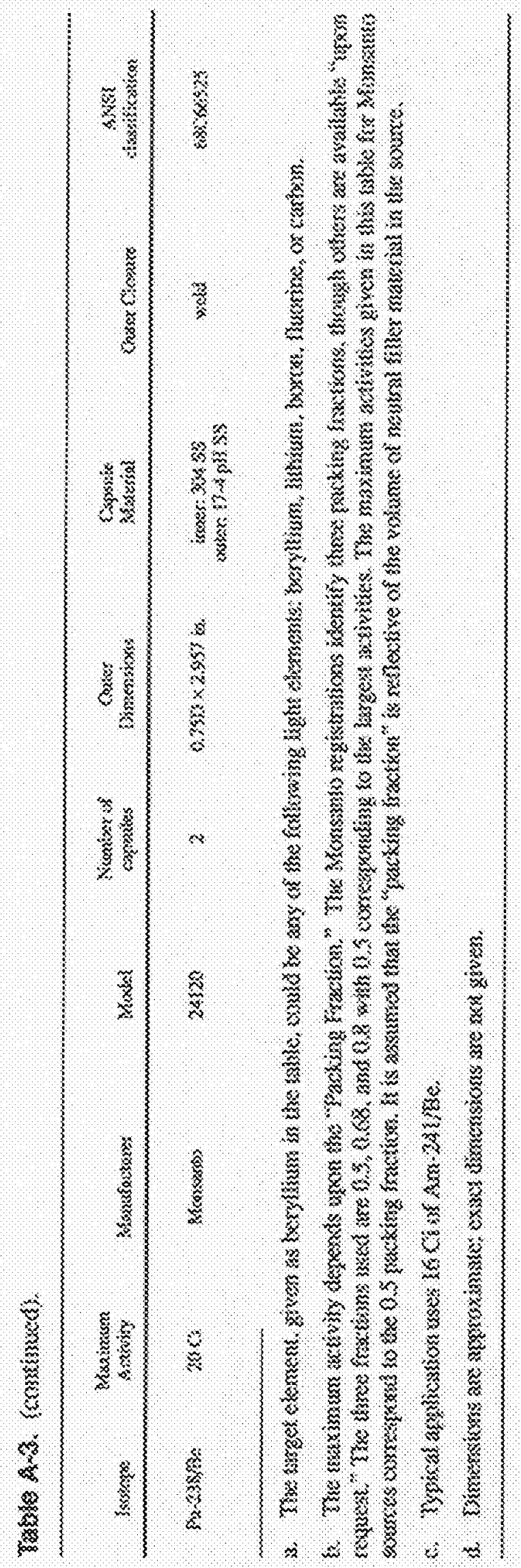




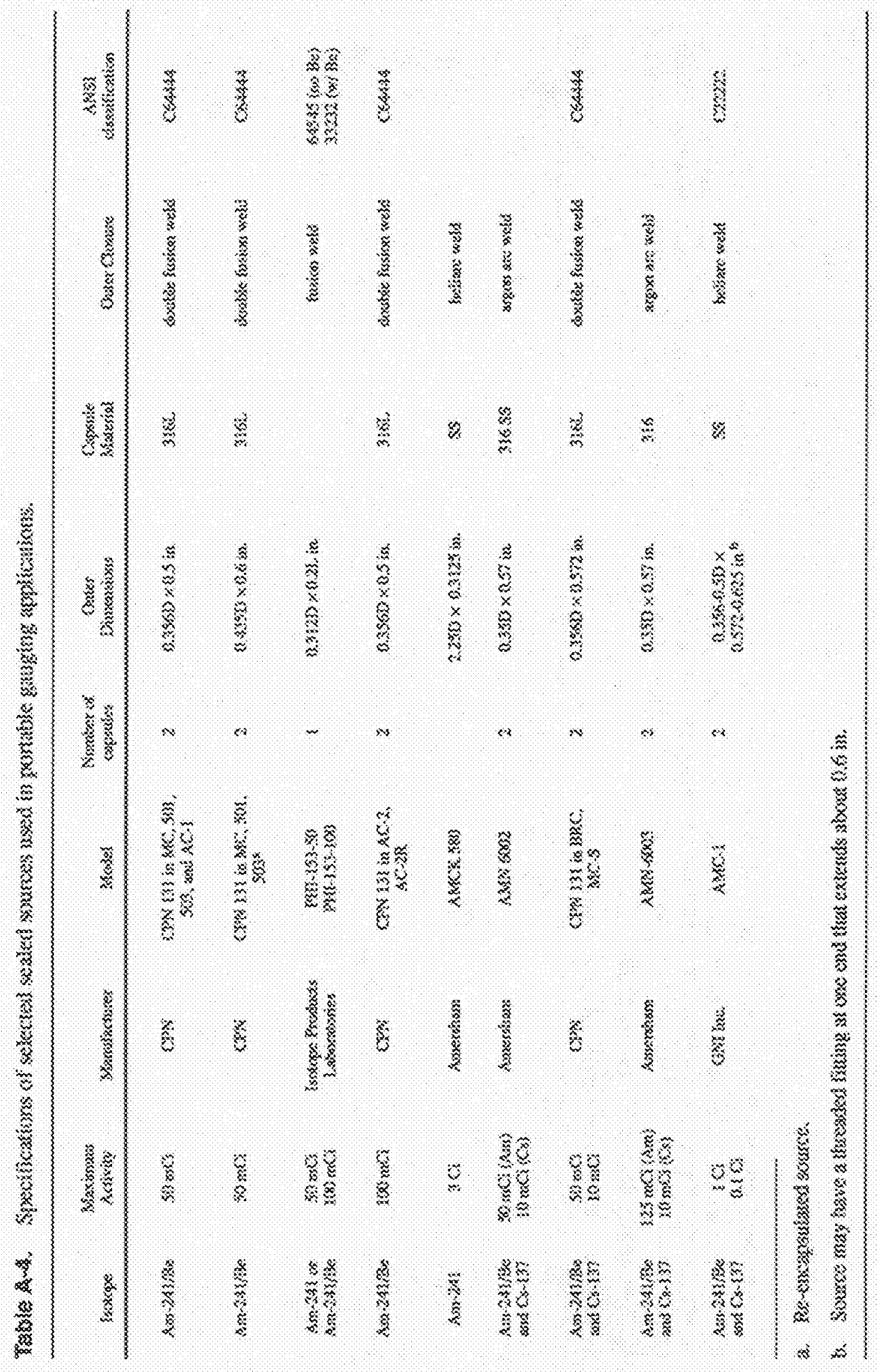




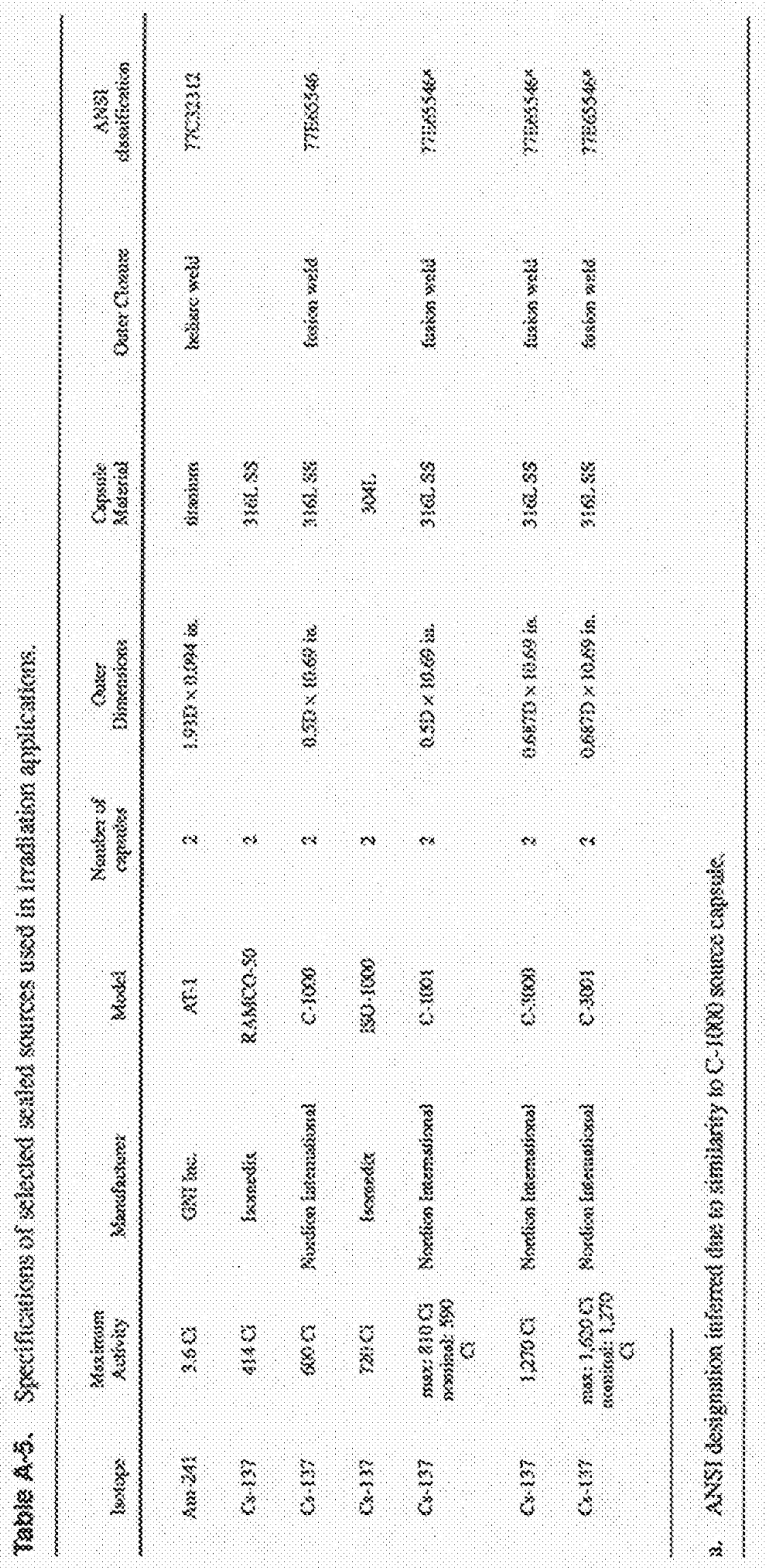




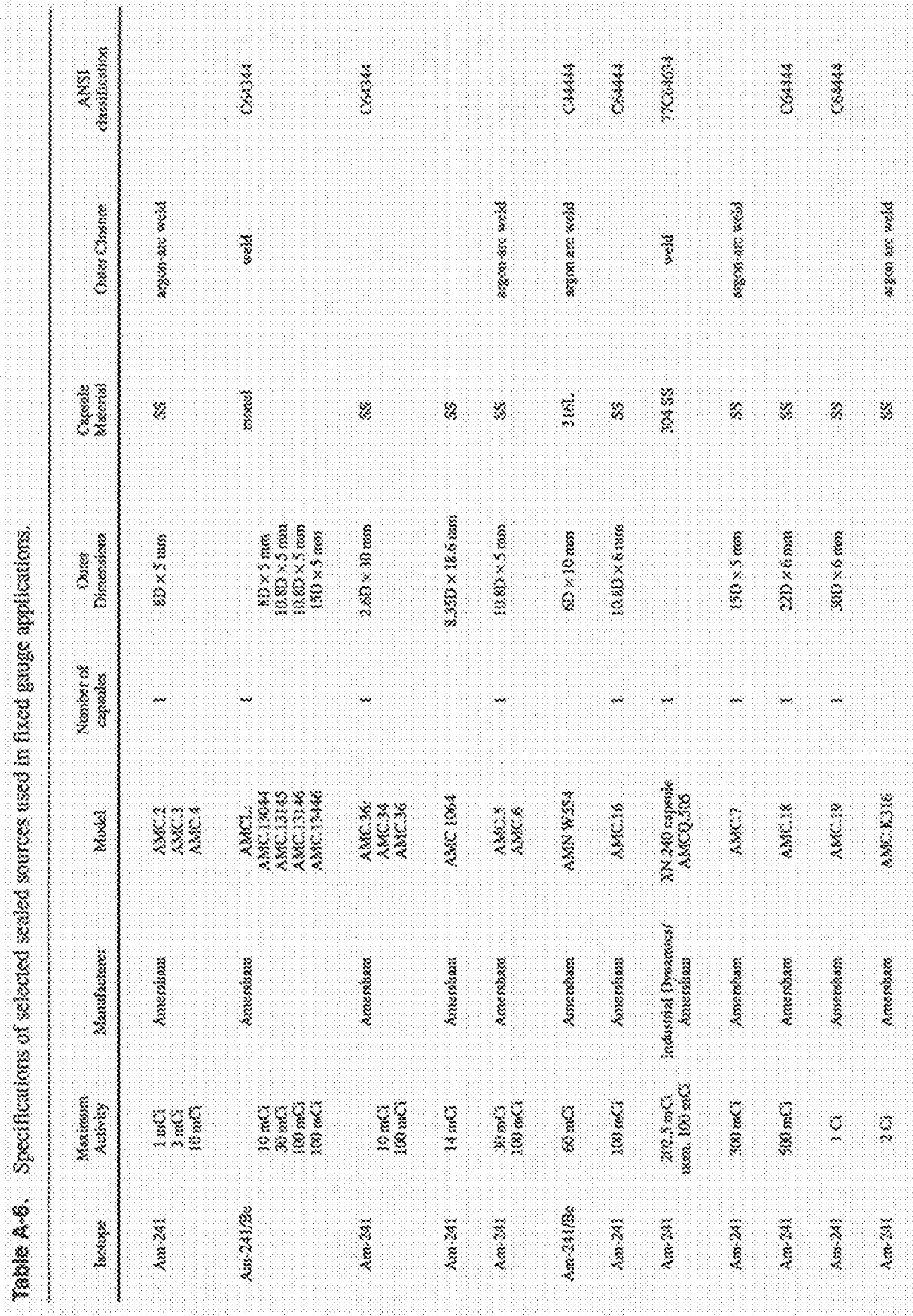




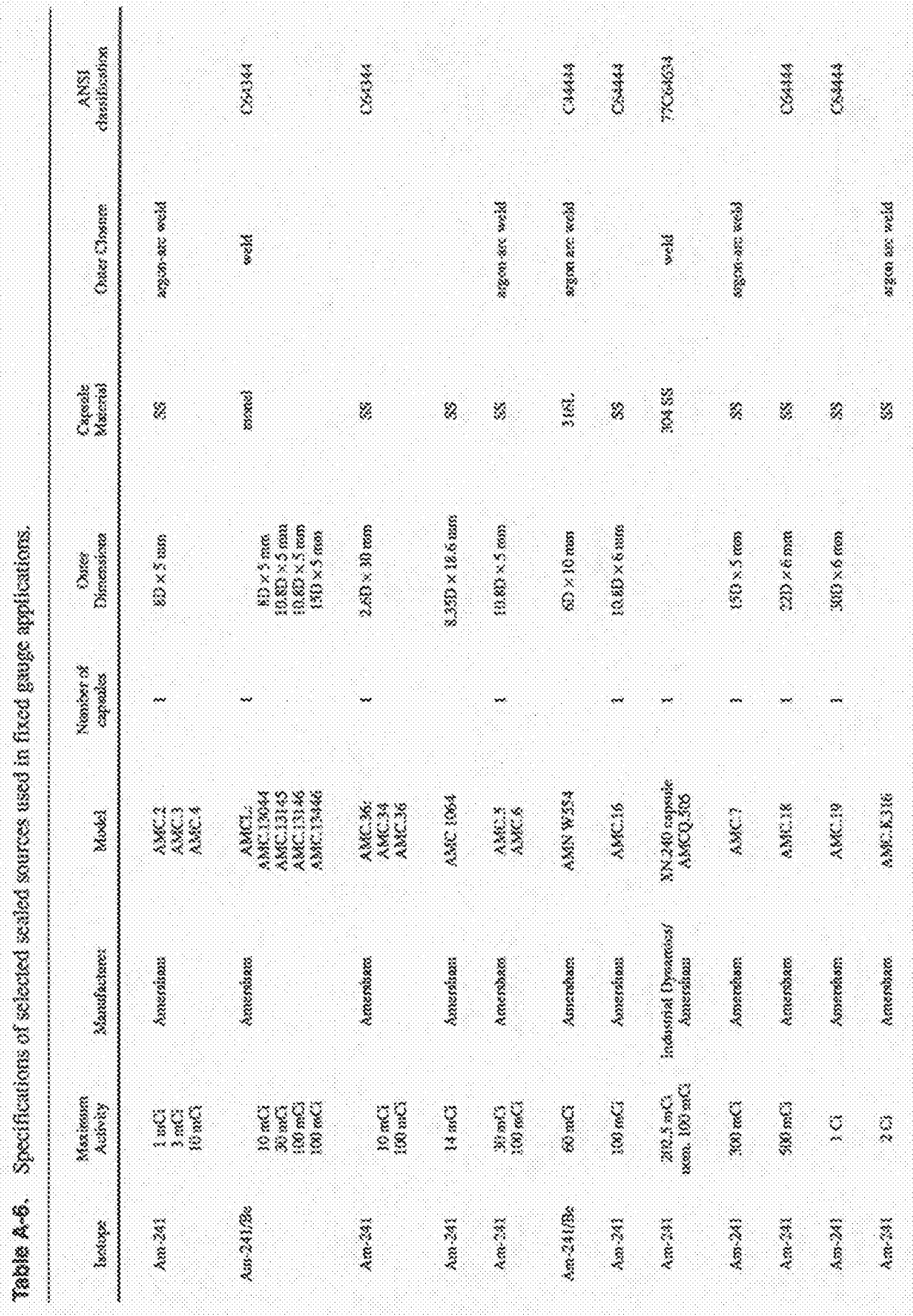




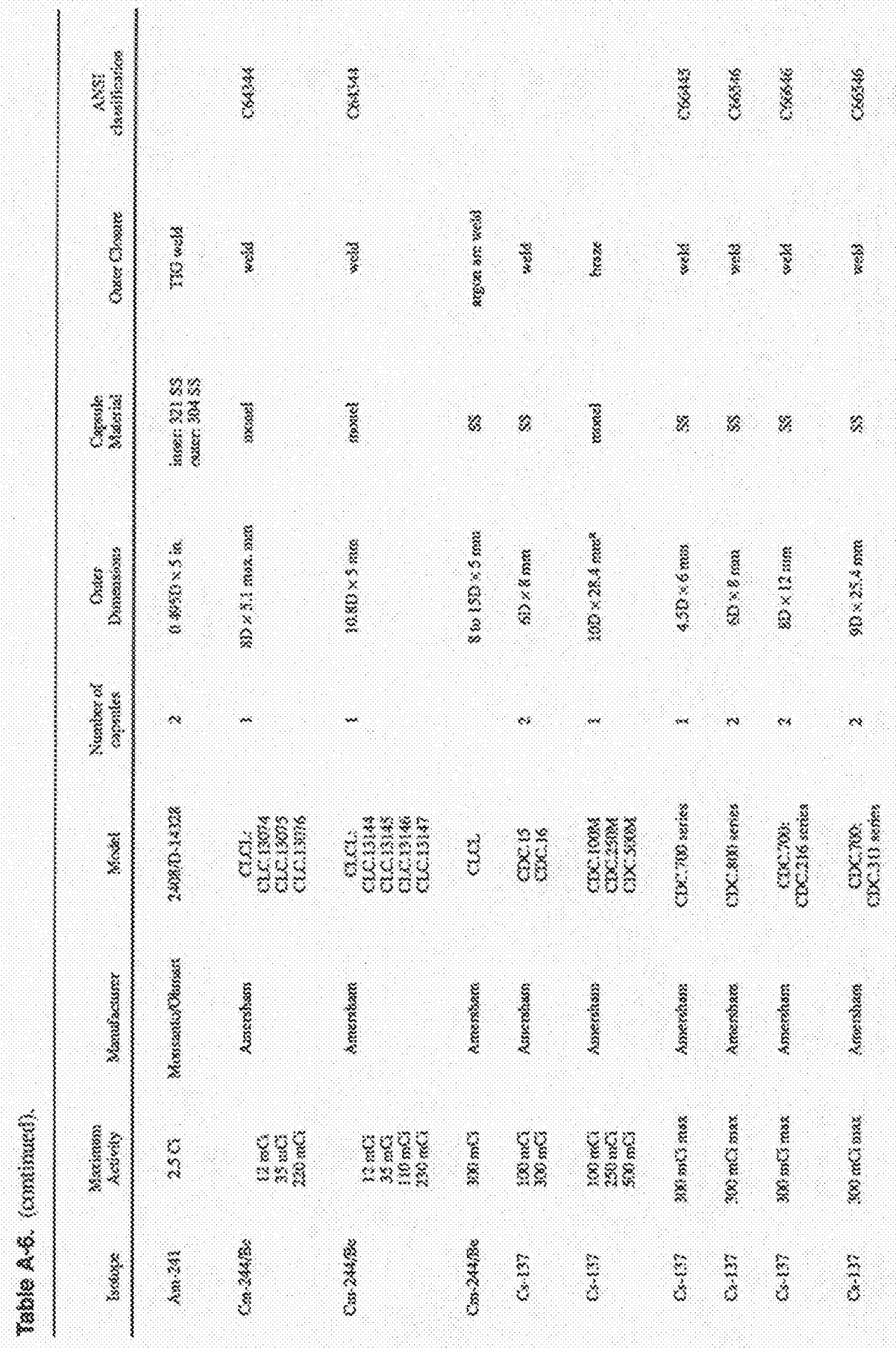




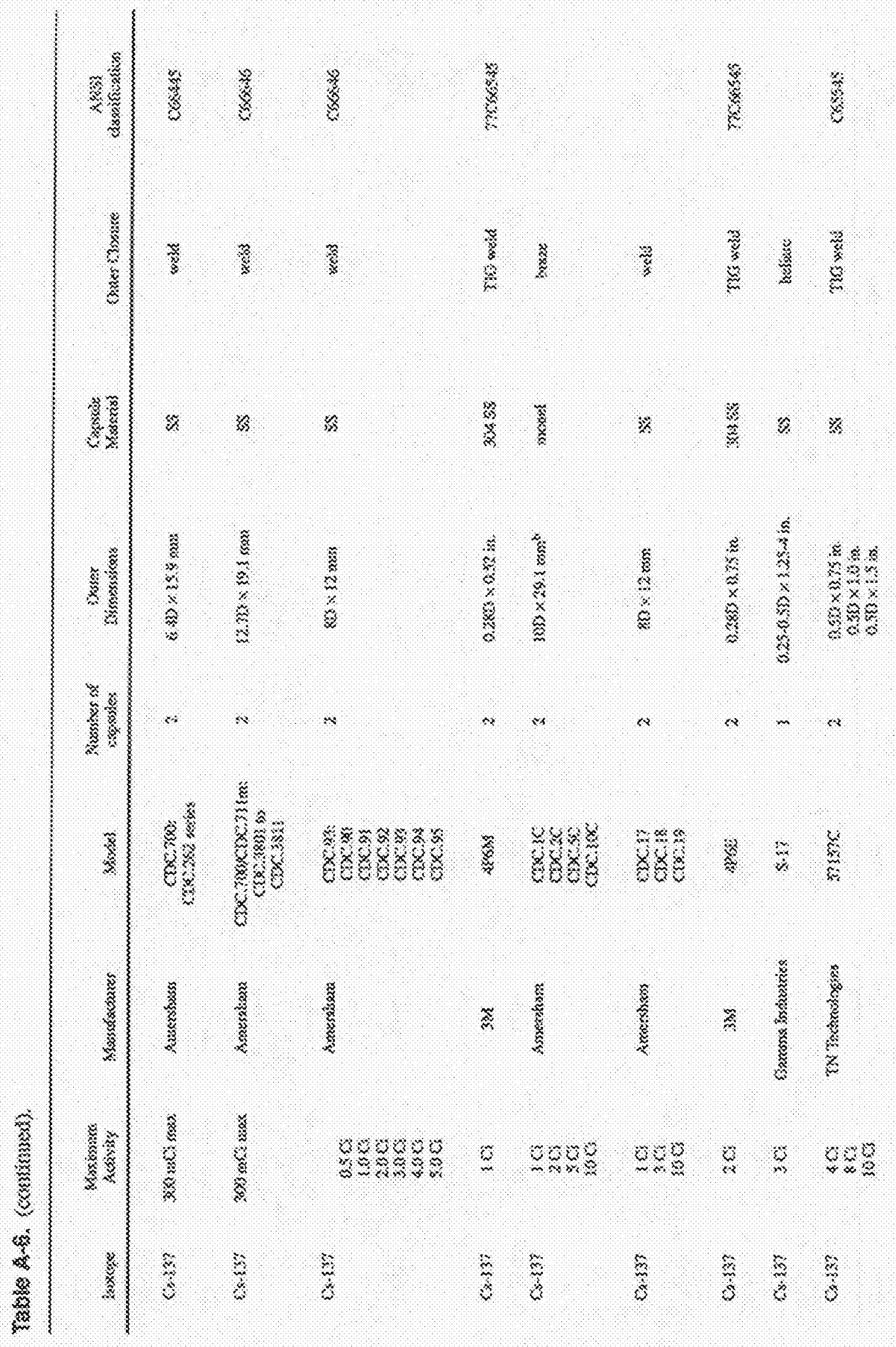




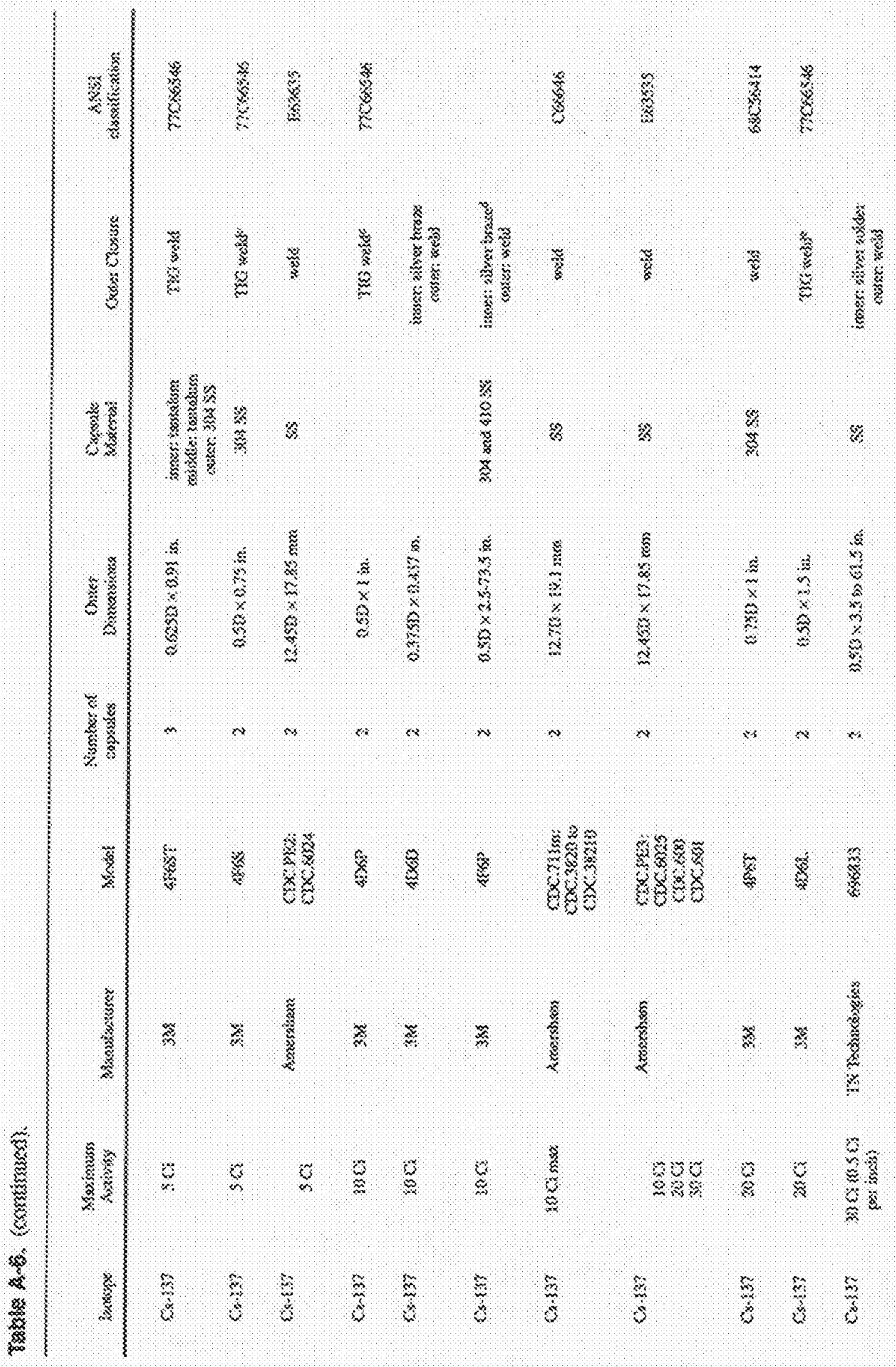




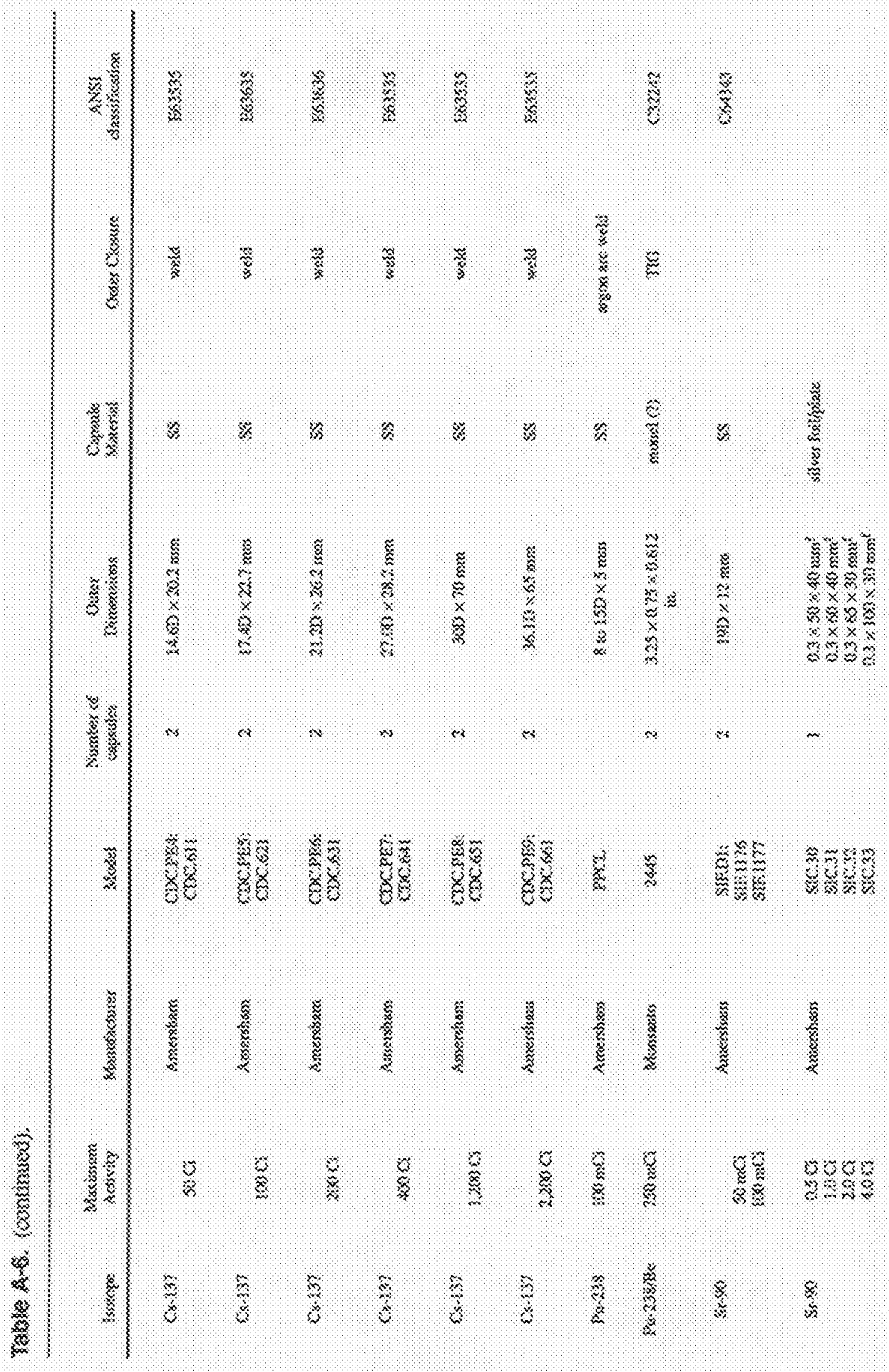




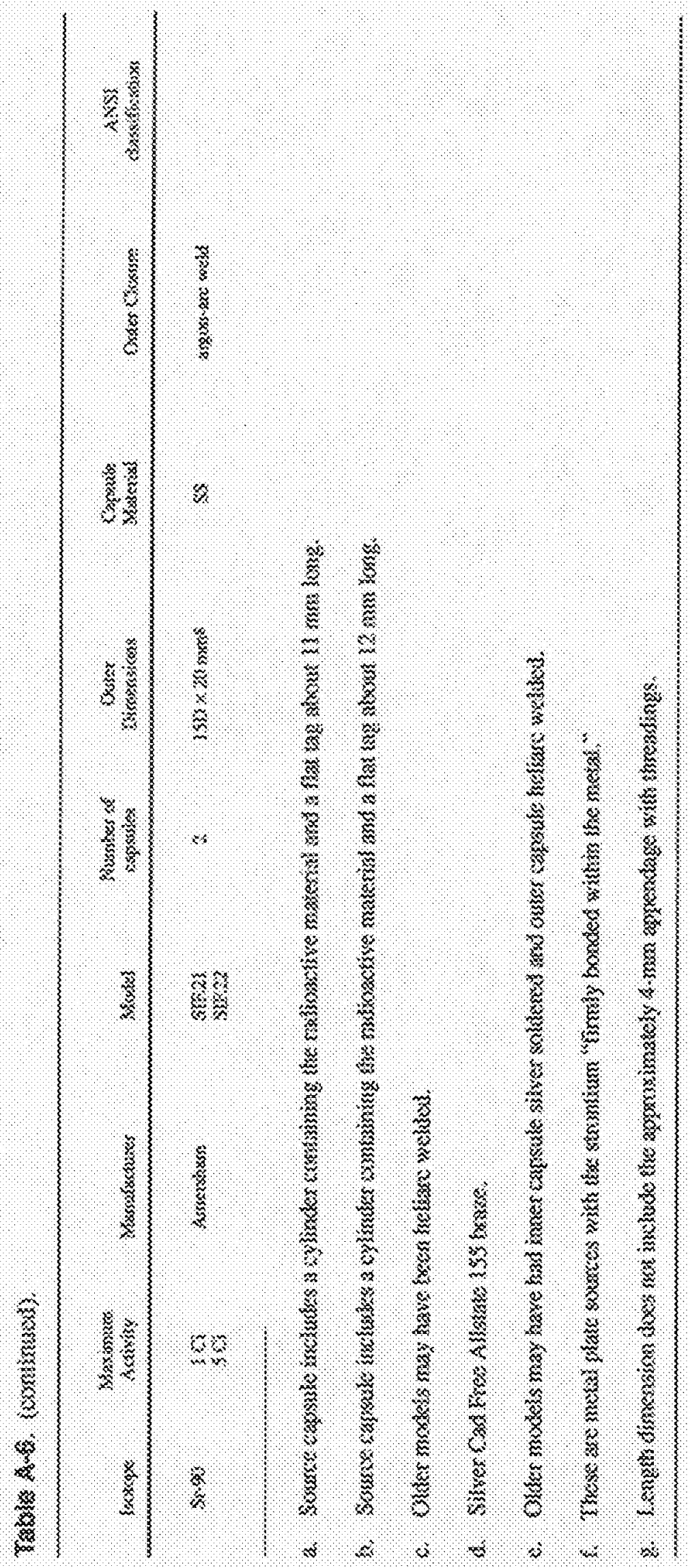

a 17 


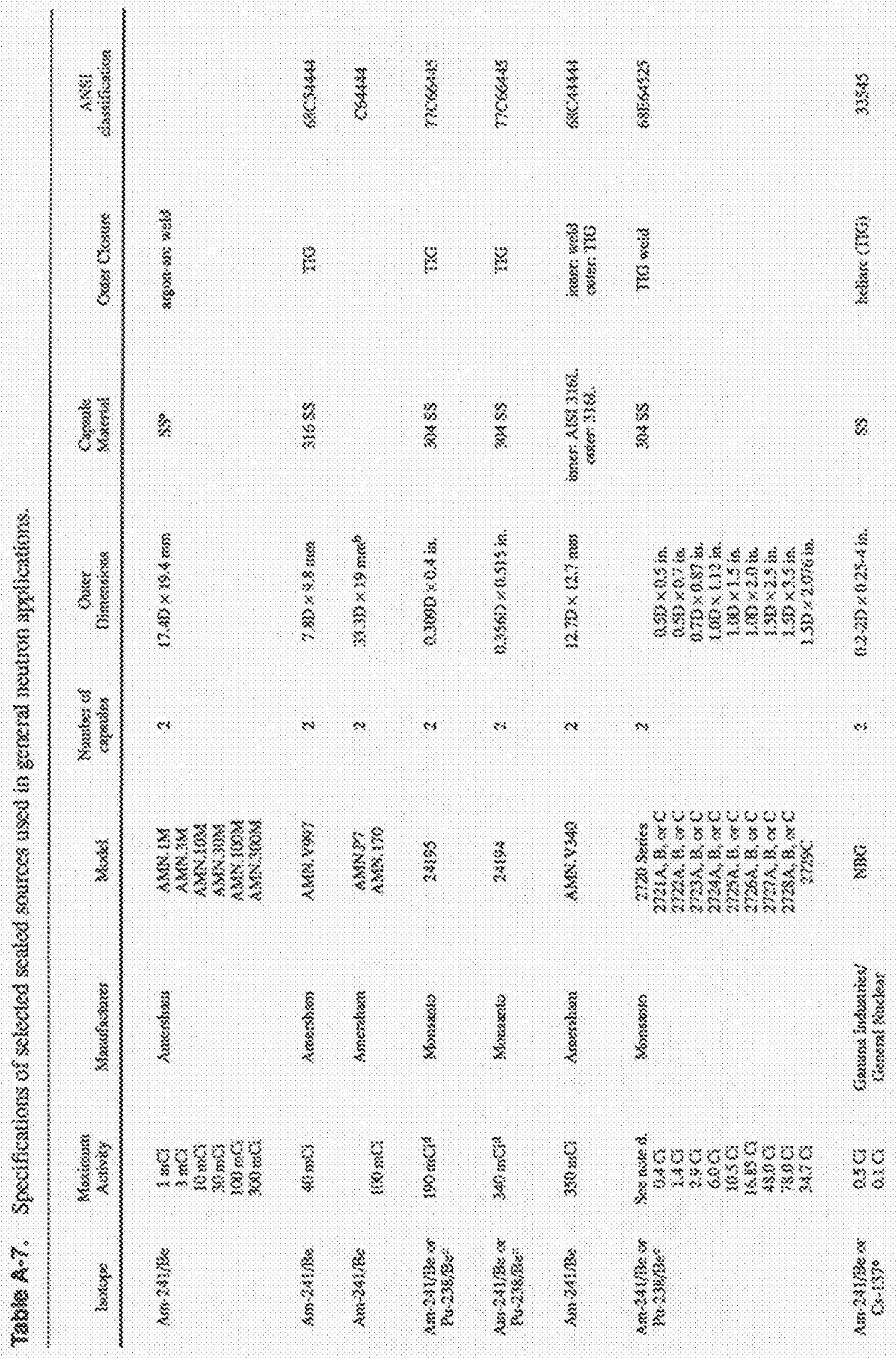




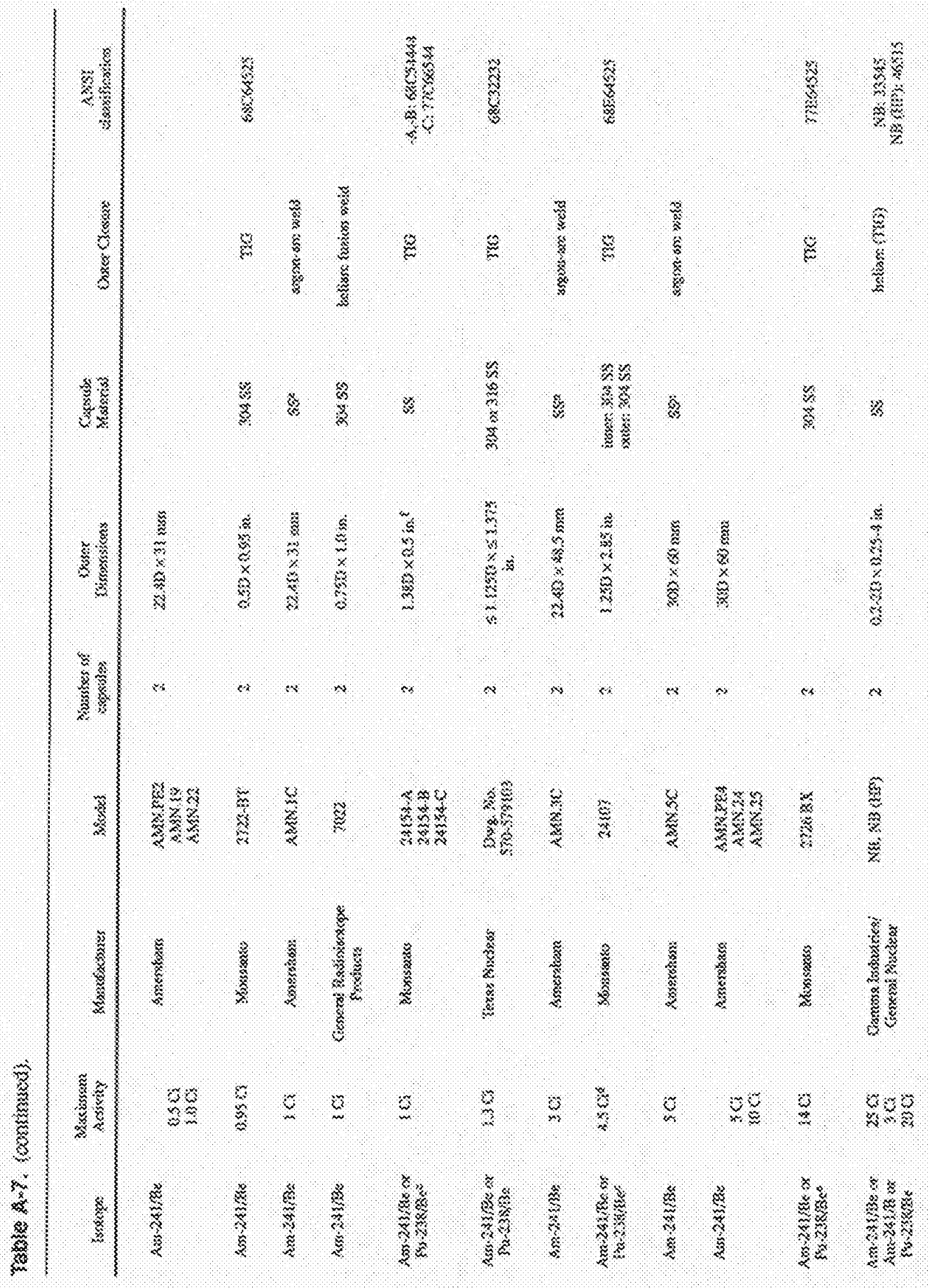




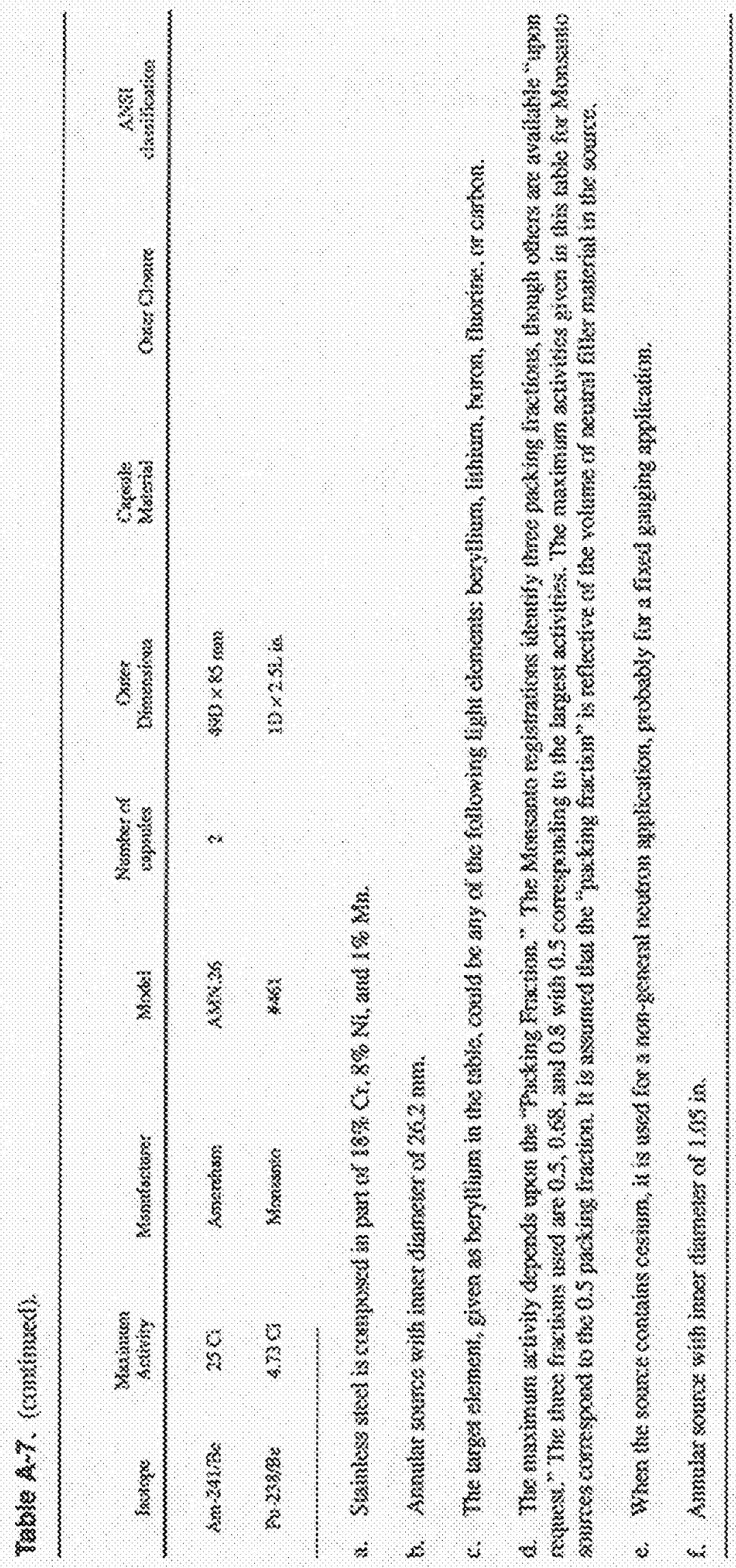




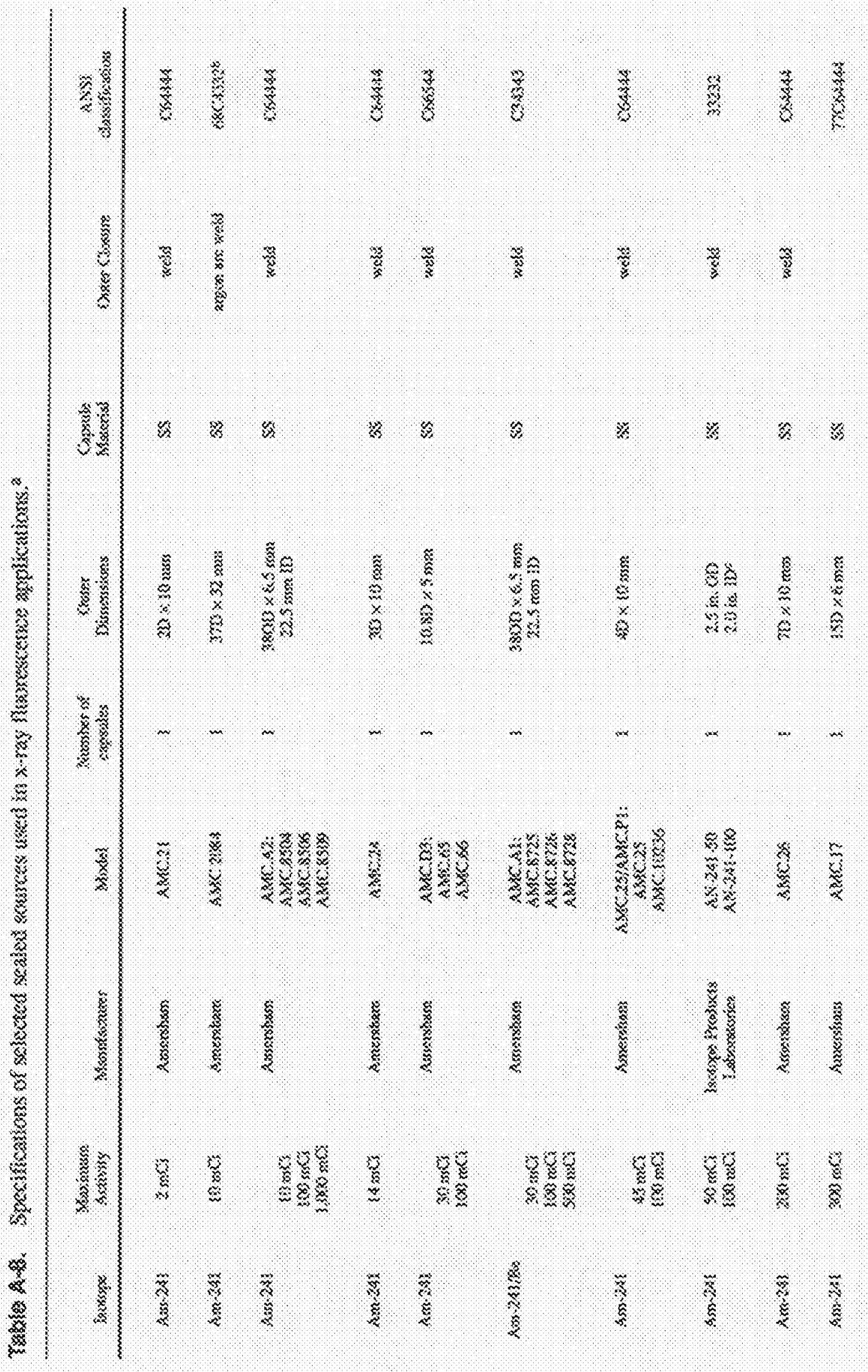




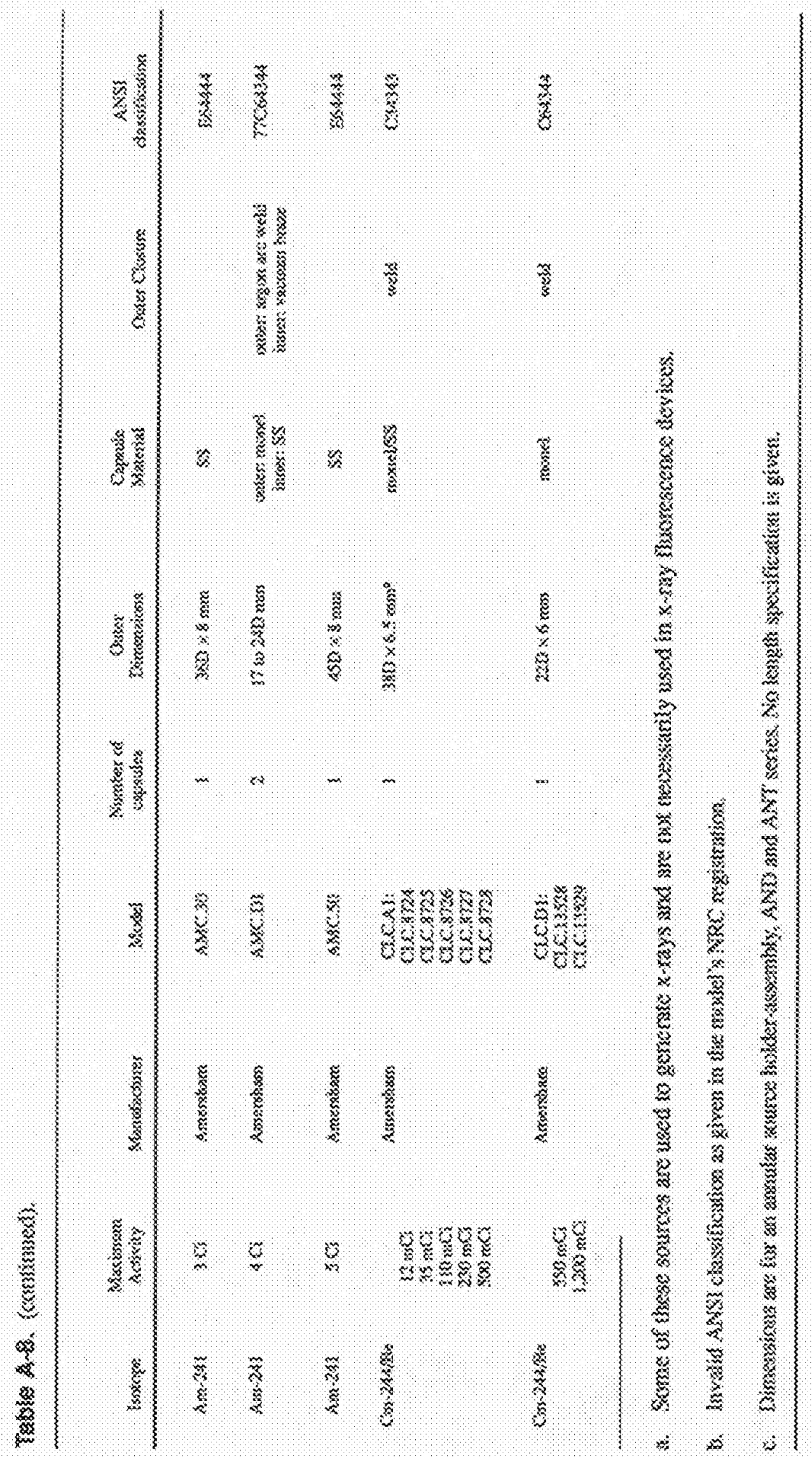




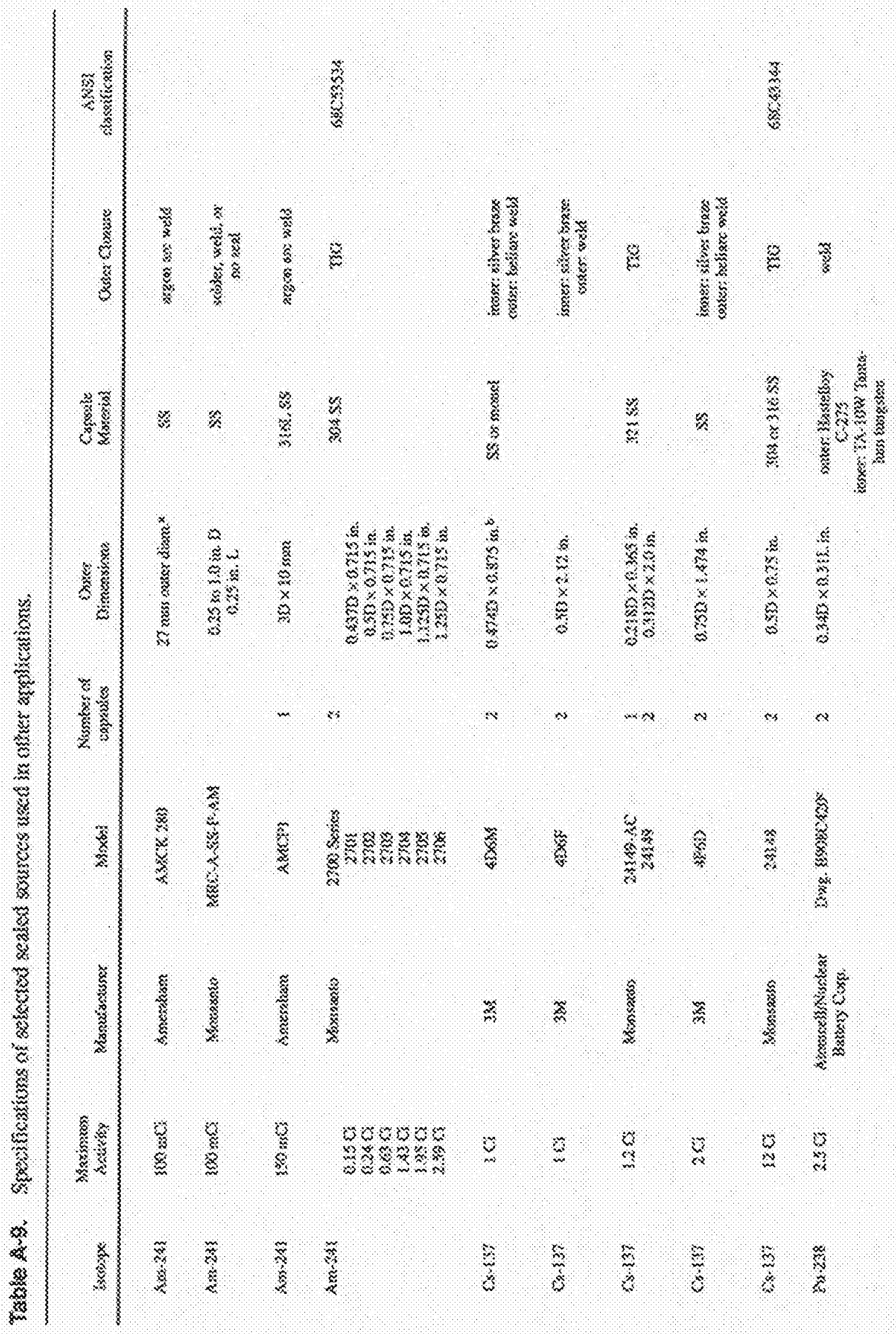




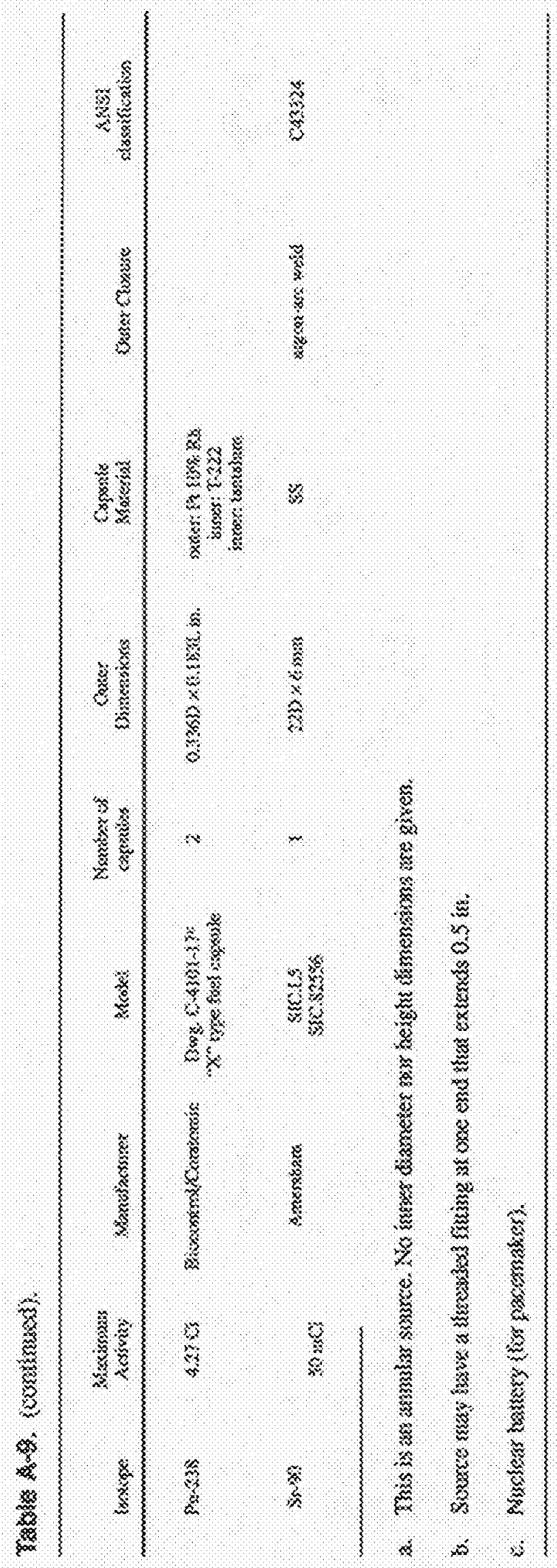




\section{Apparaix}

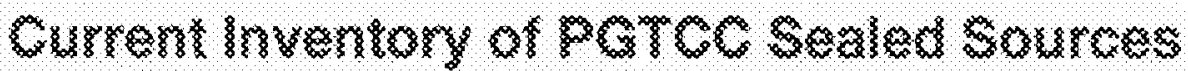

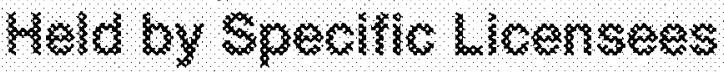




\section{Aprardix}

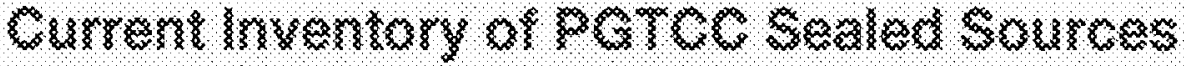

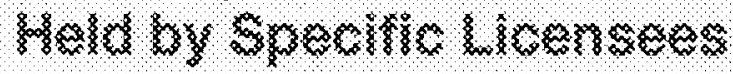

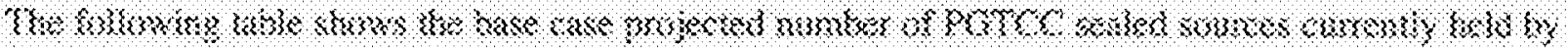

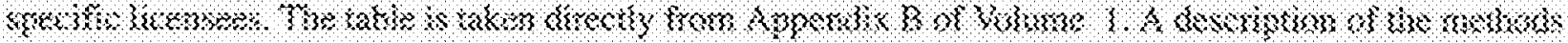

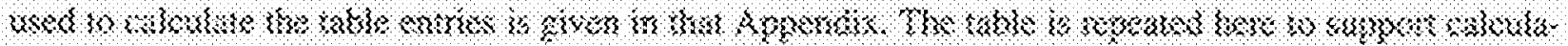

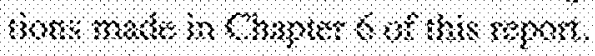




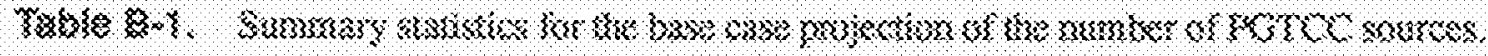

\begin{tabular}{|c|c|c|c|c|c|}
\hline $3 \times 0 \times 320330$ & \$s & 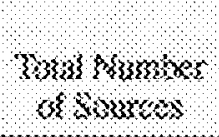 & cromorof romal & 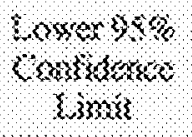 & $\begin{array}{l}\text { Snger } 48,8 \\
\text { Onnoms }\end{array}$ \\
\hline QH3isnowims & $\{43,243$ & $3, \infty \infty 0$ & 85 & 3,318 & 6,6x? \\
\hline C.S33isxakik333 & C.36 & 21 & 8 & $?$ & 43 \\
\hline Sorisousinar & 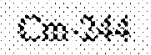 & 37 & 3? & 83 & 88 \\
\hline Solstronsion & $0,33)$ & 3,830 & 50 & 2,63 & 4,2, \\
\hline sabremensisor & 3,63 & 36 & 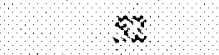 & 32 & 233 \\
\hline Xatikgasbors & $x_{x}-28$ & 39 & 3 & ४ & 3 \\
\hline Cuibrakius & $q_{3} z_{3} s$ & 4 & 8 & 32 & $\lambda$ \\
\hline Canibaratisns & $8, n 233$ & 35 & 36 & Bns & 386 \\
\hline Cabikwassas & P\&s 3$\}$ & 3 & 14 & ) & 38 \\
\hline Estitamsison & 5.64 & 1,027 & 3.18 & 8 & $48 \times$ \\
\hline 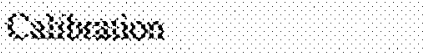 & 739 & 1 & $\&$ & 2 & 32 \\
\hline gasionaricos & $x<23 x$ & 3 & $\$ \xi$ & 2 & $m$ \\
\hline Rkukukar & $\$ m 2 \times 3$ & 3 络 & 23 & 178 & 308 \\
\hline Mrotisuas & $5 \times 38\}$ & 3,106 & 352 & $48 ;$ & 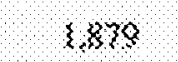 \\
\hline Assisic:sis & $S s+8 s$ & 23 & 8 & 9 & 3) \\
\hline $8830,3<\times 3$ & 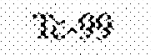 & 3 & 3 & 3 & 8 \\
\hline krobinss & $8<238$ & 38 & 8 & 10 & 65 \\
\hline Well Krogsings & 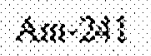 & \$.SI & 3,83 & 3,03 & 7,48 \\
\hline 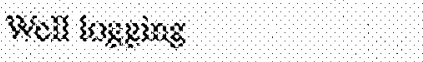 & 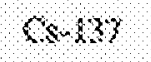 & 2,356 & 836 & $43 \%$ & $3 \times 81$ \\
\hline Woll bostris: & $33 \times 338$ & 372 & 365 & 9 & 426 \\
\hline 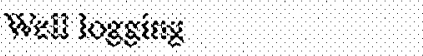 & 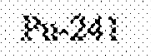 & 3 & 3 & 8 & 3 \\
\hline 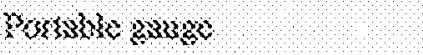 & $3 x y-24 s$ & $3 \times 333$ & $3 \times x$ & 12,720 & \{\}$, 0\}$ \\
\hline 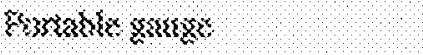 & So- \{\}$\}$ & 138 & $\$$ & 56 & $9 \% 3$ \\
\hline 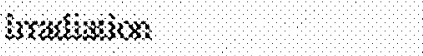 & $x m-243$ & 359 & 33 & 6 & 330 \\
\hline$B r a b i<3<x$ & $\mathrm{C} s .33$ & 3,393 & $2 \pi$ & s.sos & $233 \times 1$ \\
\hline Brobroukn & $3 \times \times 0$ & $\{0$ & 3 & 3 & 21 \\
\hline 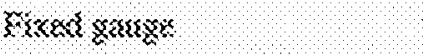 & $10 \times 2 \times 1$ & 2,28 & 310 & 6,634 & 3,002 \\
\hline 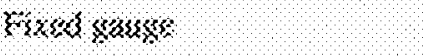 & 86 & 3 & 3 & 8 & 93 \\
\hline $53>033833383$ & $\mathrm{Cn} \times 46$ & $3 \%$ & 3 & 8 & 3 \\
\hline$(53>033333328$ & Soly & 30,80 & 2,38 & $24 \times 63$ & $8 \times 3 \times 8$ \\
\hline$\xi_{3} \times 3 \times 3,233320$ & $83>38$ & 3 & 3 & 3 & 3 \\
\hline 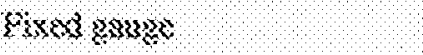 & $3 x+30$ & $\{S$ & 25 & 83 & $\left\{\begin{array}{l}3 x \\
x\end{array}\right.$ \\
\hline 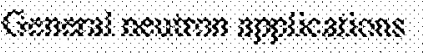 & 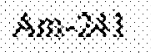 & $3<\times 3$ & 226 & 3,887 & 1,222 \\
\hline 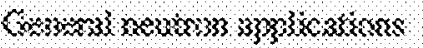 & $0,-28$ & 336 & 3) & 33 & $\xi \infty$ \\
\hline
\end{tabular}




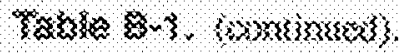

\begin{tabular}{|c|c|c|c|c|c|}
\hline $2 x+3,5,1 / x)$ & $800833 \%$ & 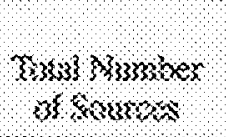 & sombrom bor & 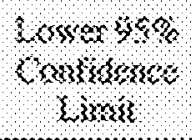 & 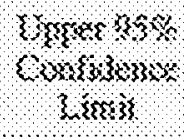 \\
\hline 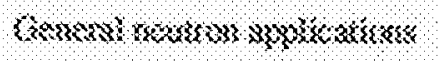 & 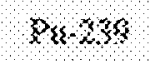 & 286 & $\infty$ & 332 & 321 \\
\hline 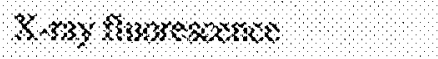 & sonosi & 688 & 343 & 483 & 98 \\
\hline 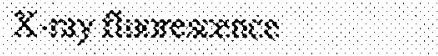 & $0,33.284$ & 243 & $8 \%$ & 5 & 4YI \\
\hline 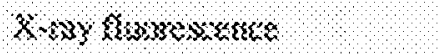 & Sos? & 3 & 3 & () & 3 \\
\hline 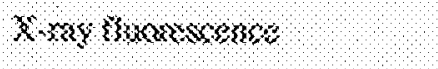 & $\xi_{3} 223$ & 182 & 3 & 33 & 834 \\
\hline$\infty_{33} \times 3$ & $(x, m-2 \times 3$ & 1,123 & 83 & 886 & 3.663 \\
\hline Bxines & $\mathrm{S}\}$ & 6 & 88 & 35 & 92 \\
\hline Estater & C 332.4 & 36 & 12 & 31) & 50 \\
\hline onsos & $\cos 3 \%$ & $3 \leqslant \leqslant \&$ & $5,2 * 3$ & $2 \%$ & 21,308 \\
\hline $6 \mathrm{kr}$ & 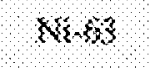 & 3,843 & 3,8 & 33 & $32 \times 5$ \\
\hline Bitios & 3,323 & 3 & 3 & 6 & 3 \\
\hline Jtwo & $p_{3,} \geq 3,3$ & 3,536 & $1,8 s$ & 63 & $3,3, s$ \\
\hline 3368 & $83>339$ & 658 & 34 & 32 & $33 *$ \\
\hline skex & 820.243 & 28 & 38 & ) & 40 \\
\hline Gros: & S- $>0$ & 203 & 3 & 333 & 442 \\
\hline Vtrtes & 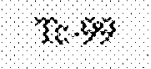 & ast & 388 & 0 & $3,0 \times 8$ \\
\hline ORkser & ४23 & 78 & 23 & 34 & $32\}$ \\
\hline So3ronawow & 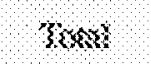 & $8,2 s$ & s, $x$, & s, 30 & $82,32\}$ \\
\hline $3 k \pi k n$ & knok & 1883 & $36 \%$ & $\$ \$$ & 2,286 \\
\hline 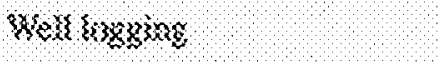 & Takal & 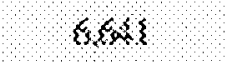 & 2000 & 1.583 & $x, x \geq 3$ \\
\hline fouratis xasax & Tomis & 15,618 & 3200 & $2 \geq 882$ & 18917 \\
\hline 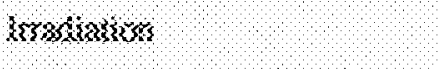 & Tosis: & $35 \%$ & 200 & 3,33 & 2249 \\
\hline$r<x a t<x a x$ & 8081 & 31000 & 2,456 & 22,283 & $363 \times 88$ \\
\hline 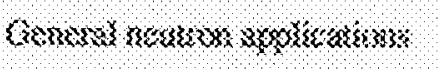 & Tarat & 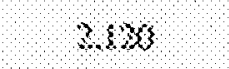 & 251 & 1,020 & 2,83 \\
\hline 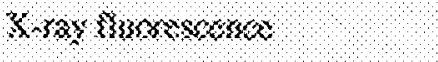 & ratar & 0,318 & $28 x$ & 735 & 3,513 \\
\hline B $36 x=2$ & $30, a s$ & 38,25 & 8833 & 3,86 & 35,763 \\
\hline Yissal & $A m \times 3$ s & $28,3 \%$ & $2 \times 16$ & 23,89 & 34,230 \\
\hline$\$<<3$ & 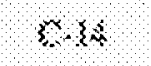 & 123 & 32 & 43 & 382 \\
\hline 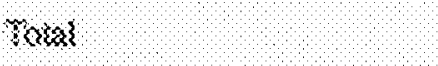 & Q 83,214 & $32 \%$ & 9 & 33 & 330 \\
\hline rorat & 20,37 & 33,2 & $623 x$ & 37,803 & 8,668 \\
\hline Koras & $x-8$ & 3984 & $108 \%$ & Q3 & 2,486 \\
\hline $3 \times<3$ & $x_{3}=23 \%$ & 34 & 3 & 3) & 32 \\
\hline
\end{tabular}




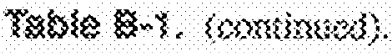

\begin{tabular}{|c|c|c|c|c|c|c|}
\hline & Bxyke $\{y$ wo & $303000 \times$ & 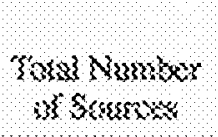 & 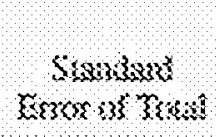 & 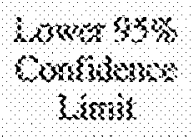 & 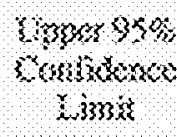 \\
\hline$\xi\{x \in\}$ & & $86-236$ & 2,189 & 1,33 & (3) & 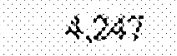 \\
\hline Trosis & & 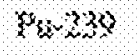 & 3,453 & 202 & $3, k 8\}$ & $1 \times 3\}$ \\
\hline Toxal & & $39 \times 2 \times 1$ & a) & 38 & 3 & 36 \\
\hline Yaxai & & 32.83 & 2378 & 1,323 & $3 \%$ & 4,331 \\
\hline Soms & & 20,99 & 435 & 308 & 9 & 1,139 \\
\hline roukat & & 3123 & $\{A\}$ & 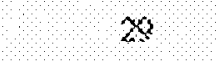 & 84 & 808 \\
\hline 203333 & & roval & 3,979 & 3.352 & $73,8 \mathrm{~m}$ & $30 \times 153$ \\
\hline
\end{tabular}




\section{Apordx}

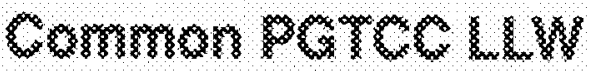 Soln}




\section{Appors:

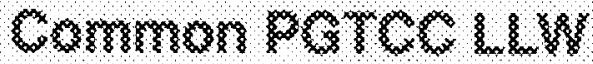

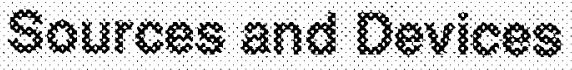

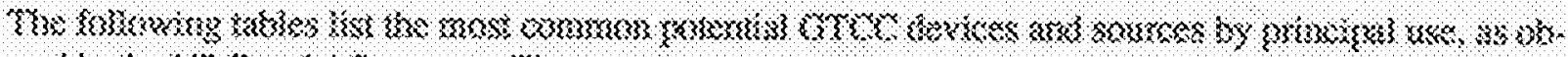

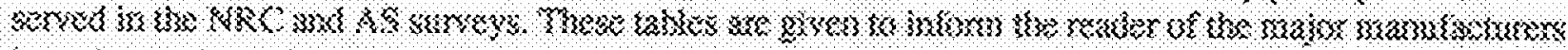

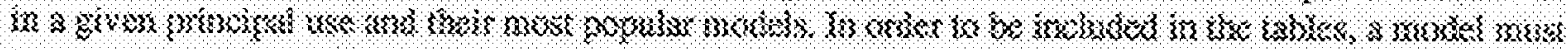

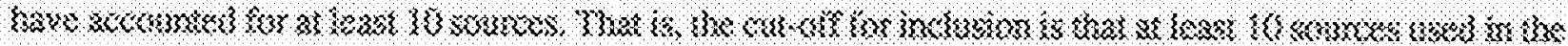

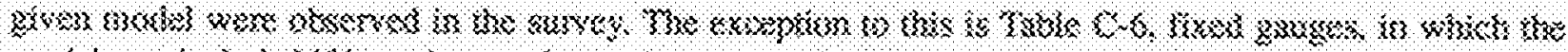

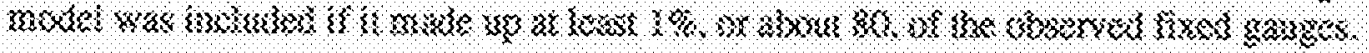

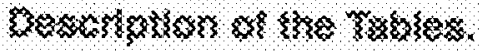

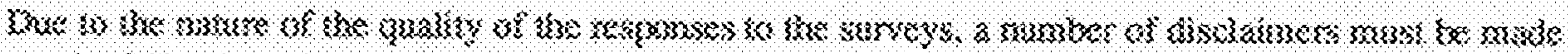

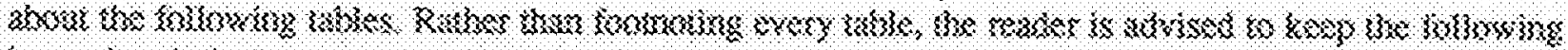

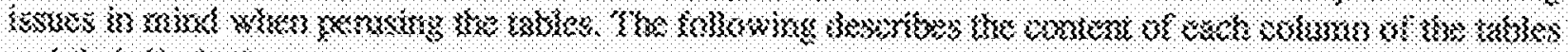

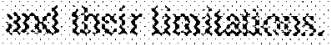

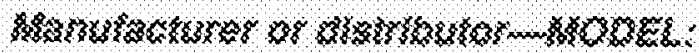

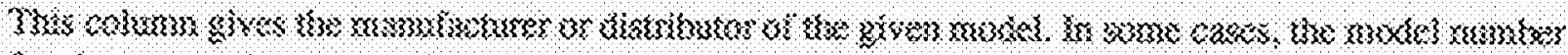

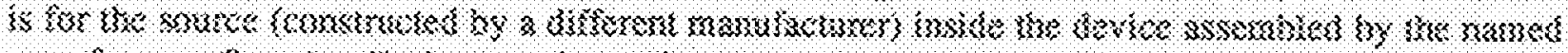

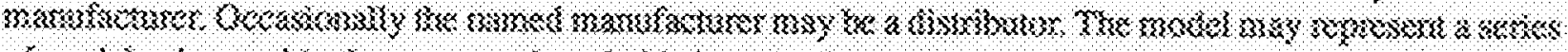

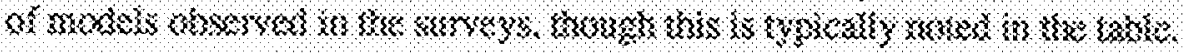

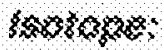

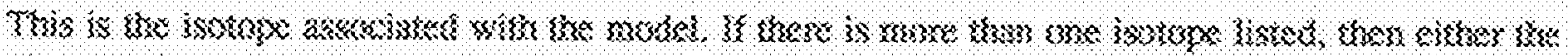

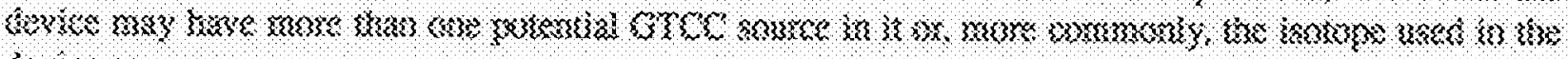
bercose can sass.

\section{ans}

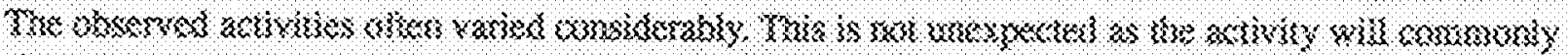

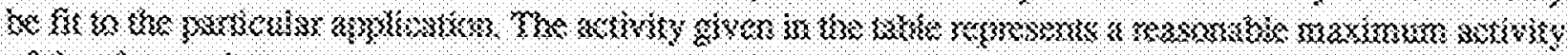

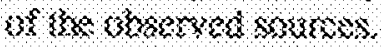

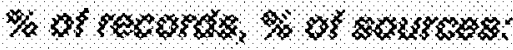

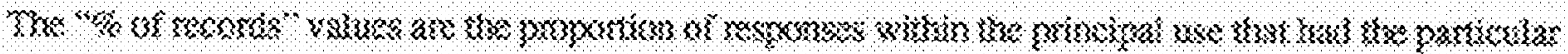

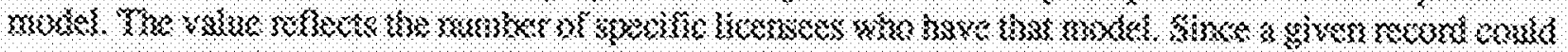

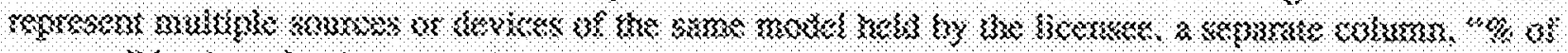

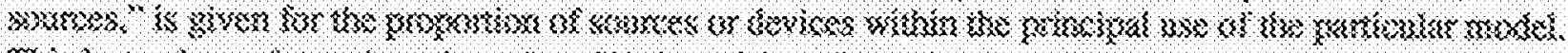

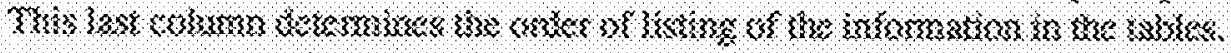




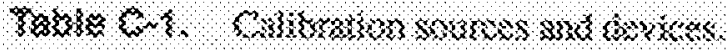

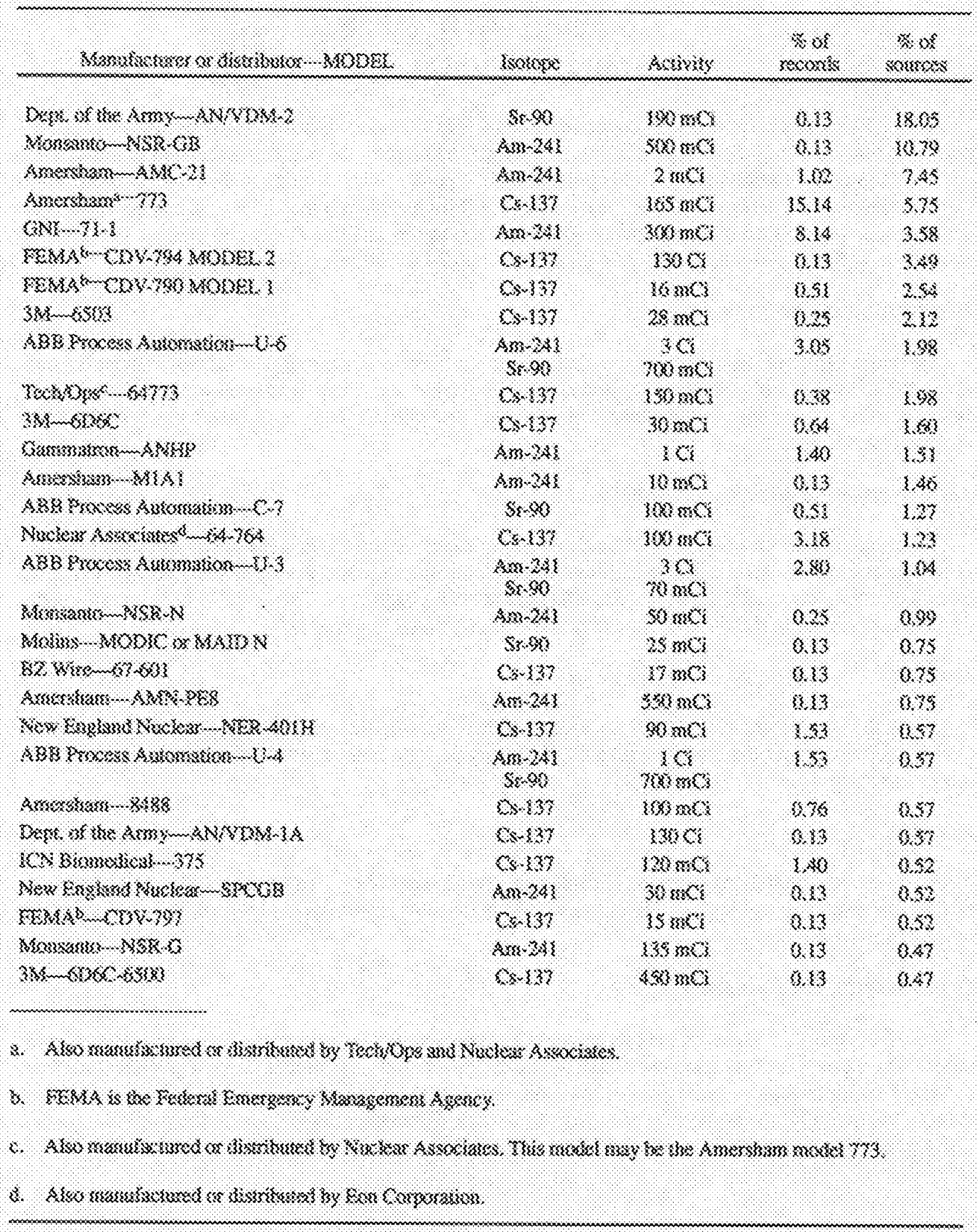




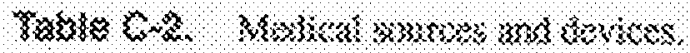

\begin{tabular}{|c|c|c|c|c|}
\hline 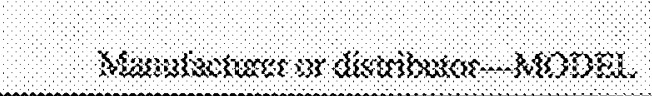 & 80018 & ansins & 800 & souscos \\
\hline $3 \times<-30<x$ & 53.3 & $x \times 333,3$ & 3\$3 & 2,24 \\
\hline $3 \times 3 \times 83 \times 8 \times, 88,36$ & 3,351 & $3 \times \mathrm{rgs}$ & 388 & 1,23 \\
\hline 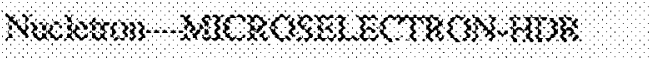 & $\$>33$ & $334 \mathrm{ks} \times$ & $B \leqslant 8$ & 8,6 \\
\hline 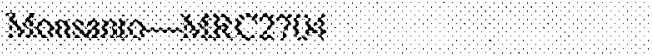 & $\$ 33 n \times 13$ & $50 \mathrm{~m} / \mathrm{s}$ & $0, \$ 5$ & 8.5 \\
\hline $832 m s=n s \quad \&<1<2<s$ & $3,33,3$, & 34383 & 8, & \$35 \\
\hline $868 \times 28 \times 8 \times 33,0 \times \times>3$ & $\{\& 3)$ & $3<\leqslant 83\} 3$ & 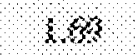 & 4,35 \\
\hline$x, 18,2, n<0$ & $8,31,20$ & $2,1, n$ & 8,8 & $\{\leqslant\}$ \\
\hline $3 \mathrm{~N} \bullet-8 \mathrm{kSS}$ & $\alpha, 33\}$ & $268 \times 0$ & 90 & $3 \times 6$ \\
\hline 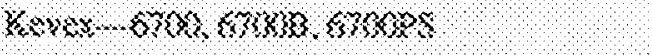 & $x, n+2 s 1$ & $31 \mathrm{no}$ & 6\%\% & 302 \\
\hline $38,-6502$ & $\alpha+3)$ & 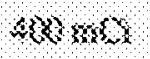 & 868 & 3,30 \\
\hline 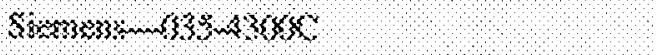 & $x_{33} \times 2$, & 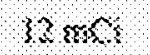 & 10 & 368 \\
\hline $36-8 k x$ & (x)3s) & 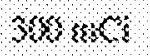 & 3,63 & $26 \times$ \\
\hline $3 \times-8,8 \%$ & $<, 3\}$ & $385 \mathrm{nol}$ & 5,58 & 2,2 \\
\hline 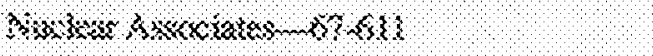 & Q -331 & $180 \mathrm{nan}$ & 960 & 200 \\
\hline
\end{tabular}




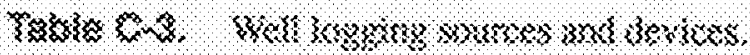

\begin{tabular}{|c|c|c|c|c|}
\hline 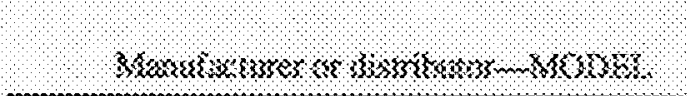 & $180,0 \mathrm{n}$ & $8 \times 1 \times 38$ & Ror & \%orck \\
\hline 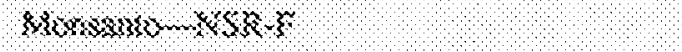 & $330 \times, 4$ & $36<$ & 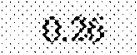 & 30,8 \\
\hline$\$ O S+\infty S$ & 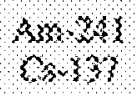 & $\begin{array}{l}3063 \\
40\end{array}$ & 393 & $3 \times 35$ \\
\hline $0 x+3>x+3$ & $4 m, \mathrm{~s}$ & $\times<$ & 32,1 & 328 \\
\hline 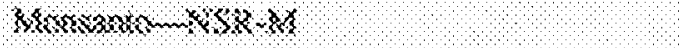 & A $3 \times 31$ & 100 & 8,8 & 988 \\
\hline 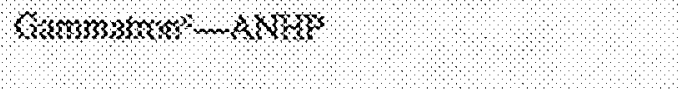 & $\varepsilon_{3} \times 236$ & $\begin{array}{l}x \times 1 \\
200\end{array}$ & 332 & 373 \\
\hline $8633 \times \times 3 \times s, \times \times 3 \times>0$ & $\mathrm{~nm} \times \mathrm{A}$ & $8 \%$ & 853 & 808 \\
\hline 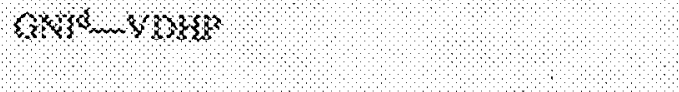 & $\begin{array}{c}A 33-34 \\
0 \times 33 ?\end{array}$ & $\begin{array}{c}51 \mathrm{ma} \\
2 \mathrm{~m}\end{array}$ & 48 & 828 \\
\hline 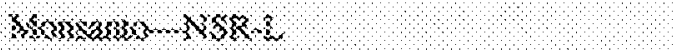 & $3 m \times 34$ & $3 \times 8$ & $8 \%$ & 36 \\
\hline 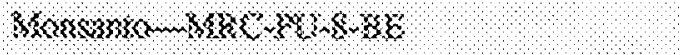 & 20238 & k४ & 33 & 28 \\
\hline 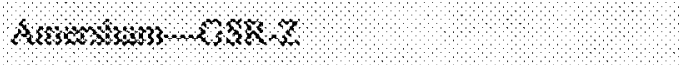 & 80,37 & 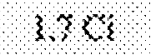 & $8 \times 3$ & 2,36 \\
\hline $3<+<1,4$ & $\mathrm{An}, 24$ & 380 & ४४४ & 221 \\
\hline $3 \times \times>\times 3 \times 3$ & $8 \times n \times 3 \times 3$ & $3 \%$ & 3,8 & 3,83 \\
\hline 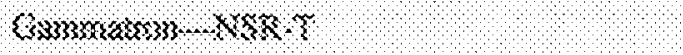 & 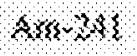 & 2,3 & 33 & 3,3 \\
\hline 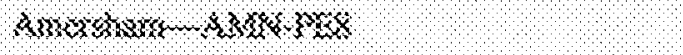 & 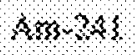 & $3 \mathrm{~ns}$ & \$26 & 330 \\
\hline 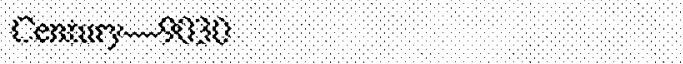 & 3031243 & 1808 & 836 & 83) \\
\hline 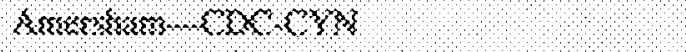 & 4831 & 28 & 38 & Q.86 \\
\hline 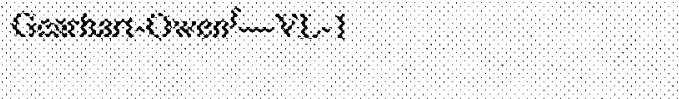 & 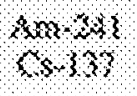 & $\begin{array}{l}3 \% \\
2 \times \mathrm{mos}\end{array}$ & 310 & 873 \\
\hline \multicolumn{5}{|c|}{ 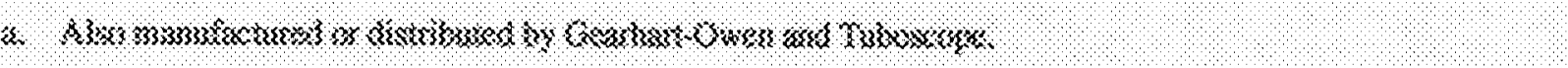 } \\
\hline \multicolumn{5}{|c|}{ 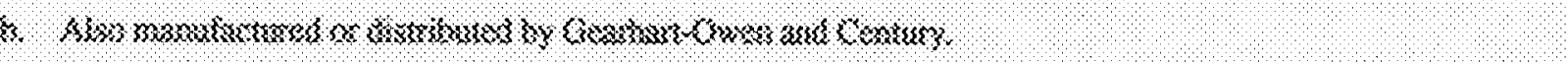 } \\
\hline \multicolumn{5}{|c|}{ 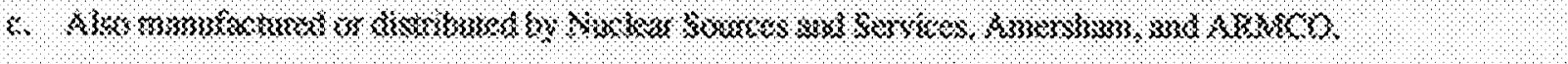 } \\
\hline \multicolumn{5}{|c|}{ 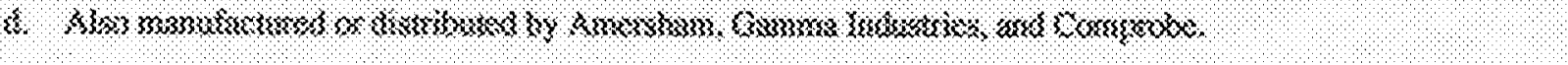 } \\
\hline \multicolumn{5}{|c|}{ 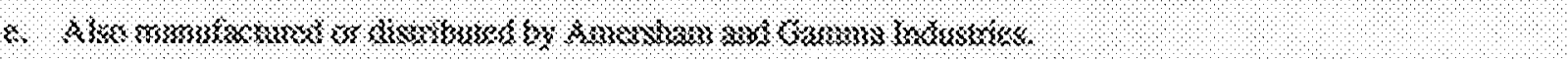 } \\
\hline \multicolumn{5}{|l|}{ 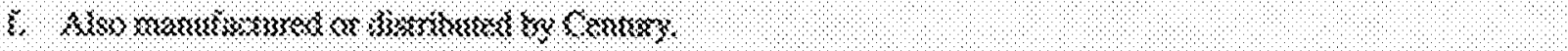 } \\
\hline
\end{tabular}




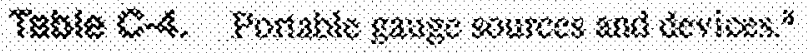

\begin{tabular}{|c|c|c|c|c|}
\hline 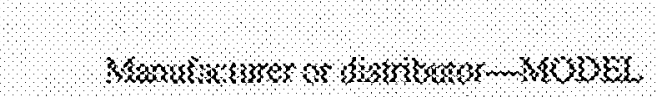 & Sknosse & ars3ring & sonsols & $\begin{array}{r}\text { s ox } \\
\text { sources }\end{array}$ \\
\hline 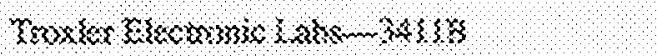 & $s_{233} 243$ & $8 \times \mathrm{msl}$ & 3,5 & 3913 \\
\hline 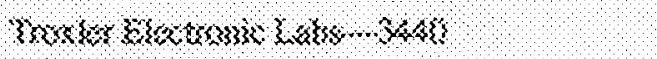 & $\$ 20<13$ & $36 \mathrm{sg} 6$ & 33,3 & 33,85 \\
\hline 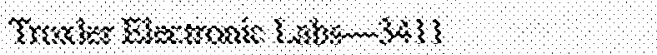 & 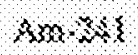 & 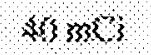 & $\$ \leqslant$ & S\$83 \\
\hline 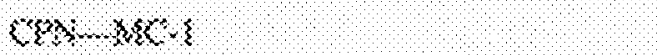 & $43 m, 26$ & 83,3353 & 839 & $\$, 9$ \\
\hline 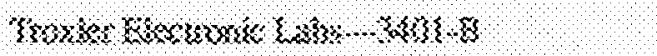 & $x \times 1,6$ & (3) $333<3$ & 3,8 & $\$ \%$ \\
\hline 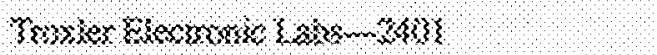 & nn, 263 & $33,33<3$ & $8\}$ & 322 \\
\hline 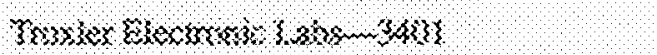 & $3 \mathrm{~mm} 2 \mathrm{~s}$ & $48 \mathrm{nr} \Omega$ & 127 & 32 \\
\hline$\{3 \times<\leqslant 3<-3$ & $3 \times 2 \times 1$ & $30 \mathrm{mrl}$ & 221 & 183 \\
\hline 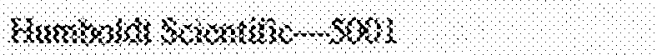 & $x, 2,3 x$ & $40 \times 2 \times$ & 182 & $18 \%$ \\
\hline 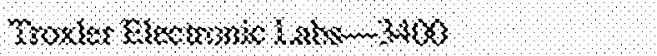 & $x_{33}, 241$ & $40 \mathrm{~m} / \mathrm{s}$ & 1,32 & 898 \\
\hline 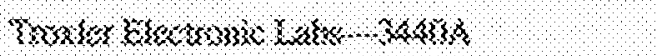 & $\alpha_{33}, 283$ & $40 \mathrm{~m} \times$ & 33 & 8,88 \\
\hline 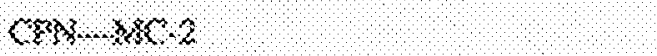 & $\operatorname{sen}, 243$ & 53,80 & 2,3 & 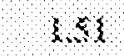 \\
\hline 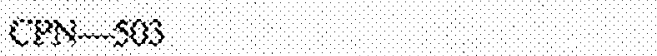 & $\operatorname{sen} 2 \sin$ & $83 \mathrm{~mol}$ & 3,38 & 3,38 \\
\hline 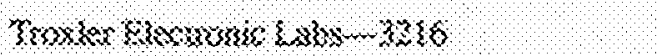 & anosus & 8033001 & 2,33 & 182 \\
\hline 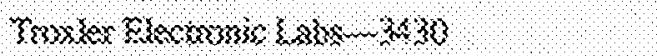 & 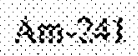 & 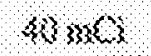 & 3,37 & 385 \\
\hline 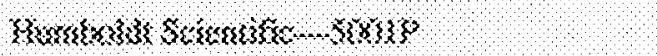 & $s_{s} 8,243$ & $81 \mathrm{~ns}$ & 8,26 & 0,3 \\
\hline 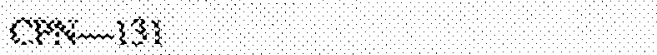 & $1,1,32 \times 3$ & $\$ 3 \mathrm{rr} \times$ & (3) & 850 \\
\hline 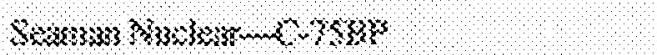 & $33 m, 3 \times 1$ & $\mathrm{~s}, \mathrm{nSO}$ & (3,3) & 8.45 \\
\hline 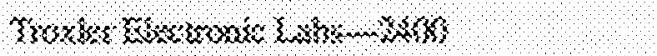 & 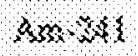 & $8, n=3$ & 0,35 & 638 \\
\hline 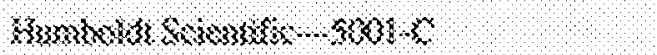 & 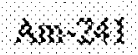 & $43 \mathrm{nnO3}$ & (3) 35 & 6.38 \\
\hline 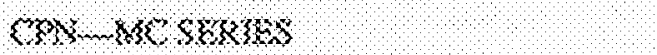 & 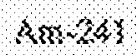 & $\$ \$ B, 3<3$ & 38,8 & 83 \\
\hline 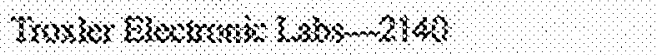 & $x<\{\{2<\}$ & $2 \mathrm{~m} 3$ & $3 \times 3$ & $\langle 32\rangle$ \\
\hline 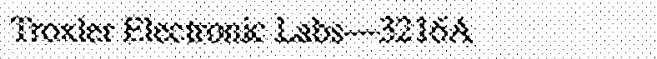 & $A m \times 2 \times 1$ & $30 \mathrm{~ms} \mathrm{x}$ & $0 \times 3$ & 325 \\
\hline 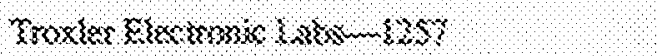 & 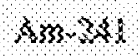 & $130 \mathrm{~ms}$ & $\$ 3$ & 023 \\
\hline 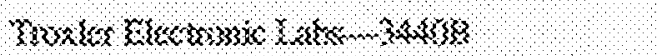 & \&333 $\approx \times 1$ & $4 \mathrm{kms}$ & 83 & $\$ 23$ \\
\hline
\end{tabular}

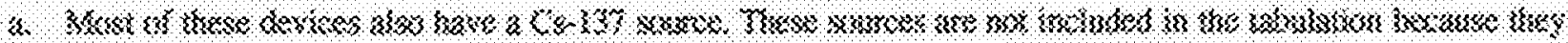

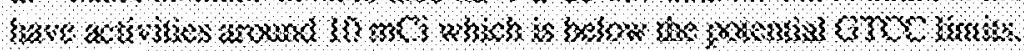




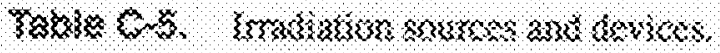

\begin{tabular}{|c|c|c|c|c|}
\hline 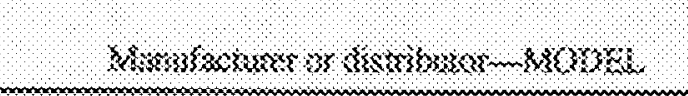 & Ysosionos: & Swisxiks & $\begin{array}{c}\text { robi } \\
\text { xecosis }\end{array}$ & 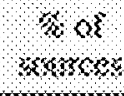 \\
\hline 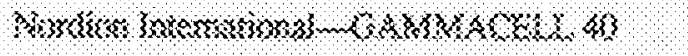 & 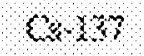 & 38383 & (8) & \$, \\
\hline 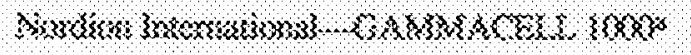 & $6.8 \%$ & $28 \times 3 \times 83$ & $1,0,6$ & 3238 \\
\hline $3 \times 3, \times<\times<\times<\times 3,3$ & $8.8 \%$ & 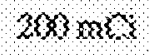 & \$13 & s.3 \\
\hline 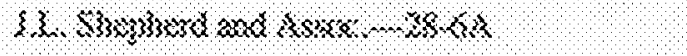 & $<\times 838$ & 1.26 & $8 \times 9$ & 28 \\
\hline 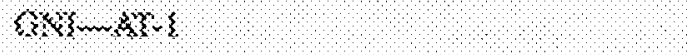 & $\Omega_{333,3} \times 1$ & $30 \times \mathbb{m} \times$ & $x<4$ & $2 \%$ \\
\hline 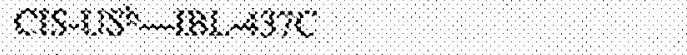 & $83 \times 3$ & 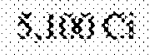 & 3.8 & 3,3 \\
\hline 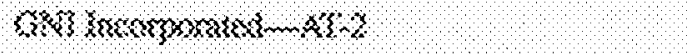 & $a_{333} \times 3$ & 28 & $3 \times$ & 3,8 \\
\hline 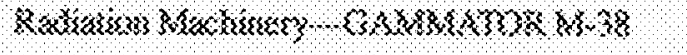 & 28.33 & $2, s, 8<1$ & 3.8. & 2,8 \\
\hline 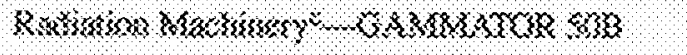 & 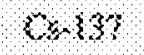 & $4 x<<$ & $3 \times 3$ & 356 \\
\hline 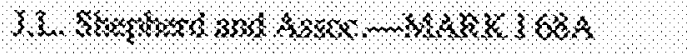 & $\infty, 3,2$ & $\$ \infty \mathrm{s}$ & 2, & $3 \leqslant 8$ \\
\hline 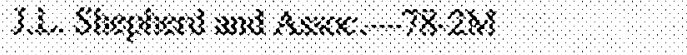 & 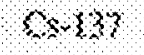 & 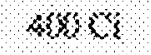 & 2,50 & $3 \%$ \\
\hline 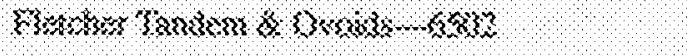 & $\alpha s+3)$ & $3 \times \times n \times 3$ & 8,63 & 338 \\
\hline 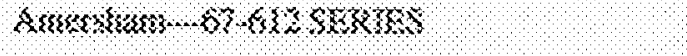 & $(5.33)$ & $204 \mathrm{sg8} \%$ & Q,31 & $3 \$ 8$ \\
\hline \multicolumn{5}{|c|}{ 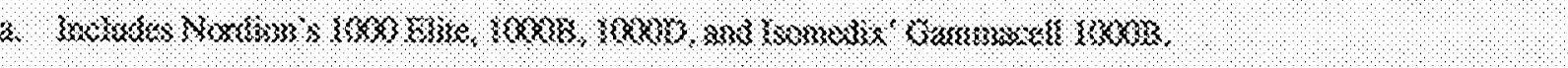 } \\
\hline \multicolumn{5}{|c|}{ 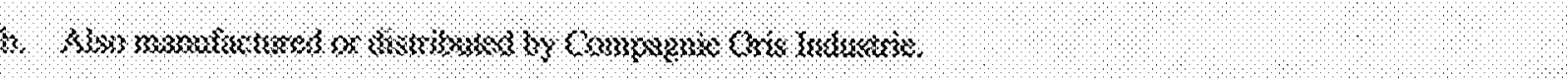 } \\
\hline 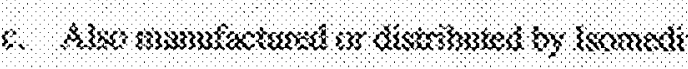 & & & & \\
\hline
\end{tabular}




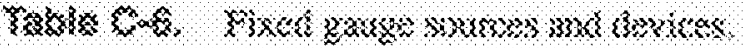

\begin{tabular}{|c|c|c|c|c|}
\hline 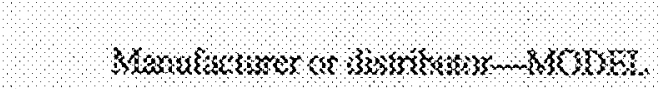 & boxops & $\$, 3 \times, 8$ & so wors & 30 of \\
\hline 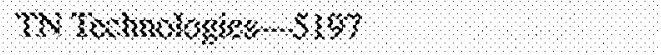 & 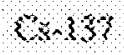 & $\mathrm{k} \times \mathrm{m} \mathrm{K}$ & 3,3 & $\otimes \&\}$ \\
\hline 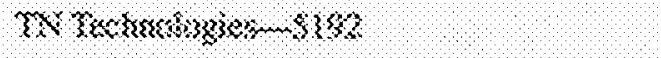 & 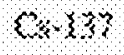 & $208 \mathrm{sm} 3$ & 3,3 & $\$ \%$ \\
\hline 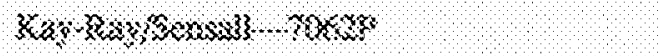 & $\{3-\{3\}$ & $1383 n 3$ & 3,8 & 4,88 \\
\hline 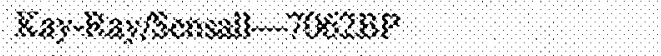 & $\hat{\beta}, 3$ & $188 \mathrm{mS}$ & 2,3 & 3.3 \\
\hline 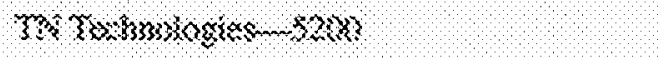 & $\alpha s-8\}$ & $5003 \mathrm{~ms} \Omega$ & $\$ 39$ & 383 \\
\hline 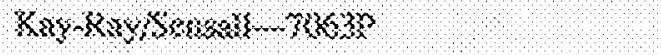 & $\sin 137$ & 8८ & 184 & 3.65 \\
\hline 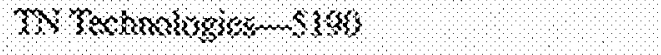 & $\{k \cdot\{3\}$ & 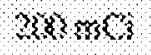 & 38 & 287 \\
\hline 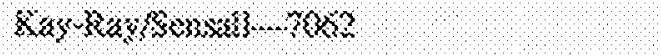 & $\cos 3 \%$ & 31818383 & $2,\{\}$ & 2,26 \\
\hline 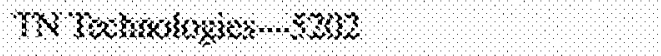 & 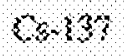 & $\$ \$ \$, 8<$ & 386 & 238 \\
\hline 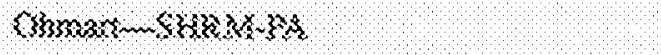 & 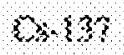 & $38 \$ 38 \%$ & 40 & (3.33 \\
\hline 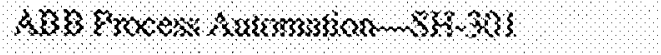 & $S \&\{3\}$ & $33 \mathrm{mos}$ & $0,8 \%$ & 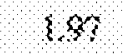 \\
\hline 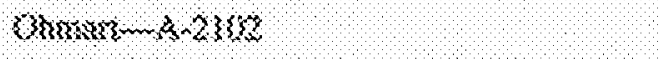 & sis $13 \%$ & $\{\leqslant$ & 163 & 168 \\
\hline 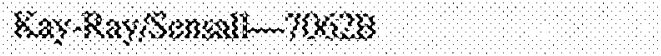 & $c s-13 y$ & $300 \mathrm{sm} \Omega$ & 1,33 & $\{, 30$ \\
\hline 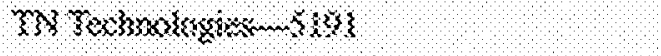 & $\langle s-3\}$ & $\left\{\varepsilon_{3}\right.$ & 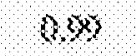 & 3,5 \\
\hline 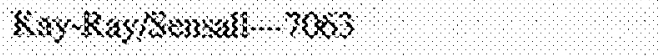 & $\langle 8 \times 33\rangle$ & 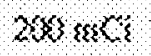 & $3 \leqslant 8$ & $3 \leqslant 2$ \\
\hline 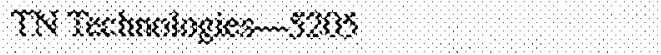 & $0 .\{3\}$ & $889 \mathrm{mos}$ & $2,3 x$ & 3.63 \\
\hline 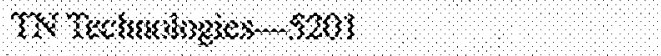 & $C x-\{3\}$ & $38 \times 33303$ & 2,8 & 33 \\
\hline 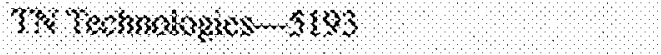 & $\int 8 \times 337$ & 36 & $\{, 0,3$ & 122 \\
\hline 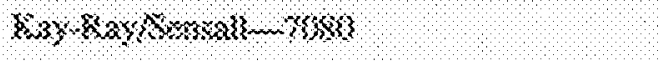 & 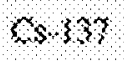 & $100 \mathrm{~ms}$ & 8.36 & $\{\leqslant 5$ \\
\hline
\end{tabular}

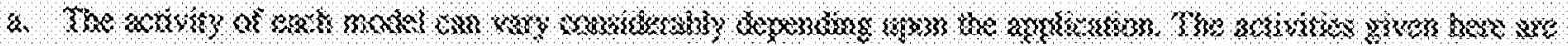

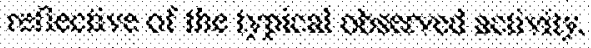

